\title{
Defining preparation and preparedness for nursing study abroad trips.
}

\author{
LEAR, $\mathrm{H}$.
}

2019

The author of this thesis retains the right to be identified as such on any occasion in which content from this thesis is referenced or re-used. The licence under which this thesis is distributed applies to the text and any original images only - re-use of any third-party content must still be cleared with the original copyright holder. 


\title{
DEFINING PREPARATION AND PREPAREDNESS
}

FOR NURSING STUDY ABROAD TRIPS

\author{
HOLLY LEAR
}

A thesis submitted in partial fulfilment of the requirements of The Robert Gordon University for the Degree of Doctor of Philosophy

September 2019 


\section{Acknowledgements}

To my husband, the Reverend Doctor Joseph M. Lear, who never tired of caring for our son, putting food on our table, supporting us financially, and having recently finished his own PhD, was an ideal conversation partner and encourager in my PhD journey.

To my father, who raised me to love books and the pursuit of knowledge. To my mother, whose fruit of the Spirit I hope to emulate one day. The foundation I received from my parents enabled me to accomplish this PhD.

To Lazarus, who was born in the middle of this journey and never allowed me to do a minute of work while he was awake. And to Barnabas, who leapt in my womb during my doctoral defence, cheering me on. You are my sons with whom I am well pleased.

To Win, who gave the utmost care in guiding me to the finish, always knowing the way I needed to go next, identifying my intellectual weaknesses before I recognised them myself, and taught me that it's about the journey. You hold my highest admiration and respect. Thank you for seeing me through to the end.

To Lesley, who joined my supervision team half way through, providing expertise, experience, and delightful conversation. It has been my great privilege to work with you.

To the various frequented coffee shops where I worked to complete this thesis with the provision of caffeine, medicating my undiagnosed ADHD.

To nursing students who study abroad: I do hope you travel, and that it brings you great depth of learning and maturity. May this work lead to change that helps you feel more prepared than I did.

And to the United States Department of Education. Thank you so much for giving me student loans, I don't think I'll ever be able to repay you. 


\section{Achievements}

\section{Publication}

Lear, H., Eboh, W., \& Diack, L. (2018). A nurse researcher's guide to reflexive interviewing. Nurse Researcher, 25(4), 35-42.

\section{Conferences}

$25^{\text {th }}$ National Evidence-Based Practice Conference, 2018

Poster presented: Preparation Recommendations for Nursing Study Abroad Trips (You're doing it differently than everyone else)

24 ${ }^{\text {th }}$ National Evidence-Based Practice Conference, 2017

Poster presented: Preparation for study abroad trips: Finding consensus

$23^{\text {rd }}$ National Evidence-Based Practice Conference, 2016 Attendee

Health Africa, Kokkola, Finland, 2015

Contributor to organisational report of involvement in international nursing study abroad trips

Enhancing Nursing through Educational Research Conference, 2014 Paper presented: "I just wanted to help: A reflexive interview of a researcher's experience"

The Royal College of Nursing Research Conference, Glasgow, Scotland 2014 Scholarship recipient of funded travel and conference costs 
$\begin{array}{lr}\text { Abstract } & 1\end{array}$

$\begin{array}{ll}\text { CHAPTER } 1 \text { INTRODUCTION } & 3\end{array}$

Originality 6

Terms

$\begin{array}{ll}\text { Cultural competence } & 7\end{array}$

Culture shock $\quad 8$

Study abroad trips $\quad 8$

Receiving institutions $\quad 8$

Sending institutions $\quad 9$

Preparation and Preparedness $\quad 9$

$\begin{array}{lr}\text { Study background } & 9\end{array}$

Personal context 9

$\begin{array}{ll}\text { Thesis overview } & 13\end{array}$

$\begin{array}{ll}\text { CHAPTER } 2 \text { REVIEW OF THE LITERATURE } & 14\end{array}$

$\begin{array}{ll}\text { Method } & 14\end{array}$

Problem identification $\quad 14$

Literature search $\quad 15$

Data evaluation $\quad 21$

Data Analysis $\quad 22$

Study Abroad Trips $\quad 23$

Benefits of nursing study abroad trips $\quad 24$

$\begin{array}{cc}\text { Cultural awareness, cultural competence, } & \\ \text { and cultural sensitivity } & 27\end{array}$

A critique of cultural competence 28

Risks and potential for harm 31

Post-colonial voyeurism 34

Preparation $\quad 36$

$\begin{array}{ll}\text { Nursing study abroad preparation } & 37\end{array}$

Content of preparatory training $\quad 37$

$\begin{array}{ll}\text { Courses } & 38\end{array}$

Preparation subjects in credited courses 42

Meetings $\quad 42$

Preparation subjects in meetings $\quad 50$

Student responsibilities $\quad 54$

Sending and receiving organisation responsibilities 54

The concept of 'underpreparedness' in current literature 55

Recently Added Literature $\quad 56$

Working Definition of Preparation $\quad 56$

Conclusion $\quad 58$

$\begin{array}{ll}\text { CHAPTER } 3 \text { REFLEXIVE INTERVIEW } & 59\end{array}$

Introduction $\quad 59$

$\begin{array}{ll}\text { Reflexivity in the Literature } & 60\end{array}$

Reflexive Interviews $\quad 63$

Justification $\quad 64$ 
Interview instrument $\quad 65$

Method

Post-interview discussion 66

Identification of researcher's potential biases 66

Analysis

Interview instrument changes $\quad 66$

Findings

Theoretical underpinnings $\quad 69$

Conclusion

Research Question and Aims

Description of the Characteristics of Qualitative Inquiry

A defence for use of qualitative research method 75

Philosophical Assumptions

76

Ontological assumption

76

Epistemological assumption $\quad 76$

Axiological assumption $\quad 77$

$\begin{array}{ll}\text { Methodological assumption } & 78\end{array}$

Ethics

Method

Phenomenology

Grounded theory

80

Ethnography/ethnonursing $\quad 81$

Design

Case study

Study question $\quad 83$

Propositions $\quad 84$

Units of analysis $\quad 84$

Logical link between data and propositions $\quad 85$

Criteria for interpreting the findings $\quad 86$

Theory Development $\quad 86$

$\begin{array}{ll}\text { Single Case Study Design } & 87\end{array}$

$\begin{array}{ll}\text { Single case rationales } & 87\end{array}$

CHAPTER 5 A PILOT CASE STUDY OF A FINNISH NURSING STUDY ABROAD PREPARATION PROGRAMME

Pilot Case Study $\quad 89$

$\begin{array}{lr}\text { Justification for undertaking a pilot case study } & 89 \\ 90\end{array}$ Method

Selection of the HEI context for the pilot study 90

Scope of pilot study $\quad 92$

Development of prompts: Interview with
study abroad coordinator

Interview with study abroad coordinator $\quad 92$

$\begin{array}{ll}\text { Student pre-trip interview } & 92\end{array}$

Student diary $\quad 94$

Student blog $\quad 95$

$\begin{array}{ll}\text { Student post-trip interview } & 95\end{array}$ 
Methodological and substantive changes to the pilot 96

Pilot interview with study abroad coordinator 96

Student diary $\quad 96$

Serendipitous benefits of student data collection 97

Analysis 98

Report of the Findings $\quad 99$

Description of the Case $\quad 99$

Context 99

$\begin{array}{ll}\text { Preparation } & 100\end{array}$

Study abroad coordinator perspective $\quad 100$

Student perspective 100

Remaining reflections from student's pre-trip interview $\quad 101$

Blog and Diary Data: Analysis of the Student's Experiences 102

$\begin{array}{ll}\text { First impressions } & 102\end{array}$

'Rollercoaster of emotions' 103

Risks and conflicts 105

Comparisons to home 108

Final words $\quad 109$

$\begin{array}{lr}\text { Conclusion } & 112\end{array}$

CHAPTER 6 CASE STUDY OF A PREPARATION PROGRAMME IN THE NETHERLANDS

Case Descriptions $\quad 114$

Case Study Procedure $\quad 115$

Selection of the case 115

Recruitment of study abroad coordinators
at the sending institution

Recruitment of nursing students 116

$\begin{array}{cc}\text { Recruitment of study abroad coordinators } & \\ \text { at the receiving institution } & 117\end{array}$

$\begin{array}{ll}\text { Data Collection } & 117\end{array}$

117

$\begin{array}{ll}\text { Interview with study abroad coordinators } & 118 \\ \text { Student pre-trip interviews } & 118\end{array}$

$\begin{array}{ll}\text { Student diaries and blogs } & 119\end{array}$

Concerning translation $\quad 120$

$\begin{array}{ll}\text { Student post-trip interviews } & 121\end{array}$

Analysis

122

Student pre-trip interview analysis $\quad 122$

$\begin{array}{ll}\text { Nursing students' diary analysis } & 126\end{array}$

Nursing students' blog analysis $\quad 127$

Student post-trip interview analysis $\quad 129$

$\begin{array}{ll}\text { Report of the Findings } & 136\end{array}$

$\begin{array}{ll}\text { The sending institution } & 137\end{array}$

$\begin{array}{ll}\text { Student retention of preparation } & 140\end{array}$

$\begin{array}{ll}\text { First impressions } & 144\end{array}$

$\begin{array}{ll}\text { Studying abroad } & 148\end{array}$

$\begin{array}{lr}\text { Struggles and conflicts } & 150\end{array}$

Support systems $\quad 153$

Risk-taking 153

Transition home 156

$\begin{array}{lr}\text { Discussion of Preparation and Preparedness } & 158\end{array}$ 
A deviant, critical, paradigmatic, and revelatory case

CHAPTER 7 DELPHI STUDY

Aim and objective

Method

Reason for method selection

165

Delphi technique

166

Pilot of Delphi Study

167

Changes following the pilot $\quad 170$

Design

Ethical considerations

Sampling strategy

171

Selection of participants

Data Collection

Delphi Round 1

173

Round 1 results

Delphi Round 2

Round 2 results

Findings

Definition of preparation

Conclusion

CHAPTER 8 DISCUSSION \& CONCLUSION

Discussion of Preparation

Experiences of Nursing Students on Study Abroad Trips

The contradiction in the stated justification versus the evidence-based reason to study abroad

Personal growth

Cultural competence

206

Outcomes from the reflexive interview

207

Do nursing students study abroad for an adventure?

208

Rollercoaster of emotions

209

Student struggles

211

Student retention of preparation $\quad 212$

First impressions

Institutional Organisation of Sending HEIs

The assumption that students are underprepared for nursing study abroad trips by their sending institutions

The assumption that study abroad trips may not benefit the host location

The study abroad trip is the preparation for students to enter the nursing workforce

Student applications to study abroad

Risk and risk-taking

Countries of experience 
A lack of standardisation in preparation $\quad 221$

Students' level of preparedness $\quad 223$

Definition of preparation $\quad 224$

Analytical framework of preparation 225

Conclusion 226

Conclusion $\quad 228$

Study design and implementation $\quad 229$

Limitations and delimitations $\quad 230$

Original contribution $\quad 230$

Future Research $\quad 232$

Significance $\quad 233$

Recommendations 233

$\begin{array}{ll}\text { REFERENCES } & 235\end{array}$

$\begin{array}{ll}\text { APPENDICES } & 253\end{array}$ 


\section{List of Figures}

Figure 1: PRISMA Flow Diagram

Figure 2: Preparation Subjects Repeated in Both Meetings and CreditedCourses

Figure 3: Experiential Education 70

Figure 4: Experiential Education with Findings 72

Figure 5: Embedded Single Case Design 85

Figure 6: Bennett's Developmental Model of Intercultural Sensitivity 94

Figure 7: Emergent Themes Informing Understanding of the Case

Figure 8: Finnish Preparation Programme Overview

Figure 9: Intended Data Source Triangulation

Figure 10: Visual Representation of Student Data Triangulation

Figure 11: Emergent Themes from Nursing Students' Pre-Trip Interviews

Figure 12: Bennett's Model with Student Predictions

Figure 13: Emergent Themes from Nursing Students' Diaries

Figure 14: Emergent Themes from Nursing Students' Blogs

Figure 15: Emergent Themes from Nursing Students' Post-trip Interviews

Figure 16: Dutch Preparation Programme Overview

Figure 17: In your experience, how prepared are nursing students to study abroad?

Figure 18: Preparation for nursing students to study abroad should include the development of clinical skills, especially those related to prevalent diseases in the host location

Figure 19: Preparation for nursing students to study abroad should include the development of managerial skills, or the ability to manage responsibilities with autonomy

Figure 20: Expert roles related to study abroad trips (Experts asked to tick all that applied)

Figure 21: Location of Expertise

Figure 22: In your experience, how prepared are nursing students

Figure 23: Student Preparation According to Location of Study Abroad Trip 
Figure 24: Nursing students preparing to study abroad should be responsible for... their own preparation to study abroad

Figure 25: Nursing students preparing to study abroad do not need an overarching aim to their trip

Figure 26: Preparation for nursing students to study abroad should include development of managerial skills, or the ability to manage responsibilities with autonomy

Figure 27: Please specify any further areas you believe nursing students should be prepared to study abroad

Figure 28: In your experience, how prepared are nursing students to study abroad?

Figure 29: Nursing students preparing to study abroad should be responsible for their own preparation to study abroad 


\section{List of Tables}

Table 1: Literature Review Paper Exclusion Criteria 16

Table 2: Literature Review Search Terms 19

Table 3: Preparation Subjects in Credited Courses 40

Table 4: Preparation Subjects in Meetings 44

Table 5: Voice-Centred Relational Analysis 69

Table 6: Timeline of Data Collection 121

Table 7: Nursing Student Pre-Trip Interview - How did you decide to study

abroad? 123

Table 8: Student Cultural Predictions from Modest to Confident 125

Table 9: Nursing Student Predicted Number on Bennett's Developmental

Model of Intercultural Sensitivity Before and After Studying Abroad 131

Table 10: Nursing Student Post-Trip Interview - What Recommendations do

you have for... 133

Table 11: Student Data - Analysis by Theme and Data Source 135

Table 12: Nursing Student Pre-Trip Interview: What will you do every day?

Table 13: Nursing Student Pre-Trip Interview: How have you prepared to study abroad?

Table 14: Nursing Student Pre-Trip Interview: What do you hope to gain from this experience?

Table 15: Nursing Student Post-Trip Interview: How has your transition been, coming back home?

Table 16: Nursing Student Post-Trip Interview: Were you adequately prepared for your study abroad trip?

Table 17: Theoretical Statements and Supporting Evidence

Table 18: Measures of Central Tendency

Table 19: Analytical Framework for Nursing Student Preparation

Table 20: Analysis by Theme and Data Source 


\section{Appendices}

APPENDIX A: $\quad$ LITERATURE REVIEW TABLE: ARTICLES THAT DESCRIBE PREPARATION BEFORE NURSING STUDY ABROAD TRIPS

APPENDIX B: $\quad$ PERMISSION FROM DAVID CITRIN 268

APPENDIX C: $\quad$ INTERVIEW QUESTIONS FROM DAVID CITRIN'S PAPER 269

APPENDIX D: $\quad$ REFLEXIVE INTERVIEW QUESTIONS 271

APPENDIX E: $\quad$ SCHOOL OF NURSING AND MIDWIFERY ETHICS REVIEW PANEL APPROVAL

APPENDIX F: $\quad$ PERMISSION FROM HEI IN FINLAND 274

APPENDIX G: $\quad$ PERMISSION FROM NGO ASSOCIATED WITH FINNISH HEI

APPENDIX H: $\quad$ PERMISSION FROM HEI IN THE NETHERLANDS 276

APPENDIX I: $\quad$ CONSENT FORM FOR STUDY ABROAD COORDINATORS

$\begin{array}{lll}\text { APPENDIX J: } \quad \text { CONSENT FORM FOR STUDENTS } & 278\end{array}$

APPENDIX K: $\quad$ EXEMPTION FROM FURTHER ETHICS REVIEW PANEL APPROVAL

APPENDIX L: $\quad$ INFORMATION SHEET FOR PARTICIPANTS 280

APPENDIX M: $\quad$ GUIDELINES FOR BLOGS AND DIARIES 283

APPENDIX N: $\quad$ INTERVIEW PROMPTS FOR HEI - PILOT 284

APPENDIX O: $\quad$ INTERVIEW QUESTIONS FOR STUDENT 286

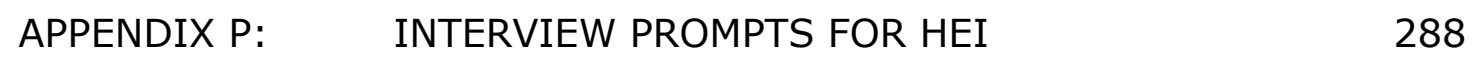

APPENDIX Q: $\quad$ EXAMPLE OF DATA ANALYSIS 290

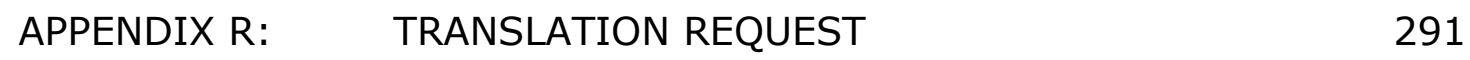

APPENDIX S: $\quad$ QUESTIONS FOR DELPHI STUDY PILOT 296

APPENDIX T: $\quad$ QUESTIONS FOR DELPHI STUDY ROUND 1

APPENDIX U: $\quad$ QUESTIONS FOR DELPHI STUDY ROUND 2 


\begin{abstract}
The aim of this study is to explore the preparation nursing students receive prior to undertaking study abroad trips. The researcher's personal context that initiated this project is representative of the findings of the literature that students often feel unprepared during study abroad trips. Evidencebased preparation for study abroad trips is absent in the literature, and the few authors who discuss how preparation is carried out indicate many students are sent out with little or no preparation, and there is no uniformity in current practice. Inconsistencies exist between Higher Education Institutions' (HEIs) justifications to study abroad (the attainment of cultural competence) versus the stated reasons students study abroad (personal benefit/growth), raising a myriad of ethical quandaries. No specific cases of malpractice arose in the literature which suggests events are either purposefully hidden or unknown. The lack of preparation is exacerbated by the potential risks nursing students can cause or incur during study abroad trips.
\end{abstract}

A reflexive interview made the researcher's biases toward nursing study abroad trips explicit. This was undertaken prior to collecting data to bracket assumptions. Using a case study method, this study explores two HEI preparation modules from the perspective of study abroad coordinators and nursing students planning to study abroad. One sending institution in Finland was the context of a pilot case, while another in the Netherlands was the context for a formal case study to holistically describe the preparation the two groups of nursing students received before studying abroad. Data is presented from interviews conducted with study abroad coordinators, interviews with students, blogs, diaries, and collection of institutional documentation. Findings are categorised according to a description of the preparation programme and the study abroad experiences that shed light as to the students' level of preparedness. Subsequently, a Delphi method is employed to achieve a consensus of experts in the field as to what should be included in a preparation curriculum.

The findings suggest no two HEIs have the same study abroad preparation programme for nursing students. Preparation is widely varying both in 
content and length. The researcher theorises preparation is so often overlooked or limited because study abroad trips are in and of themselves preparation for students' future nursing careers. A new and validated definition of nursing study abroad preparation is presented, followed by an analytical framework that study abroad coordinators, HEIs, and nursing students can utilise to guide preparation. 


\section{CHAPTER ONE INTRODUCTION}

Nursing study abroad trips are rising in popularity (Crump, Sugarman et al. 2010, Open Doors 2017). Nursing students may travel the globe studying abroad, sometimes to locations where the culture, language, and healthcare practices are very different to what the students are used to. Study abroad trips are justified by Higher Educational Institutions (HEIs) as learning opportunities that increase students' cultural competence (Kohlbry, Daugherty 2015, Westerbotn, Kneck et al. 2015, Gower, Dantas et al. 2018). Responding to an increasingly diverse patient population, study abroad trips provide students with a chance to learn about a culture different from their own to provide culturally appropriate care upon becoming newly qualified nurses. Studying abroad boasts a lengthy list of benefits for nursing students beyond increasing in cultural competence. Nursing students experience personal growth (Kent-Wilkinson, Leurer et al. 2015), develop communication skills (Westerbotn et al. 2015), and often learn about a healthcare system different from their own (Davis, Wright et al. 2015).

However, the nursing literature suggests nursing students do not receive adequate preparation to study abroad. Current practice for preparing nursing students to study abroad spans from no training at all (Tjoflåt, Razaonandrianina et al. 2017), to a one-time orientation meeting (Goldberg, Brancato 1998), to a full semester preparation course (Farmer, Raver et al. 2003). The content of preparation training is as varied as the length of time reserved for it. Some preparation only covers trip itineraries (Lachat, Zerbe 1992), while others cover a list of topics such as history, geography, sociopolitics, culture, customs, and local health problems in the country where the students will study abroad (Wros, Archer 2010). One group of students reported not knowing anything upon arrival to their study abroad site (Halcomb, Antoniou et al. 2018).

Current preparation practice lacks standardisation, and nursing students are entering foreign countries unequipped for what they will find (Reid-Searl, 
Dwyer et al. 2011, Ruddock, Turner 2007, Browne, Fetherston et al. 2015, Racine, Perron 2012, Adamshick, August-Brady 2012, Lee 2004). A study at Johns Hopkins School of Medicine and School of Nursing surveyed students regarding past study abroad trips (Kironji, Aluri et al. 2014). Most (70\%) students had been part of a healthcare study abroad trip. Of those, $48 \%$ did not receive any preparation training. Nearly half (46\%) remember needing more preparation than they received, and $80 \%$ experienced challenges. Disturbingly, $16 \%$ performed a clinical treatment for which they were unprepared. The study is representative of a myriad of study abroad trips, given the students were referring to past experiences from other HEIs. The literature exhibits low standards for study abroad trips, revealing the need for better preparation and a review of ethical procedures.

One theory for the seemingly low priority given to preparing nursing students is that study abroad trips are preparation in and of themselves. The trips are not meant to be prepared for, but to be preparation for the diversifying patient population the students will encounter upon entrance into the workforce (Conejo, Loyd 2017, Bowker, Tomlinson 2017, Aggar, Bloomfield et al. 2017, Smallheer, Hunt et al. 2018, Øgård-Repål, De Presno et al. 2018). Nursing students are, in a sense, thrust into foreign contexts, and expected to re-enter their home countries able to provide culturally competent nursing care. Some consider the attainment of such a skill audacious (Gray, Thomas 2005). A problem with using study abroad trips as vehicles to teach cultural competence is the disposition to essentialise cultures. Some patients may appear to belong to an ethnicity of a country that they have never even visited. Some patients identify with the dominant culture of a particular location, and some do not. Regardless, the immutable healthcare system is not set up in a way that nurses can drastically alter the plan of care for every cultural need. And even if it were plausible for nurses to treat patients with culture-specific care, this again would reveal the essentialising of the culture from which the nurse assumes the patient to belong. The literature is clear that nursing students do not necessarily achieve cultural competence from studying abroad (Foronda, Belknap 2012, Tam 2016). Sending students abroad, sometimes without any prior cultural training, does not logically lead to increased cultural 
competence. Thus, the primary justification for sending nursing students abroad is in question.

Indeed, the risks may outweigh the justification of potentially increasing cultural competence. Nursing students are put at risk for harm - and the risk of harming others - when preparation is inadequate. Nursing students lose passports, report rape, and involve themselves with dangerous amounts of drugs and alcohol (Seals 2013). Patients are treated by students who may have never learned about their ailments, or do not possess the clinical skills to independently practice (Sloand, Bower et al. 2008). Additionally, the recent (this thesis was submitted early 2019) Ebola outbreak and recurrent terrorist attacks represent substantial risks that are difficult to mitigate. The literature does not often specify the level of patient care students provided; with few study abroad coordinators stating they arranged indemnity insurance for their students (Shailer 1997, Mill, Yonge et al. 2005). Other articles did not mention insurance at all, suggesting most nursing study abroad trips do not have insurance and may not have permission to do more than observations. Some study abroad trips were observation-only (Edmonds 2010, Davis et al. 2015), while others were immersed alongside local nurses and encouraged to provide care (see Chapter 6).

The Nursing and Midwifery Council's (NMC) current standards (Nursing Midwifery Council 2010) requires all nurses to carry out 'systematic nursing assessments that take account of relevant physical, social, cultural, psychological, spiritual, genetic and environmental factors, in partnership with service users and others through interaction, observation and measurement' (p. 18). The inclusion of 'cultural assessment' is of particular interest in this study. The NMC continues that 'all nurses must also understand how behaviour, culture, socioeconomic and other factors, in the care environment and its location, can affect health, illness, health outcomes and public health priorities and take this into account in planning and delivering care' (p. 26). Indeed, the increasing diversity of patients makes conducting culture-specific nursing assessments difficult for nursing students. 
The first standard discussed in pre-registration nursing education is safeguarding the public. According to this NMC requirement, 'programme providers must make the needs of service users their first priority' (p. 49). Immediately following is the requirement that 'programme providers must ensure that no student activity or learning opportunity, or the performance, health or conduct of any individual student, puts people's safety at risk' ( $p$. 49). These two requirements are also of interest to this study, as the researcher posits study abroad trips carry potential risk and harm that could both mean the patient is not the first priority, and secondly that people's safety (both the student and patient) is at risk.

The NMC's new standards for education and training with regards to cultural education state that educational programmes will only be approved if cultural education is ethical and safe (among other requirements) (NMC 2018). This raises the question of whether nursing study abroad trips should be approved by the NMC when students are inadequately prepared, are at risk for harming themselves and others, and do not necessarily achieve cultural competence.

\section{Originality}

The study of preparation and preparedness is intended to be an original contribution to the body of knowledge. Preparation in HEIs has been previously unexplored as a primary point of study. The original contributions of this study will be as follows.

1. The researcher is not aware of another case study on preparation in the field of nursing, which makes this study both timely and essential in light of potential risks abroad, and the new guidelines from the NMC. The embedded case study method is also original as it explores preparation techniques from both perspectives of the HEI and nursing students. 
2. The study findings have generated rich evidence that can be extrapolated to develop best practice for future nursing students undertaking such trips. The researcher aims to develop recommendations to assist study abroad coordinators in preparing students.

3. It is the aim of the researcher that through a better understanding of current preparation, best practice can be formed and disseminated for the benefit of nursing students, supporting faculty, sending institutions, and the stakeholders least discussed in the literature: the receiving institutions and individuals who receive care.

4. While the purpose of this study is not to make grand generalisations, the researcher anticipates original research on preparation has the potential to provide sufficient baseline data for future research in other disciplines. Nursing is still considered to be a profession requiring its own preparation content within this thesis, however the definition of preparation and the analytical framework can be useful for informing best practice in other disciplines, for example allied health professions and social work.

\section{Terms}

\section{Cultural competence}

Leininger is credited with coining the term cultural competence, defined as 'the use of culturally based care and health knowledge in sensitive, creative, and meaningful ways to fit the general lifeways and needs of individuals or groups for beneficial and meaningful health and well-being or to face illness, disabilities, or death' (Leininger, McFarland 2002, p. 84) .

Campinha-Bacote (1999) defines cultural competence as the ongoing striving on the part of the healthcare provider to 'achieve the ability to effectively work within the cultural context of an individual, family or community' (p. 203). 
Purnell (2002) also defines cultural competence as the 'adaptation of care in a manner that is consistent with the culture of the client' (p. 193).

Cultural competence has been proposed to include cultural awareness, cultural sensitivity, cultural knowledge, cultural skill, cultural encounters, and cultural desire (Capers, 1994; Campinha-Bacote, 1999; Lapierre \& Padgett, 1991). However, these proposed terms are used infrequently in the literature and cultural competence carries with it an assumption that the nurse exhibits competence in every patient's culture. This demands constant education on every culture represented in a particular healthcare setting, which is arguably an unattainable ideal.

\section{Culture shock}

The feelings experienced by an individual who encounters an unfamiliar culture, including stress (such as those related to attempts of psychological adaptation), loss of one's role, fear of rejection by the members of the new culture, confusion, anxiety or disgust at cultural differences; and general feelings of helplessness (Oberg 1960).

\section{Study abroad trips}

Several terms synonymous with 'study abroad trips' were considered for use in this thesis. Indeed the researcher collected over 50 terms that could have been used to refer to the phenomenon of nursing students traveling overseas from an academic institution, often to receive academic credit to observe or practice while immersed in a different culture or location. Ultimately, 'study abroad trip' was chosen because it remains the most common term in the literature. It also encompasses, rather than excludes, one-way vs. mutual exchanges between collaborating universities, and specific terms such as Erasmus placements. In the context of this study, a 'study abroad trip' refers to the all-encompassing phenomenon of students traveling either one-way or via a mutual exchange to undertake an academic experience through the HEI in which they are enrolled as nursing students. 


\section{Receiving institutions}

Receiving institutions refer to the organisations, HEIs, or clinics in the host location nursing students travel to while studying abroad. They host the students and provide the learning (observation or practice-oriented) upon which the study abroad trips are based.

\section{Sending institutions}

Sending institutions refer to the HEIs that send nursing students abroad. They are the stakeholders that most commonly provide preparation to nursing students.

\section{Preparation and Preparedness}

The terms preparation and preparedness are used to describe the phenomenon of interest in this thesis. Preparation refers to the training students undergo or receive from their sending institutions to make them ready for a nursing study abroad trip. Their preparedness is the extent to which that preparation is absorbed, or realised. The terms are not interchangeable, but carry related meanings.

\section{Study background}

Students are sent out by their institutions into unknown contexts where risk abounds. Some had preparation, some did not. Medical emergencies of any sort may occur, potentially in a rural location without access to medical care or where communication is impossible due to language barriers or lack of internet access. External risks present another set of possibilities for which to prepare, such as the threat of violence, political unrest, and communicable diseases. The researcher is not exempt from these risks; she has experienced a peer's near death due to malaria and witnessed a firearm attack on a vehicle near her own. These risks were not able to be specifically foreseen, but should be mitigated nonetheless. The following is the background that led to this study, in the form of the researcher's personal context of studying abroad. 


\section{Personal context}

To provide context for this assessment, the researcher's experience undertaking a study abroad trip as a nursing student is discussed. A reflexive interview was undertaken of the same events to expose potential bias and add trustworthiness (Chapter 3). Gibbs Reflective Cycle (Fakude 2003, Gibbs 1988), a tool for organising reflections of an event, informs the researcher's reflection of her preparation process and study abroad trip. The cycle's stages of description, feelings, and evaluation are followed.

As with other study abroad trips undertaken, this trip fulfilled an elective requirement of the researcher's nursing curriculum (Bender, Walker 2013, Goodman, Jones et al. 2008). A fellow nursing student who had spent her childhood in Kenya had knowledge of a religious organisation that provided temporary clinics in Kenyan villages without medical care and she organized a trip that would be available for her classmates. A trained nurse who had experience organising such trips agreed to lead the students to Kenya.

While most literature justifies nursing study abroad trips in that they prepare future nurses to care for a diverse population (Jarrell, Ozymy et al. 2014, Gallagher, Polanin 2015), this was not the reason the researcher undertook the trip to Kenya. Rather she felt optimistic that she and the medical team could do good through a reputable organisation.

Preparation for the study abroad trip included an orientation meeting that concentrated on the trip location, culturally appropriate attire, and how to raise funds for the trip. One further meeting was held with a supporting faculty member who provided assignments to complete abroad in order to receive academic credit. At this point the researcher felt optimistic and equipped, with no pressing need for further preparation beyond scheduling vaccinations and securing a passport.

The researcher and seven of her fellow nursing students travelled to Kenya. Upon arrival, Kenyan nurse practitioners and members of the religious organisation joined the nursing students, which completed the medical team. The researcher remembers being transported on a bus along a dusty, uneven road to the location of the temporary clinic where she would work, 
having no idea of her location or who the driver was. This was an overwhelming experience and she feared for her reliance on people she had not met before and the potential danger she and her colleagues were in. Gunfire directed at a vehicle nearby necessitated the researcher's group to turn around and hire a police escort. The remainder of the trip, the police escort held a large firearm in his lap, and yelled at the students once to lie down on the floor while passing a vehicle he felt was threatening. As the trip progressed, the researcher's feelings intensified as she worked 17-hour days, with no access to running water or toilets. When the week of work was finished, the team closed the temporary medical clinic and drove away. The author looked out the window and could see that the queue of people waiting to receive medical care had not lessened in number; rather it had grown.

The researcher felt one source of these feelings was a lack of preparation for what she found in Kenya. During and after the trip, the researcher experienced culture shock due to surprises such as lodging consisting of camping outside the clinic. The researcher moreover felt guilt and frustration that as a foreigner her knowledge of local diseases was deficient. Remarkably, over 700 people received care as a result of the trip. However, the researcher did not sense the health needs of the local people were met sustainably. In hindsight, the researcher felt common ailments such as those developed from parasites in contaminated water would soon return as a result of the team being unprepared to address the root causes of the health needs in the community.

The researcher's feeling of inadequate preparedness is representative of many other nursing students, as shown in the Literature Review (Chapter 2). Feelings of shock, guilt, and frustration on the researcher's study abroad could have been lessened with better preparation. In hindsight, the pre-departure meetings were inadequate for preparing students to study abroad and potentially endangered them and the population that received care. Prior to the trip the researcher felt invincible as a young student and thus did not feel the need to seek out additional training prior to the trip, nor did she have any reason to think the pre- 
departure training would be inadequate. One example of preparation in the literature, however, began the process a semester before the study abroad trip (much earlier than the researcher's began), and included a full account of what to expect abroad e.g. maps and daily schedules, with an emphasis on appropriate behaviour while in a foreign context (Lachat, Zerbe 1992). It is therefore of the utmost importance that evidence-based data inform preparation, rather than simply consisting of a one-time meeting about travel details. After all, study abroad trips offer academic credit, involve international travel, and offer a platform for students to provide care in unfamiliar cultures. The researcher subsequently avoided additional opportunities to study abroad due to her past experiences. To this end the researcher felt a need to understand the training HEIs provide, as well as how preparation is perceived by nursing students undertaking study abroad trips.

The researcher studied abroad a second time in Nigeria during her postgraduate studies. The researcher recalls,

A Nigerian nurse sat with me to help translate at the clinic during my trip. While patients saw me as a 'doctor' because of my white skin, the nurse next to me was the one with the thorough understanding of the diseases in the area. One woman came to sit in front me, where I performed assessments, and the nurse next to me cautiously handed me two pairs of gloves. Through nonverbal communication, I felt the nurse was prompting me to order an HIV/AIDS test, which I did. The test came back positive - the patient had not been previously diagnosed, and the team was able to provide her with counselling before ensuring that she could begin treatment. I had not arrived at the clinic feeling there was a one-direction transfer of knowledge, but ignorant of the possibility that I would be the one who learned from the nurse next to me. My experience with the Nigerian nurse opened my eyes to the reality that the greatest benefit lies in collaboration, partnership, and mutual understanding. 
Amidst many successful surgeries and treatments to the local population in Nigeria, the medical team ran out of supplies (including gloves and soap for hand-washing) and medications before the clinic was meant to be finished. In Kenya, stocks of food and water for the medical volunteers were also inadequate to sustain the team for the length of their stay. In Nigeria, a team member contracted malaria and was misdiagnosed for over a week while it worsened. Three different courses of medication were given to the team member, and he was taken to Accident and Emergency Department upon returning home.

This was a life-changing experience for the researcher and those on the medical team. Some felt the team had failed, as only short-term treatments that would be meaningless within a few weeks were provided. It was overwhelming to think of the feeling of 'insignificance' of the team's work for years to come. The researcher had extremely high, idealistic expectations prior to the trip, which is a common theme among other students traveling overseas for the first time to offer medical care. This trip gave the researcher a drive to pursue further education, hoping that through policy change and influence, study abroad trips would be improved.

\section{Thesis overview}

This thesis is comprised of many parts. The research begins with a reflexive interview, undertaken by the researcher to expose bias and increase trustworthiness at the beginning of the research process. Following the reflexive interview is a pilot and subsequent formal case study. Located in The Netherlands and Finland, two HEIs are presented as examples of universities that send nursing students abroad as part of their studies to learn and work in a foreign context. Of interest in these two case studies is the preparation the students received prior to studying abroad. Preparation is the theme that is carried throughout the many parts of this thesis. How were the students prepared, how were they prepared compared to other nursing students in the literature, and how ought nursing students be prepared to study abroad? The following chapters seek to answer these questions through a variety of methods that will contribute to a holistic and thorough description of preparation. 


\section{CHAPTER TWO REVIEW OF THE LITERATURE}

The researcher undertook a literature review systematically on the subject of preparation in nursing study abroad trips. In this chapter, the literature relating to the concept of preparation and subsequently the preparedness, or readiness to undertake a nursing study abroad trip, will be explored looking at empirical evidence. The question guiding the literature review is how nursing students prepare for study abroad trips.

\section{Method}

Literature reviews often do not present a specific research method or method of analysis. However, a method was chosen to guide this literature review process in this chapter to give structure and focus. A systematic review method was considered and rejected due to the emphasis on selecting papers from experimental studies and clinical trials, which did not fit the description of the majority of papers in this review (Souza, Silva et al. 2010). A meta-analysis was also considered and rejected due to the need for selected papers to have nearly identical study designs and hypotheses (Whittemore, Knafl 2005). The papers on the topic of study abroad trips had widely varying designs and thus a meta-analysis was rejected. While this chapter does not follow a literature review method exactly, it is guided by the principles of an integrative method (Cooper 1998). An integrative literature review method follows a comprehensive approach, allows for a diversity of methodologies, includes theoretical as well as experimental research, and is able to define concepts (Broome 2000). Beginning with the identification of a problem, a literature search, data evaluation, data analysis, and finally a presentation, this review addresses the gap in the literature of how nursing students prepare for nursing study abroad trips.

\section{Problem identification}

Following Whittemore and Knafl (2005), the problem identification stage includes identifying the population of interest, which are defined in this review as sending HEIs, students, and receiving HEIs who participate in nursing study abroad trips. Also important in the problem identification 
stage is the type of literature to be collected. In this review, databases were chosen based on the descriptions from the researcher's university library website that included the subject of nursing, and by recommendations from a Health and Medicine librarian (Table 1 ). The review also encompassed grey literature (materials produced by organisations not necessarily belonging to an academic nature). The final component of the problem identification stage is the healthcare problem, which in this study is the need for best practice in nursing study abroad trips for the purpose of optimal nursing education, and protection and safety for patients and students.

\section{Literature search}

The next stage is the literature search. It was the researcher's intention to gather all relevant data on the topic to be included in the review. A maximum amount of databases and sources were used (see Table 1) to explore and synthesise how nursing students prepare for study abroad trips. Search terms included: nursing student, student nurse, international exchange, international program, study abroad, and preparation (for specific variations of terms used, see Tables 1 and 2). Wildcards were used (placing $a^{\prime}{ }^{\prime}$ ' following the root of a search word) to avoid excluding relevant papers. Papers that included the search terms were manually sorted to determine if articles met the inclusion criteria of 1 ) relevance to the field of nursing study abroad trips, and subsequently, 2) whether preparation was discussed (Table 2; see relevant articles column). When the search was completed, the researcher had a list of new terms synonymous with 'study abroad trip' that were not used in the first literature search. Thus, a second search began in October of 2015 in the identified databases of Table 1 to reduce the risk of omitting relevant literature as they had the highest number of hits in preliminary searches. The search included older articles due to the low number of articles that covered the subject of preparation. The researcher used ancestry searching (Whittemore, Knafl 2005) to collect new and relevant articles from the reference sections as the literature review progressed. 
Table 1: Literature Review Paper Exclusion Criteria

\begin{tabular}{|c|c|}
\hline Database & Exclusion Criteria \\
\hline CINAHL & $\begin{array}{c}\text { First search yielded } 7 \text { hits dated between } 1990 \text { and } 2010^{\wedge} \\
\text { Second search yielded } 84 \text { hits dated } 1988 \text { and } 2015^{\wedge} \\
\text { Narrowing to English yielded } 77 \text { hits } \\
\downarrow \\
\text { Narrowing to full text yielded } 25 \text { results }\end{array}$ \\
\hline Internurse & $\begin{array}{c}\text { First search yielded } 14 \text { hits dated between } 1997 \text { and } \\
2014^{\wedge} \\
\downarrow \\
\text { The } 14 \text { hits had several unrelated articles. Adapted } \\
\text { nursing student search to include quotes around 'student } \\
\text { nurs' }\end{array}$ \\
\hline ScienceDirect & $\begin{array}{l}\text { First search yielded } 160 \text { hits } \\
\text { Narrowing date published since } 2005 \text { fielded } 73 \text { hits } \\
\text { Narrowing the search to 'nursing and healthcare } \\
\text { profession' yielded } 55 \text { results } \\
\downarrow \\
\text { Narrowing 'Nurs* student' OR 'student nurs*' to be found } \\
\text { in title, abstract, or keywords yielded } 27 \text { results } \\
\downarrow \\
\text { Narrowing 'international exchange' OR 'study abroad' to } \\
\text { be found in title, abstract, or keywords yielded } 5 \text { results }\end{array}$ \\
\hline $\begin{array}{l}\text { Cochrane } \\
\text { Library }\end{array}$ & $\begin{array}{l}\text { First search yielded } 117 \text { hits } \\
\text { Narrowing all terms to be found in the abstract yielded } 40 \\
\text { results } \\
\text { Narrowing search to articles published since } 2005 \text { yielded } \\
31 \text { results } \\
\downarrow \\
\text { Narrowing 'Nurs* student OR 'student nurs*' to be found } \\
\text { in the title yielded } 6 \text { results }\end{array}$ \\
\hline Web of Science & First search yielded 8 hits \\
\hline Medline & $\begin{array}{l}\text { First search of yielded } 130 \text { hits } \\
\text { Narrowing all terms to be found in the abstract yielded }\end{array}$ \\
\hline
\end{tabular}




\begin{tabular}{|c|c|}
\hline Database & Exclusion Criteria \\
\hline & $\begin{array}{l}\text { Narrowing search to articles with a linked full text yielded } \\
\text { Several of the } 18 \text { hits did not include the word 'nursing' } \\
\text { anywhere in the article (only in references) } \\
\text { The search was repeated as the following: } \\
\text { Search of Nurs* AND student* AND 'international } \\
\text { exchange*' OR 'stud* abroad*' in the abstract yielded } 64 \\
\text { hits } \\
\downarrow \\
\text { Narrowing search to articles with a linked full text yielded } \\
26 \text { hits }\end{array}$ \\
\hline $\begin{array}{l}\text { International } \\
\text { Newsstand }\end{array}$ & $\begin{array}{l}\text { First search yielded } 5287 \text { hits } \\
\text { Narrowing all terms to be found in the abstract yielded } 47 \\
\text { Narrowing search to articles with a linked full text yielded } \\
\text { results } \\
\text { At this point the author was unable to add more helpful } \\
\text { modifications due to the nature of the International } \\
\text { Newsstand search engine. Several articles from the } 37 \\
\text { hits were irrelevant so the following was done: } \\
\downarrow \\
\text { Narrowing search terms to 'Nursing student OR student } \\
\text { nurse AND 'international exchange' OR 'study abroad' } \\
\text { yielded } 37 \text { hits } \\
\downarrow \\
\text { Narrowing search to articles with a linked full text yielded } \\
28 \text { hits. }\end{array}$ \\
\hline Google Scholar & $\begin{array}{l}\text { First search yielded } 20,400 \text { results } \\
\text { Narrowing search to find articles with all of the words } \\
\text { 'nurs* AND student' 'international exchange OR study } \\
\text { abroad' yielded } 166 \text { results } \\
\text { Narrowing search to find articles with all of the words } \\
\text { 'nurs* student OR student nurs*' 'international exchange }\end{array}$ \\
\hline
\end{tabular}




\begin{tabular}{|c|c|}
\hline Database & Exclusion Criteria \\
\hline & $\begin{array}{l}\text { OR study abroad' yielded } 143 \text { results } \\
\downarrow \\
\text { Narrowing search to find articles with all of the words } \\
\text { 'nurs* student OR student nurs*' 'international exchange } \\
\text { OR study abroad' prepar* yielded } 126 \text { results } \\
\downarrow \\
\text { Narrowing search to articles published since } 2005 \text { yielded } \\
109 \text { results } \\
\downarrow \\
\text { The search 'nursing student' 'international exchange OR } \\
\text { study abroad' was attempted which yielded } 26 \text { results* }\end{array}$ \\
\hline Grey Literature & $\begin{array}{c}\text { The researcher's university librarian was contacted and } \\
\text { asked for assistance with finding grey literature. The } \\
\text { following searches are a result of recommendation from } \\
\text { the librarian: Web of Science contains a grey literature } \\
\text { section within 'Core Collection,' searched previously. } \\
\text { Bielefeld Academic Search database is considered a grey } \\
\text { literature source. } \\
\downarrow \\
\text { First search yielded } 44 \text { hits } \\
\downarrow \\
\text { Narrowing the search to English language yielded } 15 \\
\text { results } \\
\downarrow \\
\text { Google advanced search was used next. The 'file type' } \\
\text { was narrowed to .doc files } \\
\downarrow \\
\text { The search 'nursing student' 'international exchange OR } \\
\text { study abroad' filetype:docfiletype:doc yielded } 3 \text { results, } \\
\text { seeming too narrow } \\
\downarrow \\
\text { BBC webpage was searched using the terms 'student } \\
\text { nurses' AND 'study abroad.' BBC does not give a number } \\
\text { of hits, and the results were too lengthy to sort. The } \\
\text { include articles which were pertinent to this study, } \\
\text { yielding } 0 \text { hits } \\
\text { Search was widened to 'student nurse international } \\
\text { exchange OR study abroad filetype:doc' which yielded } 10 \\
\text { results }\end{array}$ \\
\hline Scopus & First search yielded 219 hits \\
\hline
\end{tabular}




\begin{tabular}{|l|c|}
\hline \multicolumn{1}{|c|}{ Database } & $\begin{array}{c}\text { Exclusion Criteria } \\
\end{array}$ \\
& $\begin{array}{c}\text { Further efforts to narrow increased the number of hits } \\
\text { exponentially } \\
\begin{array}{c}\text { The researcher manually sorted the remaining hits for } \\
\text { new resources }\end{array}\end{array}$ \\
\hline Embase & First search yielded 19 hits \\
\hline
\end{tabular}

$\wedge$ Dates were not narrowed as articles have only been published on international exchanges from the time when international travel became a phenomenon, and all articles of this nature are of interest.

Table 2: Literature Review Search Terms

\begin{tabular}{|c|c|c|c|}
\hline $\begin{array}{c}\text { Database and } \\
\text { Date }\end{array}$ & Search Terms & $\begin{array}{c}\text { Relevant } \\
\text { Articles }\end{array}$ & $\begin{array}{c}\text { Including } \\
\text { Preparation }\end{array}$ \\
\hline \multirow{3}{*}{$\begin{array}{l}\text { CINAHL } \\
12 \text { May } 2015 \\
7 \text { October } 2015\end{array}$} & $\begin{array}{l}\text { nurs* student AND } \\
\text { international exchange }\end{array}$ & 4 & 2 \\
\hline & \multirow{2}{*}{$\begin{array}{l}\text { Nurs* student AND Stud* } \\
\text { abroad }\end{array}$} & \multirow{2}{*}{25} & 1 \\
\hline & & & Total $=3$ \\
\hline \multirow[t]{2}{*}{$\begin{array}{l}\text { Internurse } \\
19 \text { June } 2015 \\
10 \text { October } 2015\end{array}$} & $\begin{array}{l}\text { Nurs* student OR } \\
\text { 'student nurs* } \\
\text { international exchange OR } \\
\text { exchange program* OR } \\
\text { study abroad }\end{array}$ & 1 & \multirow[t]{2}{*}{1} \\
\hline & $\begin{array}{l}\text { Nurs* student AND Stud* } \\
\text { abroad }\end{array}$ & 5 & \\
\hline $\begin{array}{l}\text { ScienceDirect } \\
20 \text { June } 2015\end{array}$ & $\begin{array}{l}\text { nurs* student OR } \\
\text { student nurs* } \\
\text { 'international exchange' OR } \\
\text { 'study abroad' }\end{array}$ & 4 & 2 \\
\hline $\begin{array}{l}\text { Cochrane Library } \\
25 \text { June } 2015\end{array}$ & $\begin{array}{l}\text { nurs* student OR } \\
\text { student nurs* AND } \\
\text { 'international exchange' OR } \\
\text { 'study abroad' }\end{array}$ & 4 & 0 \\
\hline $\begin{array}{l}\text { psycARTICLES } \\
29 \text { June } 2015\end{array}$ & $\begin{array}{l}\text { nurs* student OR } \\
\text { 'student nurs*' AND } \\
\text { 'international exchange' OR } \\
\text { 'study abroad' }\end{array}$ & 0 & 0 \\
\hline $\begin{array}{l}\text { Web of Science } \\
29 \text { June } 2015\end{array}$ & $\begin{array}{l}\text { nurs* student OR } \\
\text { student nurs* AND } \\
\text { 'international exchange' OR } \\
\text { 'study abroad' }\end{array}$ & 4 & 2 \\
\hline $\begin{array}{l}\text { Medline } \\
3 \text { July } 2015\end{array}$ & $\begin{array}{l}\text { nurs* AND } \\
\text { student* AND } \\
\text { 'international exchange*' }\end{array}$ & 14 & 4 \\
\hline
\end{tabular}




\begin{tabular}{|c|c|c|c|}
\hline \multirow[t]{3}{*}{$\begin{array}{c}\text { Database and } \\
\text { Date }\end{array}$} & Search Terms & $\begin{array}{l}\text { Relevant } \\
\text { Articles }\end{array}$ & $\begin{array}{l}\text { Including } \\
\text { Preparation }\end{array}$ \\
\hline & OR 'stud* abroad*' & & \\
\hline & $\begin{array}{l}\text { Nurs* AND student* AND } \\
\text { 'international exchange*' } \\
\text { OR 'stud* abroad*' in the } \\
\text { abstract }\end{array}$ & 26 & \\
\hline \multirow{2}{*}{$\begin{array}{l}\text { International } \\
\text { Newsstand } \\
10 \text { August } 2015\end{array}$} & $\begin{array}{l}\text { Nursing student OR } \\
\text { student nurse AND } \\
\text { 'international exchange' OR } \\
\text { 'study abroad' }\end{array}$ & \multirow{2}{*}{0} & \multirow{2}{*}{0} \\
\hline & $\begin{array}{l}\text { 'Nursing student OR } \\
\text { student nurse AND } \\
\text { 'international exchange' OR } \\
\text { 'study abroad' }\end{array}$ & & \\
\hline $\begin{array}{l}\text { Google Scholar } \\
11 \text { August } 2015\end{array}$ & $\begin{array}{l}\text { nurs* student OR } \\
\text { student nurs* } \\
\text { 'international exchange' OR } \\
\text { 'study abroad' AND } \\
\text { prepar* }\end{array}$ & 14 & 5 \\
\hline $\begin{array}{l}\text { Grey literature } \\
22 \text { August } 2015 \\
\text { 1. Bielefeld } \\
\text { Academic } \\
\text { Search } \\
\text { 2. Google } \\
\text { Advanced } \\
\text { Search } \\
\text { 3. BBC } \\
\text { Webpage } \\
\text { Search }\end{array}$ & $\begin{array}{l}\text { 1. 'nurs* student' OR } \\
\text { 'student nurs*' AND } \\
\text { 'international exchange' } \\
\text { OR 'study abroad' } \\
\text { 2. 'student nurse } \\
\text { international exchange } \\
\text { OR study abroad } \\
\text { filetype:doc' } \\
\text { 3. 'student nurses' AND } \\
\text { 'study abroad' }\end{array}$ & 3 & 0 \\
\hline Scopus & $\begin{array}{l}\text { 'Nursing student' AND } \\
\text { international OR abroad } \\
\text { AND 'study abroad' }\end{array}$ & 62 & 9 \\
\hline $\begin{array}{l}\text { Embase } \\
14 \text { October } 2015\end{array}$ & $\begin{array}{l}\text { Nurs* AND student AND } \\
\text { international OR abroad }\end{array}$ & 9 & 1 \\
\hline $\begin{array}{l}\text { Ancestry } \\
\text { searching }\end{array}$ & $\begin{array}{l}\text { Articles mentioned in } \\
\text { above articles } \\
\text { references }\end{array}$ & 39 & 3 \\
\hline Total & & 214 & 30 \\
\hline
\end{tabular}

The process of narrowing the literature search results from the 'relevant articles' column of Table 2 was based on the preferred reporting items for 
systematic reviews and meta-analysis (PRISMA) in Figure 1 (Liberati, Altman et al. 2009). The researcher excluded papers for which her institution did not have full text access. Some papers were on the subject of nursing study abroad trips, but upon closer inspection were not applicable to this study, and thus excluded. Papers were occasionally repeated hits in differing databases, which were omitted. The final result was 30 relevant papers.

Figure 1: PRISMA Flow Diagram

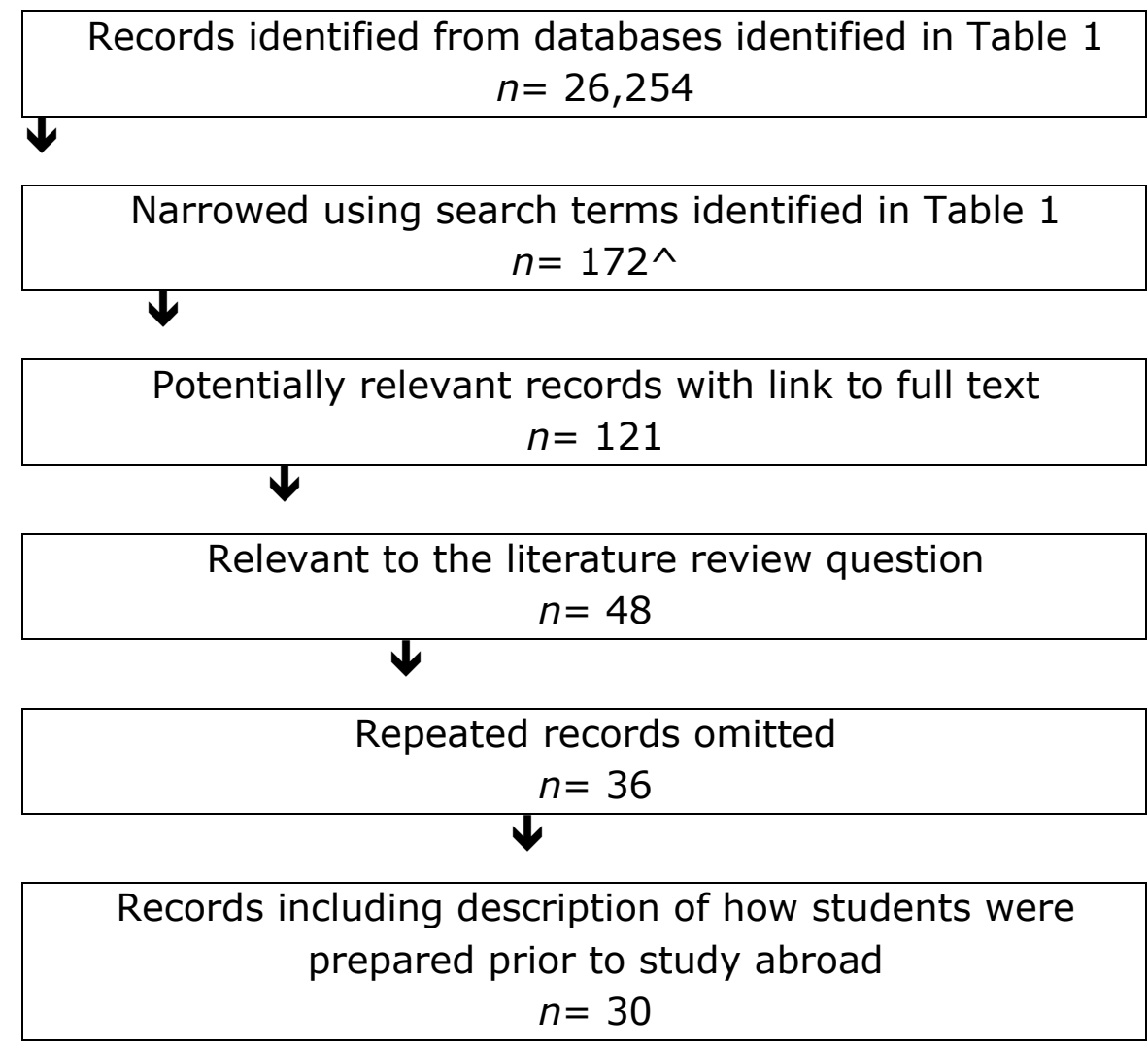

$\wedge 172$ excludes grey literature and ancestry searching; thus the difference between 214 from the final number in Table 2 and 172 in Figure 1.

\section{Data evaluation}

Data evaluation was only partially done in this review. Databases and sources of data were evaluated, with the number of papers found in Table 1 and the right column of Table 2. Evaluating the quality of sources for the review was deemed somewhat inapplicable due to the scarcity of papers on the subject. Nursing study abroad trips are a popular subject in the literature, however the preparation associated with them is rarely discussed. The search was expanded to a wide range of literature sources (Table 1) to 
avoid excluding relevant data, and little concern was given to the quality of sources, but rather to the subject matter. The topic of nursing study abroad trips pre-emptively excluded authors without experience in the subject, and meant papers were probably associated with HEIs which support students on study abroad trips. No papers chosen to include in the analysis were rejected on the grounds of poor quality. Appendix A contains a table of all included papers in the review with the type of empirical reporting used, however descriptive reports were the most commonly found papers. These papers described the journeys of students undertaking study abroad trips, but lacked empirical evidence. The number of papers descriptive in nature in nursing study abroad literature implies a low rigour in the way this subject has been presented, pointing to the need for more research of higher empirical quality.

\section{Data Analysis}

The common themes in nursing literature related to study abroad trips are discussed first to introduce the topic of 'preparation'. Themes that emerged from a content analysis of reading, rereading, and looking for common themes amongst included papers included benefits of study abroad trips and cultural competence. Other themes included risks and potential for harm, and post-colonial voyeurism. Preparation did not emerge as a prominent theme in the literature as it is rarely the topic under investigation.

The papers that matched inclusion criteria are below (see preparation), separated into several sections. Firstly, papers were separated according to the content of preparation. Some sending institutions offered academic credit for the preparation (referred to as 'courses') or meetings, which came to mean any preparation that was less formal and did not offer academic credit. Preparation curriculums were then discussed according to student responsibilities, and underpreparedness. 


\section{Study Abroad Trips}

Study abroad trips are increasingly popular (Crump, Sugarman et al. 2010), as the number of students studying abroad from the United Kingdom and the United States has increased every year (Open Doors 2017). United Nations Educational, Scientific and Cultural Organisation (UNESCO) reported that in the period of 2016/2017 academic year 34,025 Britons studied abroad, and 432,001 students came to the United Kingdom to study abroad (2018). The Bologna Goal (see Chapter 6; The Sending Institution) is striving for $20 \%$ of European students to study abroad from HEI's, many through the Erasmus programme (Dobrowolska, McGonagle et al. 2015). Alternatives to study abroad trips allow students to stay in their home country via videoconferencing (Kemppainen, Kim-Godwin et al. 2012, Chipps 2010), taking online courses with universities abroad (Falleiros de Mello, Larcher Caliri et al. 2018) or visiting public health clinics known for serving immigrant or refugee populations from other countries that still allow students to encounter a different culture (Lenz, Warner 2011, Riner 2011).

The themes that emerged following a content analysis are as follows:

1. Benefits of nursing study abroad trips to the following groups:
a. Nursing students
b. Sending institutions
c. Receiving institutions

2. Cultural competence

3. Risk and potential for harm

4. Preparation 


\section{Benefits of nursing study abroad trips}

Nursing students who study abroad reap an extensive list of benefits that are largely the focus of the literature. The following benefits are grouped, showing the most common to be personal growth and the development of cultural competence.

- Personal growth (Kent-Wilkinson, Leurer et al. 2015, Read 2011, Button, Green et al. 2005, Duffy, Farmer et al. 2005, Inglis, Rolls et al. 1998, Che, Spearman et al. 2010, Browne, Fetherston et al. 2015, Mill, Yonge et al. 2005, Kokko 2011, Davis, Wright et al. 2015, Westerbotn, Kneck et al. 2015, Zanchetta, Schwind et al. 2013, Keogh, Russel-Roberts 2009). Mill et al. (2011) found greater benefit to students from wealthier countries when studying in low human development countries.

- Development of cultural awareness/sensitivity/competence (KentWilkinson et al. 2015, Read 2011, Button et al. 2005, Duffy et al. 2005, Koskinen, Tossavainen 2003, Kokko 2011, Davis et al. 2015)

- Development of global citizenship (Kent-Wilkinson et al. 2015, Che et al. 2010, Browne et al. 2015, Smith, Weaver 2006, Tuckett, Crompton 2014)

- Comparison of healthcare systems between countries (Myhre 2011, Button et al. 2005, Duffy et al. 2005, Leh, Waldspurger et al. 2004, Reid-Searl, Dwyer et al. 2011, Davis et al. 2015)

- Enhanced future career prospects (Shailer 1997, Kent-Wilkinson et al. 2015, Duffy et al. 2005)

- Enhanced communication or language skills (Myhre 2011, Carpenter, Garcia 2012, Westerbotn et al. 2015)

- Contribution to global health, global relationships (Read 2011, Leh et al. 2004)

- Higher graduation rates, especially among 'at-risk students' or 'students of colour' (Smith, Curry 2011)

- Mutual transfer of knowledge and skills (Kelly 2000, Leh et al. 2004).

- Personal development (Zorn 1996, Tuckett, Crompton 2014)

- Improvement to nursing curriculum (Read 2011, Leh et al. 2004)

- Development of compassion (Davis et al. 2015) 
Certain student benefits are not equally distributed among cohorts. The typical student who studies abroad from North America and Europe is young, affluent, and white (Sherraden, Bopp et al. 2013), meaning that the benefits are disproportionately affecting a certain group of new nurses entering the workforce (see Post-Colonial Voyeurism, below). One study abroad trip found less confident students standing back, allowing the confident students to get the bulk of experience and thus learning while studying abroad (Tam 2016). Even within study abroad groups, educational divides exist.

The greatest justification that propels the continuation of study abroad trips is that of increasing the cultural competence of new nursing graduates (see Cultural Awareness, Cultural Competence, and Cultural Sensitivity, below) (Petzold, Peter 2015). The theory of planned behaviour (Ajzen 1985, Ajzen 1991) supports the rising popularity of study abroad trips, as the academy's perception towards them is the sum of the positively valued benefits, as listed above. Considering the benefits associated with studying abroad, such trips are not required, but rather optional elective courses.

However, while cultural competence justifies the pattern of study abroad trips, the most commonly discussed benefit is not cultural competence - it is students' personal growth. There is no doubt that nursing students learn and grow personally from studying abroad, but one study found such trips had little impact on students' intellectual development (Inglis et al. 1998) an important distinction from the frequently cited benefit of personal growth (see list above). HEIs may expect more culturally competent nursing graduates from those who study abroad, but the literature lacks evidence to support benefits due to the primarily descriptive, self-reported data used to measure said benefits (see cultural awareness, cultural competence, and cultural sensitivity), which leaves little justification for the continuation of an unrequired, expensive, journey abroad for students.

Benefits for sending institutions such as HEIs and the NHS are discussed less than the benefits accruing to nursing students. Study abroad trips provide for an innovative transfer of ideas, many of which can challenge 
current practice (All-Party Parliamentary Group 2013, Kelly 2000, Leh, Waldspurger et al. 2004), for example when study abroad trips are evaluated (Read 2011, Leh, Waldspurger et al. 2004). Familiarity of caring for patients from different cultural backgrounds leads to improved patient care (NHS 2010). Employers and HEIs can benefit from increased skills from newly qualified nurses who studied abroad previously, and as a result may require less training (All-Party Parliamentary Group 2013, NHS 2010), as well as prestige for working in global health (All-Party Parliamentary Group 2013, NHS 2010).

Benefits for the receiving institution and the recipients of care are the least discussed group in the literature. The All-Party Parliamentary Group suggests the presence of healthcare workers may strengthen the capacity of local health systems (2013). Conversely, medical trips can also fragment local health systems, forcing reliance on foreign aid and healthcare workers (Mellett 2010, Pfeiffer 2003). Healthcare workers who are unfamiliar with local health needs may cause harm rather than benefit (Sherraden, Lough et al. 2008; see Chapter 1, Personal Context). Healthcare workers may nullify benefits to receiving populations by leaving behind large amounts of medical waste (Suchdev, Ahrens et al. 2007) or burdening local healthcare structures with follow-up care after performing invasive procedures (Asgary, Junck 2012). A further critique is the supposed lack of government protocols to guide practice for trips, or a regulatory body from sending countries with the authority to judge harmful practices (All-Party Parliamentary Group 2013, Papi 2013). Still, international relationships are strengthened through study abroad programmes (All-Party Parliamentary Group 2013, World Health Organisation 2009), which benefit both sending and receiving institutions. Local populations also thank medical volunteers for coming so far, seeking to understand, and exhibiting that people care (DeCamp 2007) while accepting care (All-Party Parliamentary Group 2013, Kelly 2000, Leh, Waldspurger et al. 2004). 


\section{Cultural awareness, cultural competence, and cultural sensitivity}

The only theme in the literature more prominent than study abroad benefits for the nursing student is cultural awareness, cultural competence, and cultural sensitivity. The need for nurses to enter the workforce with cultural competence is a prominent - if not oversaturated theme in the literature (Koskinen, Tossavainen 2003, Egenes 2012, Kemppainen et al. 2012, Kokko 2011, Ruddock, Turner 2007, Button et al. 2005, Koskinen, Tossavainen 2004, Delpech 2013, Amerson 2010, Green, Comer et al. 2011, Bosworth, Haloburdo et al. 2006, Hu, Andreatta et al. 2010, Johns, Thompson 2010, Kohlbry, Daugherty 2015, Westerbotn et al. 2015, Duffy et al. 2005, Leh et al. 2004, Kreye, Oetker-Black 2013, Gower, Dantas et al. 2018). Indeed it is difficult to find literature on the subject of nursing study abroad trips that does not mention a term synonymous to cultural competence/awareness.

All known cultural competence assessment tools use self-reporting data (Durrant, Brown et al. 2008, Ingraham, Peterson 2004, Loftin, Hartin et al. 2013). This begs the question 'should cultural competence be measured with a more reliable technique which does not pose the risk of choosing socially desirable answers?' (Curtin, Martins et al. 2015). A systematic review of self-administered cultural competency tools found only two methods: self-assessments and written exams, with only $13 \%$ of articles demonstrating trustworthiness and reliability (Gozu, Beach et al. 2007). Typically, self-reported surveys are completed immediately following students' return home, which introduces bias due to the euphoric emotions many students experience at this time (Seals 2013, Inglis et al. 1998) or equally negative, angry emotions at the lack of empathy of those who did not have the same experience (Kirkham, Van Hofwegen et al. 2009). The lack of rigour in cultural competency assessment methods limits the trustworthiness of the findings, and discredits the primary justification for nursing study abroad trips.

Indeed, some students do not even report progressing toward cultural competence, showing no signs of new perspective following a study abroad trip (Foronda, Belknap 2012, Tam 2016). In other words, study abroad trips do not necessarily guarantee a cultural benefit to students. Upon graduation, 
Kardong-Edgren and Campinha-Bacote (2008) found nursing students only achieved cultural awareness, not cultural competence. Carpenter and Garcia (2012) did not see noteworthy change in nursing students' cultural thinking after studying abroad. Others found study abroad trips gave nursing students increased cultural sensitivity (Bosworth et al. 2006, Hu et al. 2010, Johns, Thompson 2010), suggesting the international experience provides students with an extra boost to reach cultural competence than standard nursing curriculum alone.

The study abroad trip has become a case study, by which students encounter and learn about a new culture. In other words, students are expected to learn one culture through immersion in the study abroad location, and then return home having learned cultural competence. This is done so nursing students can then achieve cultural competence before entering the increasingly diverse healthcare workplace (Halcomb, Antoniou et al. 2018). The case study method was used in this thesis (see Chapter 4; Case Study, Chapters $5 \& 6$ ) as a method best suited to study a phenomenon at a specific level, to later move on to a generalised understanding of the phenomenon. Of course students can learn in the classroom a generalised knowledge of culture, but encountering a new environment and culture, even for a short time, has been shown via the case study method to be more effective than beginning with generalizations (and the researcher would hope no educators would posit that a nursing student is 'culturally competent' after a classroom study of generalised cultural studies). Still, the act of sending nursing students abroad to achieve culture competence is arrogant.

\section{A critique of cultural competence}

Leininger's definition of cultural competence (see Chapter 1 ) is based on her role as an ethnologist. She immersed herself in the culture of one group for long periods of time and thus was able to offer culturally specific care to her patients. There is an assumption in cultural competence discussions that optimal care is provided when a nurse either shares the same culture, or is knowledgeable about the patient's culture. Ironically, and contrary to all best efforts, the immutable healthcare system is not set up in a way to 
make drastic changes for every variance in culture represented across the patient population. Still, cultural competence has become a popular, widespread requirement for healthcare practitioners, which is an unreasonable expectation. Instead a different perspective of 'cultural humility' is explored.

Current literature and the methods of educating students on the subject of culture are unexamined and noncritical (Gray, Thomas 2005). Culture is often portrayed in an 'essentialist' view, that is every member of a certain culture identifies with a set of unifying features. This encourages 'geographical straitjackets', or 'essentialising' the myriad of backgrounds, values, and experiences of a location when teaching a student about the culture in the study abroad location (Härkönen, Dervin 2016). The nurses' responsibility is not to ensure cultural competence, but to facilitate the patient's navigation through the healthcare encounter through the nurse acting as 'mediator' (Gray, Thomas 2005).

Nursing study abroad trips are largely justified as preparation for future nurses in an increasingly diverse population. However, cultural diversity establishes that there is a dominant culture and deviants of the dominant culture. What is labelled as the 'other' (Canales 2000) is subsequently labelled as 'diverse'. Othering is a phenomenological term that means people unlike the 'Self' are in a subordinate class; excluding someone from belonging to the norm (Racine, Perron 2012). Erasmus' new learning objectives encourage students to learn to engage the 'other' in a nonessentialising manner (Härkönen, Dervin 2016), which arguably exceeds the abilities of a preparation curriculum that has no specified content or length - if preparation happens at all. Study abroad trips are intended for students to learn from the 'international Other', but it is ambitious to assume students will achieve cultural competence through a study abroad trip. It requires more than good intentions to help the 'Other' (Racine, Perron 2012), and relying on all healthcare workers to embody cultural competence is unrealistic. 
Culture is inherently a socio-historical construction (Gray, Thomas 2005). Considering this gives rise to a range of questions around what purpose the concept of cultural competence serves in nursing pedagogy and the credibility of striving to achieve it in healthcare systems. Further, who was the first person to use the cultural label, was it self-assigned or placed on another human being? What consequences, intended or unintended, exist for people groups as a result of this label for 'culture' and its associated characteristics? Finally, what benefit comes from dichotomizing one person as an insider or an outsider? The researcher agrees with the suggestion that culture is a construct and suspects it does not need to play as prominent a part in nursing education as it currently does (Dreher, MacNaughton 2002, Kardong-Edgren, Campinha-Bacote 2008).

An alternative approach would draw on a primary Aristotelian moral principle as the starting point for cultural education: that nursing students learn to treat all humans with value and respect. This could be coupled with a practice in cultural humility (Kulbok, Mitchell et al. 2012). Tervalon and Murray-Garcia (1998) describe cultural humility as contradictory to cultural competence, calling for an attitude of continued reflection and critique on the part of the healthcare provider, who is called to collaborate with the person being provided care in a respectful manner, hoping to understand difference wherever it is found. To clarify the concepts of cultural competence and cultural humility, one must acknowledge the wider context of health inequalities and structural constraints. On one side, cultural competence supposes an arrogance that the healthcare provider already understands the culture of that patient. On the other side, cultural humility assumes the healthcare practitioner does not understand the patient's culture, and remains aware that health inequalities or otherwise structural barriers exist over which the patient may not have control. The patient is then invited to guide the healthcare encounter in a culturally safe, appropriate manner. Newly qualified nurses should not enter the workforce thinking they will understand a patient's culture while working in a quickpaced clinical environment. The researcher posits that the conversation should shift away from cultural competence. Cultural competency is missing 
the mark, but is not far from a more worthwhile goal of cultural humility, attention to dignified care, and respect to all persons.

\section{Risks and potential for harm}

To ensure nurses enter the workforce able to care for patients from different cultures, study abroad trips have become an expensive, high-risk solution. As stated in the previous section (see Cultural Awareness, Cultural Competence, and Cultural Sensitivity), the study abroad trip becomes the preparation for students to enter the nursing workforce with greater cultural awareness, language skills, and expanded worldviews. Rather than prepare nursing students to study abroad, HEIs prepare students for their future career via the study abroad trip (Conejo, Loyd 2017, Bowker, Tomlinson 2017, Aggar, Bloomfield et al. 2017, Smallheer, Hunt et al. 2018, ØgårdRepål, De Presno et al. 2018). The problem is that articles on cultural competence are preoccupied with the impact and benefit on nursing students who have travelled abroad, and little mention is given to the patient populations for which care is provided (Crump et al. 2010). The following risks are present for nursing students and patients in study abroad locations.

Study abroad trips can induce feelings of discomfort in students, arguably aiding in the education process. Greatrex-White (2008) discusses how study abroad trips trigger a 'positive disturbance', able to expose racism, beliefs, and assumptions. Others identify stressors students may experience abroad as a time ripe for learning (Lear, Eboh et al. 2018), referring to the phenomenon as constructive disequilibrium (Che et al. 2010). However, feelings of discomfort can quickly become more serious while studying abroad, as difficult living conditions, lack of resources, dangerous environments, the desire to make a positive impact with limited time, and trying to replicate practices from one's home country can induce culture shock (Chisholm, Pettigrew 2012). The number of students who reported culture shock in the literature is high (Kent-Wilkinson, Starr et al. 2010, Egenes 2012, Heuer, Russell et al. 1997, Button et al. 2005, Duffy et al. 2005, Caldwell, Purtzer 2015, Arthur 2001) (this is by no means an exhaustive list). Some students felt prepared logistically but not ready for 
culture shock, with one student reporting that maybe her group should not have come, and that perhaps they did more harm than good (Caldwell, Purtzer 2015). Others reported feeling unprepared for the level of poverty they saw and the struggle of daily life, which induced culture shock (Arthur 2001). A student described her 'massive culture shock' after realising her inability to communicate even with the presence of translators (Tuckett, Crompton 2014). Finally, inaccurate predictions about what students would find upon arrival to their study abroad site were found to be as detrimental as culture shock (Härkönen, Dervin 2016).

Beyond culture shock, risks span physical, clinical-professional, and sociocultural harm (Bell 2014). Unforeseen risks may include accidents, political unrest, ill health due to climate, psychological disorders, and assault (Morgan 2012). When a group of study abroad coordinators was asked what advice they had for future study abroad trips, one recommendation was for students to be told not to partake of drugs and alcohol, along with a warning that they had lost count of the times students had lost passports, reported rape, or ended up in dangerous situations (Seals 2013). The risks involved in international travel for young students, some of whom have never travelled outside their home country before, are too great for a laissez-faire approach to preparation.

Physical harm and culture shock for students are indeed a concern, and are equally important to physical harm done to patients. Interestingly, examples of harm are not present in the literature, presumably due to fear of legal ramifications or damaged reputation of an academic institution. Presumably, there would be at least one case of a post-surgical infection after a medical team returns to their home country. Just as likely would be a patient who exhibits an allergic reaction to a medication, or perhaps children who consumed a month supply of sweet-tasting vitamins for a meal in food-insecure locations. Putting physical harm aside, malpractice stories are unnecessary to warrant more scrutiny of study abroad trips. An understanding of ethical requirements that occur in all other subjects, it seems, except study abroad trips warrants more scrutiny. 
Allowing students to provide care in a foreign context for the purpose of gaining a skill is ethically problematic, especially when the trend of study abroad trips takes students from wealthier countries to areas with marginalised populations who lack access to medical care. Some HEIs mandated that their students acquire indemnity insurance to practice (Shailer 1997, Mill et al. 2005) while others prohibited hands-on learning and only allowed observation, due to the possibility of legal ramifications should a student cause harm while providing care. Still, only a few of the articles specified whether students could observe (Folse, Jarvis et al. 2015, Leh et al. 2004) or practice (Green, Johansson et al. 2008, Davis et al. 2015), leaving the reader to question whether many HEIs had even considered the issue and left students to practice abroad without insurance.

Clinical trials and medical research must receive permission from governing and ethical bodies to be undertaken (DeCamp 2007). The same scrutiny does not exist in study abroad trips. A review of sending institutions found that ethics regarding global health was listed as a core topic, but rarely discussed (Pinto, Upshur 2009). Medical students often perform their first clinical skills while studying abroad, performing acts that are not yet allowed in their home countries (Bhat 2008) - a Voluntary Service Overseas (VSO) survey found $80 \%$ of respondents believed they gained expertise that they would not have been able to get in their home countries (NHS 2010). Perhaps this explains why students reportedly learn more when studying abroad in 'developing countries' (Miranda, Yudkin et al. 2005). Stanford University's dean of global health was quoted as saying short-term study abroad trips are no longer appropriate, but even still, universities are pressured to offer them due to the pressure of students having such experiences for acceptance into medical schools and public health schools (Cole 2016).

The Nursing and Midwifery Council (NMC) published standards for education and training with regards to cultural education. The NMC standards delineate educational programmes will only be approved if cultural education is ethical and safe (among other requirements) (NMC 2018). It does not appear from the current discussion of nursing study abroad trips, 
which are justified to provide cultural education, are following the standards laid out by the NMC. If this claim is true, the researcher questions whether the NMC would either exempt study abroad trips from academic credit, or entire programmes that offer such trips if ethical practice are indeed found to be in question.

The academy has failed to consider the ethical ramifications of study abroad trips, and the question remains, why do short-term study abroad trips have so little scrutiny? The focus is not on the population receiving care at the study abroad trip site - but on the learning opportunities for the students. Risks and potential for harm affect both students and patients, and lack of scrutiny for study abroad trips has led some to call them voyeuristic.

\section{Post-colonial voyeurism}

The absence of preparation, inconsistent learning objectives, and lack of benefits for the hosting institution have led some to criticise study abroad trips as tourism under the guise of volunteerism, or as the portmanteau word suggests, mere 'voluntourism' (Myles 2013, Mellett 2010), where usually the most affluent students benefit (Miranda et al. 2005). The emphasis is not benevolence, but acquisitive desire. Study abroad trips have the potential to take advantage of local populations to use them as a means to an end, the end being the nursing students learning about one culture which will hopefully, but not necessarily, lead to culturally competent nurses. It is also noteworthy that the sending HEIs primarily originate from the United Kingdom, the United States of America, and Scandinavian countries (Kulbok et al. 2012), and often travel to low-income countries. While it is difficult to amass data from all sending HEIs, one report found that $40 \%$ of students studying abroad go to 'developing countries' (Dowell, Merrylees 2009). Nursing study abroad trips have been called acts of conspicuous altruism (Sochan 2008); or an acceptable way of improving international relations while benefiting the sending institution's reputation. Such trips carry benevolent ideals, but have great potential for educational exploitation (Racine, Perron 2012). 
Ramsden (2002) tells of a nursing student who assessed an 'interesting' and 'exotic' [sic] patient from a position of power and with a patronizing attitude. Ramsden described the trip as 'cultural tourism' or 'voyeurism'. In another study meant to assess students' cultural sensitivity, Walsh and DeJoseph (2003) found a group of students felt deserving of a higher status due to their presence in a country less developed than their own. Whereas, when a group of students studied abroad and for the first time saw the extreme poverty experienced in another country, they felt gratitude for their higher socioeconomic status (Edmonds 2012). The authors stated that the students felt so confident that many felt they were already nurses and reported an increase in self-confidence after the trip. Along the same lines is Lord Nigel Crisp's account of overhearing a colleague in Ghana, who blissfully spoke of how wonderful it was to do humanitarian aid there because he could do and teach whatever he wanted (Crisp 2007).

Recommendations exist for developing the study abroad trips to be carried out in a culturally safe and ethically sound manner (Racine, Perron 2012). Practically speaking, one step the nursing profession can take towards cultural safety is to follow the suggestion of Anderson et al (2003): to consider preconceived ideas that may arise due to the patient's perceived race or ethnicity, and identify how that may impact care that ought to be delivered in a respectful, dignified manner. A possibility to reduce the risk of harming the local population and avoid replicating colonialist tendencies have been suggested by theorists such as Bakhtin's concepts of dialogism and unfinalisability (1984, Bakhtin 2006). Critical consciousness (Kumagai, Lypson 2009) is a concept that requires students to become aware of the societal injustices that perpetuate health inequalities (among other inequalities) in minority groups. In other words, once the healthcare providing community understands the power injustices that affect the health of those not belonging to the 'dominant' group, this leads to the appropriate treatment of patients in a diverse and dynamic patient population. Another theoretical tool describes three perspectives (Wright, Zerbe et al. 2001) that can be used as models to create international health programs: the traditional, transitional, and new perspectives. The traditional perspective views developing countries as dependent on 
developed countries; that dependent countries 'need help' and require a one-way transfer of knowledge. (When asked, nursing students tend to speak from the traditional, arguably colonialist perspective (Leh et al. 2004)). The transitional perspective holds the belief that developing to developed countries exist on a continuum, a continuum which has many of the same health problems, and thus the underdeveloped and developed countries can collaborate and help one another. The new perspective focuses on equality and partnerships between high and low-income countries. All parties have something to offer.

The discussion on cultural competence, risk for harm, and colonialist tendencies are only rarely mentioned in the nursing study abroad literature. How could students be prepared to arrive to a new location with cultural safety in mind when no preparation for this has been given?

\section{Preparation}

Preparation was chosen for the topic of this thesis for two reasons: firstly, the researcher encountered study abroad trips that lacked preparation (see Chapter 1; Personal Context), and thus a question arose of whether this was the experience of other nursing students. Secondly, while reading the literature on study abroad trips early in the research process, the topic of preparation was found to be lacking in most articles, and when discussed, preparation was incidental - a recommendation found in concluding remarks rather than a thoroughly described process (Edmonds 2012, Folse et al. 2015, Kulbok et al. 2012, Ruddock, Turner 2007, Maginnis, Anderson 2017, Morgan 2012).

Descriptive accounts of student experiences undertaking trips abroad are widely published (Aarts et al., 2010; De Natale \& Waltz, 2015; KentWilkinson et al., 2010; Kent-Wilkinson et al., 2015; Price, Janicki, McKee, Nurse, \& Gray, 2014), however preparation for such trips is underrepresented. It was the researcher's task to systematically uncover information about preparation scattered throughout the literature, to determine how students are being prepared to study abroad. 


\section{Nursing study abroad preparation}

Of the 214 articles collected on nursing study abroad trips, 30 of them (14\%) discussed preparation (see Table 2; see Appendix A for a table summarising the findings of the 30 articles). No two methods of preparation were the same, however certain themes overlapped in some cases (see bullet point lists in preparation subjects in credited courses; meetings below).

The following is a discussion of the 30 articles that highlight preparation, most of which scarcely met the criteria for inclusion having one sentence spent on the subject. Considering other fields, $14 \%$ is lower than what is seen among medical student literature, with just fewer than $30 \%$ participating in preparation before studying abroad; and $48 \%$ of students in a general category of health professions reporting never receiving any preparation prior to studying abroad (Kironji, Aluri et al. 2014). Preparation is discussed more frequently among medical students before studying abroad, however preparation is still lacking among this group (Miranda et al. 2005). Still, nursing was the group with the lowest percentage of preparation discussed in the literature.

The following discussion of the 30 articles is categorised according to content of preparatory training, whether sending institutions offered courses or meetings, student responsibilities, sending and receiving organisation responsibilities, and underpreparedness in the literature. The $86 \%$ of articles that made no mention of preparation are a justification for this research, and the need for evidence-based practice in the field of nursing study abroad trips.

\section{Content of preparatory training}

The purpose of this section is to answer the literature review question by reporting the many ways in which nursing students are prepared to study abroad. The total content of preparation training is below (see Courses; Meetings). To provide an example of the widely varying preparation styles, consider the following. At one sending institution, a required preparation course covered the culture of the study aboard host location (Farmer, Raver 
et al. 2003). At another sending institution, a course taught applied research strategies, global health/health disparities, expectations of daily activities while abroad, and the culture and values of the host country (Anderson, Friedemann et al. 2012). Two different tracks were offered at another HEI - one for students planning to study abroad, and one for those who were not - but offered little explanation as to the difference (Read 2011). At another institution, language courses were recommended, however the language courses were not always offered at the appropriate semester before students would study abroad, complicating students' ability to prepare linguistically (Critchley, Richardson et al. 2009). Two consortiums of universities had differing preparation courses, even within their collaborative institutions (Koskinen, Jokinen 2007, Duffy et al. 2005). In one consortium (Koskinen, Jokinen 2007), a Finnish university had an 18-month preparation course, while partnering universities in other countries did not receive credit. The Finnish students were more prepared than students from other countries due to a longer preparation period. A by-product of a longer duration of preparation training is relationship building (Egenes 2012). Students get to know one another and the faculty members who will support them prior to travelling together. Others saw students' anxieties decrease throughout the preparation process as the group's camaraderie strengthened (Lachat, Zerbe 1992).

Another article referred to preparation that started 'anywhere from one week to a year prior to departure' (Pross 2005 p. 629). Some subjects overlapped, but preparation for study abroad trips lacks standardization, best practice, and criticality. It places an undue burden on study abroad coordinators of reinventing the preparatory wheel at each HEI. The following sections on courses and meetings further display the differences in preparation styles, with a complete account of all preparation subjects included articles in Appendix A.

\section{Courses}

Some students took courses that received academic credit, while others simply attended a meeting or two with their study abroad coordinator. It was challenging to differentiate whether preparation trainings were informal 
orientation meetings, or required courses. Several terms were used interchangeably in the literature. In this section, 'course' refers to mandatory preparation that held academic credit, and 'meeting' refers to any other sort of preparation that students attended without academic credit. Preparation subjects were separated into two groups for discussion: those that offered academic credit and those that did not. Confusingly, many study abroad trips are courses in and of themselves, but preparation is not necessarily part of this credited course. Courses with academic credit were more comprehensive than meetings, but had widely varying content. Similarities occurred, but preparation content was never repeated in any two articles - all methods were unique. Content that was repeated in both courses and meetings are displayed separately (see Figure 2). The varying content of the courses is below in Table 3 (see also bullet point list for number of articles using each approach): 
Table 3: Preparation Subjects in Credited Courses

\begin{tabular}{|c|c|c|c|c|c|}
\hline & Author & Title & Publisher & Countries & Preparation \\
\hline 1. & $\begin{array}{l}\text { Duffy ME; } \\
\text { Farmer S; } \\
\text { Ravert P; } \\
\text { Huittinen L }\end{array}$ & $\begin{array}{l}\text { Institutional issues in } \\
\text { the implementation } \\
\text { of an international } \\
\text { student exchange } \\
\text { program. }\end{array}$ & $\begin{array}{l}\text { Journal of } \\
\text { Nursing } \\
\text { Education } \\
2003\end{array}$ & $\begin{array}{l}\text { USA, } \\
\text { Finland, UK, } \\
\text { Portugal }\end{array}$ & $\begin{array}{l}\text { Two-credit course, semester before exchange covering culture of host } \\
\text { country. }\end{array}$ \\
\hline 2. & Read, CY & $\begin{array}{l}\text { Semester abroad } \\
\text { opportunities in } \\
\text { Baccalaureate } \\
\text { nursing programs }\end{array}$ & $\begin{array}{l}\text { Journal of } \\
\text { Professional } \\
\text { Nursing } \\
2011\end{array}$ & USA & $\begin{array}{l}\text { Preparation is presented in terms of curriculum. Students are presented } \\
\text { with two tracks: those who will study abroad and those who will not. } \\
\text { Students are guided on how to plan courses differently if they intend to } \\
\text { study abroad, and states the HEI's infrastructure can assist students with } \\
\text { common limitations such as transferring credits and housing while abroad. }\end{array}$ \\
\hline 3. & $\begin{array}{l}\text { Anderson } \\
\mathrm{KH} ; \\
\text { Friedemann, } \\
\text { ML; Büscher, } \\
\text { A; Sansoni, } \\
\text { J; Hodnicki, } \\
\text { D } \\
\end{array}$ & $\begin{array}{l}\text { Immersion research } \\
\text { education: Students } \\
\text { as catalysts in } \\
\text { international } \\
\text { collaboration } \\
\text { research. }\end{array}$ & $\begin{array}{l}\text { Internation } \\
\text { al Nursing } \\
\text { Review } \\
2012\end{array}$ & $\begin{array}{l}\text { USA, } \\
\text { Germany, } \\
\text { Italy, } \\
\text { Columbia, } \\
\text { Austria, } \\
\text { Thailand }\end{array}$ & $\begin{array}{l}\text { Students take a course providing training in applied research strategies, } \\
\text { global health/health disparities, and expectations of daily activities while } \\
\text { abroad. A three-week online seminar is mandatory for students, which } \\
\text { details the culture and values of the host country. Students are connected } \\
\text { with a contact person in the host country with whom they dialogue about } \\
\text { the research topic to be addressed upon arrival. }\end{array}$ \\
\hline 4. & $\begin{array}{l}\text { Bosworth, } \\
\text { TL; } \\
\text { Haloburdo, } \\
\text { EP; Hetrick, } \\
\text { C; Patchett, } \\
\text { K; } \\
\text { Thompson, } \\
\text { MA; Welch, } \\
\text { M }\end{array}$ & $\begin{array}{l}\text { International } \\
\text { partnerships to } \\
\text { promote quality } \\
\text { care: faculty } \\
\text { groundwork, student } \\
\text { projects, and } \\
\text { outcomes. }\end{array}$ & $\begin{array}{l}\text { Journal of } \\
\text { Continuing } \\
\text { Education } \\
\text { In Nursing } \\
2006\end{array}$ & $\begin{array}{l}\text { USA, } \\
\text { Guyana }\end{array}$ & $\begin{array}{l}\text { US students took a course on international health, globalisation, history, } \\
\text { and culture of Guyana, were given information on the economics, politics, } \\
\text { and health problems in Guyana. Students then identified a topic of health } \\
\text { education for a health talk, and finally wrote research questions about the } \\
\text { beliefs, health, and culture of the Guyanese. }\end{array}$ \\
\hline 5. & Czanderna, & $\begin{array}{l}\text { A qualitative study } \\
\text { on the impact of a }\end{array}$ & PhD & USA, India, & Study abroad course including various requirements. Students were also \\
\hline
\end{tabular}




\begin{tabular}{|c|c|c|c|c|c|}
\hline & Author & Title & Publisher & Countries & Preparation \\
\hline & $\mathrm{KH}$ & $\begin{array}{l}\text { short-term global } \\
\text { healthcare } \\
\text { immersion } \\
\text { experience in } \\
\text { Bachelor of Science } \\
\text { nursing students }\end{array}$ & $\begin{array}{l}\text { dissertation } \\
2013\end{array}$ & $\begin{array}{l}\text { Ecuador, } \\
\text { South } \\
\text { Africa, The } \\
\text { Netherlands }\end{array}$ & $\begin{array}{l}\text { given information from many sources. The physician coordinator of the } \\
\text { trip handed out instructions for the trip. Advice from previous study } \\
\text { abroad students added to the preparation process. The international } \\
\text { resource office offered guidebooks of the host country. Students were } \\
\text { required to attend meetings, complete assigned readings and paperwork } \\
\text { as well as attend discussion forums. Preparation was underpinned by } \\
\text { Jeffrey's Cultural Competence and Confidence model. (Jeffreys \& } \\
\text { Smodlaka, 1996). }\end{array}$ \\
\hline 6. & Kreye, J & $\begin{array}{l}\text { A global service- } \\
\text { learning experience } \\
\text { for nursing students } \\
\text { in Tanzania: A model } \\
\text { for collaboration }\end{array}$ & $\begin{array}{l}\text { Nursing } \\
\text { Forum } \\
2013\end{array}$ & $\begin{array}{l}\text { USA, } \\
\text { Tanzania }\end{array}$ & $\begin{array}{l}\text { Students prepared to team teach in Tanzania and took a semester-long } \\
\text { transcultural nursing course underpinned by Ray's (2010) transcultural } \\
\text { caring dynamics. }\end{array}$ \\
\hline 7. & $\begin{array}{l}\text { Koskinen, L; } \\
\text { Jokinen, P }\end{array}$ & $\begin{array}{l}\text { Multicultural } \\
\text { healthcare: A } \\
\text { transatlantic project }\end{array}$ & $\begin{array}{l}\text { Nurse } \\
\text { Educator } \\
2007\end{array}$ & $\begin{array}{l}\text { Finland, } \\
\text { England, } \\
\text { Sweden, } \\
\text { USA }\end{array}$ & $\begin{array}{l}\text { Students had the option of completing an intercultural orientation credit } \\
\text { course prior to studying abroad. } \\
\text { The courses varied based on the university from which students studied } \\
\text { abroad. Preparation may have included virtual learning that included } \\
\text { games. Courses were underpinned by two theories, Howell's (1982) } \\
\text { communication theory and Bennett's (1993) developmental theory of } \\
\text { intercultural sensitivity. However, between the six universities in the } \\
\text { article, there was variance in how the theories were taught to students. } \\
\text { The Finnish students were more prepared than the American students due } \\
\text { to a longer preparation period. The preparation described was in relation } \\
\text { to achieving cultural competence more than to the trip in general. }\end{array}$ \\
\hline
\end{tabular}




\section{Preparation subjects in credited courses}

Topics of information

- What to expect daily while abroad (Anderson et al. 2012)

- Different academic track for students intending to study abroad (Read 2011)

- Students compose research questions about host location (Bosworth et al. 2006)

- Applied research strategies (Anderson et al. 2012)

- Virtual learning, including games (Koskinen, Jokinen 2007)

- Global health (Bosworth et al. 2006, Anderson et al. 2012)

- Globalisation (Bosworth et al. 2006)

Sources of information

- Physician coordinator on trip handed out preparation information (Czanderna 2013)

- Students attend discussion forums (Czanderna 2013)

\section{Meetings}

Several terms were used that referred to students preparing together without receiving academic credit. Terms for meetings from the literature included: one evening orientation, discussions, seminars, modules, prerequisite weekend classes, sessions, weekly meetings, a six month group preparation, and workshops. All such words were changed to 'meetings' for the purpose of this thesis and to find similarities within preparation methods.

Like courses, meetings had widely varying content. Perhaps the most notable variation was length of preparation training. Some studies suggested that longer preparation benefited students (Koskinen, Jokinen 2007). The shortest preparation students received was one meeting (Goldberg, Brancato 1998), with other universities offering four (Egenes 2012, Saenz, Holcomb 2009, Rolls, Inglis et al. 1997), five (Curtin, Martins et al. 2013), six (Ferranto 2013), or an unspecified number of meetings (Wros, Archer 2010, Shailer 1997, Delpech 2013, Bohman, Borglin 2014, Green et al. 2008, Currier, Omar et al. 2000, Mill et al. 2005). Others were defined not by number of meetings, but by the amount of time before the 
study abroad trip, such as six months before studying abroad (Ter Maten \& Garcia-Maas, 2009).

Where there was one preparation meeting, nursing students were given information covering course requirements, cultural similarities and differences, and a copy of their travel itinerary (Goldberg, Brancato 1998). Presumably, the students may not have retained all the information in such a short time. Meetings covered any number of the following styles, with the most similar two being Egenes (2012) and Bosworth (2006), which were courses and meeting, respectively. Content that was repeated in both courses and meetings are displayed separately (see Figure 1). The varying content of the meetings is below in Table 4 (see also bullet point list for number of articles using each technique): 
Table 4: Preparation Subjects in Meetings

\begin{tabular}{|c|c|c|c|c|c|}
\hline & Author & Title & Publisher & Countries & Preparation \\
\hline 1. & $\begin{array}{l}\text { Goldberg, } \\
\text { LK; } \\
\text { Brancato, } \\
\text { VC } \\
\end{array}$ & $\begin{array}{l}\text { International } \\
\text { education: A United } \\
\text { Kingdom nursing } \\
\text { student partnership }\end{array}$ & $\begin{array}{l}\text { Nurse Educator } \\
1998\end{array}$ & USA, UK & $\begin{array}{l}\text { One evening orientation session covering course requirements, cultural } \\
\text { similarities and differences, and travel itinerary. }\end{array}$ \\
\hline 2. & $\begin{array}{l}\text { De Natale, } \\
\text { ML; Waltz, } \\
\text { CL }\end{array}$ & $\begin{array}{l}\text { Reflections of nursing } \\
\text { students travel } \\
\text { abroad experiences } \\
\text { in Ireland: A global } \\
\text { nursing perspective. }\end{array}$ & $\begin{array}{l}\text { Nursing } \\
\text { Education } \\
\text { Perspectives } \\
2015\end{array}$ & Ireland, USA & $\begin{array}{l}\text { Pre-immersion seminar meetings, selected journal readings, and } \\
\text { collaborative preparation for a health-teaching project that provided } \\
\text { opportunities for dialogue with Irish nurses at a local hospital. The time } \\
\text { given to the preparation was valuable in building community among the } \\
\text { nursing students before they began the study abroad experience. }\end{array}$ \\
\hline 3. & Shailer, B & $\begin{array}{l}\text { Clinical electives: } \\
\text { The challenges and } \\
\text { benefits of student } \\
\text { choice }\end{array}$ & $\begin{array}{l}\text { British Journal } \\
\text { of Nursing } \\
1997\end{array}$ & $\begin{array}{l}\text { UK, USA, West } \\
\text { Indies, Canada }\end{array}$ & $\begin{array}{l}\text { Preparatory discussions with students by faculty. Students responsible to } \\
\text { seek out their own preparation through university's international } \\
\text { department. Students write contract of what they hope to achieve during } \\
\text { elective course. }\end{array}$ \\
\hline 4. & Egenes, KJ & $\begin{array}{l}\text { Health care delivery } \\
\text { through a different } \\
\text { lens: The lived } \\
\text { experience of culture } \\
\text { shock while } \\
\text { participating in an } \\
\text { international } \\
\text { educational program }\end{array}$ & $\begin{array}{l}\text { Nurse } \\
\text { Education } \\
\text { Today } \\
2012\end{array}$ & US, UK & $\begin{array}{l}\text { Students attend four three-hour seminars monthly during the fall } \\
\text { semester. Content includes a brief overview of British history, culture, } \\
\text { economics, politics, and customs, with an emphasis on nursing in } \\
\text { England. Suggests faculty should familiarise themselves with culture } \\
\text { shock prior to the trip to support students who are struggling in their new } \\
\text { environment }\end{array}$ \\
\hline 5. & $\begin{array}{l}\text { Saenz, K; } \\
\text { Holcomb, L }\end{array}$ & $\begin{array}{l}\text { Essential tools for a } \\
\text { study abroad nursing } \\
\text { course }\end{array}$ & $\begin{array}{l}\text { Nurse Educator } \\
2009\end{array}$ & Honduras & $\begin{array}{l}\text { Four global health modules labelled as prerequisites include epidemiology, } \\
\text { environmental health, community resources, and the role of the nurse in } \\
\text { healthcare. While not defined as preparatory, these modules are required } \\
\text { for students to study abroad }\end{array}$ \\
\hline
\end{tabular}




\begin{tabular}{|c|c|c|c|c|c|}
\hline & Author & Title & Publisher & Countries & Preparation \\
\hline 6. & $\begin{array}{l}\text { Ter Maten, } \\
\text { A; } \\
\text { Garcia- } \\
\text { Maas, L }\end{array}$ & $\begin{array}{l}\text { Dutch advanced } \\
\text { nursing practice } \\
\text { students: role } \\
\text { development through } \\
\text { international short- } \\
\text { term immersion. }\end{array}$ & $\begin{array}{l}\text { The Journal of } \\
\text { Nursing } \\
\text { Education } \\
2009\end{array}$ & $\begin{array}{l}\text { USA, The } \\
\text { Netherlands }\end{array}$ & $\begin{array}{l}\text { A timetable is provided of required actions leading up to the study abroad } \\
\text { trip. Six months in advance students compose curriculum vitae and begin } \\
\text { speaking host country language at meetings. All preparation in the } \\
\text { timetable encompasses language, travel logistics, or presentations to be } \\
\text { given while abroad. }\end{array}$ \\
\hline 7. & $\begin{array}{l}\text { Wros, P; } \\
\text { Archer, S }\end{array}$ & $\begin{array}{l}\text { Comparing learning } \\
\text { outcomes of } \\
\text { international and } \\
\text { local community } \\
\text { partnerships for } \\
\text { undergraduate } \\
\text { nursing students }\end{array}$ & \begin{tabular}{|l} 
Journal of \\
Community \\
Health Nursing \\
2010
\end{tabular} & $\begin{array}{l}\text { Cameroon; } \\
\text { USA }\end{array}$ & $\begin{array}{l}\text { Faculty began preparing for the study abroad trip with a scout trip; } \\
\text { students prepared by attending prerequisite weekend classes covering } \\
\text { Cameroon's history, geography, socio-politics, culture, and customs. They } \\
\text { explored health problems and health practice, and oriented students } \\
\text { about the local NGO with which they would work. Although preparation is } \\
\text { reported to have happened, the authors reported that students made } \\
\text { mistakes. }\end{array}$ \\
\hline 8. & $\begin{array}{l}\text { Curtin, AJ; } \\
\text { Martins, } \\
\text { DC; } \\
\text { Schwartz- } \\
\text { Barcott, D; } \\
\text { DiMaria, L; } \\
\text { Ogando, } \\
\text { BMS } \\
\end{array}$ & $\begin{array}{l}\text { Development and } \\
\text { Evaluation of an } \\
\text { International Service } \\
\text { Learning Program for } \\
\text { Nursing Students }\end{array}$ & $\begin{array}{l}\text { Public Health } \\
\text { Nursing } \\
2013\end{array}$ & $\begin{array}{l}\text { USA, } \\
\text { Guatemala }\end{array}$ & $\begin{array}{l}\text { Four two-hour and one full day educational sessions covering what Riner } \\
\text { ( } 2011 \text { ) calls Global health Core Content, including country-specific } \\
\text { knowledge, service learning, and social consciousness. Students were } \\
\text { assigned readings, prepared presentations, and developed educational } \\
\text { health projects based on the host country's needs. }\end{array}$ \\
\hline 9. & $\begin{array}{l}\text { Delpech, } \\
\text { PA }\end{array}$ & $\begin{array}{l}\text { Developing a Short- } \\
\text { term International } \\
\text { Study- abroad } \\
\text { Program: From } \\
\text { Beginning to End }\end{array}$ & $\begin{array}{l}\text { PRISM: A } \\
\text { Journal of } \\
\text { Regional } \\
\text { Engagement } \\
2013 \\
\end{array}$ & Grenada; USA & $\begin{array}{l}\text { Detailed pre-departure phase section. Appointed liaison in Grenada to be } \\
\text { in charge of groundwork. Weekly meetings with faculty and students } \\
\text { including } 3 \text { sessions, including a liaison in Grenada contributed to } \\
\text { preparation by telling oral histories. Grenada's health system compared to } \\
\text { the USA. Final pre-departure meetings covered culture, time, and Hall's } \\
\text { (1976) Iceberg Concept of Culture to prepare students for study abroad; } \\
\text { students prepared health talks to present in Grenada and kept reflective } \\
\text { journals. }\end{array}$ \\
\hline
\end{tabular}




\begin{tabular}{|c|c|c|c|c|c|}
\hline & Author & Title & Publisher & Countries & Preparation \\
\hline 10. & $\begin{array}{l}\text { Ferranto, } \\
\text { MLG }\end{array}$ & $\begin{array}{l}\text { An interpretive } \\
\text { qualitative study of } \\
\text { baccalaureate } \\
\text { nursing students } \\
\text { following an eight- } \\
\text { day international } \\
\text { cultural experience in } \\
\text { Tanzania }\end{array}$ & $\begin{array}{l}\text { PhD } \\
\text { dissertation } \\
2013\end{array}$ & Tanzania & $\begin{array}{l}\text { Required coursework attendance at six seminars discussing language, } \\
\text { social norms, rituals, traditions, worldview, and an overview of ethnic } \\
\text { groups in the host location. Seminars were underpinned by Langer's } \\
\text { theory of Mindfulness, Campinha-Bacote's Process of Cultural Competence } \\
\text { in the Delivery of Healthcare, and Bennett's Developmental Model of } \\
\text { Intercultural Sensitivity (DMIS). Also used was the Culture General } \\
\text { Assimilator tool and cross-cultural sensitizer. Students stopped in Geneva } \\
\text { on their way to Tanzania for additional meetings and training in an } \\
\text { environment that was foreign but thought to have had more similarities to } \\
\text { the students' home culture than Tanzania. }\end{array}$ \\
\hline 11. & $\begin{array}{l}\text { Davis, LI; } \\
\text { Wright, DJ; } \\
\text { Gutierrez, } \\
\text { MS; } \\
\text { Nam, JJ; } \\
\text { Nguyena, } \\
\text { J; Waite, } \\
\text { AT }\end{array}$ & $\begin{array}{l}\text { Interprofessional } \\
\text { global service } \\
\text { learning: A pharmacy } \\
\text { and nursing practice } \\
\text { experience in } \\
\text { Botswana }\end{array}$ & $\begin{array}{l}\text { Currents in } \\
\text { Pharmacy } \\
\text { Teaching and } \\
\text { Learning } \\
2015\end{array}$ & $\begin{array}{l}\text { Botswana; } \\
\text { USA }\end{array}$ & $\begin{array}{l}\text { Faculty members on trip served as preceptors and arranged clinical sites } \\
\text { prior to arrival; however not until arrival were lodging, travel and food } \\
\text { arranged. Faculty members coordinated with local hospital and church for } \\
\text { students to observe surgeries, etc. and be involved in religious activities. } \\
\text { Students debriefed daily with a faculty member. Students attended } \\
\text { additional training on HIV. Students met several times to learn about their } \\
\text { host location where they learned about the host country, prevalent } \\
\text { diseases, learned from online resources, and learned from students who } \\
\text { had studied abroad previously. }\end{array}$ \\
\hline 12. & Bohman, D & $\begin{array}{l}\text { Student exchange for } \\
\text { nursing students: } \\
\text { Does it raise cultural } \\
\text { awareness'? A } \\
\text { descriptive, } \\
\text { qualitative study }\end{array}$ & $\begin{array}{l}\text { Nurse } \\
\text { Education in } \\
\text { Practice } 2013\end{array}$ & $\begin{array}{l}\text { Sweden, South } \\
\text { Africa }\end{array}$ & $\begin{array}{l}\text { Preparation is discussed as students reading about the placement location } \\
\text { online, preparation meetings, and individual consultations with the study } \\
\text { coordinator. }\end{array}$ \\
\hline 13. & $\begin{array}{l}\text { Green, B; } \\
\text { Johansson, } \\
\text { I; Rosser, } \\
\text { M; }\end{array}$ & $\begin{array}{l}\text { Studying abroad: A } \\
\text { multiple case study } \\
\text { of nursing students' } \\
\text { international }\end{array}$ & $\begin{array}{l}\text { Nurse } \\
\text { Education } \\
\text { Today } \\
2008 \\
\end{array}$ & UK, Sweden & $\begin{array}{l}\text { Students are prepared to study abroad with individual and group } \\
\text { meetings. Details of the trip as well as objectives are discussed. Students } \\
\text { are given instruction on lines of support and communication. Information } \\
\text { packets are distributed that include previous study abroad student }\end{array}$ \\
\hline
\end{tabular}




\begin{tabular}{|c|c|c|c|c|c|}
\hline & Author & Title & Publisher & Countries & Preparation \\
\hline & $\begin{array}{l}\text { Tengnah, } \\
\text { C; Segrott, } \\
\text { J }\end{array}$ & experiences & & & $\begin{array}{l}\text { experiences. The authors suggest a change is needed in current } \\
\text { preparation practice and monitoring of students who study abroad. The } \\
\text { authors further call for greater engagement with partner HEIs, and more } \\
\text { effective training of staff. }\end{array}$ \\
\hline 14. & Pross, E & $\begin{array}{l}\text { International nursing } \\
\text { students: a } \\
\text { phenomenological } \\
\text { perspective }\end{array}$ & $\begin{array}{l}\text { Nurse } \\
\text { Education } \\
\text { Today } \\
2005\end{array}$ & $\begin{array}{l}\text { USA, Mexico, } \\
\text { Guatemala, } \\
\text { Norway, } \\
\text { Russia, } \\
\text { Honduras, } \\
\text { China, West } \\
\text { Africa, New } \\
\text { Zealand, and } \\
\text { The } \\
\text { Mediterranean }\end{array}$ & $\begin{array}{l}\text { Nursing students began planning 'anywhere from one week to a year prior } \\
\text { to departure' (p. 629). Preparation ranged from researching culture, } \\
\text { studying the local language, fund raising, and preparing educational } \\
\text { materials. One student applied to study abroad only four days before } \\
\text { departure. She reported bawling the entirety of the first day of the study } \\
\text { abroad trip, stating 'it was so horrible' (p. 630). The author refers to a } \\
\text { six-month group preparation, however the student above was allowed to } \\
\text { study abroad without the group preparations. This article contains student } \\
\text { quotes of being afraid, hearing gunshots, etc. }\end{array}$ \\
\hline 15. & $\begin{array}{l}\text { Currier, C; } \\
\text { Omar, M; } \\
\text { Talarczyk, } \\
\text { G; Diaz, } \\
\text { RG }\end{array}$ & $\begin{array}{l}\text { Development and } \\
\text { implementation of a } \\
\text { semester program in } \\
\text { Mexico for senior } \\
\text { nursing students }\end{array}$ & $\begin{array}{l}\text { Journal of } \\
\text { Professional } \\
\text { Nursing, } 2000\end{array}$ & USA, Mexico & $\begin{array}{l}\text { Students attended preparation meetings prior to departure and after } \\
\text { arriving in Mexico. Meetings were focused on the transition of students } \\
\text { living in Mexico, navigating their life and work whilst speaking Spanish, } \\
\text { and culture shock. A conference was held to communicate course } \\
\text { expectations and create personal learning objectives. Upon arrival in } \\
\text { Mexico, students received an orientation on basic requirements such as } \\
\text { the transportation system. }\end{array}$ \\
\hline 16. & $\begin{array}{l}\text { Inglis, A; } \\
\text { Rolls, C; } \\
\text { Kristy, S }\end{array}$ & $\begin{array}{l}\text { The impact on } \\
\text { attitudes towards } \\
\text { cultural difference of } \\
\text { participation in a } \\
\text { health focused study } \\
\text { abroad program }\end{array}$ & $\begin{array}{l}\text { Contemporary } \\
\text { Nurse } \\
2000\end{array}$ & $\begin{array}{l}\text { Australia, } \\
\text { Nepal }\end{array}$ & $\begin{array}{l}\text { One sentence description of preparation included lectures on the health } \\
\text { care system of Nepal, health problems of women and children and } \\
\text { Nepalese culture. }\end{array}$ \\
\hline
\end{tabular}




\begin{tabular}{|c|c|c|c|c|c|}
\hline & Author & Title & Publisher & Countries & Preparation \\
\hline 17. & $\begin{array}{l}\text { Rolls, C; } \\
\text { Inglis, A; } \\
\text { Kristy, S }\end{array}$ & $\begin{array}{l}\text { Study abroad } \\
\text { programs: Creating } \\
\text { awareness of and } \\
\text { changing attitudes to } \\
\text { nursing, health and } \\
\text { ways of living in } \\
\text { other cultures }\end{array}$ & $\begin{array}{l}\text { Contemporary } \\
\text { Nurse } \\
1997\end{array}$ & $\begin{array}{l}\text { Australia, } \\
\text { Thailand }\end{array}$ & $\begin{array}{l}\text { Students attend four workshops that cover Thai culture and etiquette. } \\
\text { Literature is provided for students to read about the Thai health system, } \\
\text { practices, and needs. Finally, students are encouraged to undertake their } \\
\text { own preparation. }\end{array}$ \\
\hline 18. & $\begin{array}{l}\text { Mill, JE; } \\
\text { Yonge, OJ; } \\
\text { Cameron, } \\
\text { BL }\end{array}$ & $\begin{array}{l}\text { Challenges and } \\
\text { opportunities of } \\
\text { international clinical } \\
\text { practica }\end{array}$ & \begin{tabular}{|l|} 
International \\
Journal of \\
Nursing \\
Education \\
Scholarship \\
2005
\end{tabular} & $\begin{array}{l}\text { Canada, } \\
\text { Guatemala, } \\
\text { Ghana }\end{array}$ & $\begin{array}{l}\text { Preparation process includes general knowledge about the destination } \\
\text { country, culture, healthcare systems, role of nurses, common health } \\
\text { conditions, and language training. Perhaps the greatest emphasis of the } \\
\text { preparation is for students to be culturally aware and sensitive to the } \\
\text { differences in health and clinical practices. The authors stress the need to } \\
\text { teach safe sex, safety regarding drug and alcohol use, and worker's } \\
\text { compensation - implying risk management of sending students abroad is } \\
\text { becoming more complex. }\end{array}$ \\
\hline
\end{tabular}




\begin{tabular}{|c|c|c|c|c|c|}
\hline & Author & Title & Publisher & Countries & Preparation \\
\hline 19. & $\begin{array}{l}\text { Johns, A; } \\
\text { Thompson, } \\
\text { C }\end{array}$ & $\begin{array}{l}\text { Developing cultural } \\
\text { sensitivity through } \\
\text { study abroad }\end{array}$ & \begin{tabular}{|l} 
Home Health \\
Care \\
Management \& \\
Practice \\
2010
\end{tabular} & $\begin{array}{l}\text { Guatemala, } \\
\text { USA }\end{array}$ & $\begin{array}{l}\text { The university is small, with no prior experience sending students to study } \\
\text { abroad trips. A decision was made to outsource the study abroad logistics } \\
\text { to a local religious organisation familiar with volunteer trips to low-income } \\
\text { countries, including Guatemala. } \\
\text { The religious organisation had logistical details in place from prior trips } \\
\text { (including vaccination requirements, travel arrangements, personal safety } \\
\text { provisions, etc.), allowing the faculty extra time to prepare students for } \\
\text { the nursing-related aspects of the trip. States faculty met with the } \\
\text { students 'regularly' leading up to the trip. Discussions focused on culture } \\
\text { wherein the faculty gave examples of cultural norms students could } \\
\text { expect to see in Guatemala. Students were required to keep a journal as } \\
\text { part of their preparation, writing their reflections of preparation } \\
\text { discussions prior to entering into a different cultural context. Students } \\
\text { completed a cultural assessment test prior to departure. }\end{array}$ \\
\hline
\end{tabular}




\section{Preparation subjects in meetings}

Culture

- Culture in general (Pross 2005, Critchley et al. 2009)

- Encouraged to be culturally aware/sensitive (Mill et al. 2005)

- Students travelled halfway to host location, stopping in Geneva for more preparation training which was thought to have had more similarities to the students' home culture, providing a more gentle entry into host location (Ferranto 2013)

- Cultural similarities/differences (Goldberg, Brancato 1998)

- Culture of time in host location (Delpech 2013)

- Dealing with culture shock (Currier et al. 2000)

Requirements for students

- Students learn basic language skills (Ferranto 2013, Pross 2005, Currier et al. 2000, Mill et al. 2005)

- Students compose learning contract (Shailer 1997)

- Students compose curriculum vitae (Ter Maten, Garcia-Maas 2009)

- Students compose learning objectives (Wright 2010, Currier et al. 2000)

- Students compose reflective journals (Delpech 2013, Mill et al. 2005)

- Students complete cultural assessment (Mill et al. 2005)

- Culture General Assimilator tool and cross-cultural sensitizer (Ferranto 2013)

- Create educational materials for host location (Pross 2005)

Topics discussed

- Nursing/Health care system in host location (Egenes 2012, Saenz, Holcomb 2009, Mill et al. 2005, Inglis, Rolls et al. 2000)

- Travel itinerary (Goldberg, Brancato 1998, Ter Maten, Garcia-Maas 2009, Lachat, Zerbe 1992)

- General trip details are discussed (Green et al. 2008, Currier et al. 2000)

- Students are told appropriate lines of support (Green et al. 2008)

- Customs in host location (Egenes 2012, Wros, Archer 2010, Ferranto 2013)

- Country-specific knowledge (Curtin et al. 2013, Mill et al. 2005, Davis et al. 2015) 
- Epidemiology (Saenz, Holcomb 2009)

- Environmental health (Saenz, Holcomb 2009)

- Comparisons of host and home health systems (Delpech 2013)

- Social consciousness (Curtin et al. 2013)

- Social norms (Ferranto 2013)

- Geography of host location (Wros, Archer 2010)

- Health practices in host location (Wros, Archer 2010)

- Discussions about living in a foreign country (Currier et al. 2000)

- Local ethnic groups (Ferranto 2013)

Sources of information

- Presented to fellow students to increase knowledge (Hu et al. 2010)

- Outsourced practicalities to local organisation (Mill et al. 2005)

- Preparation largely supported by parental involvement (Mill et al. 2005, W. Green, Gannaway et al. 2015)

- Information packets are available to students (Green et al. 2008)

- Host location liaison taught oral history (Delpech 2013)

- Orientation to receiving organisation in host location (Wros, Archer 2010)

- Community resources (Saenz, Holcomb 2009) 
Figure 2: Preparation Subjects Repeated in Both Meetings and CreditedCourses

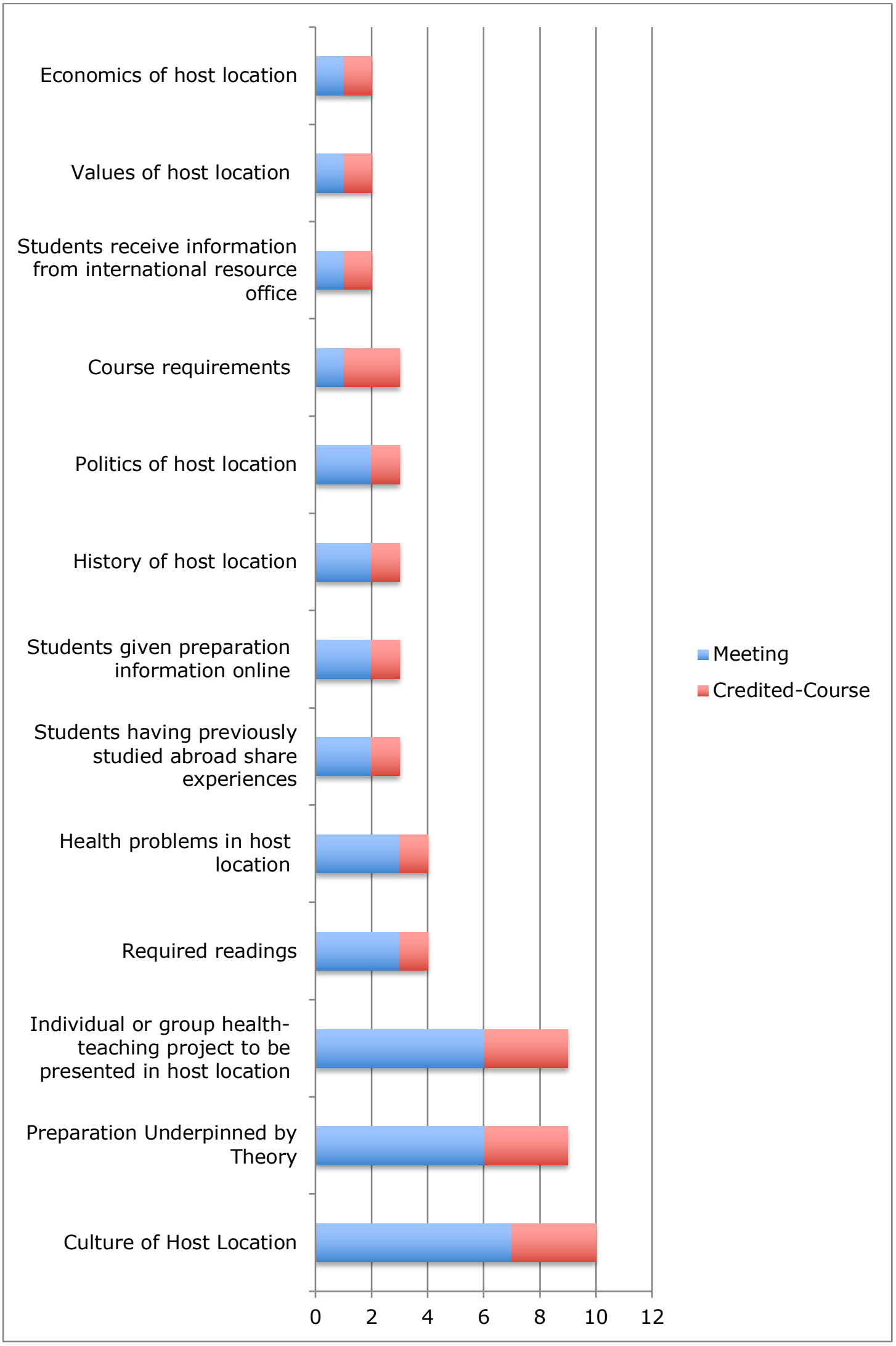


Courses:

- Culture of host location (Bosworth et al. 2006, K. H. Anderson et al. 2012, Farmer et al. 2003)

- Individual or group health-teaching project to be presented in host location (K. H. Anderson et al. 2012, Kreye, Oetker-Black 2013, Brown 2017)

- $\quad$ Course requirements (Czanderna 2013, Brown 2017)

- Underpinned by theory

- Jeffrey's (1996) Cultural Competence and Confidence model (Czanderna 2013)

- Ray's(2010) transcultural caring dynamics (Kreye, Oetker-Black 2013)

- Purnell's (2005) Model of Cultural Competence (Brown 2017)

- History of host location (Bosworth et al. 2006)

- Health problems in host location (Bosworth et al. 2006)

- Values of host location (K. H. Anderson et al. 2012)

- Economics in host location (Bosworth et al. 2006)

- Politics in host location (Bosworth et al. 2006)

- Required readings (Czanderna 2013)

- $\quad$ Students receive information from international resource office(Czanderna 2013)

- $\quad$ Students given preparation information online (K. H. Anderson et al. 2012)

- $\quad$ Students having previously studied abroad share experiences (Czanderna 2013)

Meetings

- Culture of host location (Egenes 2012, Wros, Archer 2010, Delpech 2013, Ferranto 2013, Rolls et al. 1997, Mill et al. 2005, Inglis et al. 2000)

- Preparation underpinned by theory

- Riner's (2011) framework for globally engaged nursing education, including global health core content of including country-specific knowledge, service learning, and social consciousness (Curtin et al. 2013)

- Hall's (1976) Iceberg Concept of Culture (Delpech 2013)

Langer's $(1989,1992)$ theory of Mindfulness (Ferranto 2013)

- Bennett's $(1986,1993)$ Developmental Model of Intercultural

Sensitivity(Ferranto 2013, B. F. Green et al. 2008)

- Campinha-Bacote's (2002) Process of Cultural Competence in the Delivery of Healthcare (Ferranto 2013)

- Howell's (1982) communication theory (B. F. Green et al. 2008)

- Individual or group health-teaching project to be presented in host location (De Natale, Waltz 2015, Ter Maten, Garcia-Maas 2009, Lachat, Zerbe 1992, Curtin et al. 2013, Delpech 2013, Hu et al. 2010)

- $\quad$ Required readings (De Natale, Waltz 2015, Curtin et al. 2013, Rolls et al. 1997)

- $\quad$ Students having previously studied abroad share experiences (Ferranto 2013, Davis et al. 2015)

- Health problems in host location (Wros, Archer 2010, Mill et al. 2005, Davis et al. 2015, Inglis et al. 2000)

- $\quad$ Students given preparation information online (Bohman, Borglin 2014, Critchley et al. 2009, Davis et al. 2015)

- History of host location (Egenes 2012, Wros, Archer 2010)

- Politics in host location (Egenes 2012, Wros, Archer 2010)

- Course requirements (Goldberg, Brancato 1998)

- $\quad$ Students receive information from international resource office (Currier et al. 2000)

- Values of host location (Currier et al. 2000)

- $\quad$ Economics in host location (Egenes 2012) 
Figure 1 displays the subjects of preparation that were repeated in both courses and meetings. The elements of preparation content in Figure 1 represent the most commonly used subjects to prepare students to study abroad regardless of credit offerings or length of time. Culture remains the top subject discussed during preparation, followed by using a theory to underpin preparation and the creation of health teaching projects to be presented while abroad.

\section{Student responsibilities}

Four of the 30 articles (13\%) mentioned students preparing themselves for their study abroad experiences. Justified by new science leadership theory (Doyle 2004), students travelling to Nepal were told to prepare for a study abroad trip autonomously. Other students were given minimal guidance from their faculty, but primarily sought their own preparation through their university's international department (Shailer 1997). Other students proactively prepared by seeking out students who had studied abroad (or other acquaintances) who had useful information regarding study abroad trips (Davis et al. 2015, W. Green et al. 2015). Some students attended preparatory workshops organised by their sending HEI, but were encouraged to pursue further preparation on their own (Rolls et al. 1997).

\section{Sending and receiving organisation responsibilities}

At the institutional level, preparation varied among the literature. Two HEIs prepared for study abroad trips by sending faculty on a preparatory trip ahead of the students (Wros, Archer 2010). One of the HEIs also arranged for a faculty site visit, which provided ample opportunity for faculty to become acquainted (Critchley et al. 2009). This was useful in appointing a liaison in the host location to coordinate student clinical needs and to assist in orienting students to their new environment (Delpech 2013). The receiving institution coordinator worked with the local healthcare workers to improve the quality of observation-based student experiences (Davis et al. 2015).

Preparation was recommended to begin early at the administrative level to confirm study abroad trips would receive academic credit. Some data 
suggests an optimal study abroad length for student learning to be 12-16 weeks in length (Read 2011). Particularly when creating a new study abroad course, faculty work with different university offices to secure everything the study abroad student would require. Parameters for location of study abroad trips, i.e. rural or urban, observation or hands-on, were decided by the faculty (Critchley et al. 2009). Possible emergencies were predicted to plan appropriate responses in advance. Faculty preparations included selecting an international site, receiving authorisation from the host location's health authority, and arranging for student accommodation (Lachat, Zerbe 1992). Faculties were responsible for familiarizing themselves with the concept of culture shock prior to the student travelling so that they could identify and support students who might struggle in their new environment (Egenes 2012).

Before departure, one sending institution connected students with a contact person in the host country with whom they had discussions prior to studying abroad (Anderson et al. 2012). Another arranged for malpractice insurance for students (see Risks and Potential for Harm). Once students had arrived at the study abroad site, they received an orientation on basic requirements such as the transportation system (Currier et al. 2000). Another sending HEI did not arrange lodging, travel, or food until the students arrived in the host country (Davis et al. 2015). These examples suggest 'just in time preparation' at times, or a process of disseminating information when needed, rather than in advance.

\section{The concept of 'underpreparedness' in current literature}

Three of the 30 articles (10\%) that discussed preparation referred to students' underpreparedness. A group of students made mistakes while studying abroad, although they reported learning from that experience (Wros, Archer 2010). Another sending HEI began preparing students six months before the trip, but a student from this institution enrolled to study abroad just four days prior to studying abroad, reported crying the entirety of the first day abroad, saying 'it was so horrible' (Pross 2005 p. 630). The other students that had six months of preparation still experienced fearfulness and hearing gunshots, which made them anxious. Another group 
of students expressed difficulty anticipating their preparation needs, not knowing certain details of the trip until immediately before departure (Critchley et al. 2009).

\section{Recently added literature}

Recent literature on the subject includes an article with one sentence reserved for preparation (the inclusion criteria for the literature review), stating preparatory sessions were provided that included host country culture, clinical practice, safety, and a daily itinerary (Gower, Duggan et al. 2017). Another recent article described preparation as a credited transcultural nursing course including assignments, group work underpinned by Purnell's (2005) Model of Cultural Competence, and preparing health talks. The study abroad coordinators faced a challenge of preparing this particular group of students due to an inadequate amount of information regarding the exact location of the study abroad trip (Brown 2017). The final paper discussed preparation with more detail; Australian students going to Cambodia received two meetings from the organisation that coordinated the study abroad trip. Students were told basic information regarding what to wear, cultural advice, safety, and discussed what it would be like to provide primary care in a developing country (Halcomb et al. 2018). Students were asked in follow-up interviews whether they felt they were prepared, which was not seen in other literature. As a whole, students responded that they were 'somewhat underprepared' specifically about culture and clinical responsibilities. Two students reported they were unsure of what to expect until arrival in Cambodia, and several alluded to not being able to prepare emotionally until arrival: 'once there I thought how could you prepare for this?' (Halcomb et al. 2018 p. 315). The recently added literature supports the claim that the topic of preparation remains largely unexplored in the subject of nursing study abroad trips.

\section{Working Definition of Preparation}

This review of the literature supports the need for an accepted definition, and standardisation and consistency of preparation for nursing study abroad. Study abroad coordinators are concerned, after decades of sending students abroad, how best to prepare students prior to their study abroad trips 
(Johns, Thompson 2010). Researchers are calling for a critical examination of current practice, development of evidence-based practice (Browne et al. 2015), and for better-prepared students and volunteers (Crisp 2007, AllParty Parliamentary Group 2013). Moreover, the researcher's personal context of underpreparedness supports the need to find best practice on the subject of preparation.

Informed by the literature review, the researcher composed a working definition of what preparation could encompass. Seven components will later be validated in the Delphi study (Chapter 7). The definition of preparation is as follows:

a) Acquisition of practical information, i.e. vaccinations, what to bring (Institute for the International Education of Students 2008);

b) Development of clinical skills, especially those related to prevalent diseases in the host location that may be uncommon in the student's country of residence (Mill et al. 2005);

c) Development of managerial skills, or the ability to overcome a lack of resources with innovation as well as the ability to identify points of improvement while abroad (NHS 2010);

d) Development of communication skills, or the ability to work in a multi-disciplinary team across cultures (Department of Health, Department for International Development 2014)

e) Development of cultural skills, or gaining understanding of cultural practices in the host location to best provide care within the patient's culture, providing dignity (Leininger 1996)

f) Development of emotional skills, or the ability to recognise and articulate feelings (Koskinen, Campbell et al. 2009, Riner 2011, Davis et al. 2015) 
g) Creation of a mission statement (Currier et al. 2000) on the part of the sending institution denoting the goals of the trip; a needs statement from the receiving institution stating what needs to be done along with an invitation to come (Crisp 2007); a learning contract on the part of the student as supported by Joplin's theory of Experiential Education (1981).

\section{Conclusion}

This review followed certain elements of an integrated review that informed the layout and supported the diversity of papers needed. The first literature search resulted in additional terms collected that warranted a second literature search to avoid excluding relevant papers. Key themes from nursing study abroad literature were benefits (to nursing students, sending HEIs, and receiving institutions), cultural competence (and other synonymous cultural terms), and risk and potential for harm. A critique of cultural competence and a discussion of post-colonial voyeurism are offered. A key finding was the lack of standardisation in preparation. A second key finding was the supposed ability of study abroad trips to produce nurses who will enter the workforce as culturally competent nurses has perpetuated the trend of study abroad trips. However, the most frequently cited benefit to students who study abroad was not cultural competence, but personal growth. This exposed a contradiction in the stated justification versus the evidence-based reason nursing students study abroad.

The literature review produced a description of the myriad of ways nursing students are prepared to study abroad. Student preparation spanned from parental involvement to autonomously student led preparation to semesterlong credited preparation courses. No preparation content were repeated among institutions, even within consortiums of universities who collaborated or studied abroad together. A working definition of preparation was composed by the researcher from the findings of the literature review. 


\title{
CHAPTER THREE \\ REFLEXIVE INTERVIEW
}

\author{
'Through reason man observes himself; \\ but he knows himself only through consciousness' \\ -Tolstoy, War and Peace
}

\section{Introduction}

On commencement of the doctoral study, the researcher undertook a reflexive interview to highlight potential areas where she may be prone to bias due to her negative experiences whilst undertaking nursing study abroad trips (see Chapter 1, Personal Context), and to pilot an original interview instrument created specifically for this research study. Reflexive interviews are data collection tools that increase understanding of the researcher's potential for unconscious bias. Personal experiences and beliefs have the power to influence research studies by introducing bias throughout the research process - from choice of topic to the interpretation of analysis. To provide a clear and transparent process during this study, the researcher used a reflexive interview to understand her thoughts, beliefs, and positioning concerning the preparation that nursing students receive prior to studying abroad.

Reflexivity is a term that has widely differing interpretations, and therefore a brief review of reflexivity is needed to set the context for its use within this study. There is no single source that describes how to conduct a reflexive interview; methodological guidance was gathered from various resources that had varying definitions of reflexivity. Consistent with the reflexive interview method, a reflexive analysis led to the explication of the researcher's potential biases. Biases emerged through the Listening Guide, a reflexive method of analysis, underpinned by Experiential Education (Joplin, 1981). Within this chapter, the researcher is referred to as the 'respondent' when discussing her role in answering the questions posed in the reflexive interview; for all other instances she will remain the 'researcher'. 


\section{Reflexivity in the Literature}

The variations of reflexivity claim the following benefits to research: to demonstrate credibility; disclose the 'position of', or 'situate' the researcher; produce a decision trail of methodological choices; expose bias; 'bracket' or 'suspend' said bias; and add rigour. There is a general consensus that reflexivity can be described both as 'methodological self-consciousness' (Seale 1999, p. 159) and 'explicit self-aware meta-analysis' (Finlay 2002, p. 209). Reflexivity presents an opportunity for researchers to speak of their own experiences actively and critically (Ryan, Gwinner et al. 2017), thus improving transparency to the research process (McDermid et al., 2014).

'Confessional' or 'reflexive' accounts began influencing qualitative research in the 1970s following a long-established trend of researchers recording observations for scientific credibility (Bell, Newby 1977). Autoethnography followed confessional reflexivity, described by Ecker (2016) as marrying autobiography and narrative inquiry via research diaries. Autoethnography allows a researcher to, in a sense, 'represent oneself to oneself' (Dowling, 2006). This type of reflexivity is present throughout the entire research process, and is inclusive of wider settings and cultures.

Among the definitive works in the field are Finlay's (2002) five variants of reflexivity. According to Finlay, reflexivity as 'introspection' focuses on the researcher's experiences, to act as the beginning of a research process, as primary evidence (Creswell, 2012). Finlay's second variant, 'intersubjective reflection', allows the researcher to use past experiences to gather more information during interviews (Hollway \& Jefferson 2000). The researcher attempts to find a bridge of similarity with respondents, increasing rapport and giving added opportunity to probe. Reflexivity as 'mutual collaboration' utilises respondents as co-researchers. Multiple voices, perhaps with differing views, are all given the opportunity for reflexive dialogue. Reflexivity as 'social critique' seeks to minimise the researcher's authority over the respondent. For example, a researcher may use self-deprecating humour during an interview in an attempt to lessen the power imbalance that exists with the respondent. Finally, reflexivity as 'discursive deconstruction' deals with textual meaning, or the ambiguity within 
language that may produce multiple meanings rather than one. Finlay's five variants of reflexivity highlight the wide range of possibilities for reflexive research.

While several other types of reflexivity are discussed in the literature (see Marcus, 1998; Willig, 2013), for additional reading on reflexivity), a review would not be complete without discussing Dowling's (2006) four types of reflexivity. The first type of reflexivity according to Dowling is aimed at sustaining objectivity through the use of 'bracketing', and is associated with the positivist paradigm. Dowling uses diaries as an example of data collection for this type of reflexivity. Another type is epistemological reflexivity, which explores for example researcher's assumptions, and determines their possible impact on the research study. Epistemological reflexivity asks the question, how does the chosen research question limit what can be known, and could it have been explored differently? The third type is 'politics of location', wherein the researcher is implored to move beyond the navel-gazing act of writing in a research diary - and move toward a critical standpoint. Wider contexts are examined and discussed as potential threats to introduce bias. A strength of this type of reflexivity is that social constructions are identified for the purpose of reducing limitations. Finally, 'positioning', is a feminist theory associated with reflexivity in which interviews are the most common form of data collection. Typically interviews exist within a power dynamic in which the respondent feels, whether intentioned by the interviewer or not, similarly to being across from a therapist. Alternatively, feminist interviews seek nonhierarchical partnerships. A weakness of the feminist positioning of reflexivity is that many researchers may feel uncomfortable being open with participants, just as participants may not feel comfortable being open during interviews. Unfortunately, objectivity can be perceived in this type of reflexivity as detachment or inauthenticity.

The seminal works in the field of reflexivity are over a decade old, with recent authors attempting to increase methodological rigour in the form of claims to reflexive methods without explanation or definition (Hawamdeh, Raigangar 2014, Jefford, Sundin 2013). Reflexivity is an attractive practice 
of qualitative research (Banister, 2011) because it is clear that researchers unintentionally influence the direction of their studies (Hall \& Callery, 2001), with some claiming the process of conducting research and experience are inseparable (Hugill, 2012). A researcher's influence may include the subject of the study chosen, the particular focus taken on the subject, and how the analysis is interpreted (Colbourne \& Sque, 2004). Reflexivity can be seen as a measure of how much a researcher influences a study (Cassidy, 2013). By implementing reflexive practice, the reader can better inspect the integrity of the decisions made (Hall \& Callery, 2001) due to the transparent documentation of research decisions and ability to 'situate' the researcher (Finlay, 2002a; Finlay, 2002b; Louis \& Barton, 2002). Particularly in qualitative studies, the researcher is not an inanimate object such as an online survey. Rather, the researcher is a living being, existing in a social context, positioned in a certain way that is worth disclosing to the reader. Reflexivity therefore presents an opportunity for transparency and authenticity, adding rigour.

Researchers cannot reduce biases about which they are unaware. Colbourne and Sque (2004) refer to a study in which their past work as clinical nurses made them overly critical as researchers. They reported being more critical of their participant's healthcare experiences than the participants were of their own experiences. The authors continued that once they adopted reflexivity into the same study, they realised their bias and, simply, 'became more aware'. This example highlights how researchers used reflexivity to 'suspend' or 'bracket' bias (Creswell \& Miller, 2000), at least in the context of the research study.

Considering the array of choices, researchers may view reflexivity as a continuum from which to select a type that will benefit their research. Researchers may position themselves, offer decision trails, disclose statements of assumptions and past experiences, but this is ultimately reduced to navel-gazing (Seale, 1999) with opportunity for the researcher to offer an exhaustive amount of information that ceases to provide relevance to the study. Reflexive methods should provide no information 
beyond what is necessary for the purpose of adding rigour and reducing bias.

To add clarity for the reader, researchers are implored to identify and discuss which type of reflexivity they use and to be explicit how this process minimises bias. In this chapter, various reflexive methods were extracted from the literature discussed above. Bracketing, was used, allowing the researcher to 'become more aware' as referred to by Colbourne and Sque (2004). Autoethnography (Dowling, 2006) was used to allow the researcher to 'represent oneself to oneself'. Finally, 'introspection' (Finlay 2002) was used in the form of a reflexive interview, which allowed biases to be exposed at the beginning of this doctoral study.

\section{Reflexive Interviews}

Reflexive interviews can be compared to the act of storytelling. Various meanings may lie beneath what is said and what is heard in both reflexive interviews and storytelling. The listener/interviewer probes and reacts, waiting for a full account of the story. Unspoken undercurrents of biases and beliefs accumulated from life experiences accompany the words spoken in an interview. The listener/analyst also brings bias and may sway the original message intended in the interview or story. Both the words being spoken, and the meaning that lies beneath make up sources of qualitative reflexive data that add richness to a study while simultaneously exposing bias.

Reflexive interviews are the most commonly used reflexive tool (Creswell, Miller 2000, Cho, Trent 2006). Other techniques include reflexive field notes (Hollway 2016) reflexive diaries (Clancy 2013), reflexive member checking (Cho, Trent 2006), and reflexive video focus groups (Liu, Gerdtz, \& Manias, 2016). Reflexive interviews are sometimes called 'bracketing interviews' (Crotty, 1996), implying that they are conducted to allow the researcher to bracket assumptions realised during the interview. 'Bracketing interview' was not used in this study due to the wide variability of definitions of reflexivity, which could be misunderstood to be a method only able to bracket. A reflexive interview is used to bracket, but it is also adaptable for 
use in any of the multiple types of reflexivity reviewed above. Thus the term 'reflexive interview' is used in this chapter so not to limit the perceived versatility of the method.

\section{Justification}

The reflexive interview was undertaken in this doctoral study with a twofold justification: to reduce bias of the researcher's experiences (see Chapter 1, Personal Context) and to pilot an interview instrument. The researcher's study abroad experiences included firstly, witnessing a peer's near death due to misdiagnosed malaria and secondly, avoiding assault by armed personnel who attacked a vehicle ahead of the one she was travelling in. Rolls and Relf (2006) undertook a series of reflexive interviews for the purpose of situating the principal researcher when a study topic was expected to induce strong emotion. Similarly, the researcher responded to the challenging subject matter of nursing study trips following her traumatic experiences by undertaking a reflexive interview early in the research process (Behar, 2014). Lincoln and Guba's (1985) methods for reducing bias were employed in the study (adhering to credibility, transferability, dependability, and confirmability), however the researcher's experiences while studying abroad compelled her to add an additional bias reducing method early in the research process to uncover implicit feelings (Liamputtong, 2008) that needed to be exposed regarding nursing study abroad trips. This was in an effort to reduce the possibility of the researcher's voice overpowering that of the student's, and to understand her position and potential biases at the onset of the study (Valentine, 2007).

A second justification of the reflexive interview was to pilot and validate the questions used. The questions posed in the reflexive interview were used to interview the nursing student participants as discussed in Chapters 5 and 6. These questions had not been used previously, and thus the reflexive interview tested and validated the interview instrument. 


\section{Interview instrument}

The researcher was unable to find any suitable questions from nursing studies in the literature and felt the questions should be informed from a study in a related field such as medicine. Citrin's (2011) qualitative study of short-term medical volunteer workers in Nepal was chosen with permission to inform the interview questions for the reflexive interview (see Appendix $B$ for Citrin's permission). Citrin's interview questions (see Appendix C) focused on the goals of the medical volunteer trip (in pre-trip interviews) and what could be improved about the trip (in post-trip interviews). Similarly, the questions for the reflexive interview (see Appendix D) included asking why the respondent enrolled in a study abroad trip and any recommendations the respondent had for future trips. The questions focused on how the respondent had prepared to study abroad, what a typical day might look like while studying abroad, and what information the respondent had about the location.

\section{Method}

Prior to the commencement of the reflexive interview, the researcher was keen to document her journey and formalise how these experiences shaped her views and research. A colleague who was not associated with this project conducted the reflexive interview in which the researcher answered all of the pre- and post-trip interview questions from her point of view retrospectively. This reflexive interview provided a self-aware analysis and highlighted the relationship between the researcher and the research study (Cho \& Trent, 2006; Creswell \& Miller, 2000; Finlay, 2002a; Finlay, 2002b; Finlay \& Gough, 2008; Woolgar, 1988). Data were recorded in the interview using a digital audio recorder and transcribed verbatim by the researcher using Microsoft Excel. The researcher sought a reflexive method of analysis to match the reflexive nature of the interview, choosing the Listening Guide adapted by Mauthner and Doucet (1997) from Brown and Gilligan (1992), along with Joplin's Experiential Education (1981). Reflexive interviews are not typically analysed with traditional qualitative (i.e. thematic) analysis techniques; instead the aim of analysis is to find undercurrents of values or beliefs that may not be found through thematic analysis. 


\section{Post-interview discussion}

In a post-interview discussion with the interviewer, the researcher (who for the purpose of this section will be called the 'respondent') considered her feelings towards the interview experience. Throughout the interview, the respondent assessed her own interviewing skills as questions were being asked. Answering questions was an educational process made possible by observing the style of the more experienced interviewer. His use of voice inflections and pauses facilitated a positive interview environment. The interviewer also kept an inquisitive facial expression, which was later discussed as a useful interviewing technique that draws more detail from the respondent. Perhaps the most important lesson learned was the speed at which the interviewer spoke - slowly and methodically, providing ample time for the respondent to gather her thoughts to answer in rich detail. The skills gained from the reflexive interview were used in subsequent interviews the respondent conducted, such as slowing her speech, making eye contact before writing notes, and showing interest.

The interviewer provided the researcher with comments on how to improve the instrument, including sequence and style of questions, and potential biases. The discussion provided the following preliminary analysis of the interview instrument.

\section{Identification of researcher's potential biases}

Reflexivity requires researchers to express how their subjectivity has been called into question (Cho \& Trent, 2006). Due to the researcher's perception that her study abroad trips had many shortcomings in terms of preparation, an underlying assumption arose during the reflexive interview that all study abroad trips carry numerous risks for which students are unprepared.

\section{Interview instrument changes}

The reflexive interview was an opportunity to pilot the questions and make necessary amendments. As part of the post-interview discussion with the interviewer, two questions were added. The first was to introduce the subject of study abroad trips. To further probe into the respondent's level of preparedness, a second question was added concerning the daily 
expectations while studying abroad. Finally, a question beginning with 'why' was changed to 'how' as it felt as though the respondent was being challenged perhaps coming across as aggressive. The adapted interview instrument is available (Appendix $\mathrm{E}$; and used in Chapters 5 and 6).

\section{Analysis}

Reflexivity allowed the researcher to analyse the data as if it were obtained from another person. The researcher contemplated her own words, which were recorded and transcribed, and appeared as if they were indeed the words of another person (Foley, 2002). This made the reflexive interview methodologically possible wherein the researcher acted as respondent, researcher, and analyst. The researcher began to see how she was situated, and her biases became more explicit.

The Listening Guide adapted by Mauthner and Doucet (1997) from Brown and Gilligan (1992) informed the reflexive interview analysis, along with Joplin's Experiential Education (1981), which facilitated understanding of the reflexive notes extracted through the Listening Guide. The reflexive analysis focuses on self-awareness, where the researcher reports how each decision is made based on values and techniques that are realised through a reflexive process (Finlay 2002b). The following provides key points of the adapted listening guide used in the analysis of the reflexive interview; this consisted of four readings:

Reading 1: The researcher identifies the plot and associated main events.

a. Within this first reading, the researcher also employs the element of 'reader-response' wherein she makes explicit her reactions to the text. This is done by comparing herself, or relating to the respondent (in this case, the researcher was the respondent, however the researcher ought to relate to any respondent during the readerresponse step). The researcher should immediately document her response - emotional, intellectual, etc. toward the transcripts while reading. The purpose of the 
reader-response step is to situate the researcher socially in relation to the respondent, drawing out implicit biases.

Reading 2: The researcher listens for the use of ' $I$ ' in the transcript. The purpose of this reading is to determine how the respondent feels and speaks about herself. This process amplifies the terms and language used by the respondent to describe herself, forcing the researcher to consider how the respondent defines herself. Tracing the ' $\mathrm{I}$ ' in the transcript leads the researcher to interpret the respondent with similar language to what she used for herself.

Reading 3: The researcher notices what relationships are present in the transcript. Relationships are not limited to interpersonal ones, but can include workplace and wider contexts. Relationships may surface in which the respondent feels silenced or empowered. For example, in the case of a study abroad trip, the relationship of the sending Higher Education Institution (HEI) to the student could be 'provider of academic credit', 'arranger of travel details', or 'preparer, encourager to develop global citizenship' where the latter communicates more commitment to the student's education than the former.

Reading 4: The respondent being placed within her wider social, political, cultural, and structural contexts. The researcher seeks to describe the situation in which the story in the interview occurred. In the wider study an 'ideological context' is of interest, i.e. the expectations associated with study abroad trips.

As stated previously, the researcher adapted Mauthner's version of the listening guide with an additional step of selecting themes from within her reflexive notes taken during the four readings. It is important to state that 
the themes below were extracted from the listening guide's reflexive responses taken during the four readings, not from the interview transcripts. Table 5 displays the qualitative analysis findings, showing 'shock' and 'relationship to HEI' as the only themes carried throughout all four readings.

Table 5: Voice-Centred Relational Analysis

\begin{tabular}{l} 
Theme \\
\begin{tabular}{|l|l|l|l|l|}
\multicolumn{3}{l}{ Reading } \\
\hline Altruism & $1^{\text {st }}$ & $2^{\text {nd }}$ & $3^{\text {rd }}$ & $4^{\text {th }}$ \\
\hline Expectations & $x$ & $x$ & $x$ & \\
\hline Shock & $x$ & & $x$ \\
\hline Descriptions of the 'I' & $x$ & $x$ & $x$ & $x$ \\
\hline Relationship to sending HEI & & $x$ & & \\
\hline Relationship to patients & $x$ & $x$ & $x$ & $x$ \\
\hline Relationships to fellow students & & & $x$ & \\
\hline
\end{tabular} \\
\hline
\end{tabular}

\section{Theoretical underpinnings}

Joplin's Experiential Education (1981) informed the reflexive interview analysis. As the four readings of the listening guide analysis were followed, the researcher's reflexive notes were viewed through the lens of experiential education. This model was chosen based on the subject of the reflexive interview being nursing study abroad trips, which rely on education through experience. At this point, it would be permissible to use any number of models and theories to interpret reflexive notes taken from the listening guide analysis to fit the directional needs of a study. Doucet and Mauthner (2008) advocate a flexible approach, allowing the listening guide to be used across a wide variety of research methods, e.g. in student personal reflection diaries (Petrovic et al., 2015), or to inform theoretical perspectives on feminist theory (Mauthner \& Doucet, 2003). 
Joplin's (1981) five-stage model of experiential education resembles a hurricane and illustrates the stages of an educational experience (see Figure 3 below). The first stage of focus precedes the hurricane portion of the model and isolates the student's attention to concentrate on the upcoming trip. Inside the model's hurricane is challenging action, representing the stressors the student could experience in an unfamiliar setting. Support and feedback surround the entire model as stages that should be present throughout the educational journey. The fifth stage of debrief follows the hurricane and signifies the end of the student's experience. The challenging action stage requires attention as the student struggles, evaluates, and embraces the new experiences around her. This is a time ripe for learning (Che et al. 2010). While the challenging action stage requires autonomy, the support stage provides the confidence that help is available. This stage also encourages sharing with others about experiences and frustrations. The feedback stage enables forward movement in the learning process.

Discussion allows students to speak with peers and supporting faculty during the debrief stage wherein learning is recognized, articulated, and evaluated (Joplin 1981).

Figure 3: Experiential Education

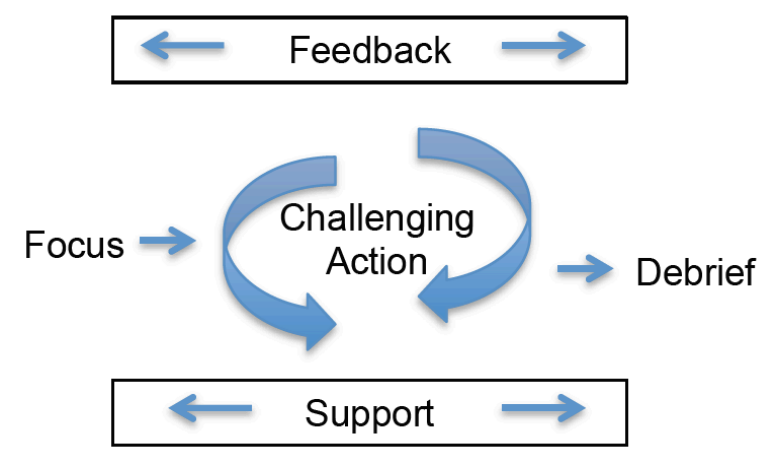

Findings

Joplin's (1981) experiential education informed the interpretation of reflexive notes taken during the four readings of the listening guide. According to Joplin, the five stages represented in the model are necessary for experiential education to be complete. However the five stages were not present in the story of the study abroad trip during the reflexive interview 
(see Figure 4 below). For example, focus was not present during the respondent's preparation phase prior to her study abroad trip. The respondent was excited for an adventure, and did not focus at this pivotal time in which she was given some, albeit scarce, information regarding her trip. Challenging action was especially severe for the respondent, as she stated she experienced shock frequently throughout the trip. Joplin suggests the challenging action stage requires considerable support, however this was not the respondent's experience. The study abroad trip began with a long drive to a blistering hot clinic site - the first of many unexpected struggles encountered during the 'hurricane' stage. While the support stage encourages sharing and communication, this was not possible due to the respondent's feelings of anger towards one peer, and the remaining peers feeling excited rather than disappointed about the impact of the trip. Only one peer had similarly critical feelings about the trip, which did not allow for a full group discussion regarding how to learn from the experiences on the trip. The respondent remembered feeling she would not need support before her trip, followed by a reversal of this view post-trip, stating 'it would have been helpful to know there was someone back home supporting us'. The feedback stage was not discussed in the reflexive interview as the respondent did not receive any feedback throughout the trip. A lack of feedback may have restricted her ability to learn and process her experiences studying abroad. However, the respondent's lack of opportunity to receive feedback may have been the driving force behind the desire to tell her story, thus the decision to undertake a reflexive interview. 
Figure 4: Experiential Education with Findings

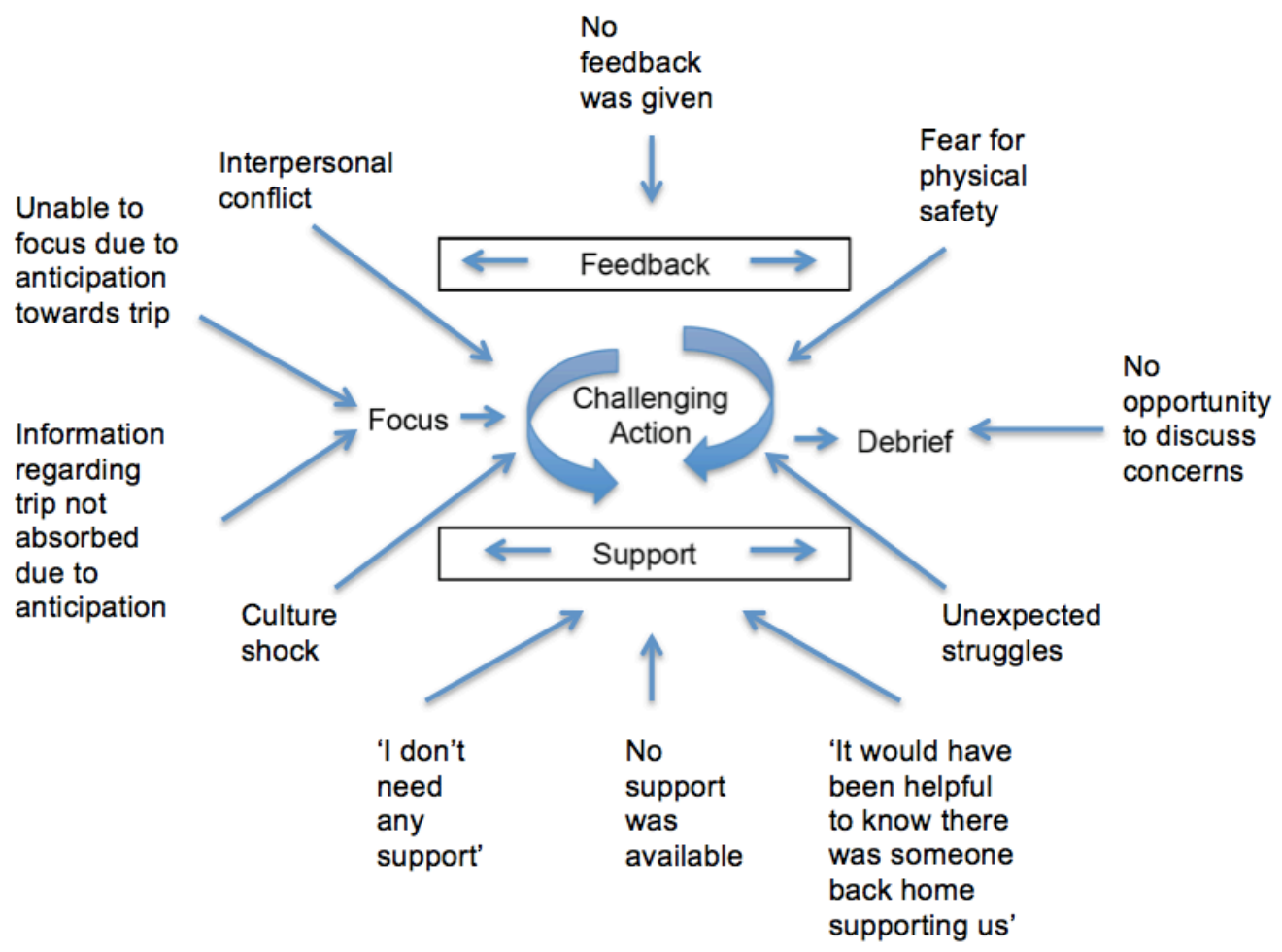

\section{Realisation of bias}

The reflexive interview was conducted to explore the researcher's potential biases toward study abroad trips; the subject of this doctoral study. The reflexive interview analysis shed light on biases that the researcher had not previously been aware of; she was highly critical of study abroad trips and felt that students are unprepared to study abroad, and may feel they have positively cared for an underprivileged community even if they had not. $A$ further bias exposed through the reflexive interview was that students might be focused on the consumerist expectations - the adventure of the trip - to the extent that they disregard the preparatory training they receive. The most prominent themes from the listening guide were 'shock' and 'relationship to sending $\mathrm{HEI}^{\prime}$ which were consistent with the post-interview discussion between the interviewer and respondent, which shed further light on a bias that preparation is inadequate in nursing study abroad trips.

Realising her biases that nursing students are unprepared to study abroad, that study abroad trips may not benefit the host location, and that students merely study abroad to have an adventure enabled the researcher to take steps not to ask leading questions or apply pressure on students during the 
interviews. It was only through realising these thoughts and attitudes towards study abroad trips that the researcher was able to move past the subconscious drive to ask leading - and potentially cynical - questions in upcoming interviews with participants (see Chapters $5 \& 6$ ).

The reflexive interview enabled the researcher to identify previously undisclosed beliefs, which led to a conscious decision to put them in abeyance, to disallow them from affecting the upcoming interviews with participants. The researcher bracketed her assumptions (see Reflexivity in the Literature; Reflexive Interviews, above), and subsequently the wider study resulted in data collected from a more neutral stance, made possible through the use of this initial a reflexive interview. The researcher's journey through the data and ultimately to the findings becomes apparent through the use of a reflexive interview.

\section{Conclusion}

A reflexive interview was conducted on the subject of the researcher's previous nursing study abroad trip. Questions were answered retrospectively concerning this trip to reduce the risk of the experience biasing a study on the same subject (Chapters 5 and 6 ). The use of a reflexive interview was an appropriate methodological tool to undertake at the onset of the study. It exposed implicit biases and enabled the researcher to pilot an original interview instrument. This chapter responds to a gap in the nursing literature on the topic of reflexive interviews, and is original in its use of researcher-reflexivity in the field of nursing, which is currently absent from the literature prior to the researcher publishing on the topic (Lear, Eboh et al. 2018). The following chapter discusses the methods chosen to study nursing study abroad trip preparation at two HEIs. 


\section{CHAPTER FOUR}

\section{METHODS}

The purpose of this chapter is to discuss the method chosen to explore nursing study abroad preparation within Higher Education Institutions (HEIs). As discussed in Chapter 2, nursing students who undertake study abroad trips have widely disparate preparation prior to undertaking their study abroad trips. In Chapter 3 the researcher highlighted potential areas of bias after reflecting on her own study abroad trips undertaken during her undergraduate programme. A case study method was selected to gain rich, holistic data on study abroad preparation programmes offered to nursing students as part of their undergraduate programme.

\section{Research Question and Aims}

The question guiding this chapter is, 'how do nursing students prepare to study abroad?' This question will be answered by exploring:

1) Nursing students' views, experiences, and perceptions of their preparation

2) Perceptions of study abroad coordinators from sending and receiving institutions

3) The content of preparation curriculum used by institutions that send students abroad

\section{Description of the Characteristics of Qualitative Inquiry}

The researcher chose a qualitative paradigm to study preparation because:

1) It allows for a rich descriptive exploration of student perceptions of preparation training (Corbin, Strauss 1998, Jones, Torres et al. 2013)

2) The research at hand is cross-cultural, which has unique methodological challenges (Liamputtong 2010). The context of the study abroad trip research is of interest, best explored through a qualitative paradigm (Brod, Tesler et al. 2009)

3) Qualitative characteristics include research questions beginning with 'how' and 'why' (Yin 2014), which matched the questions at the onset of this study 
4) A reflexive approach is encouraged, meaning the researcher's perspective is welcomed and integral to the research process (Ritchie, Lewis et al. 2013)

5) The researcher is able to collect data by different exploratory means including a reflexive interview, face-to-face interviews, documentation, blogs, and diaries (Brod et al. 2009).

\section{A defence for use of qualitative research method}

A positivistic method such as a survey was considered and rejected for use in this study. A widespread survey was considered, but ultimately would not capture the richness of data needed in exploring the unique context of the phenomenon of preparation. A qualitative method was ultimately chosen to best fit within the philosophical assumptions discussed below.

The choice to follow a qualitative paradigm led to a more detailed and holistic study of preparation than a quantitative study would have allowed. In a qualitative study, a participant could say a sentence in an interview, which, if not previously considered by the researcher, demands to be introduced into the study (George, Bennett 2005). A qualitative method allowed the researcher to add new ideas to the study of preparation that may not have been present in the literature or the researcher's mind when designing the data collection instruments.

The use of a quantitative approach may allow more of the researcher's subjectivity to enter a study (such as the choice of categories or variables used on a questionnaire with predefined, standard answers) than a qualitative approach. For this reason, qualitative studies should be seen as less likely to leave out variables as is possible with quantitative, statistical methods (Flyvbjerg 2011). Qualitative methods allow for deeper exploration, clarity of questions, and an openness for rich data not afforded in quantitative questions. The monopolisation of quantitative methods in scientific literature, more commonly known as 'quantitative hegemony', impacted this study. Additional layers of validation and bias reduction are expected from qualitative researchers (Geertz 1995), such as the reflexive 
interview found in Chapter 3, and the triangulation of data sources and collection methods found in Chapters 5 and 6.

\section{Philosophical Assumptions}

Erickson (1986) states that a primary responsibility of the qualitative researcher is that of interpretation. Qualitative inquiry requires constant interpretation by the researcher due to the sheer breadth of data, lived experiences, and multiple realities presented. Indeed such data are expected in a qualitative study to achieve complex meaning (Denzin, Lincoln 2014). In the context of this research there is need to interpret how nursing students are prepared for their study abroad and subsequently their perception of their level of preparedness, guiding understanding.

Because philosophical assumptions may change over time, the researcher states her current assumptions that have been shaped from her own personal journey to date. It is hoped that disagreement with this research on the topic of study abroad trip preparation will not arise from a lack of awareness about the philosophical assumptions that drive the work (Creswell 2012). The researcher's ontological, epistemological, axiological, and methodological premises (Guba 1990), support the interpretive framework that guided the exploration of preparation.

\section{Ontological assumption}

This study follows a constructivist worldview. Multiple views were gathered and synthesised on the subject of preparation from participants and study abroad coordinators. The study of preparation was constructed from the lived experiences of nursing students on their study abroad trips (Moustakas 1994).

\section{Epistemological assumption}

Epistemological assumption posits that the researcher interacts with the research, attempting to lessen the distance between the two (Creswell 2012). Constructivism, often referred to as interpretivism (Denzin, Lincoln 2011), was the worldview utilised to understand the phenomenon of preparation in this study. Data was acquired through multiple perspectives, 
creating a co-constructed reality from the researcher (see Chapter 3 for the researcher's experiences studying abroad) and participants. While the researcher was not present during the participant's preparation or study abroad trip, triangulation increased the trustworthiness of the collected data (see Design, below).

Stake (1995), a case study researcher, considers qualitative inquiry to be existential and constructivist. He supports triangulation as a constructive epistemology due to the multiple perspectives that are represented in the data, where all views are needed, and one view is not necessarily more accurate than another. A description of preparation was thus constructed out of a triangulation of sources with rich content, including the study abroad coordinators, students, and curriculum content. Further, triangulation was utilised in terms of the type of data collected, including student blogs, diaries, and the interview data to produce a detailed account of preparation.

\section{Axiological assumption}

Research captures values and biases, but researchers may attempt to lessen such effects through transparency (Creswell 2012). The axiological assumptions of the researcher may be best understood from reading the reflexive interview (see Chapter 3), which was undertaken in part to reduce bias. It is significant to note that values may also be a cause for concern. A value of providing healthcare to underserved populations may be a noble cause to study abroad - but such a value may also expose populations to incredible risk if healthcare providers are unfamiliar with common illnesses, among a myriad of other risks discussed in Chapter 2. Further, the benevolently minded students were shown in Chapter 2 (see benefits of nursing study abroad trips) to reap personal benefit before gaining cultural competence/awareness and thus study abroad trips introduce an ethical quandary. 


\section{Methodological assumption}

The qualitative paradigm led the researcher to follow an inductive logic. Inductive logic emerges out of the data, from the ground up, and is collected with that context in mind; as evidenced by the researcher collecting data throughout nursing students' study abroad trips and traveling to The Netherlands for face-to-face interviews (see Chapter 5). Inductive logic allows for the research trajectory to evolve if and when a change is needed to better understand the phenomenon under study (Creswell 2012). Significant changes occurred throughout this study, which are discussed.

Firstly, this study evolved in its unit of analysis. The researcher planned to study non-profit organisations and the preparation and perceived impacts of their volunteers. To fully understand the subject area, the unit of analysis was changed to a HEI as academic institutions have longevity and supportive staff able to handle the frequent communication and governance required by a doctoral study. Following the decision to study preparation in the context of a HEI, units of study were restructured from seemingly unrelated groups (i.e. non-profit organisations, volunteers who may have been nursing students or nurses) to a cohesive group, narrowed to a single case study of a nursing study abroad preparation programme. Lastly, the study of 'perceived impact' was excluded due to the impossibility of the researcher measuring such a variable without seeing the medical clinics (see Chapter 8; Limitations). Further, preparation became the primary focus of the study upon realising the scarcity of the subject in the literature and secondarily upon finding that each sending HEI appeared to have unique preparation training.

\section{Ethics}

Ethical approval was gained from the School of Nursing and Midwifery Ethics Committee (Appendix E). The researcher also gained permission from the HEIs represented (Appendices F-H). Consent forms were given to all interviewees (Appendices I-J), allowing the researcher to record audio files of the interviews both for the purpose of this study and for future publications. Permission was also obtained to use anonymised quotes. No 
incentives or payments were given to participants. All data collected and used in this study has been managed and stored in compliance with UK Data Protection Act 1998 and the General Data Protection Regulation of 2018, which was published towards the end of this work. This project also adhered to the Research Governance Policies of the University and to principles of ethics including but not limited to beneficence and nonmaleficence (Gillon 1994).

\section{Method}

A qualitative research paradigm was chosen to explore the multi-faceted preparation nursing students receive prior to studying abroad. The following research methods were considered and rejected before ultimately selecting a case study approach.

\section{Phenomenology}

Phenomenology is the study of an idea or concept and seeks to reduce the experiences individuals have with a phenomenon into a collective description (Van Manen 2015). The method can be broad, as noted by the German mathematician Edmund Husserl, who was known to classify any particular work as phenomenology (Creswell 2012). Participants in phenomenological research offer both a subjective experience of the phenomenon, and an objective commonality shared with other individuals. Data is typically collected via interviews from 5 to 25 participants who have experienced the phenomenon of interest (Moustakas 1994). A feature regularly used in phenomenology is bracketing, in which the researcher explains her experiences that might influence her interpretation of the phenomenon under study. The purpose of bracketing is to set assumptions aside and to allow the reader to decide whether the researcher's experiences have introduced bias in the study. Bracketing is discussed further in Chapter 3 as a method that was used for the reflexive interview.

Phenomenology was deemed inappropriate because it is best suited to study a group of individuals that have all encountered a similar phenomenon. This study went a step further, preferring a holistic description that required perspectives from students, but also perspectives 
from study abroad coordinators including sending HEIs and receiving institutions.

\section{Grounded theory}

Grounded theory (Glaser, Strauss 1967) is an inductive approach that was also considered for this study. In grounded theory, the researcher creates a theory as the research progresses. Data collection is complete when no further information can be found in a particular category, known as data saturation. After the completion of data analysis, the newly emerged theory is introduced into the discipline amongst other existing theories. The analysis can follow categories that will be the focus of the theory. Analysis is done throughout the data collection process, in a 'zigzag' pattern of collecting, analysing, collecting, analysing (Creswell 2012).

Grounded theory was not suitable because concepts (Mauthner, Doucet 1997) are typically the topic of study with less attention to the experiences of participants than this study required (Corbin, Strauss 2014). A holistic understanding of the experiences of nursing students was necessary in order for preparation to be studied holistically, and thus participants in this study were of the utmost importance. Grounded theory requires no preconceived ideas at the beginning of data collection (Allan 2003, Glaser, Strauss 1967), which was not the case at the start of this study. Further, grounded theory usually relies on data collection in the form of 20 or more interviews (Creswell 2012), which was not anticipated as a feasible number of participants who would enrol to study abroad and agree to take part in this study. Creswell also states that grounded theory participants are likely to share similar experiences from many different backgrounds or locations. In this study, students are a homogenous group (see Chapter 6; Recruitment of nursing students) but other participants including study abroad coordinators from both sending and receiving institutions cannot be considered to be sharing similar experiences - only contributing to a shared experience on behalf of the students. 


\section{Ethnography/ethnonursing}

Ethnography is a prevalent research method in nursing literature (Morse 1994, Corbin, Strauss 1998, Munhall 2012). Leininger's (2006)

ethnonursing research method was considered for use in this study, as it is a nursing-specific ethnographic method. In ethnonursing, research examines cultural groups in their natural setting, requiring the researcher to be present to make observations (Brewer 2000). The ethnonursing method studies can for example study a patient's culture and care factors comprehensively using 'key informants', defined as people who are associated with the culture being studied. Ethnonursing has been recognised for addressing social inequalities - a continuous problem in low human development countries, which are attractive locations where nursing students often study abroad (Abrums 2004, Chamber, Alexis 2004, Daniel, Chamberlain et al. 2001, Lancellotti 2008, McFarland, Mixer et al. 2012).

An ethnographic method was also considered to be unsuitable for this study because the researcher could not travel to the respective countries where participants studied abroad. The study abroad location would have needed to be the primary source of data collection for ethnographic research. Further, due to the nursing students being out of their natural setting, this would not represent an ethnographic case but rather a group that is experiencing a new culture.

\section{Case study}

A case study method was chosen for this study because it has a strong presence in nursing research (Munhall 2012, Li, Gao et al. 2014, Bell 2014, Puskar, Rudolph et al. 2017) and is defined as an empirical inquiry that holistically investigates an existing phenomenon with attention to its context. Case studies are especially useful when boundaries of the phenomenon of interest are unclear or poorly defined (Yin 2014) which represented the knowledge the researcher had of preparation at the onset of the study.

Case studies are not typically associated with generalising to wider populations. However, Flyvbjerg (2011) argues that in fact one can 
generalize a great deal based on a single case study. The single case can generalize to a wider phenomenon or supplement other research methods given the holistic and in-depth data acquired from the case. In other words, 'the force of example' and transferability are underestimated in the method (p. 305). A detailed description of a case can lead to theory development and raise questions about specificities in a way that would not be possible by studying a generalised population. Observation methods such as case studies have produced more discoveries than large-scale groups that are associated with generalizability.

Case studies are ideal for studying complex phenomena (Dooley 2002). An example lies within the study topic presented in this this thesis. HEIs have chosen nursing study abroad trips as the ideal way for studying the complex phenomenon of culture. Nursing study abroad trips are the example or 'case' HEIs have chosen as the best way for students to learn a new culture and presumably achieve cultural competence. In Chapter 2, cultural competence is identified as the primary justification for nursing study abroad trips. Therefore, HEIs use the case study approach to teach cultural competence to nursing students. This example shows how cultural competence is a difficult concept to understand theoretically, or without examples. Indeed the idea may be introduced in the classroom, but a study abroad trip takes students out of the classroom of theoretical knowledge, and into a realworld context of a different culture in order to learn about that culture. Attaining cultural competence is believed to be accomplished through studying a holistic and in-depth cultural 'case': sending nursing students to see the context, hear the language, taste the food; all tangible real life experiences rather than theoretical, classroom teaching. Therein lies the strength of the case study.

As explained by Flyvbjerg (2011), a case study method ought to be employed if a particular phenomenon needs to be understood. It is only afterward that such a phenomenon can be used in statistical or quantitative methods to see how widespread the phenomenon is, and how it correlates with other phenomena. This suggestion is applied in Chapter 7, wherein a 
statistical method was used following analysis of the case study data in Chapters 5 and 6.

\section{Design}

The purpose of this study is to explore the preparation that nursing students receive prior to undertaking a study abroad trip, gathered from a triangulation of data types and data sources. Case studies rely on multiple sources of evidence, allowing data to converge in a triangulating fashion. Boehrer and Linsky helpfully compare case study design to 'bringing a scattered group of parachutists into contact from all the random places they have landed' (1990, p. 41). Triangulation was used in this study to minimise bias, compensating for the limitations of each type of data collection method, strengthening the trustworthiness of the results (Guba 1981, Brewer, Hunter 1989, Westie 1957, Campbell, Fiske 1959, Webb, Campbell et al. 1966, Begley 1996, Sandelowski 1995, Denzin 1970).

Three major methods exist within case study research, which include Yin (2014), Merriam (1998), and Stake (1995). The researcher chose Yin to guide the study design as it was the most transparent of the three in terms of following a specific study design, and because of his work regarding case descriptions, which was the chosen method for reporting the preparation training offered to nursing students. The following is Yin's five-component case study research design framework.

\section{Study question}

The first of Yin's (2014) five components of case study design is the study question, as stated in the section Research Question and Aims of this chapter: how do nursing students prepare to study abroad? 


\section{Propositions}

The second component of Yin's design guides the focus of the case study beyond the study question.

1. How do sending HEIs prepare nursing students to study abroad?

2. How do nursing students perceive or understand their preparation?

3. How do nursing students perceive or understand their level of preparedness before studying abroad?

4. How do nursing students articulate their level of preparedness upon their arrival to the host location?

5. How do nursing students understand their level of preparedness upon their return home when reflecting back on their trip?

6. How prepared are nursing students according to receiving institutions?

Following propositional statements, Yin suggests theoretical statements dovetail from propositional statements and hold significant analytical value. Propositional statements guide the research design and data collection; theoretical statements (below, Theory Development) guide the analytical strategy.

\section{Units of analysis}

The third component to Yin's case study design is defining and setting boundaries for the case. Figure 5 provides a visual representation of an embedded single case design. 
Figure 5: Embedded Single Case Design

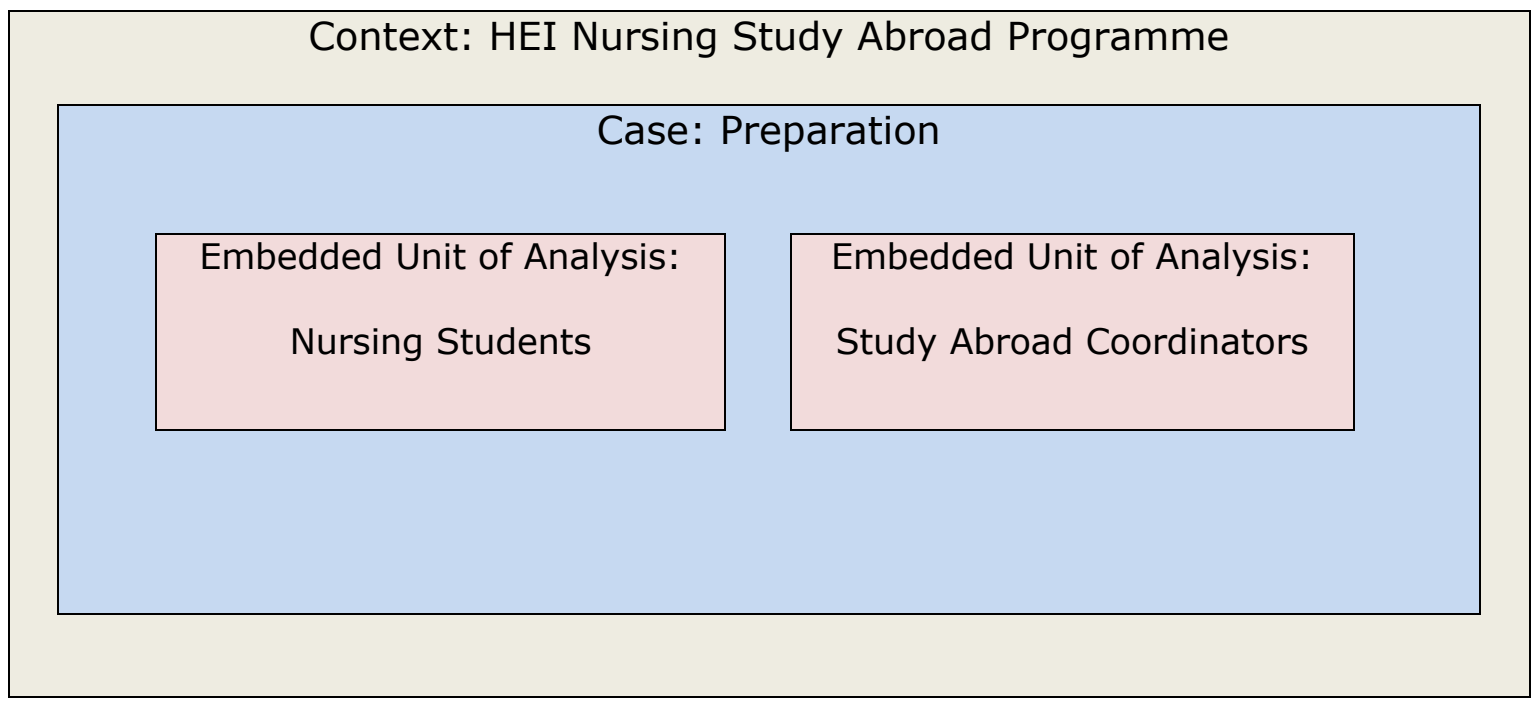

The nursing study abroad programme acts as the context, in which the preparation provided to students is the case. Nursing students enrolled to study abroad and the coordinators act as 'embedded units of analysis' (Yin 2014 , p. 50). For the purposes of this project the researcher will use the term 'participants' instead of 'embedded units' which is the term used by Yin. Boundaries of the case include:

- Scope: an empirical enquiry of the HEI study abroad preparation programme offered to nursing students;

- Participants: enrolment in nursing study abroad trip through HEI; study abroad coordinators at receiving and sending institutions

- Time: Preparation associated with three-month study abroad trip at the end of 2014, throughout the length of the study abroad trip, and until final post-trip interviews following the student's return home

\section{Logical link between data and propositions}

According to Yin the fourth component of case study research connects the collected data with the analytical strategy. Data must be collected with a justification to answer propositional statements (see propositions). 
Data collection included documentation of the HEI study abroad preparation within its curriculum. Additionally, interviews were conducted with study abroad coordinators; students at two different times: before and after their trip. Students also wrote diaries and blogs whist they were away. Finally, receiving institution study abroad coordinators were contacted and asked for interviews, however these interviews were not conducted due to a lack of prompt email correspondence as explained in Chapter 8 (limitations and delimitations). These data collection techniques were chosen to support each propositional statement.

\section{Criteria for interpreting the findings}

Yin's final component for case study design is criteria to analysis the data. A common analytical strategy is the development of a case description wherein data are organised according to a framework or matrix (see Chapter 6, Table 11). This provided the opportunity to develop a robust definition of 'preparedness' as the literature lacked a holistic description of a study abroad preparation programme.

\section{Theory Development}

Case study method requires that a theory is developed prior to data collection - a unique characteristic compared to other qualitative methods such as ethnography (Lincoln, Guba 1985) and grounded theory (Strauss, Corbin 2007). Propositional statements (above) outline the directional needs of the study, while theoretical statements guide the analytical strategy.

The following are theoretical statements which informed analysis:

1. The case study will provide a holistic description of the process of preparing nursing students to fill knowledge gaps in the available literature

2. The case study will reveal students' preparedness for their study abroad trips by considering their emotional response to daily experiences. 
3. The case study will show how preparing a student for a study abroad trip based on the country's power, wealth, or continent is insufficient for the needs of the nursing students.

\section{Single Case Study Design}

A single case design was preferred to a multiple case study design for the following reasons. Firstly, the researcher had a timeline of a doctoral degree that did not allow for multiple study abroad programs and HEIs to be studied in the amount of depth necessary for a multiple case study. Secondly, single case study designs were attractive in that they allow for more depth of description, including the single case rationales listed below.

\section{Single case rationales}

Case studies may be categorised as deviant, maximum variation, critical, or paradigmatic (Flyvbjerg 2011). Yin's (2014) design has two additional categories, revelatory and longitudinal cases. Deviant cases raise questions about the norm, allowing for new concepts to be studied that may not have been noticed otherwise. Maximum variation is often seen in multiple case studies rather than single case studies, in which one component of the case changes, and other components remain the same to test the difference caused by the varied component. Another category is the critical case study, described as most likely or least likely cases that will clearly confirm or deny a proposition. The critical case is generalizable to many others of the same type. Paradigmatic cases transcend criteria, and become the standard. A paradigmatic case is identified intuitively because it outshines other cases (Dreyfus, Dreyfus 1986). A critical case can redirect future research in an entire field. A noteworthy critical single case study in the literature examined the barriers to innovation of a school. The research findings added new knowledge to the field as previous literature had only focused on barriers rather than procedures for implementing new change (Gross, Giacquinta et al. 1971). This critical case changed the trajectory of its field.

Yin's two additional categories were revelatory and longitudinal cases. A revelatory case adds new knowledge to the literature due to a unique unavailability. For example, a watershed revelatory case studied the lives of 
a group of men in an inner-city American neighbourhood, and how socioeconomic conditions affected them. The subject had not been studied to date, and Liebow (1967) stimulated further research that led to the development of policy change. The second type according to Yin is longitudinal, in which a case in studied over multiple points in time.

A case can be simultaneously deviant, critical, paradigmatic, and revelatory. For example, one could argue that if an HEI that is established and reputable, having a long standing and established nursing study abroad programme, offers inadequate preparation training for study abroad trips, then presumably this happens at other HEIs.

The following chapters present a pilot case study and subsequent formal case study. In both chapters, the preparation undertaken by nursing students before studying abroad is the case under study. 


\section{CHAPTER FIVE}

\section{A PILOT CASE STUDY OF A FINNISH NURSING STUDY ABROAD PREPARATION PROGRAMME}

This case study explores a preparation programme given to nursing students prior to studying abroad, offered by an institution in Finland. The pilot guided the development of the case study method for a subsequent study in The Netherlands (see Chapter 6), referred to in this chapter as the formal study.

\section{Pilot Case Study}

Yin (2014) defines a pilot case study as a preliminary work that is necessary in circumstances where data collection tools or methods need to be refined or developed before undertaking a formal case study. Pilot case studies are useful for describing the lessons learned and guiding the journey to use certain methods and instruments before embarking on a formal case study. Analysis is not typically reported in the same depth as the formal case study. There is little guidance in the literature for researchers who choose to report pilot study findings, mostly dealing with 'internal' pilots. In contradiction of standard pilot study practice, this chapter provides a brief analysis of the data to confirm the chosen methods produce an insightful discussion of preparation.

\section{Justification for undertaking a pilot case study}

Prior to conducting the formal case study in The Netherlands, the researcher contacted a study abroad coordinator in Finland to pilot a set of original interview prompts as supported in the literature (Dobrowolska et al., 2015; Duffy et al., 2005; Lenz \& Warner, 2011; Read, 2011). Following the pilot interview, an exploration of case study data collection possibilities led the researcher on a search to find the best practice for exploring preparation within a case study method.

Firstly, the pilot case study was undertaken due to preparation being an undefined and widely varying phenomenon in the literature, and thus the 
researcher expanded the pilot interview to a full pilot case study. This allowed for flexibility to finalise a protocol, which otherwise would not have been methodologically rigorous during a formal case study. The pilot enabled the researcher to develop changes necessary to select additional participants and data collection tools as needed. Secondly, the researcher had not undertaken a case study previously and felt the pilot would be an educational tool that would also mitigate overlooked aspects in the subsequent formal case study. The institution in Finland agreed to this new development as performing a pilot can be beneficial to the case under study in that the researcher acts as an external observer, able to produce feedback that can be highly valuable (Yin 2014). Thirdly, in preparation for the formal case study, the researcher used the pilot to validate original data collecting instruments that guided interviews with study abroad coordinators, the collection of student blog and diary data, and students' pre- and post-trip interview prompts.

\section{Method}

Yin's (2014) approach was used to report this pilot case study (the choice to follow Yin's design is discussed in Chapter 4). Yin employed the most transparent formula of the three case study methods as discussed in Chapter 4. The researcher gained ethical approval from the HEI in Finland (Appendix F) and the Health Africa consortium (Appendix G) to conduct this pilot study. All other forms including consent forms for interviews (Appendix I-J) and information sheets were the same as used for the formal case study (see Appendix L-M), as well as ethical procedures (see Ethics, Chapter 4). The researcher's School of Nursing and Midwifery ethics committee approved the pilot case study of the Finnish institution's preparation programme (Appendix $\mathrm{K}$ ), which was not included in the original research approval (Appendix E). The following is a discussion of the selection of the pilot, the scope of pilot inquiry, methodological changes, and pilot data.

\section{Selection of the HEI context for the pilot study}

The researcher chose to study a Higher Education Institution (HEI) study abroad programme; this was preferred over religious institutions and non- 
governmental organisations (NGOs) which also organise similar trips. The rationale for this was primarily because HEIs have cohorts of nursing students who can be followed over a period of time as opposed to multidisciplinary groups of health professionals who volunteer to work abroad for varying periods of time. A further reason for selecting HEIs was because attempts made to recruit religious institutions and NGOs proved challenging due to delayed responses and not being able to find one person as a point of contact.

A HEI in Finland offering study abroad programmes to nursing students was identified through a sampling technique called information-oriented selection (Flyvbjerg 2011). Information-oriented selections are characterized by maximizing the utility of small sample sizes. Cases are selected based on the expectation that they will provide rich data. Choosing a HEI included an interest in the location of study abroad trips. The selected HEI was connected to the researcher's university through the Erasmus Programme. The study abroad coordinator who agreed to take part in the pilot presented attractive credentials, having years of experience working in the field of nursing study abroad trips as well as a willingness to take part in the study. These are important characteristics for a pilot case participant (Yin 2011).

More than one perspective was desired to study the phenomenon of preparation. The researcher asked for the study abroad coordinator's assistance making contact with nursing students planning to study abroad in their next cohort. The study abroad coordinator forwarded students an information sheet about this research to gauge interest. One nursing student agreed to take part in the pilot case study. The researcher also asked the study abroad coordinator to connect her with a contact in one of their receiving institutions in Uganda or Kenya to hear their perspective of student preparedness. The study abroad coordinators in Africa responded too late to participate in the pilot study however, they still wanted to offer information from their perspective (see Chapter 7). 


\section{Scope of pilot study}

As data was collected, the researcher made informed decisions that strengthened the method for the subsequent formal case study. Embracing the theoretical statements in Chapter 4 (see Theory Development), the scope of the pilot inquiry includes the following types of data collection.

\section{Development of prompts: Interview with study abroad coordinator}

Prompts were informed by an extensive literature review making them open-ended and chronological (Miles, Huberman 1994). Key issues were identified in the literature necessitating that prompts generate a description of the institutional context (Green et al. 2008, Curtin et al. 2013, Flyvbjerg 2011). Prompts were firstly related to the ways in which students were prepared to study abroad, followed by prompts inquiring as to how students were enrolled to study abroad, and later, risk assessment concerns i.e. the protocol to follow should problems arise while students are abroad (see Chapter 2, Risks and Potential for Harm; Appendix $\mathrm{N}$ for the interview prompts).

\section{Interview with study abroad coordinator}

The Finnish nursing study abroad coordinator was interviewed in part to validate the original prompts and confirm that they produced rich information for the formal case study. After signing a consent form (Appendix I), an interview was arranged via Skype as the coordinator was based in Finland; the use of Skype for this purpose is well documented and endorsed (Bertrand, Bourdeau 2010, Couper 2011, Hanna 2012, Lasater, Upvall et al. 2012, Kemppainen et al. 2012). No translation services were required as the coordinator was fluent in English.

\section{Student pre-trip interview}

The Finnish nursing student who agreed to take part in the study was interviewed next. This interview was conducted using a validated set of questions adapted from a study by David Citrin (2011) that were used previously in the reflexive interview (see Chapter 3, Interview Instrument; Interview Instrument Changes; see Appendix $O$ for student interview 
questions). The reflexive interview acted as a validation tool in preparation for using the same questions during the Finnish student's pre-trip interview. These interview questions were used to identify the student's understanding of her preparedness and to elicit feelings about her pending study abroad trip. During the interview, the student spoke frequently of her excitement to study abroad and her life goal of travelling to Africa. A translator was not required for the interview because the student was fluent in English.

One further question was added informed by the extensive reference to cultural competency within the literature (see Chapter 2, Cultural Awareness, Cultural Competence, and Cultural Sensitivity). This question was informed from Bennett's Developmental Model of Intercultural Sensitivity (DMIS), displayed in Figure 6. The fundamental belief of this model is that a person's cultural competence increases as cultural experiences progress. Bennett's continuum (see Figure 6) has six stages: three on the side of ethnocentrism (the belief that one's culture is central to reality); three on the side of ethnorelativism (an indigenous culture is viewed within other cultural contexts, all of which are appreciated) (Anderson, Lawton, Rexeisen, \& Hubbard, 2006). Thus, Bennett's DMIS provided theoretical support to assess the nursing student's cultural competence, and possible changes that could have arisen showing a shift between ethnocentrism and ethnorelativism whilst on the study abroad trip (1986; 1993). 
Figure 6: Bennett's Developmental Model of Intercultural Sensitivity

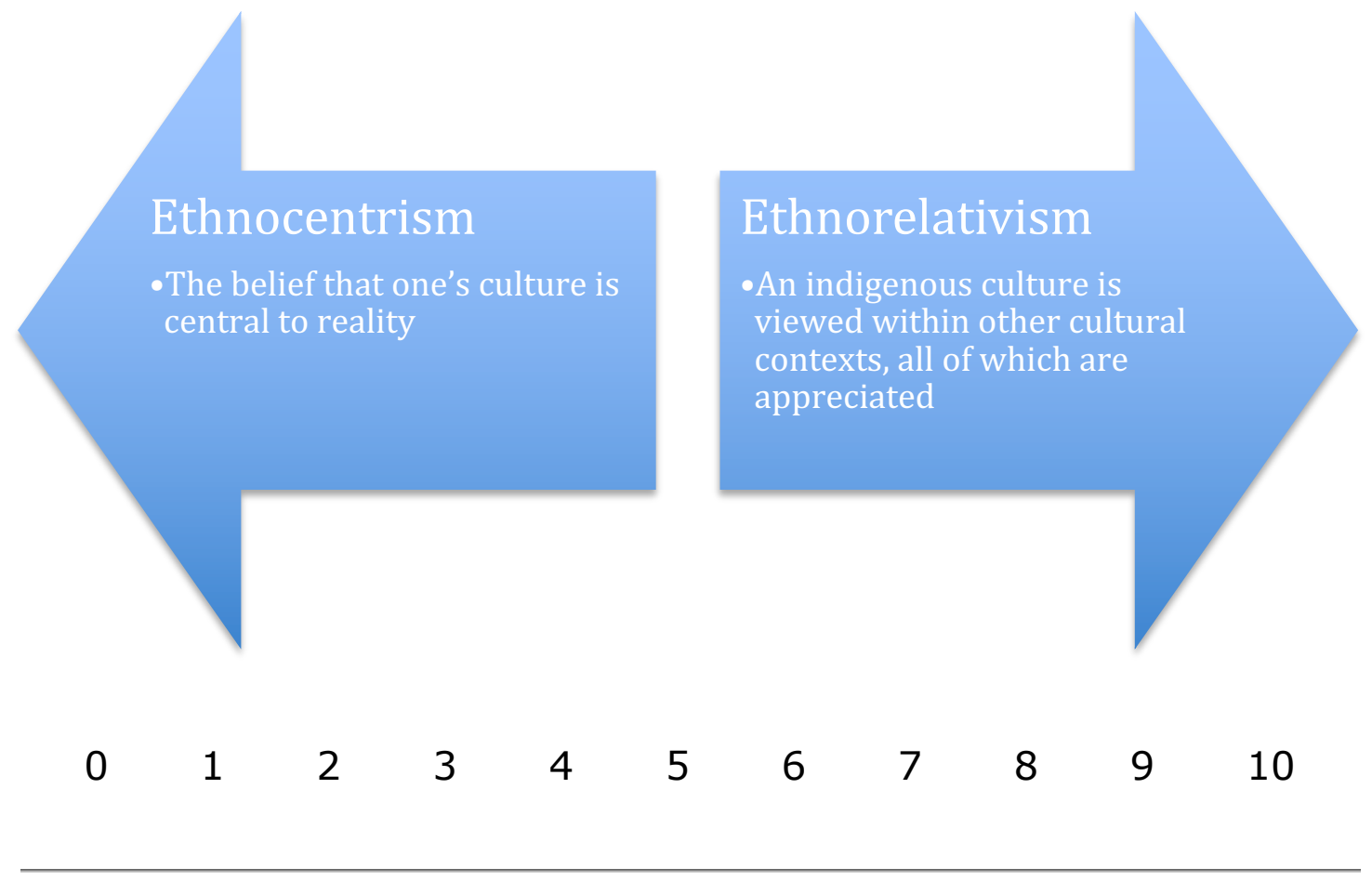

\section{Student diary}

A data collection method was sought that captured the student's

experiences while abroad, as this would provide insight into circumstances for which the student may or may not have been prepared. A diary method was chosen for the following reasons.

Diaries have been used as early as 1957 for medical research (Merton, Reader et al.) and are an effective way of collecting data given their natural form and minimal intrusion into the diarist's life (Alaszewski 2006). They are useful when the researcher cannot undertake the observations the diarist sees, and can assist nursing students to reflect on practice (MorrellScott 2018). Diary entries are typically treated as rich data sources and identified as individual critical case studies (see Chapter 4 for categories of case studies, including critical cases) (Alaszewski 2006). The guidance the student received for completion of the diaries and blogs is available in Appendix M. 


\section{Student blog}

The HEI in Finland recommended that students kept a blog while studying abroad. The student had made plans to keep a blog, and shared her web address with the researcher, inviting the researcher to follow her experiences and encounters throughout the study abroad trip. Considering it as an opportunity for additional rich data, the researcher included the blog as a third data source, creating a triangulation of data collected (see Chapter 4; Triangulation).

Blogs are distinguishable from diaries in that they are socially interactive and community-like in nature (Herring, Scheidt et al. 2004). Unlike diaries, blogs are meant to be publicised on the internet for others to read and respond. The student was asked to update the blog weekly as supported by Alaszewi's (2006) that states that diaries and blog entries must be accurate, precise and regular. Blogs gave the author a reason to consider opinions and ideas, and assurances that his or her views are valuable (Williams, Jacobs 2004). Bloggers have redefined the media as a public, participatory endeavour (Blood 2000), and offer a unique, modern source for data collection (Hookway 2008, Punch 2013). They can also promote chosen characteristics of identity, particularly in the case of the nursing student who has lived internationally and is multilingual (Luzón 2018). If a student is able to blog in a manner that enhances readership, it can attract advertisers who can make the blog a source of employment (Stainton, Iordanova 2017). Thus, it is in the blogger's best interest to keep entries as interesting as possible, portraying the study abroad experience with an audience of family and friends in mind, but still aware that publically published content could reach any number of potential viewers.

\section{Student post-trip interview}

The student dropped out of the study prior to the post-trip interview. Therefore the blog and diary data were the final sources of data, collected until the end of the study abroad trip. 


\section{Methodological and substantive changes to the pilot}

The development of interview prompts, pilot interviews, student diaries and blogs were improved as a result of the pilot. The following changes were made prior to conducting the formal case study:

\section{Pilot interview with study abroad coordinator}

During the pilot interview with the study abroad coordinator, the researcher elicited the type of information needed. However, following the analysis, the information collected on the institution's preparation programme was not as rich a data source as the researcher had expected. A change was made for the formal case study to request additional data sources such as documentation (e.g. student handouts, presentation materials) related to student preparation that would supplement the interview data regarding the curriculum and content of student preparation.

Two prompts were omitted from the study abroad coordinator's interview ('What is the rationale for sending students to Africa?' and 'Are vaccinations required before leaving on trips?') because the answers were repetitious from other prompts in the interview (see Appendix P for updated interview prompts).

\section{Student diary}

The student was asked to make audio recordings of a diary each week. The instruction sheet provided ideas to help begin entries, such as the adequacy of preparation for weekly occurrences, and how she felt she was impacting those around her. Instead, the student uploaded videos to a YouTube channel. This did not comply with the researcher's request; it was felt that sharing on a public platform such as YouTube compromised the integrity of what the diary was meant to produce in a private space, and would simply repeat content of the student's blog. The student's action raised a question as to the plausibility of the chosen form of data collection, and was ultimately decided to be too demanding on the student to complete such a task. The researcher contacted the student and requested a written diary, which was provided on a weekly basis thereafter. 
A change was made for the formal case study to instruct students to write diaries in Microsoft Word documents, which would be easier to upload during times of unreliable internet connection while abroad.

The instructions remained the same as the outset of the student's involvement in the study; only the diary's mode of communication changed from an audio recording to a written document. The difference between blogs and diaries is above (Student Diary; Student Blog).

\section{Serendipitous benefits of student data collection}

The researcher was mindful to avoid collecting unnecessary data beyond the scope of the study. While the student was abroad, the breadth of data from blogs and diaries in particular seemed beyond the scope of what was deemed sufficient for this study. The student would write at length about her experiences outside of her clinical duties, seeming to veer off the path of what was suggested in the instruction sheet for her diaries and blogs. The researcher considered collecting less data from students in the subsequent formal case study. However, upon closer inspection, the student narratives provided a serendipitous benefit to the research.

Serendipity refers to a critical issue in research in which an unexpected event can lead to an improvement (Keikelame 2018) and not as a mere accident (Ryan, Lőrinc 2016). The Methods Chapter (see theory development; theoretical statement 2 ) stated the study would provide an insight into the preparedness of students based on their reactions to events. However, the student surpassed the anticipation of the researcher by providing long narratives containing details such as a response to the cultural context, workload, communication challenges, etc. Such storytelling implicitly described whether she had been prepared for various events.

The student inadvertently provided more information regarding her preparedness in narratives while talking about real life examples than when simply responding to the question, 'do you feel prepared?' The researcher considered changing the student data collection, reducing the amount of data, but ultimately decided to keep the same format for the subsequent formal case study due to the serendipitous, implicit references the student 
made to her own preparedness. The student narratives provided a picture into her wide range of emotions that happened alongside her daily encounters while studying abroad, sometimes dangerous, other times oncein-a-lifetime learning opportunities.

\section{Analysis}

While pilot case study findings are not typically reported in detail, the researcher conducted an analysis and presented the findings to confirm rich data was collected and methodological decisions were finalised for the formal case study. Firstly, all data regarding preparation were organised into a case description of preparation (below). Next, the remaining data that did not explicitly discuss preparation were analysed as it was felt this data included implicit dialogue of preparedness. The data that did not explicitly discuss preparation was analysed thematically. It was worth exploring the student data beyond preparation alone to achieve a fuller picture of the case under study. The thematic analysis followed the first five steps of Colaizzi's (1978) method: reading and rereading the transcribed interview documents; extracting significant words and phrases; formulating, categorising, and integrating deeper meanings into the description of study abroad trips. It is worth noting that Colaizzi's seven-step analysis was never meant to be a rigid requirement; but rather to guide a flexible, thorough exploration of the phenomenon under study (Wirihana, Welch et al. 2018). The purpose of Colaizzi's thematic steps include acquiring a sense of what the participant was feeling at the time the entry was written, and similar to the reflexive interview analysis in Chapter 3, revealing implicit meaning (Wojnar, Swanson 2007). Others have used Colaizzi's method (Maltby, Abrams 2009), or other thematic forms of analysis (Walsh, DeJoseph 2003) for analysing data related to nursing study abroad trips. An example of a coded section of an interview transcript with the Finnish student is available in Appendix Q. 


\section{Report of the Findings}

The pilot provided an insightful view of the preparation programme given to nursing students prior to studying abroad. The study abroad coordinator's interview and triangulation of student data produced the following description.

\section{Description of the Case}

\section{Context}

The Finnish institution has a strong national profile and an established Erasmus Programme, which enables study abroad trips to 16 countries. Nurse education in Finland lasts three and a half years, and the second and third year students may travel through the Erasmus Programme to Kenya or Uganda facilitated by the Health Africa Network, amongst other destinations. Every two years, Finnish, Kenyan, and Ugandan students are able to take part in a student exchange program for three months. African students may study in any of eight Finnish institutions associated with a consortium called Health Africa. Finnish students may go to an institution associated with Health Africa in Uganda or Kenya. The HEIs application process begins the preparation, requiring Finnish students to be interviewed, submit an account of academic record, consider personality traits, and inquire as to the student's understanding of working in Africa. These measures ensure stability, and avoid students returning home before the study abroad trip is complete as this can interfere with funding among other logistical difficulties. It is uncommon in the literature, but worthwhile for HEIs to investigate any troublesome traits students may exhibit prior to their departure rather than discovering them while abroad. Otherwise, students simply enrol into a study abroad programme and enter a context inducing high stress having no knowledge of whether the student possessed reflective skills, resilience, or communication skills to proceed with the trip or return home early (see Serendipitous Benefits of Student Data Collection). 


\section{Preparation}

\section{Study abroad coordinator perspective}

The institution selects the study abroad site based on the objectives and experience the students would like to achieve. Students receive three days of preparation training before leaving. Food, hygiene, safety, flights, and accommodation are among the topics discussed at preparation meetings. The three days of preparation also include what the students can expect to work on during their trip, what to bring, dress code, and safety. Lists of items to bring including those that are unavailable to purchase in Kenya are distributed. Students are prepared with a vaccination programme and medical tests required before departure. Once the students arrive on site, they attend an orientation week and visit the site where their study abroad experience will take place. The students are supported by a link lecturer from the home institution who visits them while studying abroad, and are able to contact their institution's coordinator in the event of a problem. Upon returning home to Finland, students have the support of assigned 'teacher-tutors' and receive health screening when they return based on their place of employment.

\section{Student perspective}

Prior to the trip the student was asked what she knew about her study abroad trip; she responded by stating that she knew 'a little about it' and would be working in surgery. Her responsibilities included doing 'elderly training' in a nursing home located outside of the city, and she would also work in a hospital. In terms of accommodation, she knew she would share a room with another student coming from the HEI in Finland.

From her preparation the student recalled that the patients in the receiving country 'don't use drugs as much, like pain relief'. This was brought up throughout the interview; the student considered other pain management therapies she could use to keep the patients as comfortable as possible. Another preparation topic was safety; students were told not to go out after dark and what to do in case of an emergency. The student remembered, 'they kind of tried to prepare us for the worst possible scenarios, and I thought that was great.' A related safety topic was the 2014 Ebola outbreak 
in West Africa, which was discussed during preparation training as a potential threat (another consideration of Chapter 2 section Risks and Potential for Harm).

The student said her HEI provided an ample amount of paperwork and information leading up to the trip: 'yeah, lots, they're really organised. The university plus the university in Africa, it's a lot of information and organisation.' Culture was also discussed, during which the students were

told that their presence in Kenya ought to be helpful and how they should dress appropriately.

When asked if she felt prepared, the student said,

Yeah, I'm pretty like, just go with the flow, kind of live in the moment, but I do feel like they've given me a lot, I do feel good that they've talked to us about this stuff. And also they had some other people come talk to us who had already been on the exchange a year ago, so that helped, someone that actually went.

The interview was optimistic regarding the study abroad trip until the student displayed apprehension regarding hygiene. During preparation, the student learned of her study abroad location, 'there's like no hand disinfectant, gloves, we've got to bring all that with us'.

Following the interview, the student travelled to Kenya where she undertook a three-month study abroad trip. She composed blogs and diaries that informed the following analysis of her experiences in Kenya.

\section{Remaining reflections from student's pre-trip interview}

During the pre-trip interview, the student expressed what she hoped to achieve through her time in Kenya. One hope was to compare the health structures between Finland and Kenya, wanting to 'bring understanding to Finland' and 'appreciate what we have in Finland'. She felt her time abroad would bring a greater acknowledgment for what she had back home, and 
learn more about a new culture. She also hoped her patients would be 'comforted' by her presence, and that she would be able to make them 'feel a bit better'. The student displayed an open mind with the statement, 'I hope I will understand more about the cultures there, not just our way? Like the culture is important in my opinion. There's a lot of foreigners in Finland at the moment, and not many people who get that they're actually people, just because they're a different colour, I would like to bring that understanding to Finland, of different cultures and religion.'

\section{Blog and Diary Data:}

\section{Analysis of the Student's Experiences}

\section{First impressions}

The student appeared to have a grasp of what her responsibilities would include upon arriving in Kenya. Clinical time was split between three sites, including a nursing home, an orphanage, and a hospital. The Finnish institution required certain academic requirements while abroad which included a thesis on the pain experiences in different cultures which she took a day a week to complete at home.

Orientation was provided by the receiving organisations at all three study abroad sites (the hospital provided the shortest orientation, which the student felt was inadequate). The student reported having responsibilities other than what she had understood from her preparation. For example, in her pre-trip interview she was told she would only be working during the day at the hospital. Soon after beginning her placement she was assigned to work night shifts. Similarly, the student knew she would be working in a hospital (see above Student Perspective), but not an orphanage.

Widely acknowledged as a benefit of studying abroad (see Chapter 2, Benefits of Nursing Study Abroad Trips), the student felt that she expanded her worldview. The student admitted that she had a stereotype of Africa before arriving in Kenya:

Poverty, hunger and diseases everywhere? That's what I used to think. I also thought everyone spoke English, few could 
write and close to nobody went to school. Plus I thought all the countries were more-or-less the same. Oh how wrong I was!

The student reflected on her new understanding of Kenya,

People here have a joie de vivre not found in us Westerners. They are happy just to be alive and to get something to eat or drink and to have some sort of shelter from the elements, be it a house, shack or a tree.

The blog also contained details of new and exciting learning experiences. 'So on Sunday nothing too exciting happened but I did go "potty" in a holein-the-ground toilet!!! :D SO EXCITING!' The group of students undertook excursions for example when they saw a hippopotamus whilst on a boat ride on Lake Victoria. They also went on a safari, posting pictures of giraffes, zebras, hyenas, and saw a cheetah. The old adage, 'a picture is worth a thousand words', rang true as the pictures of the hospital and the safari were more insightful than the wording in the blog posts to understand what the student was experiencing.

The student talked negatively about the smells of Kenya in her blog, finding them unpleasant. She found Kenyan people to smell of body odour, and also complained about the smells when she was at the outdoor market: Sometimes, when the breeze hits just right, you can smell human excrement, sweat, sewage and rotten food all at once! Just try to imagine that.

\section{'Rollercoaster of emotions'}

Anticipation was high at the start of the placement with the student writing in her diary: 'this week we're starting at a hospital and this should be an interesting and new experience!' In terms of accommodations, the students seemed to 'get along together': 'we're all fairly comfortable here and with each other as well.' Nevertheless, emotions began to rise and fall, with statements peppering the student's diary such as:

This past week has been a rollercoaster of emotions!

I've had great days and I've had downright rotten days.

I've been missing my husband a lot lately.

Let me tell you it was frustrating! 
Everything's been all exciting and new and hunky-dory!

He makes my blood boil!

I went to calm down and burst out crying.

The student was open about her emotions throughout the study abroad trip. She was married, and leaving a spouse behind for three months proved to be extremely difficult for her. Occasionally she would say things such as:

I've been feeling so much better about everything lately, I've not been missing my husband as much lately, I've sort of gotten used to being here alone.

Yet emotions remained somewhat unpredictable. As the student articulated her emotions throughout the trip, her views changed:

I've personally been really homesick for the past few weeks, on and off. While I'm at work practice I feel fine, but when I get back to the apartment and if I don't do anything to distract myself I feel very homesick. I also feel like I'm a little snappier than before. I don't mean to and I try not to snap at people but I can tell I'm not the only one feeling like this. And we've talked about it with some of the girls.

The blog content was mostly enthusiastic, but the student was not afraid to speak of her struggles on a public platform:

I don't think I can even begin to describe what I'm feeling right now. I've never felt so helpless, so unable to express my feelings, so confused. On the other hand I'm having a blast. Near the end of the trip, her emotions seemed to settle on:

I just want to go home and get back to "reality", even though this is my reality at the moment. It's strange. This whole exchange feels very surreal at times.

Another day near the end of the trip her emotions were bittersweet:

I feel like I have my life set here and everything is great. I might just cry a little today. 
Interestingly, the act of keeping a diary occasioned an unintended benefit of this study. The student said that sending the researcher weekly diaries was helpful:

I'm honestly glad to get that off my chest! It helps in dealing with these things while I'm here. We talk a lot with the other girls but it's nice to tell a complete stranger too! It's therapeutic!

And a second time:

It's great to be able to write out feelings and thoughts because it helps to clear my mind and not dwell on ridiculous little things that might make this experience difficult. I appreciate it!

\section{Risks and conflicts}

The student kept a busy schedule during the study abroad trip amidst frequent illnesses. She and her peers travelled on the weekends including visiting a safari, a rainforest, and travelling to Nairobi and Mombasa.

An aspect of the trip that emerged from the student's diary were the risks to her personal safety. A dangerous situation arose while the students were on holiday in Mombasa:

Our holiday was spent mostly at the hotel pool and the beach in front of the hotel. We weren't allowed to leave the hotel premises or the beach because of a terrorist threat (ongoing) in Mombasa. There were some raids in three mosques in Mombasa and there was a retaliation in Northern Kenya where a bus on its way to Nairobi was stopped and all the nonMuslims were killed in cold blood. So we were instructed to stay in the hotel or else leave Mombasa ASAP. We stayed at the hotel for the whole week, even though I didn't fully agree with the school's instructions. And I did actually go to the shopping centre with a local and one of the other girls to get some snacks, because we were running out of money eating out twice a day (luckily breakfast was included). 
The student reported not following guidance from her HEI, albeit as safely as possible, having been accompanied by a local. Still, this exposed the student to considerable risk and there was no mention of the student being told to stay away from the city under threat, only to stay at the hotel. Perhaps the study abroad coordinator should have foreseen the student would disobey an order to stay indoors for several days and developed approaches to fulfil essential tasks such as buying food safely. The student misunderstood or failed to appreciate the gravity of the situation, or perhaps felt she was better placed to judge the risk given her location.

A further threat was the Ebola epidemic only a few countries away in West Africa. With frequent travel through the city of Nairobi on the African continent, the student was at risk of contracting Ebola especially working in a healthcare environment. This coupled with the student's reports of frequent illnesses and that of her fellow students demonstrates the heightened risk to her personal health.

The student also reported unreliable means of communication, which was due to limited internet and power connections: 'I've not been able to connect to email for over a week'. Inability to access the internet was the most frequent reason given for sending diary entries late to the researcher; this posed a significant risk had she needed to contact her sending institution in the event of an emergency. Further, the emotional turmoil seen throughout the student's diary entries suggests that on occasion she might have required psychological support for some of the crises that she witnessed and being unable to make contact with her study abroad coordinator or family for over a week could have left her extremely vulnerable and at risk to her mental health.

One evening, a surgeon let the student assist in:

Stitching and keeping the wound clean. It was nice to actually do something for a change instead of just watching.

From the student's statement this action was more than likely not permitted by the hospital regulations, however due to boredom the student was 
pleased to have the opportunity to practice some nursing skills for the first time. She also recalls:

I got to cannulate a child! I've never done that before! Plus he was black. And sedated (the veins disappear). And the first time I've cannulated an actual patient! It may not sound like much but because I was successful I felt a real rush of pride in myself.

The student had many opportunities for learning, however some of the practices may have been beyond the bounds of approval, which raises the question of implications for professional remit following nursing study abroad trips. The student's excitement of cannulating the child appeared to suggest that it would not have been permissible in her home country of Finland. This echoes the sentiments in Chapter 2 (post-colonial voyeurism) that many students may prefer studying abroad in countries where they can practice beyond what their home countries would allow.

An uncomfortable situation related to the study abroad trip was a complaint regarding the students. A situation arose in the student's blog wherein no local coordinator had responsibility over the students at one of their study abroad sites. The students had somewhat of a dispute with a coordinator back home in Finland regarding their need to have a local supervisor. This situation was perpetuated by a student who attended a conference near the Ugandan border, raising alarms regarding the Marburg virus:

It's like the Ebola virus except deadlier... the symptoms develop in two weeks whereas it's three weeks with Ebola. So there have been a few cases in Uganda, right across the border and the students that went to Uganda aren't being sent back after the conference next week. They're either going to stay here or get sent back to Finland.

The student seemed sympathetic to the disappointment of being sent home but said little about the ramifications of her or her peers actually contracting such a disease. 
Other risks that the student experienced included a day when she arrived home to find her purse with an ominous tear from an attempted robbery:

I even got a slash on my bag where someone was hoping for something to fall out. That, thankfully, didn't happen!

In her final blog post before returning home, the student remembered her preparation training warned against theft:

We were told that people here were dangerous and armed.

Armed robberies are common, a daily occurrence and thieves roam about. Okay, that last one is partially true but the rest are exaggerations! Sure, some are dangerous and armed, but I've not come across any in the three months I've been here and I doubt they are as common as we were led to believe before we came here.

During her study abroad trip, the student was subjected to sexism, racism, and attempted theft. She received negative attention that made her feel uncomfortable and angry at times. Despite all of these experiences she seemed to feel that her sending institution's preparation regarding safety was too severe, and dismissed parts of it as an exaggeration:

We were walking around shitting our pants the first few weeks, no kidding. We couldn't walk in a group without a local to show us around, we kept our handbags in a tight grip at all times and almost ran everywhere to avoid being robbed. Ridiculous. The student was unhappy about the extent to which she was told to be careful and displayed a strong trust with the Kenyan people she met. Perhaps this displays an invincible attitude, also expressed in Chapter 3 wherein the respondent did not feel she needed help or support prior to studying abroad.

\section{Comparisons to home}

The student compared her experiences to her home in Finland regularly. One of her first realisations was the differing attitudes to time:

Time isn't very precise. If you set up a meeting they might arrive an hour late and barely apologise.

She demonstrated an understanding of why these situations arose: 
I just have to get used to it, because I like things organised and in their place. Here it's not so important. They have more pressing issues to worry about, like food and shelter.

At the hospital, nursing home, and orphanage, she compared healthcare differences as well. Some instances that stood out were physiotherapy practices where pain management was less available than in Finland, so patients were not typically medicated prior to therapy. The student reported hearing screaming and crying from the physical therapy room, as patients were reportedly forced into painful positions; this was deeply distressing for the student to witness. Another difference in healthcare was resuscitation, which was carried out one evening shift while the student was working: 'they tried for about FOUR minutes and gave up! I was shocked!' Finally, the student saw a difference in the culture of terminal care. The student reported frustration over the lack of medical care given to one patient at the end of life:

Things like this drive me crazy here sometimes! I didn't see her get any medicine, just fluids to keep her hydrated. No sense in that. That just prolongs her life! They couldn't get the oxygen working and nobody was in a hurry to fix the bottle (unlike in Finland where we get oxygen from the wall) they have separate bottles that are wheeled in whenever needed. They weigh a ton and don't ever seem to work.

These experiences no doubt displayed the difference in availability of resources for patients in Kenya compared to those in Finland. The student did not report learning new techniques or skills in Kenya but seemed to enjoy the experiences she had abroad. She stated in her last diary entry, I've loved Kenya and I've grown accustomed to the culture, but I'm also very happy to go back to the 'safety' of my own culture.

\section{Final words}

The student showed a great deal of enthusiasm in learning, 'we had our last practice week in the surgical ward and I tried my best to do as much as 
possible on the one day that I was there'. She also attended a local conference where teachers from Finland, Kenya and Uganda came to share presentations on subjects related to health education. The student reported crying several times at the thought of leaving, and had a memorable goodbye with her peers before returning home to Finland.

Her experience at the orphanage made a lasting impact:

Friday was the last day at the orphanage and we came bearing gifts. I was chosen to do the talking and I got about half way through thanking the owner of the place and then I burst out crying. It sounds ridiculous but I'm just so touched by their dedication to the cause, how well they take care of especially the handicapped kids and nurture them and love them and talk to them.

The emergent themes that make up the description of the case are displayed in Figure 7. 
Figure 7: Emergent Themes Informing Understanding of the Case

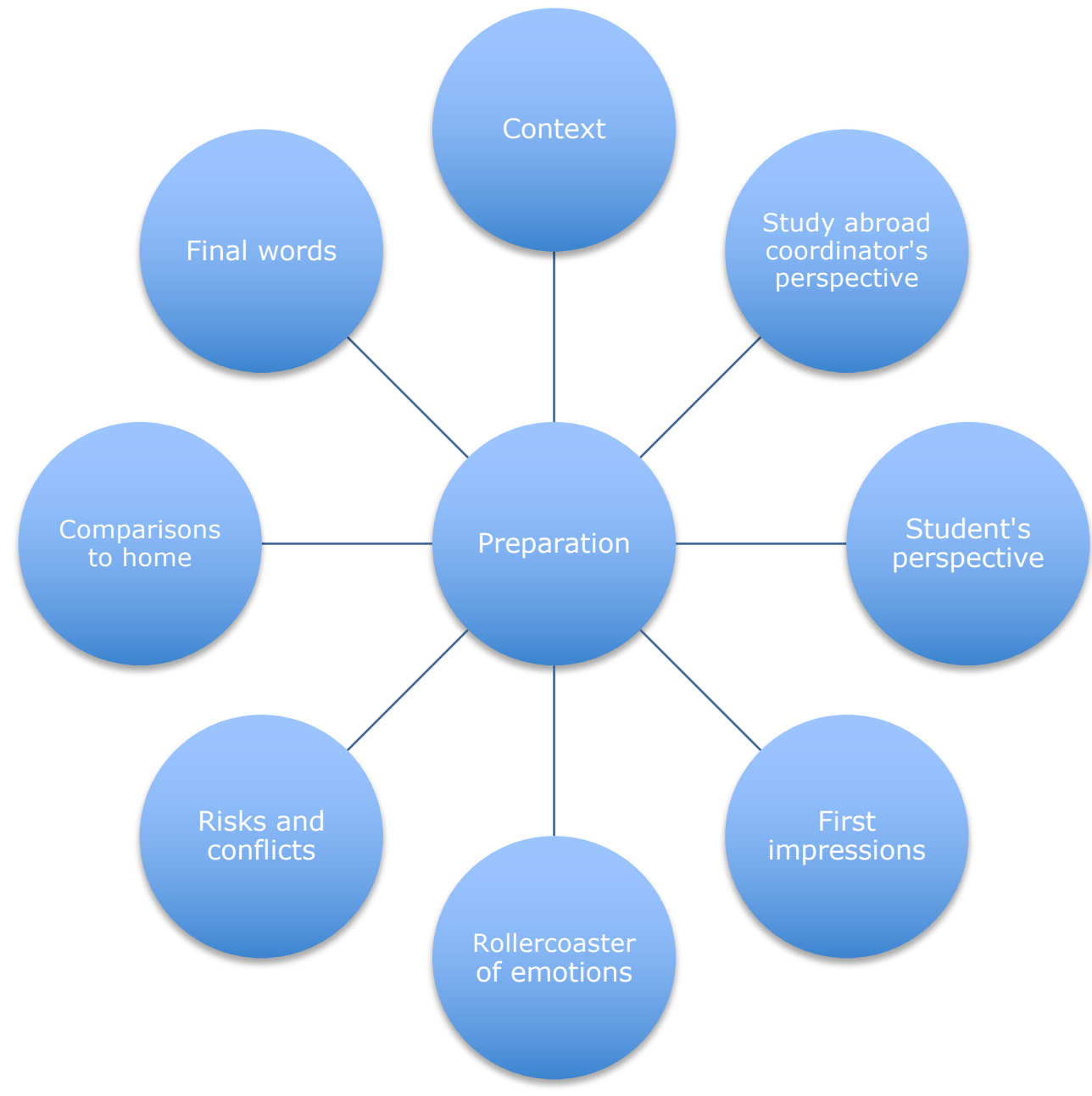

Finally, Figure 8 displays an overview of the collected data from this chapter, as well as which research questions were answered. 
Figure 8: Finnish Preparation Programme Overview

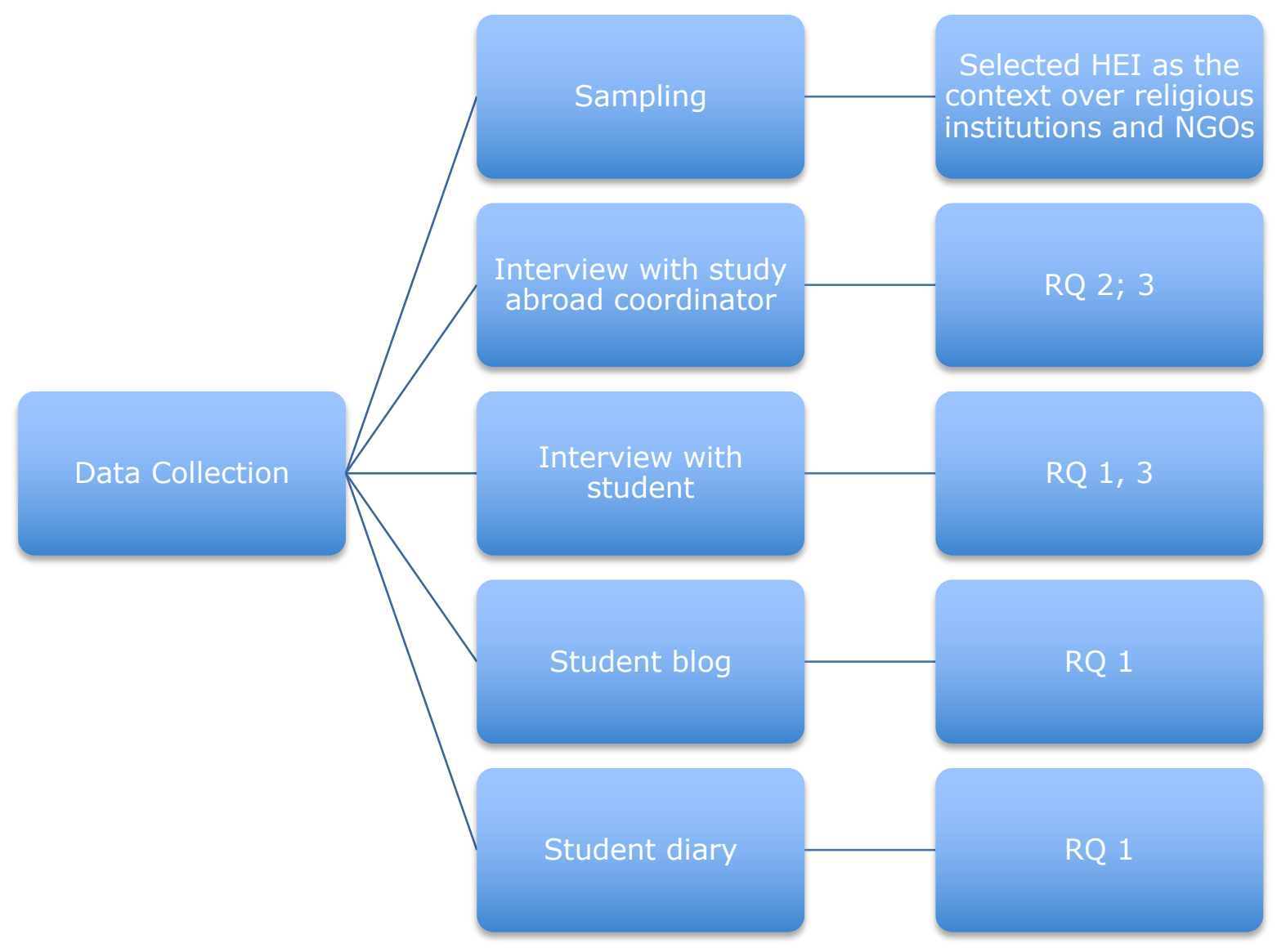

\section{Conclusion}

The scope of the pilot study included the development of prompts and the undertaking of an interview with a Finnish Study Abroad Coordinator. Student data was collected from a triangulation of sources, including a pretrip interview, diaries, and blogs. Methodological changes were made in preparation for the subsequent formal case study, proving the value of the pilot case. Changes included the decision to request additional data sources related to student preparation during the interview with the Study Abroad Coordinator. Further, two prompts were omitted. The student diary requirements were changed from an audio recording to a written document, making uploading easier during times of infrequent internet access. Reducing the amount of student data collection was considered but due to the serendipitous benefit of the student's level of preparedness, which was subtly revealed within the long narratives, no changes were made. The nursing student displayed autonomy and reflective skills while abroad, and 
reported she was given a great deal of information to prepare for her studies abroad. Although she could not think of many specific examples of what would occur during her study abroad trip when interviewed before her trip, she still felt the preparation she received was excessive. The student seemed to carry a sense of invincibility, given her ability to seek out educational experiences sometimes to the point of increased risk, for example when she helped stitch a patient following surgery, and felt her preparation was excessive even though she was a victim of sexism, discrimination, and attempted theft. Similarly, the student's behaviour could be seen as confidence and maturity, seeing beyond the immediate experience to the wider benefits in the context of her experiences. Colaizzi's thematic analysis revealed blog and diary data focused mostly on the student's first impressions, her 'rollercoaster' emotions, risks and conflicts, and comparisons to home. The pilot ultimately produced a case description of a preparation programme given to nursing students prior to studying abroad in Kenya. It therefore fulfilled its purpose helping formalise the method for the subsequent chapter. In Chapter 6 the formal case study of a nursing study abroad preparation programme in the Netherlands is reported. 


\section{CHAPTER SIX}

\section{CASE STUDY OF A PREPARATION PROGRAMME IN THE NETHERLANDS}

\section{Case Descriptions}

With the decision to follow a case study method (see Chapter 4; Method), a descriptive case study approach was chosen. Yin (2014) defines a descriptive case study as one that identifies a phenomenon with attention to its context. A descriptive case study informs the analytical strategy, in which the explicit purpose of the study is to achieve a rich and holistic description of a phenomenon, or case.

Readers of case descriptions are invited to play a particular role. Stake (1995), a case study methodologist, suggests readers develop their own 'naturalistic generalizations' based on their life experience. For example, a reader may have undertaken a nursing study abroad trip, and, when finished reading this chapter, make assumptions - or generalisations - that arise from a mixture of personal experience and the findings of this chapter (Melrose 2009). Stake also explains that this can occur just as easily from living vicariously through a story, told in such vivid detail that the reader feels it happened to him or her. The case description should present rich ingredients that allow sufficient detail for the reader to arrive at naturalistic generalisation.

Case study findings may generalise to similar populations, but only when the integrity of the narrative is intact and the narrative description uncompromised. For this reason, case study findings are typically written in a narrative format because of a wrongful tendency to reduce data to a compact story, or summarising a narrative that is rich in content, can lead to narrative fallacy (Riessman 1993). The dense case study is more useful than statistical findings or highly generalizable theories (Flyvbjerg 2011, Peattie 2001). 
A notable case description from the literature explains categories of income, housing, leisure, etc. to portray its case: a Midwestern city in the United States (Lynd, Lynd 1937). Relevant topics were arranged into a framework that described the city. Such categories may or may not have been identified prior to data collection and thus may only emerge during analysis when further data collection is unavailable. The second noteworthy contribution from the literature was a public health initiative that was decidedly best reported through a description of all the necessary actions that led to its implementation (Pressman, Wildavsky 1973). The public health initiative case description was unique in that a descriptive case approach was chosen late in the study's implementation (Yin 1982).

Following Lynd \& Lynd, the case in this chapter is reported through eight categories that make up a descriptive framework of the preparation that nursing students receive before studying abroad. The content of preparation curriculum and the multiple perspectives of study abroad coordinators and nursing students contributed to an understanding of the case. Major categories such as the sending institution, student retention of preparation, first impressions, studying abroad, struggles and conflicts, support systems, risk-taking, and transition home inform the descriptive case study.

\section{Case Study Procedure}

This chapter uses Yin's (2014) approach for reporting cases as discussed in Chapter 4. The following is a discussion of the selection of the case sample, recruitment of participants, data collection procedures, and a report of the findings. The researcher gained ethical approval from the Higher Education Institution (HEI) in The Netherlands (see Appendix $\mathrm{H}$ ) to perform the study. All other forms including consent forms for interviews (Appendix I-J) and information sheets (Appendix $L$ ) were the same as used for the pilot case.

\section{Selection of the case}

The HEI in The Netherlands was identified from a sample of partnerships to the researcher's university through the European Union's Erasmus Programme using information-oriented selections (Flyvbjerg 2011) (see Chapter 5; Selection of the Pilot for a description of information-oriented 
selections). The decision to study within the context of HEIs is discussed previously (see Chapter 5; Selection of the Pilot). After selecting the HEI in The Netherlands as the context of the case, the researcher began recruiting study abroad coordinators, nursing students, and study abroad coordinators at the receiving institution in South Africa.

\section{Recruitment of study abroad coordinators at the sending institution}

Study abroad coordinators responsible for the nursing study abroad trip to South Africa were contacted via email and asked if they would join the study. The coordinators agreed to take part and invited the researcher to travel to The Netherlands to conduct face-to-face interviews, see the HEI, and meet the cohort of nursing students planning to study abroad that year.

\section{Recruitment of nursing students}

While in The Netherlands, the researcher spoke about her study with students who planned to undertake their study abroad trips that year scheduled for the last 12 weeks of 2014. After meeting the students, the researcher confirmed she would invite them to join the study nearer the time when students were to commence their trip. An invitation was sent via email and included an information sheet and consent form (Appendix $L, J$ ) should they decide to participate. A non-random, purposive and homogenous sample (Holloway, Wheeler 1996, Patton 2002, Robson 2002) of nursing students were recruited. Due to low numbers, all students registered to study abroad were invited to take part in this study. All participants were female, aged 20 - 29, and of Dutch nationality. Participants were informed of their right to withdraw from the study at any point with no pressure to give their reasons. The sample provided an opportunity to gain the desired insight into the phenomenon of student experiences, based on their potential contributions to the theory development of this study (Ritchie, Lewis 2003). Previously, Figure 5 displays the case study design including the context of the HEI, the case, and the embedded units of analysis. As stated previously (see Chapter 5), the researcher is hesitant to refer to participants as embedded units and thus will refer to study abroad coordinators and students as such. 


\section{Recruitment of study abroad coordinators at the receiving institution}

Receiving study abroad coordinators in South Africa were contacted and asked if they would participate in this study. Their involvement was to facilitate triangulation of intended data sources desired for this study (see Figure 9, also see Chapter 4; Propositions). Unfortunately, the receiving institution study abroad coordinators did not respond to interview requests until this part of the study was complete. However, they were willing to offer their opinion later in the research and they took part in the Delphi study (see Chapter 7).

Figure 9: Intended Data Source Triangulation

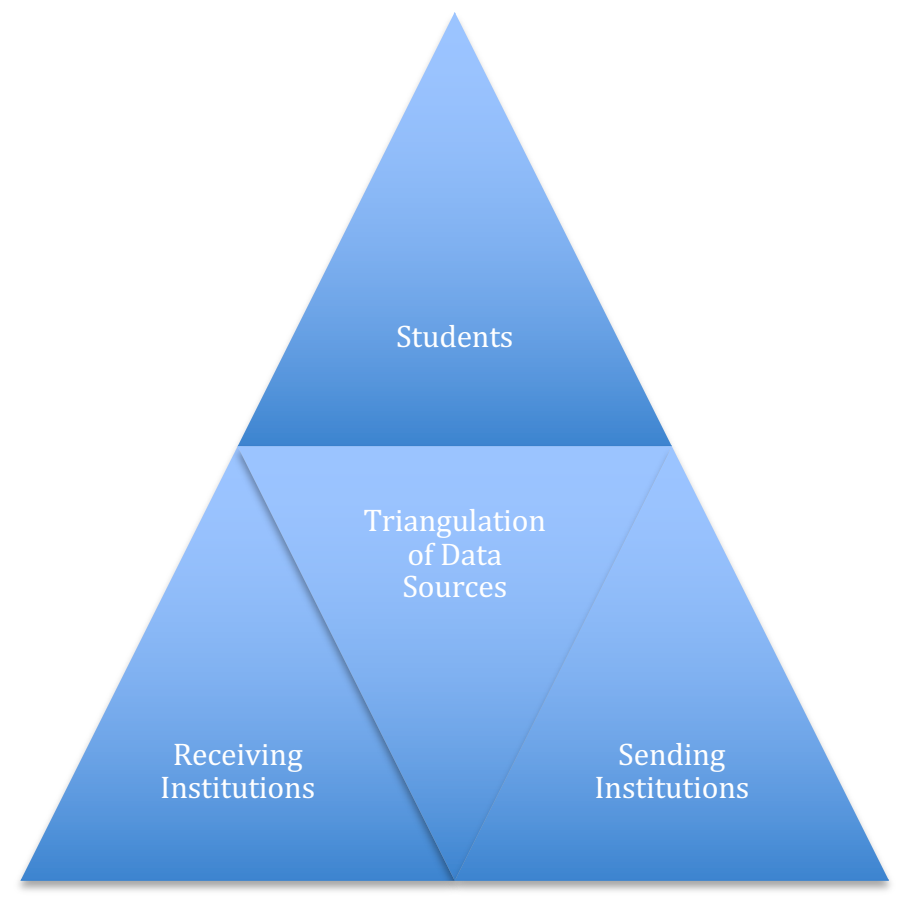

\section{Data Collection}

Data collection began by conducting an interview with two study abroad coordinators. This was followed by a triangulating data collection from four students, including interviews, diaries, and blogs (see Figure 10, below). 


\section{Interview with study abroad coordinators}

The researcher travelled to The Netherlands in April 2014 to conduct interviews with two study abroad coordinators who supported nursing students during preparation and during their study abroad trips. After the coordinators signed a consent form, an interview was carried out with the validated prompts used previously with the Finnish institution (see Chapter 5: development of prompts for study abroad coordinator interview). It was identified through the pilot study that further documentation was needed to provide a full insight into their study abroad programme (see Chapter 5; pilot interview with study abroad coordinator), the study abroad coordinators provided the researcher with information regarding the study abroad trip (i.e. handouts given to students, PowerPoint slides, content of preparation curriculum) per the researcher's request. Data were recorded in each interview using a digital audio recorder and transcribed verbatim by the researcher using Microsoft Excel as it was the researcher's preference.

\section{Student pre-trip interviews}

Data collection with the four nursing student participants began by scheduling pre-trip interviews via Skype. Interviews were not conducted face-to-face while the researcher was in the Netherlands because the students had not yet been recruited to join the study. The researcher conducted a pilot interview with the first Dutch student (Student L) using updated prompts from the reflexive interview and pilot case study (see Chapter 3; Method, see Chapter 5; Student Pre-trip Interview). This third pilot was completed before the other three student interviews with sufficient time to transcribe and analyse the data, allowing the researcher to test whether the prompts would elicit a rich account of the students' preparation process leading to the study abroad trip. Further, the pilot ensured the underlying meaning of the prompts were 'culturally equivalent' given the new country of context (Peña 2007) and confirmed the Dutch students' level of fluency in English.

At the end of the first students' pilot interview the researcher concluded there was a need to probe deeper to gain richer data because unlike the 
pilot study with the Finnish student (see Chapter 5) the same enthusiasm to share her experience was lacking.

The data collected from nursing students represented a second source of data triangulation (see Figure 10). Students were one source of a triangulation of data sources, but also provided three types of data that were triangulated to increase trustworthiness and reliability, and to compensate for the limitations of each data source (see Chapter 4; epistemological assumption; design).

Figure 10: Visual Representation of Student Data Triangulation

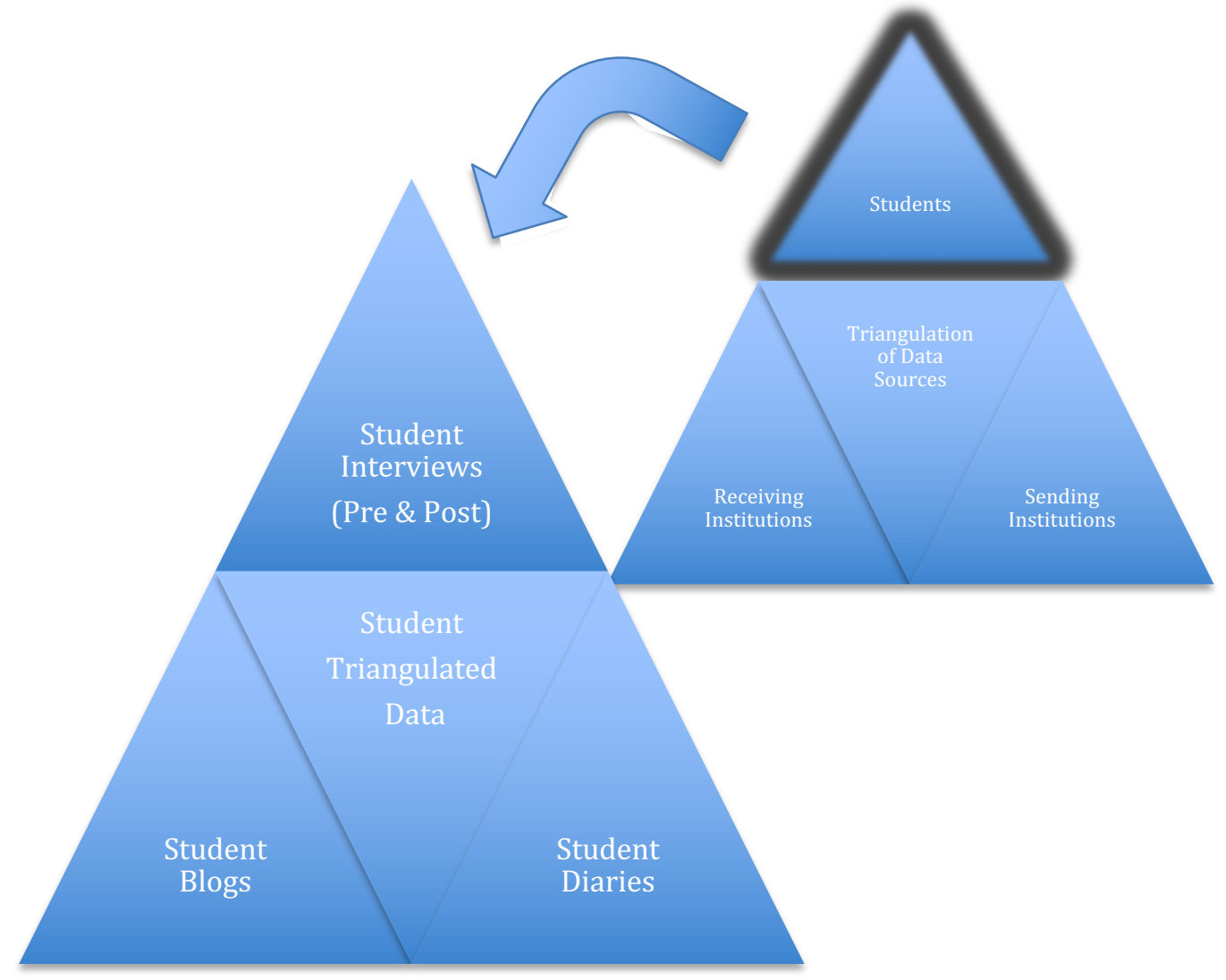

\section{Student diaries and blogs}

Student diaries and blogs were collected throughout the 12-week study abroad trip (Alaszewski 2006, Redlich 1975, MacFarland 1970, Huff 1985), and were completed in December 2014. The diaries and blog data collection procedures, justification, and instruction sheet are available in Chapter 5 
(see Student Diary; Student Blog; Appendix M). The researcher expected superficial writing from the students due to the potential for culture shock or feeling overwhelmed in the new culture as seen in the literature (Aarts, Nordstrom et al. 2010). However, as seen in Chapter 5, the use of blog and diary data proved to be a serendipitous form of data collection, in that they provided more depth than the researcher expected.

\section{Concerning translation}

Unlike the Finnish student from the pilot case study who wrote all data in English, the Dutch students wrote their blogs in Dutch. This was in part because the blogs were intended for family and friends to keep track of their journey, preferring to read the blogs in their native language (see Report of the Findings; The Sending Institution below). The Dutch students were otherwise required to speak and write in English throughout their preparation and study abroad trip.

Intending to utilise this rich source of data, the researcher considered how to translate the student blogs from Dutch to English. She began by professionally translating a blog entry which proved to be time consuming and costly. The researcher then compared the professionally translated blog with Google's free translation service, Google Translate. What was apparent from this exercise was that the translations did not differ substantively in content (see Appendix R) except for a rare grammatical or punctuation error.

While Google Translate is new in its use to academia, justification is present in the literature (Groves, Mundt 2015). Google's translation services are improving due to the increasing number of documents uploaded, that continuously make translations more accurate (Le, Schuster 2016). Google Translate was used to convert the remainder of the students' blogs into English, and this use can be justified: firstly, the blogs from the Dutch students were not written using any technical language or details; the sociolinguistic aspects of which might require professional services (Mundt, Groves 2016). Rather, they were written conversationally - as an informal communication tool. Secondly, the blogs were part of a larger picture of 
data including interviews and diaries that made up a detailed description of student preparation. The triangulated nature of the blog data meant that themes and stories could still be easily extracted regardless of a subtle imperfection in translation.

\section{Student post-trip interviews}

Post-trip interviews with the students consisted of questions that encouraged them to speak retrospectively about their preparedness prior to and during their study abroad trip and also reflect on their preparation and its impact on their trip. Questions were used to encourage descriptive narratives from the students, and the researcher planned for 60-90 minutes (Onwuegbuzie, Leech 2007) during the narrative response (Riessman 1993). The researcher reminded the students of one response from pre-trip interviews, when they were asked what they hoped to achieve. The researcher then asked whether the students felt they had achieved their goals during their study abroad trips. A timeline of all student data collection is available below in Table 6 .

Table 6: Timeline of Data Collection

\begin{tabular}{|c|c|c|c|c|c|c|}
\hline Activities & $\begin{array}{l}\text { Apr } \\
2014\end{array}$ & $\begin{array}{l}\text { Jun } \\
2014\end{array}$ & $\begin{array}{l}\text { Aug } \\
2014\end{array}$ & $\begin{array}{l}\text { Sep } \\
2014\end{array}$ & $\begin{array}{l}\text { Dec } \\
2014\end{array}$ & $\begin{array}{l}\text { Jan } \\
2015\end{array}$ \\
\hline \begin{tabular}{|l|} 
Pilot interview prompts with \\
Finnish Study Abroad Coordinator
\end{tabular} & $1 / 4$ & & & & & \\
\hline $\begin{array}{l}\text { Travel to academic institution in } \\
\text { The NL to conduct interviews with } \\
\text { Dutch Study Abroad Coordinators }\end{array}$ & $\begin{array}{l}17 / 4- \\
21 / 4\end{array}$ & & & & & \\
\hline $\begin{array}{l}\text { Recruit Dutch nursing student } \\
\text { participants }\end{array}$ & $21 / 4$ & & & & & \\
\hline Undergo reflexive interview & & $2 / 6$ & & & & \\
\hline $\begin{array}{l}\text { Conduct pre-trip interviews with } \\
\text { Dutch students }\end{array}$ & & & $\begin{array}{l}15 / 8- \\
17 / 8\end{array}$ & & & \\
\hline $\begin{array}{l}\text { Conduct pre-trip interviews with } \\
\text { student in Finland }\end{array}$ & & & $30 / 8$ & & & \\
\hline $\begin{array}{l}\text { Gather data from blogs and } \\
\text { diaries }\end{array}$ & & & & $10 / 9-$ & $23 / 12$ & \\
\hline $\begin{array}{l}\text { Conduct post-trip interviews with } \\
\text { Dutch students }\end{array}$ & & & & & & $\begin{array}{l}18- \\
25 / 1\end{array}$ \\
\hline
\end{tabular}




\section{Analysis}

A thematic analysis using Colaizzi's (1978) method was undertaken, described in Chapter 5 (see Analysis). Themes emerged which collectively made up the description of preparation (see below; Report of the Findings). Analysis relied on data triangulation and data source triangulation (see Chapter 4; Epistemological assumption; Design).

Analysis of student data showed a wide array of themes at the onset of the trip, followed by a more unified experience once the students spent more time together in South Africa. A short description of each data analysis method that ultimately made up the case description is given below. All emergent themes according to data type are available in Table 11.

\section{Student pre-trip interview analysis}

The pre-trip interviews had the highest amount of emergent themes when compared with the other sources of data (see Figure 11, 13-15). This could be attributed to the differences in personality, background, and expectations of the four students interviewed. Table 7 displays the differences in student feedback regarding how they decided to study abroad. 
Figure 11: Emergent Themes from Nursing Students' Pre-Trip Interviews

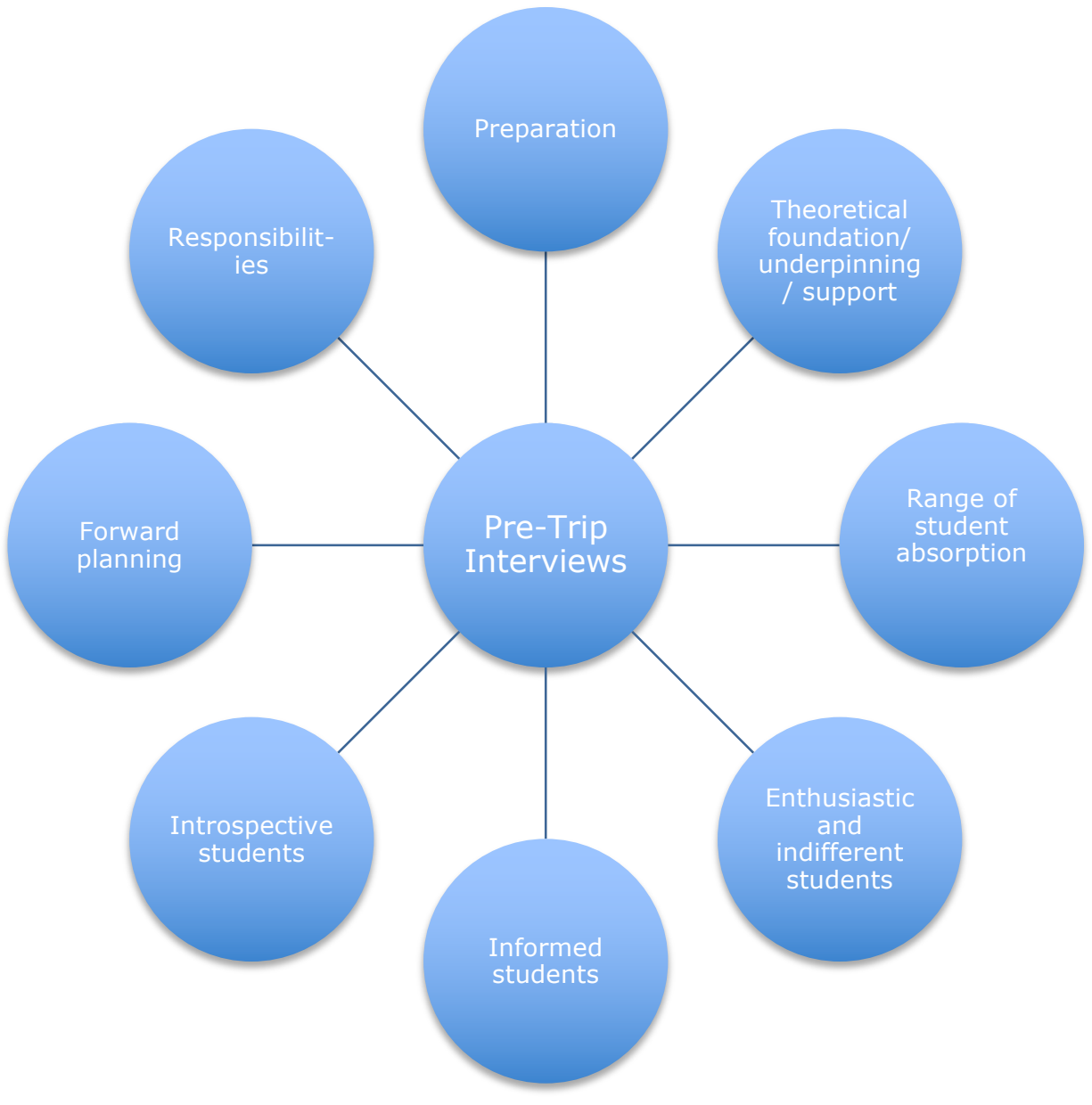

Table 7: Nursing Student Pre-Trip Interview - How did you decide to study abroad?

\begin{tabular}{|l|l|}
\hline Student A & Well the teacher talked about it \\
\hline Student L & $\begin{array}{l}\text { Well in the first year we had like a college with } \\
\text { the possibility to go abroad with the possibility } \\
\text { to go to Zambia, India, or South Africa and I } \\
\text { don't know why but South Africa was my choice, } \\
\text { right away, so, yeah. Then the second year... I } \\
\text { was getting more and more excited so, yeah } \\
\text { that's why. }\end{array}$ \\
\hline Student M & $\begin{array}{l}\text { Uhh it came through the college at school. I } \\
\text { think first year or something? And [study } \\
\text { abroad coordinator] was the guy who talked a } \\
\text { lot about South Africa. It became my interest } \\
\text { bigger and bigger. I just always wanted to do } \\
\text { that. }\end{array}$ \\
\hline
\end{tabular}




\begin{tabular}{|l|l|}
\hline Student R & $\begin{array}{l}\text { I think it was when I was in high school, I } \\
\text { thought well I will do something um like a study } \\
\text { abroad, and when I was in nursing school, I } \\
\text { hear about an opportunity in what we have. And } \\
\text { in South Africa, I think the country and people } \\
\text { and the nature and everything together it's } \\
\text { something for me. }\end{array}$ \\
\hline
\end{tabular}

Before the students travelled to South Africa, differing levels of retention were exhibited from their preparation training (see Tables 7, 11, 12). The pre-trip interviews showed widely varying levels of confidence, maturity, and enthusiasm (see Table 11).

The pre-trip interviews also included a theoretical question underpinned by Bennett's Developmental Model of Intercultural Sensitivity, discussed in Chapter 3 (see Method). Students were asked to predict which number they would identify with from Bennett's Model (see Figure 12, Table 8) upon arrival in South Africa. 
Figure 12: Bennett's Model with Student Predictions

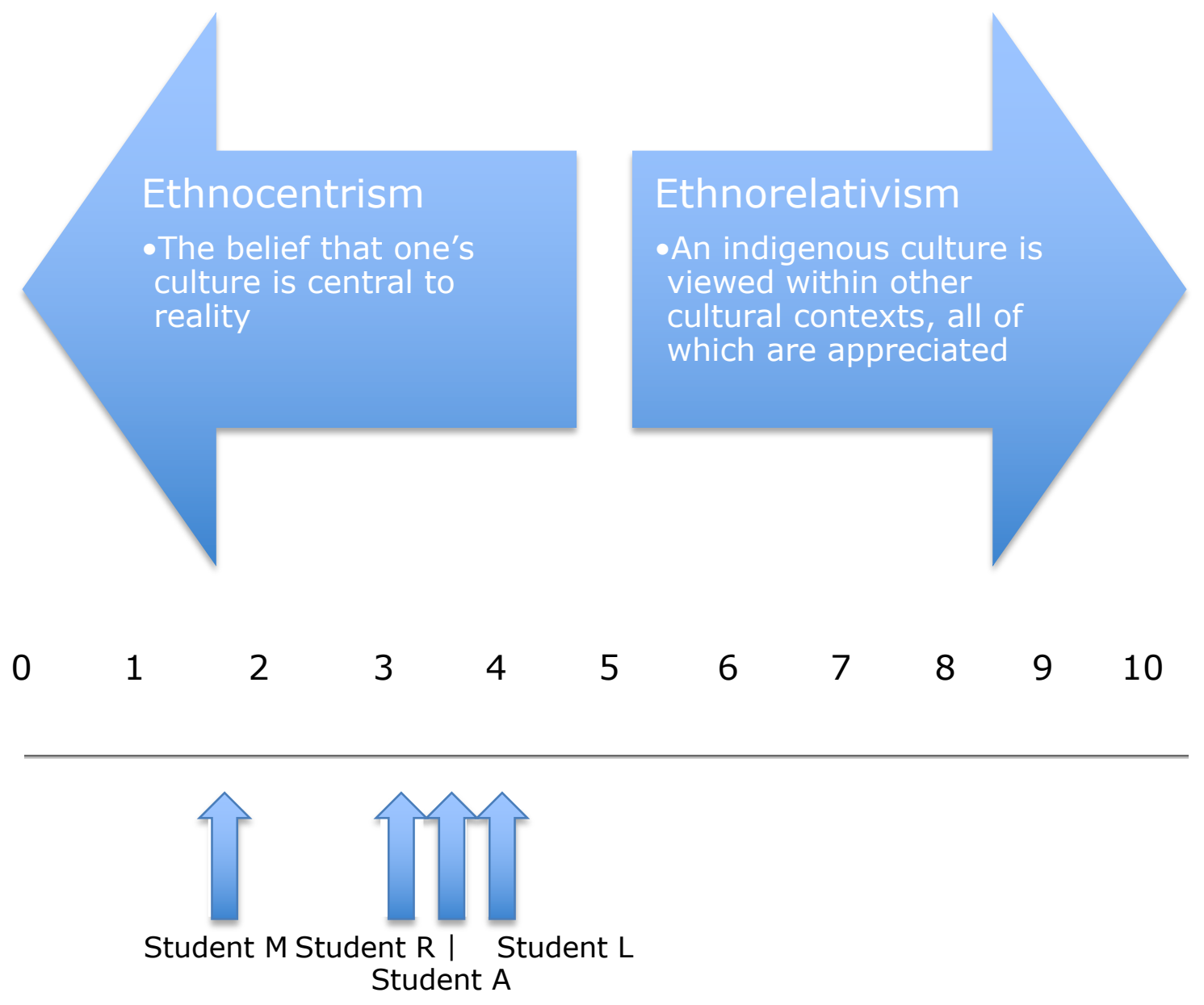

Table 8: Student Cultural Predictions from Modest to Confident

\begin{tabular}{|c|c|c|}
\hline $\begin{array}{l}\text { Student Ranking } \\
\text { (Modest to } \\
\text { Confident) }\end{array}$ & $\begin{array}{l}\text { Researcher's Feeling } \\
\text { After Student } \\
\text { Interview }\end{array}$ & $\begin{array}{c}\text { Direct quotes regarding Bennett's } \\
\text { number }\end{array}$ \\
\hline $\begin{array}{l}\text { Student } M \\
(2 \text { or } 1)\end{array}$ & $\begin{array}{l}\text { Somewhat dismissive } \\
\text { of preparation } \\
\text { Knowledgeable about } \\
\text { certain trip details } \\
\text { Enthusiastic }\end{array}$ & [laughs] I think like a 2 or a 1 ! \\
\hline $\begin{array}{l}\text { Student R } \\
\text { (3) }\end{array}$ & $\begin{array}{l}\text { Strong description of } \\
\text { preparation }\end{array}$ & $\begin{array}{l}\text { I think a } 3 \text { or something because } \\
\text { I need to learn the country and } \\
\text { then I can grow. So, the number } \\
\text { will grow I think. }\end{array}$ \\
\hline
\end{tabular}




\begin{tabular}{|l|l|l|}
\hline $\begin{array}{l}\text { Student A } \\
\text { (3 or 4) }\end{array}$ & $\begin{array}{l}\text { Displayed indifference; } \\
\text { low motivation } \\
\text { Displayed low } \\
\text { expectations }\end{array}$ & $\begin{array}{l}\text { Okay, I think 3? 4? Um, because } \\
\text { I don't know a lot about South } \\
\text { Africa? And the people? So, yeah, } \\
\text { (2) I'm a little bit afraid }\end{array}$ \\
\hline $\begin{array}{l}\text { Student L } \\
\text { (4) } \\
\text { about what to expect } \\
\text { during trip }\end{array}$ & $\begin{array}{l}\text { Hmm (1.5) when I arrive? I think } \\
\text { I'll feel a little bit separate, not } \\
\text { right away comfortable, but like } \\
\text { in the emails we sent, it seemed } \\
\text { really nice, very uh, excited in } \\
\text { the emails that we're coming, so } \\
\text { that gives a good impression. So, } \\
\text { not a 0, maybe a 4 or something. } \\
\text { [laughs] I don't know. It's } \\
\text { difficult I think. I think they're } \\
\text { excited for us to come, but we } \\
\text { also have to } \\
\text { prove our knowledge, yeah that } \\
\text { we can do something and build } \\
\text { the relationship or something } \\
\text { first. }\end{array}$ \\
\hline
\end{tabular}

The researcher did not find any personality predictors during data collection that coordinated with the information students reported about Bennett's model. The most enthusiastic student (Student $M$ ) predicted she would be a 1 or 2 (see Table 8 ), showing a relationship of anticipation with a predicted cultural 'outsider' role. The researcher would posit this modest prediction shows maturity and readiness for a study abroad trip. However, the opposite rang true with Student $L$, predicting the highest number on Bennett's Model while exhibiting realistic expectations and an informed stance leading up to her trip. The students' answers were recorded and revisited in the post-trip interviews.

\section{Nursing students' diary analysis}

After deciding on diaries as a source of data collection (see Chapter 5; Student Diary for justification), a concern arose that data collected from student diaries would not be sufficiently different from student blogs. Upon analysis, the diary data proved to be rich in content, overlapping in many of the general activities throughout the trip, but with new details. The diaries provided pictures into the emotions of the students in a way that was not communicated in interviews or publicly accessible blogs. Fewer themes 
arose during analysis in Table 12 than Table 10, suggesting a more streamlined experience as the students spent more time as a group.

Figure 13: Emergent Themes from Nursing Students' Diaries

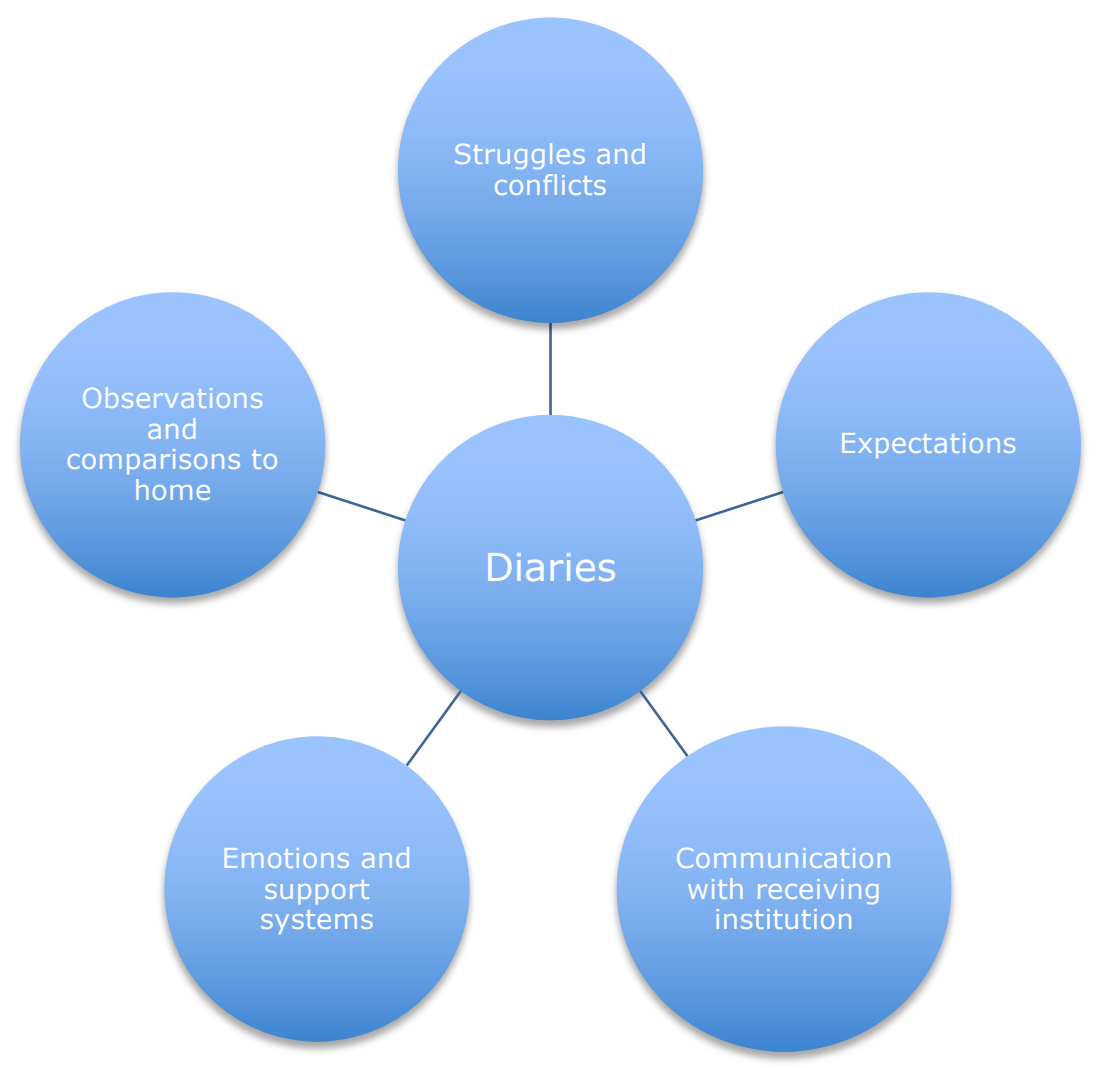

The students compared their experiences in South Africa with their lives back home. The diaries contained moments of honesty, and primarily contributed to the section 'First Impressions' below. Each of the students admitted their struggles with the slow pace of work at their study abroad site, feeling the staff had breaks too frequently and took advantage of the students' presence by delegating tasks to them. The diaries also contributed to the 'Expectations' and 'Struggles and Conflicts' sections in the case description below, again as the source where students wrote their deepest reflections.

\section{Nursing students' blog analysis}

The students reserved their blogs to highlight their adventures, and provided a snapshot of the adventurous, youthful, perhaps culturally voyeuristic (Racine, Perron 2012) mind-set of the students. Occasionally, 
students would inform their family and friends about their study abroad trip duties as well. The blogs were written for a public audience, and provided the least amount of insight into the cultural struggles and study abroad trip details compared to the other sources of data.

Whilst in South Africa, the students often sought educational experiences unrelated to their nursing duties. Weekends were filled with travels (up to 10 hour drives) to surrounding townships, museums, wildlife parks, and cultural events. Heritage Day occurred during the students' stay which was a national holiday where South Africans celebrate their culture. The students attended events and observed dancing, singing, traditional clothing, all representing several cultures within South Africa. They wrote in their blogs about trying new foods, including cow's head. Student A reported, 'what exactly have we eaten ... I still do not know'. Local parks allowed the students to interact with young lions. A trip to Mozambique required a great deal of planning, a long journey, and allowed the students a much-anticipated extra stamp in their passports.

South Africa, having relatively recently come out of apartheid in 1994, offered many eye-opening experiences for the students. Race relations were tense in various contexts, and each student mentioned this. The students noticed vast differences in patient care between the rich and poor, and the black and white at private and public hospitals. Apartheid was a unique subject found in student blogs, a stark contrast to the otherwise exciting travel and experiences of the study abroad trip. A possibility of such an inclusion in a public space could be the opportunity to include a voyeuristic, exotic addition to the blog content (see Chapter 5, Student Blog). The blogs portrayed a picture of learning and adventure, providing the most detail regarding risk-taking behaviours and new experiences of all the three types of data collected (see Table 20).

Among the blogs from all the Dutch students, only two entries contained a negative comment (one complaining that another student's accommodations was superior; the other admitted that the trip had contained ups and downs, but did not offer detail). 
Figure 14: Emergent Themes from Nursing Students' Blogs

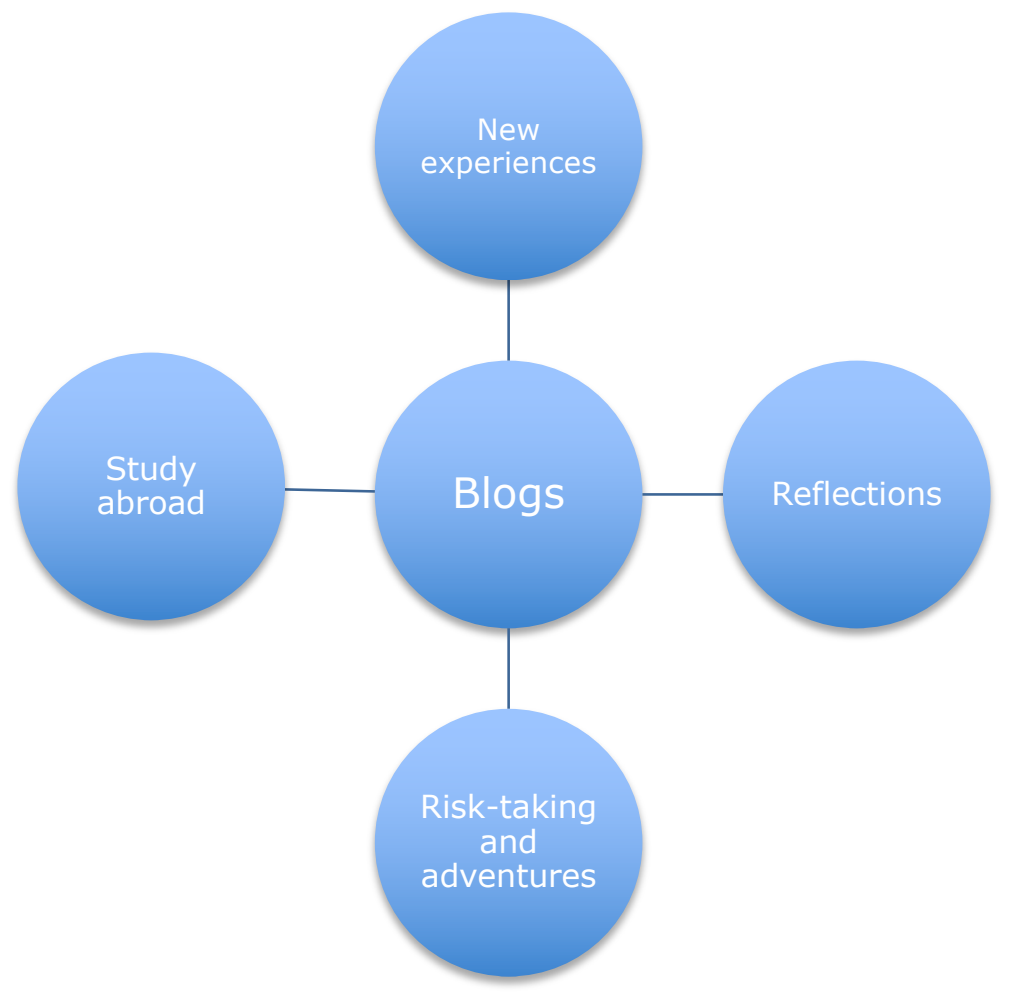

\section{Student post-trip interview analysis}

Unbeknownst to the researcher, the students undertook a month-long holiday in South Africa upon completion of their study abroad requirements. Little is known about this month - the students did not discuss it in their blogs, diaries, or interviews - except to say that it happened. Their holiday delayed post-trip interviews, which were scheduled following the study abroad trip. The themes that emerged during post-trip interviews are detailed below in Figure 15. 
Figure 15: Emergent Themes from Nursing Students' Post-trip Interviews

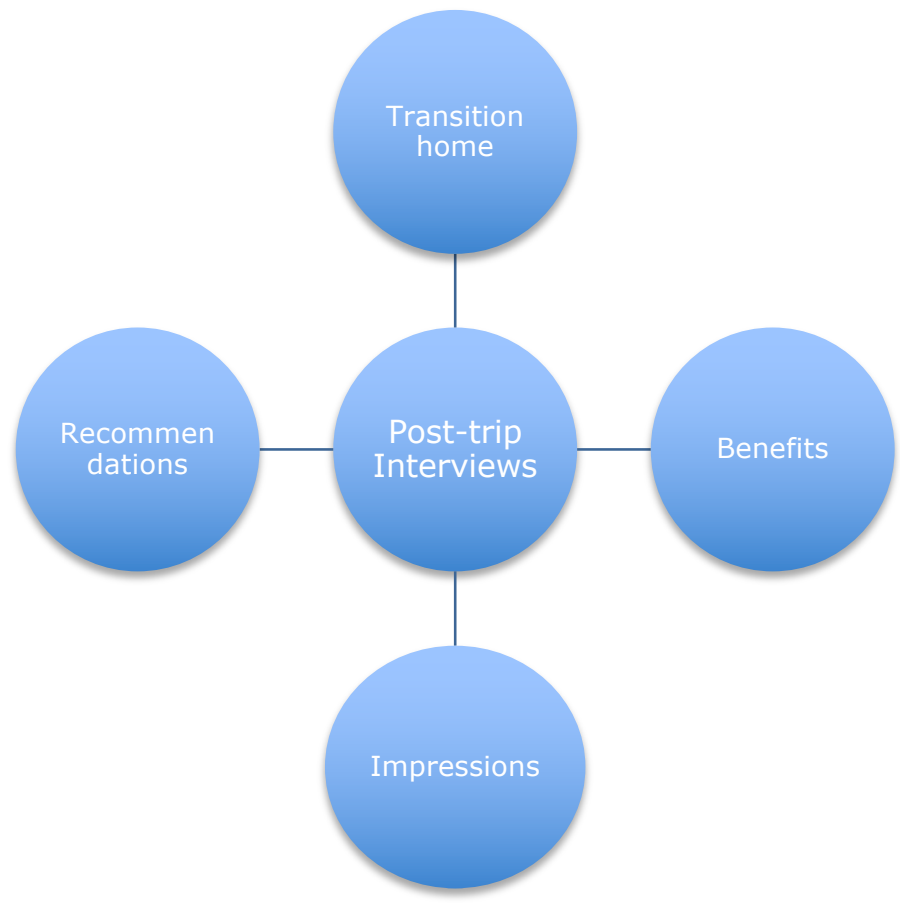

As supported in the literature (see Chapter 2), the study abroad trip boasted a long list of benefits to the students. The post-trip interviews revealed changes experienced by the Dutch students, including a new way of seeing people around them. Student M reflected:

Sometimes you're prejudiced, not like arrogant, but you put people in a little bit of a box, and I realise that everybody acts how they've been taught by their parents. I have more respect for people now.

This change in perception was echoed by Student $A$ who said she acquired the ability to:

Just have more respect. And I think also now that I can be very thankful for what I have, even the small things...the healthcare and the government. But now when somebody reacts strange, I think ok, maybe it comes from the culture. Maybe it comes from the parents that they react that way. I have a different view now.

Yet Student R felt similarly:

Yeah I think I accept people more like in the hospital, and give them more respect. The people are so friendly in SA, and now 
I think people in the Netherlands are not so friendly when you walk in the street. I'll always take that with me.

Students were reminded of the Bennett score they predicted prior to studying abroad, and were asked if they felt it was accurate after returning home. The pre- and post-trip interview responses are displayed for comparison (see Table 9).

Table 9: Nursing Student Predicted Number on Bennett's Developmental Model of Intercultural Sensitivity Before and After Studying Abroad

\begin{tabular}{|c|c|}
\hline \multirow[t]{2}{*}{ Student A } & $\begin{array}{l}\text { Pre-trip } \\
\text { Okay, I think 3? 4? Um, because I don't know a lot } \\
\text { about South Africa? And the people? So, yeah, (2) } \\
\text { I'm a little bit afraid }\end{array}$ \\
\hline & $\begin{array}{l}\text { Post-trip } \\
\text { Yeah! I think on my internship, a } 4 \text {. And in all of SA, } \\
\text { like a 5, 6. Yeah, I felt really safe, there were other } \\
\text { students and black people when you go to a shop } \\
\text { people can talk English, so you don't really feel } \\
\text { you're in SA, you feel safe } \\
\text { Researcher: Do you feel your preparation } \\
\text { contributed to that? Feeling safe? } \\
\text { Student A: Yeah, from the preparation. } \\
\text { Researcher: And while you were there for } 3 \text { months, } \\
\text { did your number change? } \\
\text { Student A: Yeah I learned a lot, I felt more safe, you } \\
\text { know where the good places are, you know what to } \\
\text { do, how to react with people, so a } 7 \text { ? } \\
\text { Researcher: Oh wow that's very high! } \\
\text { Student A: Yeah, it really feels like home there }\end{array}$ \\
\hline Student L & $\begin{array}{l}\text { Pre-trip } \\
\text { Hmm (1.5) when I arrive? I think I'll feel a little bit } \\
\text { separate, not right away comfortable, but like in the } \\
\text { emails we sent, it seemed really nice, very uh, excited } \\
\text { in the emails that we're coming, so that gives a good } \\
\text { impression. So, not a 0, maybe a } 4 \text { or something. } \\
\text { [laughs] I don't know. It's difficult I think. I think } \\
\text { they're excited for us to come, but we also have to } \\
\text { prove our knowledge, yeah that we can do something } \\
\text { and build the relationship or something first. }\end{array}$ \\
\hline
\end{tabular}




\begin{tabular}{|c|c|}
\hline & $\begin{array}{l}\text { Post-trip } \\
\text { I think a little bit lower, yeah when we were } \\
\text { welcomed and stuff, I wasn't all the way } \\
\text { comfortable, but I wasn't alone, so maybe very new, } \\
\text { took a while to get to know people, yeah, we had } \\
\text { some struggling in the beginning, maybe a } 3 \text { talking } \\
\text { to them. } \\
\text { Researcher: And when you were about to leave, } \\
\text { were you still at a } 3 \text { ? } \\
\text { Student L: Yeah I felt like we were more part of a } \\
\text { team, I think if we had stayed longer, I think after } \\
\text { we did our projects, because the German girl who } \\
\text { was there for a year, she did her own projects so we } \\
\text { were kind of in the background for her? }\end{array}$ \\
\hline \multirow[t]{2}{*}{ Student M } & $\begin{array}{c}\text { Pre-trip } \\
\text { [laughs] I think like a } 2 \text { or a } 1 \text { ! }\end{array}$ \\
\hline & $\begin{array}{l}\text { Post-trip } \\
\text { Um, I think still, like maybe a } 2 \text {. Like you don't } \\
\text { know the culture in one week. You see things, but } \\
\text { you don't know what's inside people. }\end{array}$ \\
\hline \multirow[t]{3}{*}{ Student R } & $\begin{array}{l}\text { Pre-trip } \\
\text { I think a } 3 \text { or something because I need to learn the } \\
\text { country and then I can grow. So, the number will } \\
\text { grow I think. }\end{array}$ \\
\hline & $\begin{array}{l}\text { Post-trip } \\
\text { Probably a } 7 \text { or } 8 \text { or something. And I couldn't be a } \\
10 \text { because we were not there long enough, and } \\
\text { there are always more things to learn. } \\
\text { Researcher: Oh so you felt like a } 7 \text { or } 8 \text { right when } \\
\text { you were leaving? } \\
\text { Student R: Yeah. }\end{array}$ \\
\hline & $\begin{array}{l}\text { Researcher: Ok, and what were you when you got } \\
\text { there? } \\
\text { Student R: No I think } 3 \text { was ok, but it was only that } \\
\text { moment, but after that, it was like okay. Take some } \\
\text { steps back, and it was a good lesson, right then. }\end{array}$ \\
\hline
\end{tabular}

The final questions of the post-trip interview inquired what recommendations or changes the students felt should be passed on to 
improve the experience for future students. The questions were separated into recommendations for the sending HEI, the receiving organisation, and future nursing students (see Table 10).

Table 10: Nursing Student Post-Trip Interview - What Recommendations do you have for...

\begin{tabular}{|c|c|}
\hline \multirow[t]{3}{*}{ Student A } & $\begin{array}{l}\text { Sending HEI: } \\
\text { Yeah, I was really good prepared. We also met some } \\
\text { other students from the Netherlands who were not } \\
\text { prepared? And you see really difference. Like the } \\
\text { school told us what is safe, what is not safe, also not } \\
\text { walking alone when it's dark, and taking a cab }\end{array}$ \\
\hline & $\begin{array}{l}\text { Receiving Organisation: } \\
\text { Um, when you go there, they give you the topics for } \\
\text { your presentation, but it's difficult, so they could give } \\
\text { the topic before }\end{array}$ \\
\hline & $\begin{array}{l}\text { Future nursing students: } \\
\text { Um no, just relax, and see what comes to you }\end{array}$ \\
\hline \multirow[t]{2}{*}{ Student L } & $\begin{array}{l}\text { Sending HEI: } \\
\text { Um, for preparation, no I think Crossing Borders (see } \\
\text { below, The Sending Institution) is fine, and maybe } \\
\text { just talk more to the previous students, me and } \\
\text { another girl are doing a presentation in March I think } \\
\text { for the next students, the second years, all of them, } \\
\text { and also for Crossing Borders, so they can ask you } \\
\text { what they want to know, and like, yeah, like about } \\
\text { visas, they say you don't have to worry about that } \\
\text { now, and our class was like but we want to know } \\
\text { about that now, so I think we can tell the other } \\
\text { students about it }\end{array}$ \\
\hline & $\begin{array}{l}\text { Receiving Organisation: } \\
\text { Um, the only thing I would recommend them is not } \\
\text { to take } 3 \text { nursing students, maybe } 1 \text { and } 1 \text { social } \\
\text { worker or something, but not all the nursing } \\
\text { students. Cuz we thought it was easier and we had to } \\
\text { go there alone, and then yeah the presentations, we } \\
\text { all wanted to do that but one person is enough cuz } \\
\text { they already have staff members who organise the } \\
\text { presentations, and just so that the nursing students } \\
\text { know exactly what they're going to do, so that before } \\
\text { they come they can prepare more, like if I knew I } \\
\text { was doing a project on first aid, I could have done } \\
\text { more, cuz at home I have more books and stuff }\end{array}$ \\
\hline
\end{tabular}




\begin{tabular}{|c|c|}
\hline & $\begin{array}{l}\text { Future nursing students: } \\
\text { Just the internship, try to prepare as much as you } \\
\text { can before you're there? And also maybe what you } \\
\text { can do for your project, like what are the needs } \\
\text { there? Or find out small things you can also do, } \\
\text { things like if you have information before you go, you } \\
\text { can prepare about what the organisation does }\end{array}$ \\
\hline \multirow[t]{3}{*}{ Student M } & $\begin{array}{l}\text { Sending HEI: } \\
\text { Um, it was such a long time ago. Just to have a good } \\
\text { balance to Crossing Borders and YPO (see below, The } \\
\text { Sending Institution) because a lot of things were the } \\
\text { same. And also Crossing Borders to start earlier. } \\
\text { Yeah safety, that was very good of them. But like to } \\
\text { do one evening we did a game with play cards, you } \\
\text { have to play with people but you can't speak or } \\
\text { express yourself, and how the expressions are } \\
\text { different like between here and in Spain? And we } \\
\text { were very busy with school at that time and it was } \\
\text { like ok we don't want to play this game. The visas } \\
\text { are changing a lot, so we wanted more about that. }\end{array}$ \\
\hline & $\begin{array}{l}\text { Receiving Organisation: } \\
\text { Yeah they don't need to have } 3 \text { nurses, that's too } \\
\text { much. Also we're not coming for practical, but for the } \\
\text { project. And I think also to be more open, I think } \\
\text { that's a very difficult culture thing, but yeah, } \\
\text { sometimes they were just using us, you know? So I } \\
\text { think for [the receiving organisation] that you don't } \\
\text { send students for a year, and then maybe they } \\
\text { realise what they have more. }\end{array}$ \\
\hline & $\begin{array}{l}\text { Future nursing students: } \\
\text { (Smiles) That they have to go! And not to doubt. Just } \\
\text { to go with the flow and not to expect too much. Just } \\
\text { to talk with people a lot about it, because maybe } \\
\text { some people think oh that's really difficult, but just } \\
\text { go. See what happens. }\end{array}$ \\
\hline Student R & $\begin{array}{l}\text { Sending HEI: } \\
\text { Um yeah, Crossing Borders was so general. } \\
\text { Especially the healthcare people, you have to do } \\
\text { Crossing Borders when you go abroad. And it's also } \\
\text { for people going to Spain or something. So } \\
\text { sometimes we're talking about Europe, but it's like } \\
\text { you need to know more about SA than in Spain. So } \\
\text { because you're really busy with your visa, so I think } \\
\text { it's better to split it up into countries. And in YPO we } \\
\text { had some students from management, and we think } \\
\text { oh again this is the same information again. }\end{array}$ \\
\hline
\end{tabular}




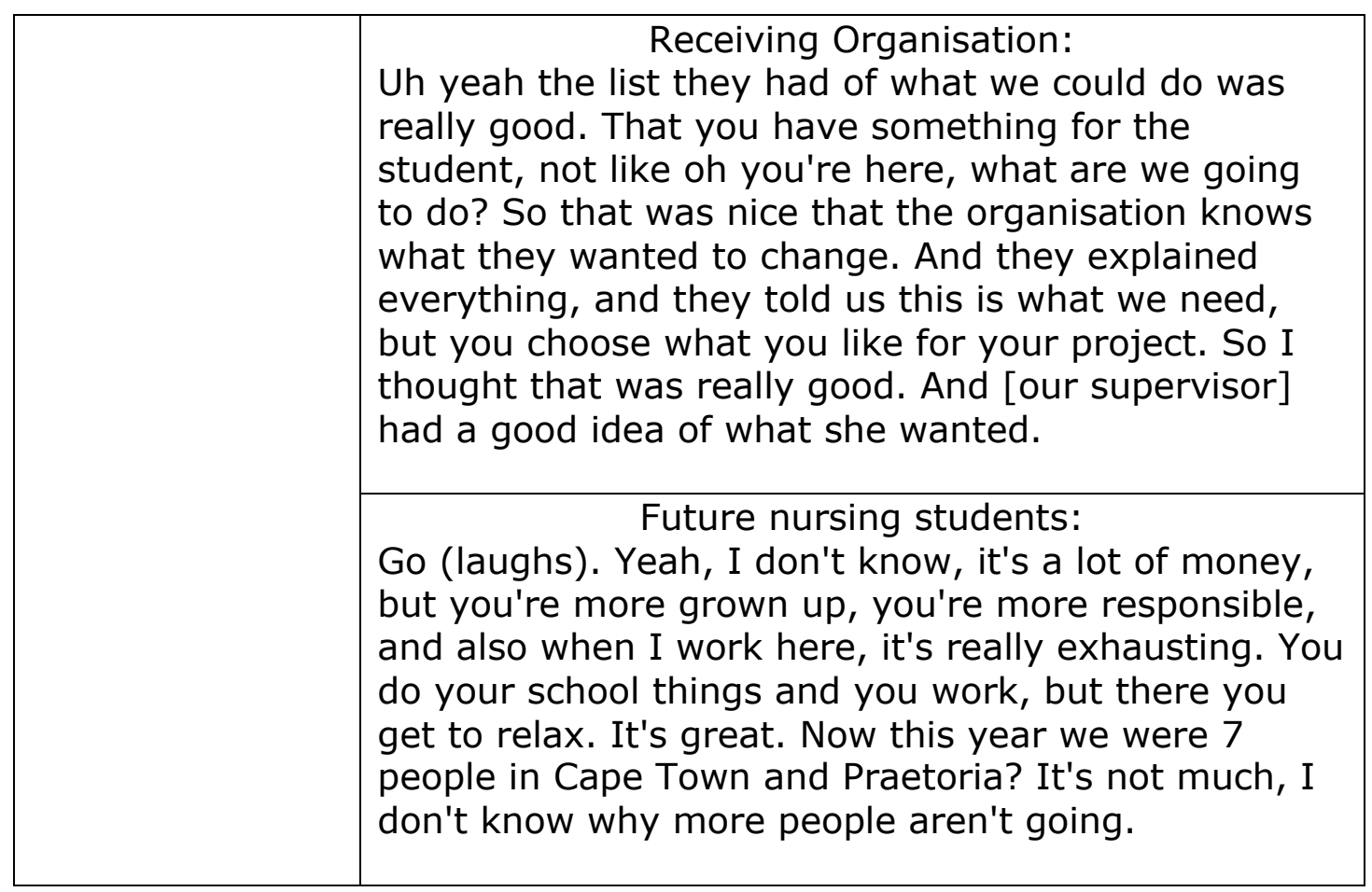

Triangulation of student data (see Figure 10) proved to be advantageous given the multiple themes that emerged twice. Students would talk about subjects in different ways based on the source of data collection, and thus offered additional perspectives that added richness to the analysis. Analysis of the case is shown in Table 11 according to theme and data source. 
Table 11: Student Data - Analysis by Theme and Data Source

\begin{tabular}{|l|c|c|c|c|}
\hline & $\begin{array}{l}\text { Pre- } \\
\text { interviews }\end{array}$ & Diaries & Blogs & Post-interviews \\
\hline Preparation & $\mathrm{x}$ & $\mathrm{x}$ & & $\begin{array}{c}\mathrm{x} \\
\text { (preparedness) }\end{array}$ \\
\hline $\begin{array}{l}\text { Theoretical foundation/ } \\
\text { underpinning/ support }\end{array}$ & $\mathrm{x}$ & & & \\
\hline Student retention of preparation & $\mathrm{x}$ & & & \\
\hline $\begin{array}{l}\text { Enthusiastic and indifferent } \\
\text { students }\end{array}$ & $\mathrm{x}$ & & & \\
\hline Informed students & $\mathrm{x}$ & & & \\
\hline Introspective students & $\mathrm{x}$ & & & \\
\hline Forward planning & $\mathrm{x}$ & & & \\
\hline Responsibilities & $\mathrm{x}$ & & & \\
\hline & & & & \\
\hline Struggles and conflicts & & $\mathrm{x}$ & $\mathrm{x}$ & \\
\hline Expectations & & $\mathrm{x}$ & & \\
\hline $\begin{array}{l}\text { Communication with receiving } \\
\text { institution }\end{array}$ & & $\mathrm{x}$ & & $\mathrm{x}$ \\
\hline Emotions and support systems & & $\mathrm{x}$ & & \\
\hline $\begin{array}{l}\text { Observations and comparisons } \\
\text { to home }\end{array}$ & & & & $\mathrm{x}$ \\
\hline & & & $\mathrm{x}$ & \\
\hline New experiences & & & & $\mathrm{x}$ \\
\hline Reflections & & & & $\mathrm{x}$ \\
\hline Risk-taking and adventures & & & & \\
\hline Study abroad & & & & \\
\hline & & & & $\mathrm{x}$ \\
\hline Transition home & & & & \\
\hline Benefits & & & & \\
\hline Impressions & & & & \\
\hline Recommendations & & & & \\
\hline
\end{tabular}

\section{Report of the Findings}

The following description of the case was informed from all types of data collected from students and study abroad coordinators (see other notable literature following a similar format above; Case Descriptions). Yin (2014) warns researchers of the temptation to analyse data separately that comes from one case. Thus, all data collected from the study abroad coordinators and nursing students are presented as one case description. Yin's case description was chosen as the analytical strategy due to the focus of this study needing a strong description of one nursing study abroad preparation programme as discussed in the findings of the literature review (see Chapter 2, Chapter 4; Single Case Rationales; Design). The case description is comprised of eight parts: the sending institution, student retention of 
preparation, first impressions, studying abroad, struggles and conflicts, support systems, risk-taking, and transition home.

\section{The sending institution}

The context of the case is a HEI in The Netherlands. The HEI has 15,000 students and focuses on international partnerships and English-taught classes. Since 2005, the HEI has been sending students aboard on internships as part of their university courses. The Netherlands, along with many European countries signed the Bologna Declaration in 1999 that allows students to study freely between participating countries in the European Union. Participating countries agreed to make common education requirements for students to allow easy transferability. However, this led to a sense of competition among countries for international education for students, and the Dutch government now mandates international activities at HEIs and also encourages training in English (Ter Maten, Garcia-Maas 2009, Dobrowolska et al. 2015).

Students considering a study abroad trip enrol in an elective course called Crossing Borders, a module that informs students about the possibilities for internships and the required competencies. Crossing Borders has no prerequisite requirements and offers information on study abroad trips to about 120 students every year. It involves 84 hours of study over eight classes covering topics such as cultural awareness, culture shock, global health, and preparation.

At the completion of the Crossing Borders module, students decide whether they would like to enrol in Young Professionals Overseas (YPO) for a more detailed, specific preparatory training related to their study abroad trip. About 70 students per year enrol in the YPO module that prepares them further for an international placement.

Three evening classes are offered to teach the students about their placement site once a location has been selected. The first meeting in YPO is called 'Prepared, Secure and Safe', which evidences that the HEI is committed to keeping students safe while overseas. Students are 
introduced to the cohort with whom they will study abroad. Appropriate behaviour is addressed, as well as the acknowledgement that Dutch culture is perceived as more direct and can be deemed as aggressive in other cultures according to handouts given to students from the HEI. Safe behaviour surrounding clothing, sex, drugs, and alcohol are addressed, and it is highlighted to students that aspects of Dutch culture may be interpreted as 'sexually inviting'. Values are presented according to the various countries where students may study abroad, which include being on time and respecting others. Students are taught to identify risks through fictional scenarios, and are encouraged to direct any concerns to their internship advisor immediately. Health insurance while abroad is addressed, as well as additional types of insurance in case of trip cancellation and damage to personal property. Health is discussed by region to safeguard students from dangerous situations including appropriate vaccinations, obtaining safe water, and prevalence of HIV/AIDS. A 'calamity card' is provided with phone numbers for various emergencies.

Recommendations of what to bring is discussed and a checklist is provided. Students are warned that laptops and smart phones can be seen as a sign of wealth, and burglaries may occur. Students are made aware of grants to assist with trip finances or spending money. An online Osiris Student form must be completed before departure that provides information accessible to all parties including flight information, phone numbers, and emergency contact information.

The second meeting covers cultural diversity. The book Cross-Cultural Communication (Jacobs 2012) is required reading for the module. Students begin this module with introspection - identifying their own culture. They discuss their own communication styles and how communication may differ with colleagues abroad. Fons Trompenaars work informed scenarios, wherein students would discuss reactions to difficult situations that might arise while abroad (Trompenaars, Hampden-Turner 1998). These are then juxtaposed with how different cultures typically respond to the same situations. Edward Hall's anthropological works are also presented to students, which describe high and low contexts of culture in which 
foreigners will encounter either many unwritten cultural rules or few, respectively (Hall 1989). The objective of this meeting is for students to learn professional skills within culturally diverse environments.

During the first two meetings, students are given assignments to be completed in preparation for studying abroad which are organised into a portfolio. Portfolios include motivation letters justifying why students should study abroad, what type of work the student would like to do, expectations, and Curriculum Vitae. Next students outline the preparation they did including books, websites, and films they utilised, and which they would recommend to future students undertaking a study abroad trip. In addition, students must interview a student who recently studied abroad through YPO. Assignments are informed by Leary's Circle Model (1957), an interpersonal model for organising behaviour. Hofstede's Model of Cultural Dimensions (1984) also informs student assignments, which describes culture within a work environment. Students must complete questionnaires and models according to their own culture and write multiple reflections on various aspects of their cultural training. Before departure, students are given a schedule of events and deadlines categorised according to weeks spent abroad. For example, by the third week of the internship, students should finalise their personal plan, including goals and objectives, an activity plan, and a timetable.

Students undertake interviews that inquire as to their current knowledge about the location of the placement, such as 'who is Nelson Mandela?' to students going to South Africa. The study abroad coordinators describe this process as a trigger to determine the students' willingness and commitment to go on an international placement. These modules are held in English, which is the language required to be spoken during preparation and while the students are on placement. Students must speak English fluently to complete the two modules.

Nursing students traveling to South Africa go to Pretoria or Cape Town for three months. Study abroad sites are chosen based on a number of criteria, including safety, reliability, and the ability of the site to offer personnel who 
can guide and support the students who are studying abroad. Further, the site must offer an opportunity for the student to work on the United Nations Millennium Development Goals (United Nations 2014), which is at the heart of the HEIs mission. The goals include: eradicate extreme poverty and hunger, achieve universal primary education, promote gender equality and empower women, reduce child mortality, improve maternal health, combat HIV/AIDS, malaria and other diseases, ensure environmental sustainability, and develop a global partnership for development. The Erasmus Programme, one of the institution's several study abroad options, enables students to study in 26 countries. The multidisciplinary Applied Science School sends and receives nursing students on exchange from South Africa, India, and Zambia.

Students are required to send a progress report each week, but it may be completed as a group. They are encouraged to keep blogs and diaries for their own benefit, and to keep in touch with friends and family back home. Students continue adding assignments to their University portfolio while overseas, such as a reflection in response to several prompts to help the students guide their study abroad journey, and evidence of the scope of their professional and intercultural development. YPO provides an evaluation feedback form for students to comment on their personal and professional assessment of YPO. Students are given the opportunity to include any additional representation of their time abroad for their portfolio examiners. The portfolio must be submitted no later than two weeks after the culmination of the study abroad experience.

\section{Student retention of preparation}

The students discussed the preparation course they received prior to studying abroad in their pre-trip interviews. Their retention of information during such training was of interest. As discussed preparation began with the course called Crossing Borders. This eight-week course met on Monday evenings, was open to all disciplines, and was generalised for a variety of trajectories. Student $M$ thought back to Crossing Borders and said it was: 
Not so good. The lessons were... boring a little bit. But when you look back you say ahh yes, but when you go through the lessons you don't see the meaning of it.

Student $L$ appeared to have a wealth of knowledge beyond her peers, but did not report having any additional preparation meetings or extra sources of information. She was able to articulate in detail what her daily routine was expected to include (see Table 12). She was the only student who brought up the possibility of having input in her assigned projects during the study abroad trip and said there were, 'several projects there' and, 'I want to do each project.' When asked what she hoped to gain from her study abroad trip, she quickly offered 'personal skills', then looked away with excitement, seeming to think about all the other potential gains that could come from the trip. This student also showed insight in her awareness that she could only prepare so much, saying she would have to travel to South Africa to determine if her feeling of preparedness was indeed accurate. An explanation for this may be that Student $L$ simply had more 'grit' than her peers; defined as a perseverance and passion to achieve goals (Duckworth, Peterson et al. 2007). Table 12 shows the difference in student retention regarding daily routines while studying abroad.

Table 12: Nursing Student Pre-Trip Interview: What will you do every day?

\begin{tabular}{|l|l|}
\hline Student A & Uh, I don't know. I will see when I'm there. \\
\hline Student L & $\begin{array}{l}\text { Yeah what we're going to do is like be giving } \\
\text { health talks and like staff training, the two girls } \\
\text { who just got back, we talked to them and they } \\
\text { had guidelines to give health talks, so we are } \\
\text { going to do that also, yeah mostly health } \\
\text { talks... we're more like improving other stuff, } \\
\text { other things, like medication lists, nutrition } \\
\text { lists, that kind of stuff, more like, yeah. } \\
\text { Organisation things. }\end{array}$ \\
\hline Student M & $\begin{array}{l}\text { [laughs] Well I don't know exactly but we need } \\
\text { to observe what's going wrong and then you } \\
\text { choose a project but I want to do the outreach, } \\
\text { which is on the street... Um there are some } \\
\text { girls in prostitution, HIV/AIDS, you can go } \\
\text { there and test for HIV/AIDS but I can't ask }\end{array}$ \\
\hline
\end{tabular}




\begin{tabular}{|l|l|}
\hline & $\begin{array}{l}\text { now, I have to wait until when I'm there. Yeah } \\
\text { several projects there I want to do each } \\
\text { project so. My main project is something like } \\
\text { healthcare, but I want to look everywhere so I } \\
\text { don't know. }\end{array}$ \\
\hline Student R & I don't know... [laughs] \\
\hline
\end{tabular}

The other extreme was Student A who showed indifference, a theme that did not arise from any other members of the study abroad trip. This particular student, when asked if she felt ready to study abroad, simply replied, 'no not really'. Student $A$ also stated that the reason she decided to study abroad is that her teacher talked about it (see Table 7). When asked what she would do on the internship, she replied, 'I don't know. I will see when I'm there' (see Table 12). Finally, when asked about the preparation classes she attended, the student said, 'I think that I didn't expect anything and I go there and didn't learn' (Table 13). These examples are clear indicators that indifference, or an otherwise impeding thought process was present, and that enthusiasm was lacking for the upcoming trip as seen in the other students.

Table 13: Nursing Student Pre-Trip Interview: How have you prepared to study abroad?

\begin{tabular}{|l|l|}
\hline Student A & $\begin{array}{l}\text { Um, I read about the culture, the country, I've } \\
\text { seen some movies. Um, I learn about food } \\
\text { there, but not a lot. I think that I didn't expect } \\
\text { anything and I go [to Crossing Borders and } \\
\text { YPO] and didn't learn }\end{array}$ \\
\hline Student L & $\begin{array}{l}\text { Um, yeah like I said... in the 3rd year you have } \\
\text { to say like yeah definitely I want to go, and } \\
\text { then the Module Crossing Borders we had to } \\
\text { do, it was } 9 \text { weeks on Monday evening so } \\
\text { yeah. We learned a lot about culture and } \\
\text { culture shock and that kind of stuff yeah and } \\
\text { of course and then you've got your intake for } \\
\text { YPO, you've got to write your motivation letter, } \\
\text { and your CV, and then for the intake you had } \\
\text { to prepare like that you know something about } \\
\text { South Africa, and why you want to go, and } \\
\text { yeah that kind of stuff, so yeah. That was kind }\end{array}$ \\
\hline
\end{tabular}




\begin{tabular}{|l|l|}
\hline of our preparation, but yeah I think it was \\
good.
\end{tabular}

Table 3: Nursing Student Pre-Trip Interview: What do you hope to gain from this experience?

\begin{tabular}{|l|l|}
\hline Student A & $\begin{array}{l}\text { Um, I think that um that the South Africa } \\
\text { people will accept our help. They don't have a } \\
\text { lot of things they can use. Here in the } \\
\text { Netherlands we have a lot of things... but the } \\
\text { people in South Africa, they don't have a lot of } \\
\text { things. }\end{array}$ \\
\hline Student L & $\begin{array}{l}\text { [smiles] Um, yeah, I hope to learn about their } \\
\text { culture, and more cultures there and yeah I } \\
\text { don't know, I think the way they work, and } \\
\text { yeah, they have the same uh also nursing, but } \\
\text { yeah I think there will be a lot of differences, } \\
\text { maybe also other things the same, but yeah I } \\
\text { don't know, like communication skills, that's } \\
\text { going to improve }\end{array}$ \\
\hline
\end{tabular}




\begin{tabular}{|l|l|}
\hline Student M & $\begin{array}{l}\text { Um personal skills? That's the main thing. I } \\
\text { mean, so much material, I don't know. }\end{array}$ \\
\hline Student R & $\begin{array}{l}\text { Umm, to know who I am I think, to be on my } \\
\text { own, away from small town I live in now, and I } \\
\text { think it's an experience for the rest of my life, } \\
\text { so. }\end{array}$ \\
\hline
\end{tabular}

The students' expectations were a picture into the range of retention of preparation content. Whether or not they comprehended what they would be doing everyday (Table 12), whether they remembered much of their preparation (Table 13) and what benefits they hoped to gain pointed to the students' level of preparation (Table 14). The following section, first impressions, was another measure of student preparedness.

\section{First impressions}

First impressions shed light on the students' level of preparation. The students experienced an abrupt trial by fire upon arrival in South Africa. The man who had arranged to pick up the students from the airport was not at the previously decided location. Not knowing what to do, and in a foreign country without communication access, the students appeared to be distressed enough that taxi drivers began approaching them asking if they needed help. Student $M$ remembers:

At the airport, we arrived and some guys want to help us with our bags, and some other girls are like aww they're so friendly! And I said no! You don't know what they will do with their bags! So I was like really careful!

Student $\mathrm{R}$ finishes the story:

And all the taxi drivers were like oh! Let me call him for you, and we think oh! That's so nice ok, and then they tell us, give us money for calling him for you. And then we thought, ok, I thought they were just nice, but they want money for everything, so we apologised. But it was only that moment, it was like okay. Take some steps back, and it was a good lesson, right then. 
The experience oriented the students to their new environment. They were reminded of their preparation training, especially safety precautions.

All of the students were eager to talk about their first impressions in South Africa. Perhaps underestimating what they would find upon arrival, the students talked about how nice their accommodations were, saying, 'I didn't expect it to be so nice...it felt like home'. They lived in 'the best neighbourhood in Praetoria' in a row of houses where students from other universities lived as well, with each student having their own room and common living areas. The house manager welcomed them warmly, giving the students a feeling of security. They were given a tour of the facilities and oriented to their new environment.

A noteworthy first impression was religion. Student A was surprised at the dedication the South Africans had to their religion:

I did not know that they believe in God really strong. Before I go I didn't understand much about it. They pray and they have devotions on Friday, and I saw, they get strong because they believe, it's nice to see, and I talked to the people and now I understand more about what they believe.

Students wrote in their diaries that the first few days were chaotic. One particular entry was especially telling: 'it is just a strange country with strange rules'. Student A stated, 'I see a lot of culture differences and sometimes it's hard to accept them'. Student M wrote in an early diary entry about the hope of returning home, imagining her family at the airport to greet her:

Not that I didn't like it at the beginning but just to leave my family and boyfriend...but after 4 weeks I didn't have that feeling anymore. I was settled...and now I don't have feelings that I want to go home, but just staying here.

She later confessed:

At the beginning I didn't feel comfortable in this country...but week by week it is getting better. 
The students were involved in street outreach projects with the clinic, entering poorer areas of the city where homelessness and substance abuse were prevalent. The students handed out meals and invited the people they met to come to the clinic for the various services available to them. Each student spoke of this as an eye-opening experience. Student $A$ remembered:

There was one guy, he was asking do you have some clothes for me? For my children, and they were laying there on the street and they didn't have any clothes. He had a child who was one month old and didn't have any clothes. That was really hard, you want to help but you can't do everything. Student $M$ said of the same evening:

And for me it was very impressive to see how the girls are there. They just live on the street, they are 12 years old, they don't have anything, just drugs.

This was an impressionable time for the students, who treated the people they met with empathy and talked at length about the experience in their interviews.

The students reported feeling a lingering tension in South Africa following the recent apartheid. According to Student L:

We went to a rugby game the first weekend, we saw the white people were enjoying the game, the black people were working. That kind of stuff. That's the first thing you realise, you're in a different country.

Similarly, of the study abroad site, more than one student noticed that the management and patients were white; while the rest of the staff was black. The students remembered the apartheid from their preparation training and reflected on the effects that were still visible.

The first day of work at the study abroad site, Student $\mathrm{R}$ recalled:

Yeah I was really nervous the first day, but they were so friendly to see us and everyone wants to see us and they were like oh! Today is your first day...they were so nice to us. They don't have enough money there, it's a non-profit organisation. 
So if a patient is in a wheelchair and needs to go to the toilet, another patient there brings that person to the toilet. They don't ask me, they ask each other. It was really nice to see, because in The Netherlands they say oh there's a nurse, ask her to go to the toilet.

The differences in healthcare accessibility seen early in the trip left positive impressions with the students.

As mentioned by Student L, 'I really had to get used to everything' was a common motif regarding the introduction to workplace culture. Each of the students were struck by the work ethic in South Africa. In the clinical setting, Students $A$ and $L$ noticed they had to get used to the different mentality and way of working. Student M spoke of her dismay the first day working at the clinic:

Well at first we didn't know what they were doing, like it was just tea time, tea time after tea time.

Student A provided more detail on the subject:

The staff thinks there is a lot of work and they said that they work very hard but I really don't see that...in the Netherlands we work very hard and sometimes we don't have time for coffee.

As time progressed, Student A realised:

You really have to do small things and be satisfied with the things you achieve.

Similarly, Student L stated:

I really felt that I did nothing the whole day and for me it seemed that the staff also didn't do much on a day. It took me a while to get used to this, because even until now it sometimes seems they are doing nothing, just sitting.

Both Students $A$ and $L$ perceived that the staff 'sat around', stating that the staff would spend an hour with the patients, then wait for tea time. The students questioned, 'is this everything that you do?'

Students also noticed the cultural difference in the concept of time. Student M stated that South Africans: 
Don't know a clock. When you have an appointment with someone, they come like easily two weeks after the appointment. And they don't have stress!

The concept of time presented problems for the students in their presentations that were required from their sending institution. Student $M$ continued with an example of scheduling a staff training with her peers:

And then they just cancel it an hour before, or they just tell you an hour before, you need to present now! ...so you just adapt and go with them.

Student $M$ felt ecstatic with the positive feedback she received from a patient who chose to attend her presentation.

\section{Studying abroad}

The students were given a great deal of autonomy at their study abroad site. Student $L$ described a typical day as waking up in the morning, eating breakfast with her housemates, and driving 45 minutes to the study abroad site. Some days they would show up early, other days they would sleep late and arrive in late morning. The drive from the student accommodation was sufficiently long that it seemed to dissuade the students and the local study abroad coordinator from mandating the students to come daily. On other days the students were told they could work from home, and at times the students themselves decided to work from home. Generally, four days a week they would be in the clinic, one day a week they would work on their presentations. The researcher probed as to how many hours the students spent at the study abroad site, having heard this from each of the students. Student R replied, 'well (laughter) maybe like 20 hours a week? Don't tell my teacher!'

A typical day consisted of several responsibilities. The students assisted the staff with various nursing skills at the clinic, and answered phone calls when patients called with medical questions. The study abroad location consisted of a grouping of various houses, which separated patient care according to need: mental health, end of life care, and a home for the homeless. While the students were to spend some time with the patients, their sending 
institution required students to provide staff training in the form of presentations.

Students were also assigned to create protocols, or written procedures concerning events about which the staff was unprepared, or had no written plan of action. The days the students stayed home to work, they would work on protocols and health presentations for the staff, which they performed weekly. Incidentally, several patients who read about the upcoming presentations on flyers distributed to the staff attended the student presentations and staff trainings. The students made protocols for when the clinic's medical staff should contact emergency services, and what to do when a patient had a fever. The presentations were based on the needs in the site location, guided by the local study abroad coordinator. The students also presented training to the staff on first aid, stoma care, menstruation, pregnancy, tuberculosis, hygiene, medical emergency protocols, and HIV/AIDS and self-testing procedure.

The students compared their study abroad experience to what they knew back home in the Netherlands. They adapted quickly as told by Student $\mathrm{L}$, and began taking initiative where they felt the internship was lacking:

Their mentality is really different than in the Netherlands. Actually the whole way of working is totally different. Everything goes really slowly comparing to my internship in the Netherlands and in the beginning I was really bored at my internship here. Later we tried to do things, take more initiative, give presentations/in house trainings and stuff like that to keep busy.

The students showed professionalism by speaking to their study abroad coordinator and taking on more responsibilities.

The autonomy given to the students could have failed had the students been of different backgrounds of culture, or perhaps had different personalities. More than one student reflected near the end of her internship that she had not yet worked one full day that required standing, the way she would have back home. Student $L$ admitted the internship 'felt 
like a holiday'. Although the students showed up late and did not come in some days, they completed their work and began to take needs-based requests for additional health presentations and protocols beyond what was assigned to them. The students were also proactive in discussing the lack of things to do amongst themselves and with their local study abroad coordinator, and all decided to split up to have more opportunities to practice their skills. The students also reported they felt the staff treated them with more kindness when they were in smaller groups. This is the context that led the students to seek out additional work for increased learning, making the most of their trip. The students went above the requirements given to them by their sending institution, and took liberty in time management with maturity and willingness to address needs as they arose.

\section{Struggles and conflicts}

A three-month study abroad trip is expected to include personal and familial struggles. During the study abroad trip, Students A's mother was made redundant from her job, and later lost her grandmother. In their diaries, students exhibited a variety of emotions, often switching back and forth rapidly from excitement to harsh complaints about the culture in South Africa. Likewise, students jumped from detailing interpersonal conflicts to heartfelt stories about bonding with patients.

As expected, situations arose for which the students were unprepared. Soon after arriving in South Africa, Student R spoke of the difficulty acclimating to the culture:

It takes time. I was prepared, but I was not prepared that is was so hard, that it takes not just one or two weeks, it takes longer.

Each of the four students wrote about the struggle to win respect from the local South African staff, and that the first few weeks were isolating and disappointing. Reportedly, the local staff would laugh and look at the students while talking in a language the students did not understand. Student L confessed: 
So for me it looks like they are talking about me and I think that's never a nice feeling.

The students discussed this problem amongst themselves and the local study abroad coordinator, who advised the students. The next time the students felt they were the object of a joke, Student $L$ made a request to the staff directly: 'I just ask them to talk in English every time.'

Emotional struggles were 'difficult to handle' according to an early diary entry. After losing her grandmother, Student A wrote:

Not that I want to go back home, but you just want to be home for 2 days and help your family, give them a big hug and that's enough.

As time progressed, the local staff increasingly relied on the students to help with basic patient care such as washing, which became a struggle for the students. The students spent the first few weeks acquiescing to the staff, but were aware that their study abroad requirements were not to help wash patients. Wanting to win the approval of the staff, Student M remembers:

So we ask ok what can we do for you? And so they say you can dust. And then they don't do anything. So that was very difficult to explain to them that we want to help you, but not like, for this. I don't want to be arrogant, like I don't want to dust, but you need to find a way to adapt.

Eventually the students had to tell local staff members that they would help with basic care in the morning, but they were not in South Africa to wash patients. They told the staff about their requirements to prepare staff training presentations and protocols. This action took a great deal of courage and acted as a learning experience to enhance communication and leadership skills. A similar situation arose with the unit management of the neighbouring houses that provided care to specific groups, mentioned above. Students had been assigned to spend the majority of their time in the main house's medical clinic, and to provide a staff training presentation to each unit of the clinic and to each of the surrounding houses. The unit managers would talk with students about the needs their staff had for training, and would ask the students to stay on their units, rather than helping the other 
units. Again, the students had to address the situation with care, saying no to the unit managers while keeping a productive working environment.

Student M said solemnly that these were 'very difficult conversations'. She continued on stating she became a more direct communicator as a result of her experiences:

If I have a problem, I'm not so shy anymore. And I improve that a lot especially in South Africa. And that's what I wanted to change, my assertive way.

The students took advice from their local study abroad coordinator, including splitting up into smaller groups, which helped alleviate tense relations (see section Studying Abroad, above).

As the study abroad trip progressed, struggles were rarely written about, and were communicated in shorter phrases such as 'I was so irritated' and, 'sometimes I have a feeling $\mathrm{SH}^{*} \mathrm{~T}^{\prime}$ ' which was a notable trend away from language depicting disappointment. Most of the students wrote about their struggles in the first half of the trip, suggesting adaptation to the new environment occurred as such entries lessened. But overall, the students were able to communicate their emotions freely and discussed their struggles with their peers. No students left the study abroad trip early and while complaints abounded in their blogs and diaries, the students held the skills necessary to cope with everything that came their way, showing flexibility and resilience.

Students compared and contrasted their home culture with their environment in South Africa. Reflections in student blogs identified that it was 'clear to see the difference between rich and poor and evidence of apartheid'. Each student noticed evidence of the recent apartheid (this thesis was submitted in early 2019) in different ways. While this was not discussed in length, the blogs did include mention of it, as well as the wide class divide between rich and poor, such as Student $L$ who felt:

It makes you realise again just how great the differences between poor and rich here and how quickly you can end up on the streets here. Most people are pretty open and tell their whole life story if you ask for it. By simply lose their jobs, they 
live on the street. One man even asked for clothes for his newborn baby.

Student A compared this sentiment to life back home, 'and how well we do in the Netherlands'. Student M concluded, 'you are really confronted by the inequality in the country'.

\section{Support systems}

One aspect of preparation is providing the support necessary for students to experience a successful study abroad trip. Support systems were plentiful for the students. The local study abroad coordinators acted as a support to the students, who had weekly conversations with students about their emotional and educational needs. Students did not offer information about the local study abroad coordinators, who are assumed to have connections to the local receiving institution. The students frequently wrote about experiencing a problem, discussing amongst themselves or talking with their local study abroad coordinator, then reporting afterward that the problem had been resolved. The students knew who to ask for help when they needed it.

A study abroad coordinator from the Netherlands visited half way through the trip to offer support and monitor progress, which raised the students' morale. The students had an enjoyable time taking their coordinator sightseeing and all parties seemed pleased with the students' progress. The students were a great comfort to each other, and several students from other European universities were studying abroad at the same location, offering an additional source of friendship and support. Access to communicate with their plentiful support systems however, proved inconsistent. Internet and phone access was frequently interrupted, often with no knowledge of how long the outage would last.

\section{Risk-taking}

As discussed in Chapter 2, study abroad trips carry significant risks for students. It is impossible to prepare students for every risk, and therefore students should have an understanding of risk management skills and the tools necessary to assess risk in any particular situation. Throughout their 
trip, students sought out extramural activities involving risk such as ziplining, skydiving, mountain biking in a canyon, and scuba diving. It is unclear if the sending or receiving institutions approved any of these activities.

Risk-taking behaviours were most prevalent in the student blogs. The students wrote that they did not feel safe in the taxis to get from their home to their study abroad site. This encouraged the renting of a car early in the trip, after asking the opinion of the local coordinator. Student $A$ stated it was a new experience to sit on the 'other side in the car and drive on the other side of the road'. This decision carried significant risk; but also showed critical thinking, awareness of surroundings, and determination to improve a high-risk situation.

The students drove hundreds of miles in a foreign context, and experienced a car accident one morning with a South African taxi driver. The students spoke of this as a potentially dangerous situation, having learned that onlookers could come and steal from or kill victims of car accidents. The students quickly noticed that the driver of the taxi was black, as were the onlookers. The students immediately noticed they were in a dangerous situation being the only white people at the scene. The scene ultimately unfolded in the best-case scenario, with the situation resolving on friendly terms. Student $M$ even remarked:

I didn't need to prepare for that I think. It was nice to have a shocking moment like okay, this is the way most of the people live here.

The students barely escaped a dangerous situation and reflected upon the event as a learning opportunity, which may have been an overly simplistic reaction given the great potential for harm. The students continued to take long car trips (one of which involved hours in the wrong direction due to a navigational error without mobile phone access) with a justification of driving long distances in search of educational opportunities.

The students refer to drinking alcohol somewhat regularly, and went dancing in 'black clubs' while reporting they felt uncomfortably aware that 
they were the only white people in the room. Student $\mathrm{R}$ also reported that people were dancing on top of vehicles. Student A reported:

We were the only white people...we were glad we had an African girl and boy with us because there were just pictures of us...and people wanted us in the picture.

This type of activity points to the culturally voyeuristic mindset mentioned above (see Student Post-trip Interviews, and Chapter 2).

Unforeseen risks arose throughout the trip. During free time, the students attended a music festival and witnessed multiple gunshots into the crowd where they were standing. All of the students spoke about this event, experiencing fear and the shock of seeing the gunshot victims in close proximity. One said, 'he shot him in the stomach but the shot also reached some other people.' Another said a young girl got shot in the shoulder who was unfortunately standing nearby.

The gunshots stunned the students, all of whom remembered this event. Student $M$ reflected on the experience:

But then happens something violence to a person you know, and that is a really good wake up call. It is maybe rude to say it on that way, but sometimes it is good that something happens. You are prepared but still you can have bad luck when something happens to you about violence.

The students ended their internship with a four-week holiday in South Africa. The students had limited communication availability during their internship, which suggests communication would be impaired even further during long travels. The students were their own chaperones for this month-long voyage. Student $M$ provided an assuring word as to the students' preparedness for their travels:

When we are going somewhere to travel, every time I am a little bit nervous to the unknown of the place. Is it safe? What kind of people can I expect? [All] the time thinking about the safety. 


\section{Transition home}

Re-entering one's home country after studying abroad can induce a myriad of feelings. Bender and Walker (2013) consider the transition home from a study abroad trip to be a pivotal time for students, calling for study abroad coordinators to formally debrief the trip with students upon returning home. The transition home was an emotional time for the Dutch students as they said goodbye to new friends and colleagues.

The study abroad trip was a positive experience for the students, full of opportunities for maturation and personal growth. Each student expressed a desire to return to South Africa. Student R talked through the possibility of how she could return, perhaps for further studies, perhaps for a holiday. She finally concluded, 'but it's also not a very realistic life, going over there', displaying her realism of adulthood and responsibility as she neared the end of her nursing studies.

Student $\mathrm{R}$ wrote in her blog these final words of the trip:

The hospitality I have experienced there was unprecedented, unbelievable how sweet and warm people are here!

The students were quick to discuss the differences between South Africa and The Netherlands, observing how easy their lives were during the study abroad trip, and how 'more is required' of them upon returning home. Student A reported, 'I am satisfied with small things now instead of big things', and continued on to explain how few possessions people had in South Africa. Many of the students said they cried during the trip back home. Student $M$ was remarkably candid when she stated she was 'homesick to Africa' (Table 15), and that her family did not understand how she felt. All of the students were quick to express that the transition home was difficult in their interviews. Their honestly and willingness to expose such a personal reflection spoke to the strong emotions they felt, and whether they were prepared to return home when they did. Table 15 displays student responses concerning their return home after studying abroad. 
Table 15: Nursing Student Post-Trip Interview: How has your transition been, coming back home?

\begin{tabular}{|l|l|}
\hline Student A & $\begin{array}{l}\text { Yeah we travelled for 4 weeks, then we travelled } \\
\text { home. }\end{array}$ \\
\hline Student L & $\begin{array}{l}\text { Yeah been back about, 6 weeks. Just going to } \\
\text { school and, yeah just getting used to this life } \\
\text { again. }\end{array}$ \\
\hline Student M & $\begin{array}{l}\text { It's been harder than I thought. Like you have to } \\
\text { plan everything, in SA it was such easy life, now I } \\
\text { must plan everything and, yeah I don't know. I } \\
\text { think also the people. Before we had friends and } \\
\text { you change a lot. I have a different view now. } \\
\text { People don't understand you that you're } \\
\text { homesick to Africa. }\end{array}$ \\
\hline Student R & $\begin{array}{l}\text { Um, sometimes a little bit difficult... It was really } \\
\text { nice, I was home... Uh, was a little bit hard, I was } \\
\text { in the airplane and I was crying. But all my } \\
\text { roommates and everything, they also left, so } \\
\text { actually it was a nice time to leave. }\end{array}$ \\
\hline
\end{tabular}

Some benefits were difficult to explain or define, but students expressed gaining a great deal of benefits from their trip. When asked if she gained anything, Student R replied, 'much more than I expected.' Students increased their worldview beyond learning about South African culture, supporting the ubiquitous study abroad benefit of increased cultural awareness and competence (see Chapter 2). Universities had sent students to study abroad to the same location from Germany, the Netherlands, Spain, Italy, and Australia. Student M said:

It was so nice to live with them because you have to adapt because each culture is different and has its own things and habits, so it was so nice to live with them and learn to adapt to people more.

Another benefit of the study abroad trip was the expanding worldview of the students. Student A remembered:

At first I think I know more than they do, but it's in a different way because they are more creative than we are. So in that way, I learned also a lot from them. 


\section{Discussion of Preparation and Preparedness}

Embracing the eight components making up the description of the case, a discussion of preparation and preparedness is presented. Students discussed their preparedness, or adequacy of their preparation (Table 16).

Table 16: Nursing Student Post-Trip Interview: Were you adequately prepared for your study abroad trip?

\begin{tabular}{|l|l|}
\hline Student A & $\begin{array}{l}\text { Yea in Crossing Borders we talked about the } \\
\text { safety? They told us about we are not allowed to } \\
\text { walk in the street when it's dark, they talk about } \\
\text { how people are going to try to help you, but it } \\
\text { was great because the street where we lived it } \\
\text { felt really safe, so I would have walked by } \\
\text { myself, but because Crossing Borders told me, I } \\
\text { didn't do that... But it takes time. I was prepared, } \\
\text { but I was not prepared that is was so hard, that } \\
\text { it takes not just one or two weeks, it takes } \\
\text { longer... } \\
\text { Yeah, I was really good prepared. We also met } \\
\text { some other students from the Netherlands who } \\
\text { were not prepared? And you see really difference. } \\
\text { Like the school told us what is safe, what is not } \\
\text { safe, also not walking alone when it's dark, and } \\
\text { taking a cab. }\end{array}$ \\
\hline Student L & $\begin{array}{l}\text { Yeah, I did. Now I think back, Crossing Borders, } \\
\text { all the meetings we had, I think so. And } \\
\text { compared to the other students, it was very } \\
\text { international, and the other students from the } \\
\text { Netherlands, and they had like one day training, } \\
\text { and yeah, other education they didn't do, like one } \\
\text { day, and we had 9 weeks. We had a whole course } \\
\text { at school and yeah. I felt prepared. I felt good. }\end{array}$ \\
\hline Student M & $\begin{array}{l}\text { Uh, yeah. Because through Crossing Borders and } \\
\text { YPO, we know we're not in your own country and } \\
\text { we have to be careful, and that you are an } \\
\text { ambassador of YPO. } \\
\text { At the beginning, I thought oh YPo, Crossing } \\
\text { Borders, why? And then you are there and you } \\
\text { start to realise okay some things are helpful. }\end{array}$ \\
this classes and homework, it's too much, but \\
over in SA I notice things, like oh yeah! So it's \\
nice to have it.
\end{tabular}


Students were asked to explain the most helpful aspects of their preparation. Each of the students reported that hearing from their fellow students about their study abroad experience the previous year, at the same location where the next cohort would travel, was immensely helpful. When asked what stood out in her preparation, Student M laughed, immediately exclaiming, 'be careful!' The theme of safety was repeated in Table 16 by Student A, who discussed not walking along at night, and her preparation training being the reason she avoided it.

The students were asked whether they felt anything should have been added to their preparation curriculum. Student R said in Table 16 she felt the classes and homework were too much, but upon reflection, it was nice to have. This repeats the feelings of the student in Chapter 5 who also felt her preparation training was excessive.

In discussions of preparation following the study abroad trip, every student was eager to compare their preparation with other students groups who studied abroad from different universities. Student $L$ said she wished her sending institution had helped a little more with practical aspects of the trips, stating she had difficulty applying for a visa to South Africa. One group of students reportedly did not receive any preparation for their trip. The students excitedly talked about this group, with Student $\mathrm{R}$ saying:

Yeah, they got nothing! They said yeah I'm doing an internship abroad and their school said yeah ok, you're going to [South Africa], yeah ok.

Student $M$ said of the unprepared group:

They didn't notice the things we did, like we were much more prepared, much more aware. We acted safer. They also lost a phone.

Student R compared her experience to different group of students from other universities, that they received preparation for:

Like one day, and we had 9 weeks. We had a whole course at school and yeah. I felt prepared. I felt good. 
While the students were in South Africa, a Dutch study abroad coordinator from their sending institution came to visit (see Support Systems). She told the students her dismay at the behaviour of the students from other universities that did not receive preparation. The coordinator said she would have sent the unprepared students home if she had possessed the authority to do so.

The students self-reported that their preparation training was adequate (see Table 16). When asked if she thought anything should have been added to her preparation training, Student $\mathrm{R}$ stated, 'I actually don' $\mathrm{t}$ '. The researcher probed a second time, ensuring preparation covered everything it should have. Again, Student R affirmed it did. The students felt the preparation classes were redundant at times, sometimes even boring. Upon post-trip reflections, each felt prepared and acknowledged the training was necessary.

\section{A deviant, critical, paradigmatic, and revelatory case}

The findings of this chapter suggest that the case is in fact simultaneously deviant, critical, paradigmatic, and revelatory, as explained in Chapter 4 (see Single Case Rationales). This rare occurrence is supported for the following reasons.

The preparation offered to nursing students has elements of a critical case because it is not necessarily unlike others around the world. Preparation is not discussed in detail to know if other study abroad programmes from other HEIs prepare their nursing students similarly to the case under study, making this study revelatory. In other words, many HEIs could possibly offer similar programmes that simply do not report their preparation method in the literature. The preparation programme under study is also somewhat paradigmatic. The preparation offered to students appears to be ideal in terms of the length of time allotted to prepare students, the wide range of subjects covered during preparation, and the attention to recently returned students' feedback about the trip. Further, the context of the case, the HEI in The Netherlands, has numerous study abroad programmes, is a member of Erasmus, strives to achieve Millennium Goals (see The Sending Institution), and is incentivised by the Dutch government to be involved in 
international affairs - making the HEI an idyllic context for a paradigmatic case. The possibility of the case also being deviant - arguably by its ideal and thorough preparation - is unknown due to the inability of the researcher to determine other preparation techniques from the available literature (revelatory). However, a key source of information from the students proves the case under study's preparation programme 'shines' when compared to that of other HEIs (if a case 'shines', this is defined as the best way to determine a paradigmatic case (Flyvbjerg 2011)). All four nursing students spoke of the lack of preparation their fellow students had, studying abroad in South Africa from other HEIs. The study abroad coordinator who travelled from The Netherlands felt the other students' lack of preparedness was sufficient that they should have been sent home. Therefore, of all preparation programmes offered through HEIs, the case under study ought to offer adequate preparation training to students - being categorised, then, as a deviant, critical, and paradigmatic case.

\section{Theoretical statements}

Chapter 4 contains theoretical statements that directed analysis in this case study. The theoretical statements are displayed in Table 17 below with supporting evidence in the column to the right.

Table 17: Theoretical Statements and Supporting Evidence

\begin{tabular}{|l|l|}
\hline $\begin{array}{l}\text { The case study will provide a } \\
\text { holistic description of the process of } \\
\text { preparing nursing students to fill } \\
\text { knowledge gaps in the available } \\
\text { literature }\end{array}$ & $\begin{array}{l}\text { This statement was achieved } \\
\text { through the case description, under } \\
\text { Report of the Findings. }\end{array}$ \\
\hline $\begin{array}{l}\text { The case study will reveal an } \\
\text { additional layer of student } \\
\text { preparedness by considering their } \\
\text { reactions in daily experiences }\end{array}$ & $\begin{array}{l}\text { Several instances revealed students } \\
\text { responded to stressful situations } \\
\text { with maturity, safety, and } \\
\text { confidence. The car accident, scene } \\
\text { of gunshots, and reaction to } \\
\text { interpersonal conflicts with local } \\
\text { staff indicate the students were } \\
\text { adequately prepared. }\end{array}$ \\
\hline
\end{tabular}




\begin{tabular}{|c|c|}
\hline $\begin{array}{l}\text { The case study will show how } \\
\text { preparing a student for a study } \\
\text { abroad trip based on the country's } \\
\text { safety, power, wealth, or continent } \\
\text { is not sufficient for the needs of } \\
\text { nursing students }\end{array}$ & $\begin{array}{l}\text { The student experiences prove, and } \\
\text { the literature supports that a } \\
\text { sending HEI or receiving institution } \\
\text { cannot prevent the inevitable (Citrin } \\
2011 \text {, Foronda, Belknap 2012). A } \\
\text { gunshot scenario could have } \\
\text { happened in any number of } \\
\text { countries that may or may not have } \\
\text { seemed like a location where guns } \\
\text { would have been a warranted } \\
\text { preparation topic. Preparation based } \\
\text { on stereotypes of the host location } \\
\text { can raise questions related to } \\
\text { diseases and political unrest, but } \\
\text { would still be plausible in locations } \\
\text { where the same stereotypes do not } \\
\text { exist. The students got in a car } \\
\text { accident that could have ended their } \\
\text { lives, and yet they were unharmed. } \\
\text { No political unrest affected the } \\
\text { students. This suggests that } \\
\text { preparation ought to cover a myriad } \\
\text { of issues, regardless of the host } \\
\text { location's reputation for safety, } \\
\text { power, wealth, or continent. }\end{array}$ \\
\hline
\end{tabular}

The theoretical statements were answered as a result of the case study findings. As stated in the supporting evidence, it is not possible to prepare students for every possibility that could arise during a study abroad trip. However, preparation can encompass broad topics that are most likely to encourage learning, guide decision-making, and guard students from danger and culture shock.

Finally, Figure 16 displays an overview of the data collected in this chapter, as well as which research questions were answered. 
Figure 16: Dutch Preparation Programme Overview

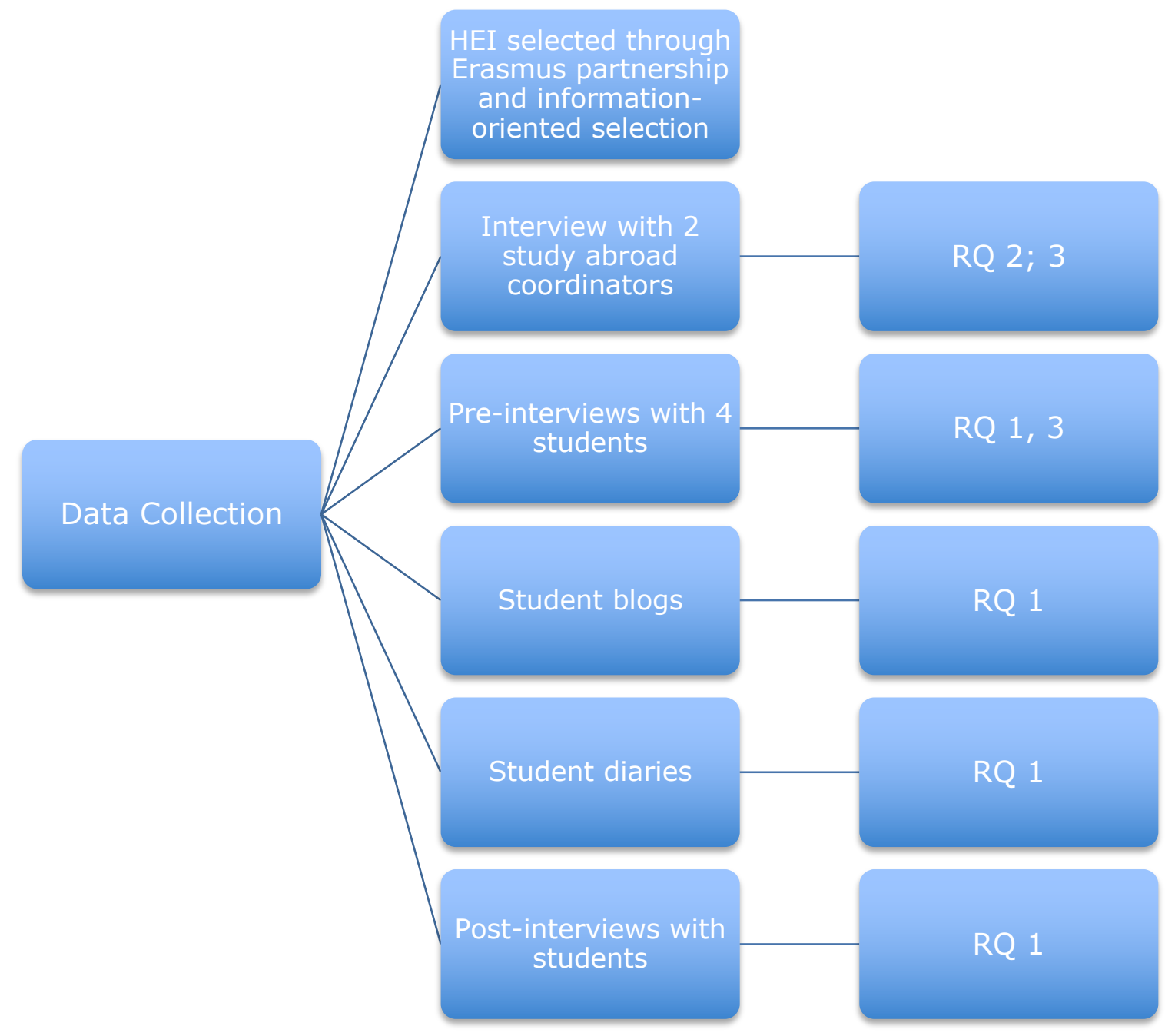

\section{Conclusion}

This chapter reports the findings of a case study that explored the preparation nursing students receive prior to studying abroad. Following the selection of the context of the case (a HEI in the Netherlands), a face-toface interview was conducted with study abroad coordinators responsible for preparing and supporting students during their trips. Nursing students were recruited during the researcher's travels to the Netherlands and provided a triangulation of data sources including interviews, blogs, and diaries regarding their preparation. Analysis followed Yin's (2014) case description method and Colaizzi's thematic analysis (1978), resulting in a description comprised of eight parts: the sending institution, student retention of preparation, first impressions, studying abroad, struggles and conflicts, 
support systems, risk-taking, and transition home. A discussion of preparation and preparedness is presented in which the case is defined as deviant, critical, and paradigmatic. 


\section{CHAPTER SEVEN \\ DELPHI STUDY}

Embracing the findings of the pilot case study (see Chapter 5) and formal case study (see Chapter 6), a definition of preparation was required that could guide nursing HEIs to inform practice for nursing study abroad trips. Due to the depth and scope of the preparation needed for nursing study abroad trips, it was challenging to identify a definition of 'preparation' and subsequently 'preparedness' (the degree to which the aspects of preparation were realised). The researcher created a working definition of preparation informed through an extensive literature review (Chapter 2). A Delphi consensus research method was chosen to validate and add rigour to a working definition of preparation.

\section{Aim and objective}

To define and gain consensus on the definition of preparation for nursing study abroad trips.

\section{Method}

The researcher considered various methods for arriving at a robust definition of preparation. There was not a clear definition supported by the literature as both the literature review (Farmer et al. 2003, Goldberg, Brancato 1998, De Natale, Waltz 2015, Shailer 1997, Folse et al. 2015, Read 2011, Egenes 2012) and this thesis (see Appendix A; see also the difference in case description between Chapters 5 and 6) that no two preparation modules are alike - even within collaborative consortiums (Farmer et al. 2003). The researcher compiled a working definition of preparation from multiple sources (see Chapter 2, working definition of preparation), however, it required validation.

\section{Reason for method selection}

Focus groups were not deemed practical to gain the consensus required for logistical reasons, such as the impossibility of scheduling face-to-face data collection from experts across multiple time zones (for definition of expert, see sampling strategy). Data collection needs were based on participant 
expertise rather than random sampling (Jones, Hunter 1995), which ultimately led to a consensus method. A consensus method was chosen because the literature discusses preparation with wide inconsistency (see Chapter 2), and the researcher needed clarification whether experts could agree upon a singular definition. Nominal Group Technique, a consensus method, was considered and rejected because of the requirement for highly structured face-to-face meetings with all experts present to discuss the topic under study (Foth, Efstathiou et al. 2016).

\section{Delphi technique}

Due to the identification of multiple styles of preparation, and the researcher's compilation of preparation components taken from a seemingly infinite amount of preparation styles to include in a definition, a Delphi technique was chosen to develop and validate the working definition of preparation. A Delphi is a consensus method, wherein each expert is able to contribute individually to a group communication process through a series of rounds. Opinions are cast by experts, then analysed for degree of consensus. Analysed opinions are fed back to the experts who may alter their consensus after further reflection of the expert panel's response in subsequent rounds. When experts reach a minimum agreement consensus level of 75\% (van Houwelingen, Moerman et al. 2016), the Delphi study is complete. If consensus is not reached, the next round ensues.

This Delphi study is justified for the following reasons. Firstly, the Delphi is a method that allows experts to access the questionnaire regardless of their geographical location, which was expected to be global due to the topic of study abroad programs (Diamond, Grant et al. 2014). Secondly, the Delphi follows a recommendation (see Chapter 4; Case Study) to use a statistical method in conjunction with a case study method as the two complement one another (Flyvbjerg 2011). Lastly, due to the lack of agreement of empirical evidence informing the process of preparation and preparedness for nursing study abroad trips, a Delphi consensus method will enhance the existing body of knowledge. 


\section{Pilot of Delphi Study}

A survey was composed that sourced demographic information from experts along with questions regarding responsibility related to study abroad trips. The working definition of preparation was turned into questions wherein experts ranked their agreement with each component (see Appendix $\mathrm{S}$ for full set of questions). In addition to the working definition, themes from the literature were included, allowing the researcher to ask the panel of experts their stance on differing styles of preparation seen in the literature. These questions were separated according to responsibility, i.e. whether the student, sending HEI, or receiving HEI was responsible for the component of preparation. For example, experts were asked to rank their agreement with the statement, 'nursing students should be responsible for their own preparation to study abroad', because this was seen in four articles in the literature review (see Chapter 2; student responsibilities). Another question under the responsibilities of the receiving institution read, 'provide appropriate preparation and orientation to students once they arrive to their study abroad location'. This question was supported by literature as well (Delpech 2013).

The Delphi was piloted to ensure the questions were clear and posed no technical difficulties. The pilot included a convenience sample of three groups of experts: students $(n=6)$, receiving organisation $(n=1)$, and sending organisations $(n=3)$. The experts were emailed a link to the Delphi survey that included an information sheet about the study. Two experts did not finish the survey, resulting in ten completed responses for the first three questions, and eight responses for the remainder of the questions. One expert reported $6-10$ years of experience, while the others had less than one year $(n=4)$ or chose 'not applicable' $(n=5)$.

The majority of questions resulted in consensus (defined as selecting 'agree' or 'strongly agree'; or similarly, 'disagree' or 'strongly disagree'), and defined consensus as $75 \%$ or more (West, Diack et al. 2015, Diamond et al. 2014, Foth et al. 2016). Apart from the two experts withdrawing from the pilot study, no questions were left unanswered. Descriptive data analysis was undertaken using SPSS version 21. Only one question asked for 
qualitative data: the final question that allowed experts to expand on the working definition of preparation by adding any component they felt was lacking. When similar statements were repeated, the similar statements were condensed into one (see Round 1 Results). The statements experts contributed were disseminated back to the panel of experts in the subsequent round to measure consensus. The questions that did not reach consensus in the Delphi pilot are discussed.

The pilot findings showed that $91 \%$ of questions reached consensus among the panel of experts. Three questions did not reach consensus, shown in Figures 17-19. Figure 19 displays that 70\% $(n=7)$ of experts felt nursing students were somewhat prepared to study abroad, two experts felt students were adequately prepared, and one expert felt students were inadequately prepared. The experts (for subsequent questions $n=8$ ) did not reach consensus on whether students should develop clinical skills related to the diseases most prevalent in the study abroad location. One quarter of the experts could not decide, while $63 \%$ agreed the skills were necessary, and the remaining disagreed that the skills were necessary (Figure 17). The last question that did not reach consensus queried managerial skills, or the ability to manage one's responsibilities with autonomy (Figure 18). Half of the experts agreed this skill should be developed, and the other half was divided between undecided and disagreeing. 
Figure 17: In your experience, how prepared are nursing students to study abroad?

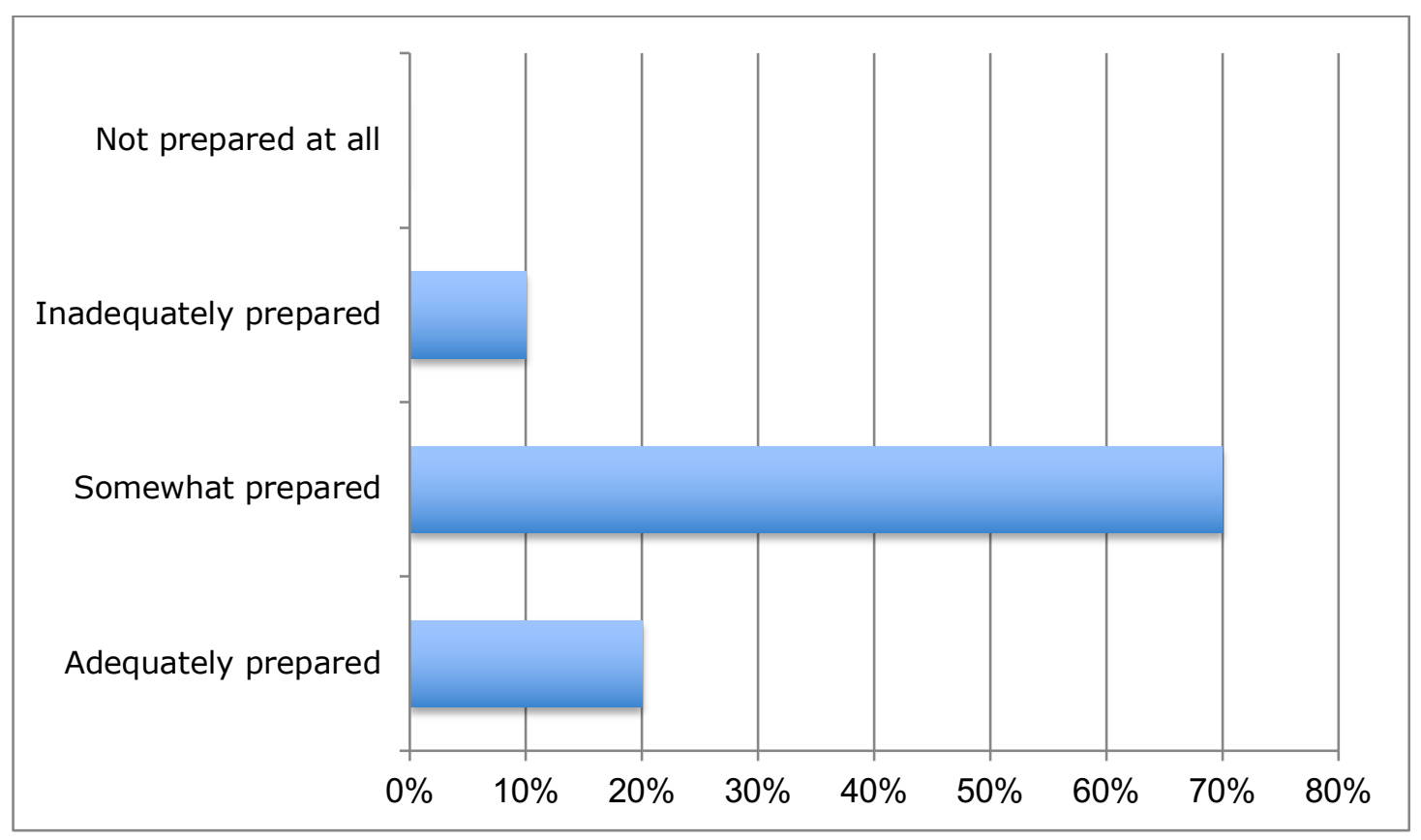

Figure 18: Preparation for nursing students to study abroad should include the development of clinical skills, especially those related to prevalent diseases in the host location

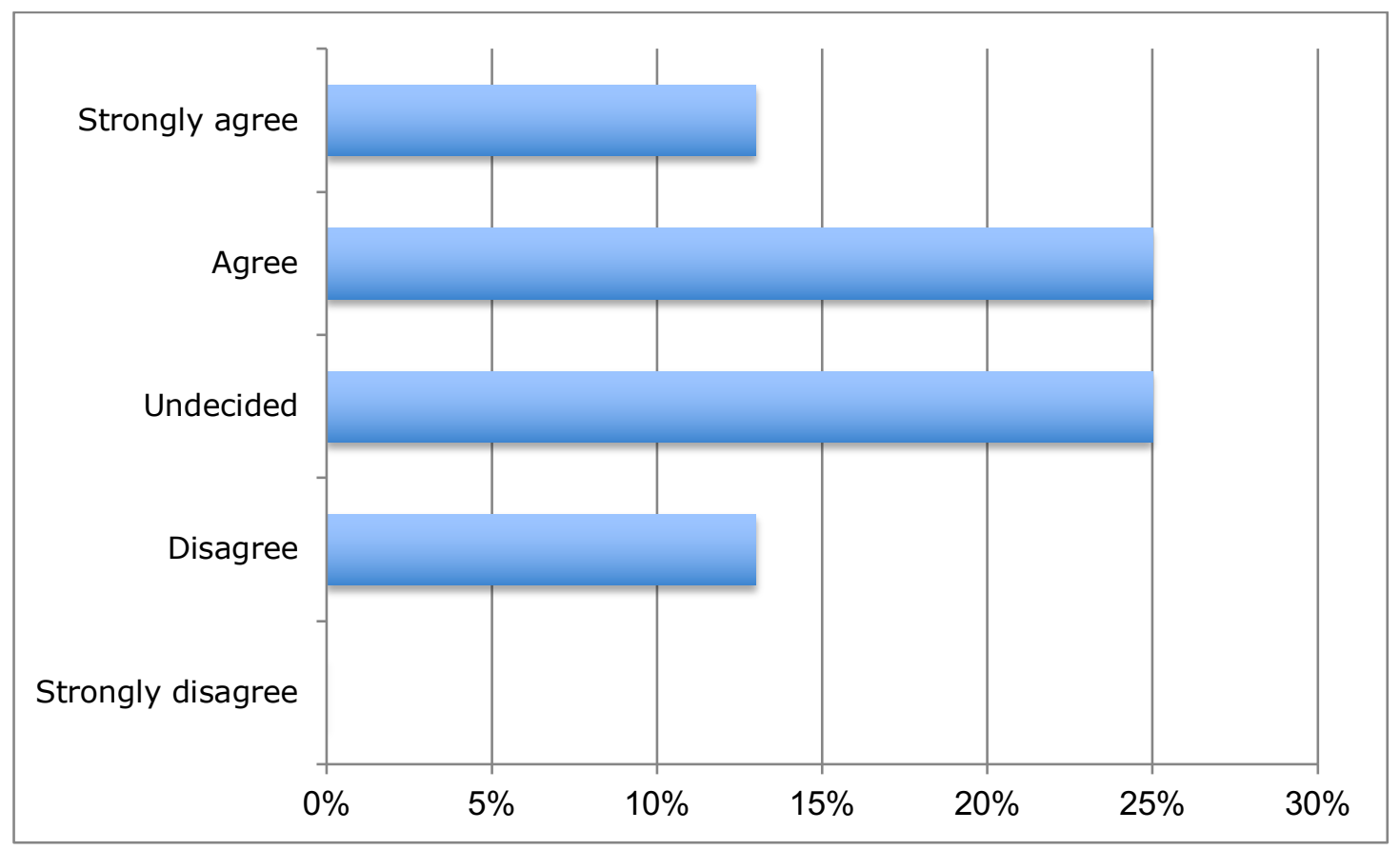


Figure 19: Preparation for nursing students to study abroad should include the development of managerial skills, or the ability to manage responsibilities with autonomy

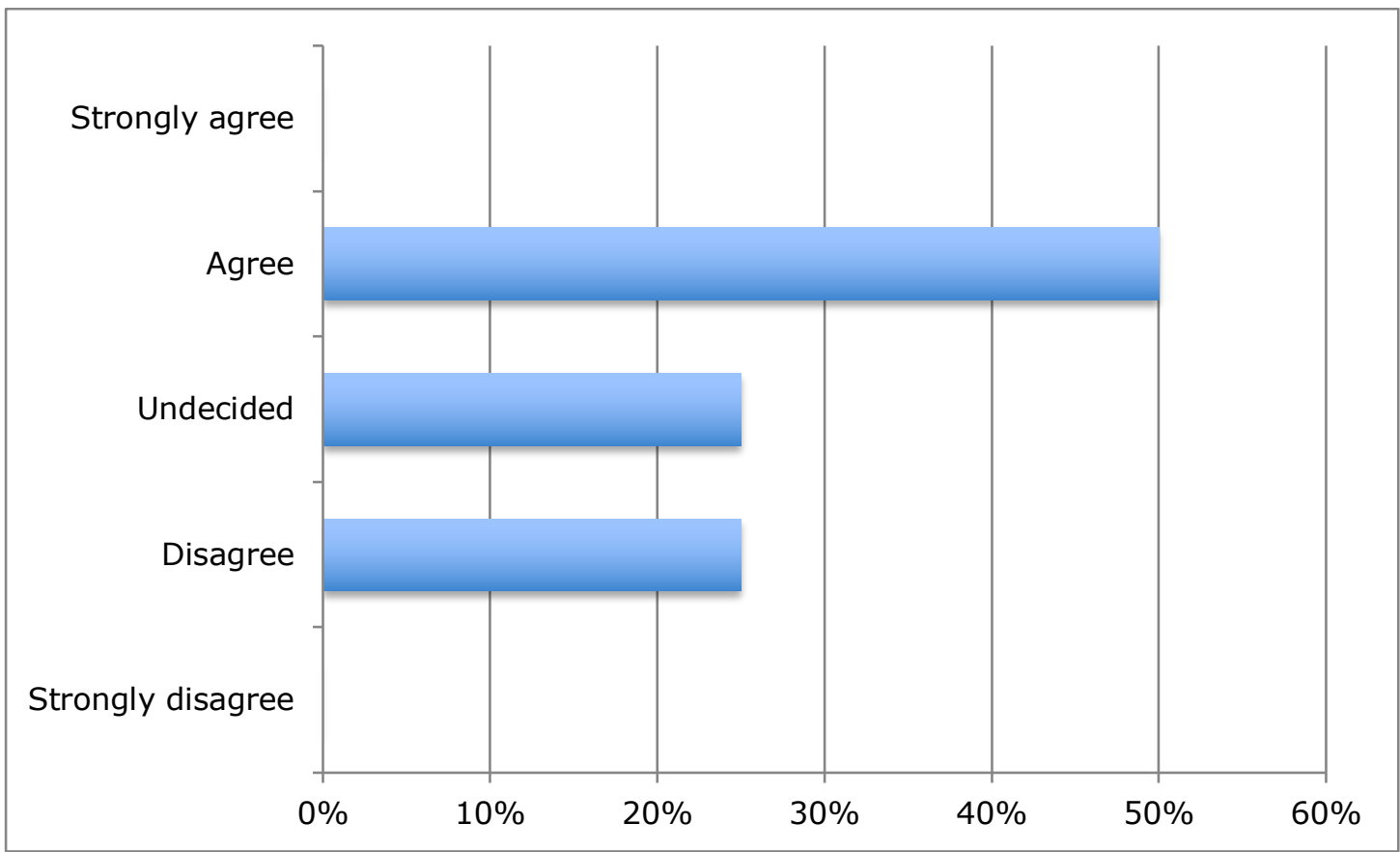

The final question of the pilot was open-ended, inviting the expert panel to specify any components they felt were lacking in the definition of preparation. No common themes emerged in their responses. To complete the pilot, experts were encouraged to provide feedback on any questions that appeared to be confusing, or other general comments to consider before conducting the formal Delphi study. One expert provided feedback that the question concerning managerial skills was not applicable to nursing students.

\section{Changes following the pilot}

One question was added to the beginning of the questionnaire, which asked for the location(s) where experts had experience with study abroad trips. This was in preparation to cross-tabulate location with level of preparedness, as the researcher was curious if location would have any effect on an expert's answers. Due to the feedback concerning the question about managerial skills, the term was redefined to 'a nursing student's ability to work autonomously, managing his or her own workload while abroad'. These were the only changes for the formal Delphi survey. 
The questions that did not reach consensus were left unchanged for the following reasons. Firstly, the pilot sample size was small and consisted of a convenience sample that had sufficient experience in nursing study abroad programmes to contribute in the pilot, but were not necessarily experts as defined below (see sampling strategy). Secondly, 91\% of the questions reached consensus among experts, and were primarily piloted to ensure trustworthiness, reliability, and to allow experts to offer feedback on clarity. Thus, analysis found the Delphi questions to be clear and supported by the experts, resulting in the questions remaining unchanged for the formal Delphi.

\section{Design}

\section{Ethical considerations}

Ethical considerations are discussed in Chapter 4 (see ethics). Nominated experts (see Selection of participants, below) were invited to join the study via email. Experts were informed they could leave the study at any time and that their completion of the Delphi questionnaire signified their consent for their quotes to be anonymised and used in the wider study and future publications. Experts were sent one reminder email per round.

\section{Sampling strategy}

A Delphi study requires 'expert' purposive sampling because it would not be appropriate to ask a randomised sample of the general nursing population questions which are specific only to those with expertise and involvement in nursing study abroad trips (Skulmoski, Hartman et al. 2007). Thus, expert purposive sampling was chosen for respondents to represent experts in the field of nursing study abroad trips (Ruemler 2016). Respondents are referred to in this chapter as 'experts'.

The requirements for an expert in this Delphi study included involvement with study abroad trips. A diverse group of individuals from different backgrounds included but was not exclusive of study abroad coordinators, faculty members, students, and receiving institution coordinators responsible for supporting students while abroad. Diversity of expert experience was suggested to ensure a robust definition of preparation 
(Parratt, Fahy et al. 2016). Experts were asked in the first questions of the Delphi to share how long they had been involved in study abroad trips, and countries they had involvement or responsibility.

In addition to the previous paragraph, general requirements for inclusion in the Delphi study adhered to Adler and Ziglio's (1996) four criteria that define 'expert' as: 1) knowledge and experience in the subject under investigation; 2) ability and choice to participate; 3) sufficient time to participate in the Delphi; and, 4) communication skills. The first criterion necessitates knowledge and experience in the subject, thus experts who did not have first-hand experience with nursing study abroad trips, or involvement in the coordination of nursing study abroad trips were excluded.

\section{Selection of participants}

Sandrey and Bulger (2008) suggest that a sample size of 5-10 per group is adequate in a heterogeneous sample. The three groups represented in this study equalled a target of $15-30$ sample size following Sandrey and Bulger's suggestion. To achieve this sample size, snowball sampling was used (van Houwelingen et al. 2016). Snowball sampling consisted of experts being asked to nominate other experts in the field in order to broaden the size and scope of the research study. The researcher asked persons responsible for overseeing study abroad trips at her university and the two European HEIs already involved in the data collection from Chapters 5 and 6 to nominate experts in the field (see Chapter 6 , Recruitment of study abroad coordinators at the receiving institution). The study abroad coordinators who had already been a source of data collection did not take part in the Delphi, but were approached only to nominate experts. This led to two willing experts. The sampling technique was widened to include two additional groups: Higher Education Statistics Agency Limited (HESA); a not-for-profit company in the United Kingdom that provides statistical data concerning study abroad trips, and the researcher's colleagues from past experiences studying abroad. HESA contributed the top ten universities that participate in nursing study abroad trips. These universities were contacted and asked for nominations of experts who fit the criteria of the Delphi study. Additionally, the researcher presented a poster at the $24^{\text {th }}$ Evidence Based 
Practice Nursing Conference in Iowa, USA. Networking with colleagues who had experience in study abroad trips led to four additional invitations to take part in the study, and subsequently led to snowballing sampling. An invitation was sent via email to all nominated persons for inclusion in the Delphi's expert panel.

\section{Data Collection}

Data collection began by creating an online survey with the assistance of technical support from the university through the software Snap Surveys. Email addresses were collected from nominated experts (see Selection of Participants) and a hyperlink was sent via email to access the survey, providing a structured, time-limited format, although the survey remained open in the first round until a desired sample size was reached. One reminder email was sent after two weeks.

The working definition of preparation (see Chapter 2, working definition of preparation) was the main component of the Delphi survey sent to the panel of experts (see Appendix $T$ for the full set of questions). The researcher selected various components informed from the literature she felt should be required learning for all nursing students studying abroad, based on her knowledge acquired throughout the doctoral study and personal experience studying abroad.

\section{Delphi Round 1}

An email was sent to nominated experts to begin the first round of the Delphi study. The expert panel expressed their opinions on each aspect of the working definition of preparation (see above) using a Likert scale. Experts were invited to add a new aspect if they felt the definition was incomplete (West et al. 2015).

For anonymity, email addresses were not tracked during the Delphi rounds. Thus, the researcher sent a reminder email to all experts approximately two weeks after the initial invitation. A completion date was not given for the first round because experts were still being recruited via snowball sampling. Snowball sampling led to the inclusion of experts from multiple countries, 
creating rich perspective from each of the desired groups (students, receiving institutions, and sending institutions). The first round of the survey remained open for five weeks until a suitable sample size of 23 was obtained.

\section{Round 1 results}

In the first round, a total of 37 experts were identified and invited to take part in the study, with 23 completed responses. Figures 18 and 19 describe the experts who agreed to take part in the Delphi. The largest group (57\%, $\mathrm{n}=13$ ) of experts defined themselves as 'professor/lecturers involved with study abroad trips'. The smallest group represented among the experts was management overseeing study abroad trips $(9 \%, n=2)$. In terms of length of experience, the largest group $(37 \% n=9)$ reported having 6-10 years of experience with study abroad trips. Involvement was widespread around the world, representing expertise that spanned Europe, North and South America, Africa, and Asia (see Figure 21, keeping in mind experts may have reported involvement in more than one location).

Figure 20: Expert roles related to study abroad trips (Experts asked to tick all that applied)

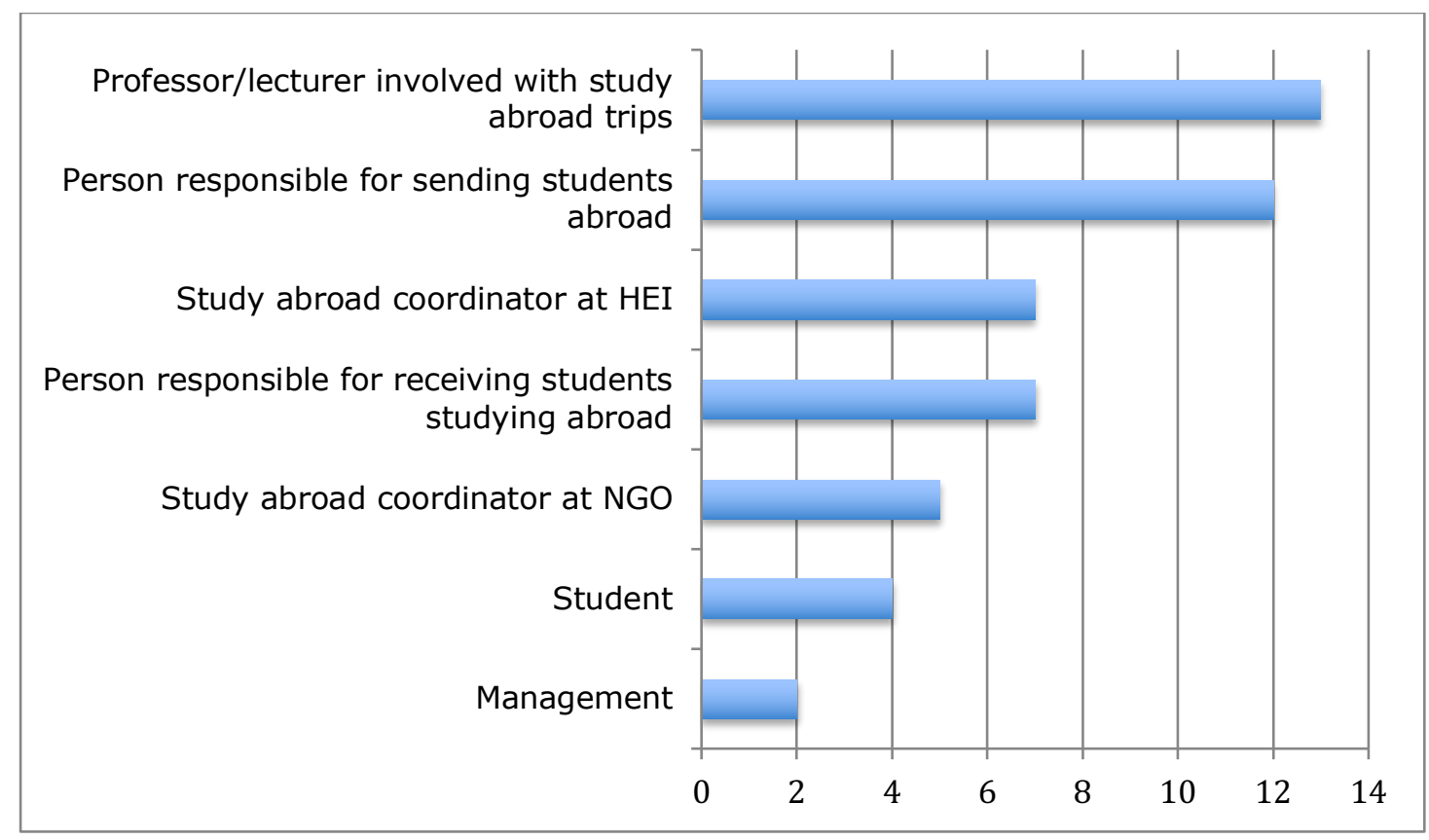


Figure 21: Location of Expertise

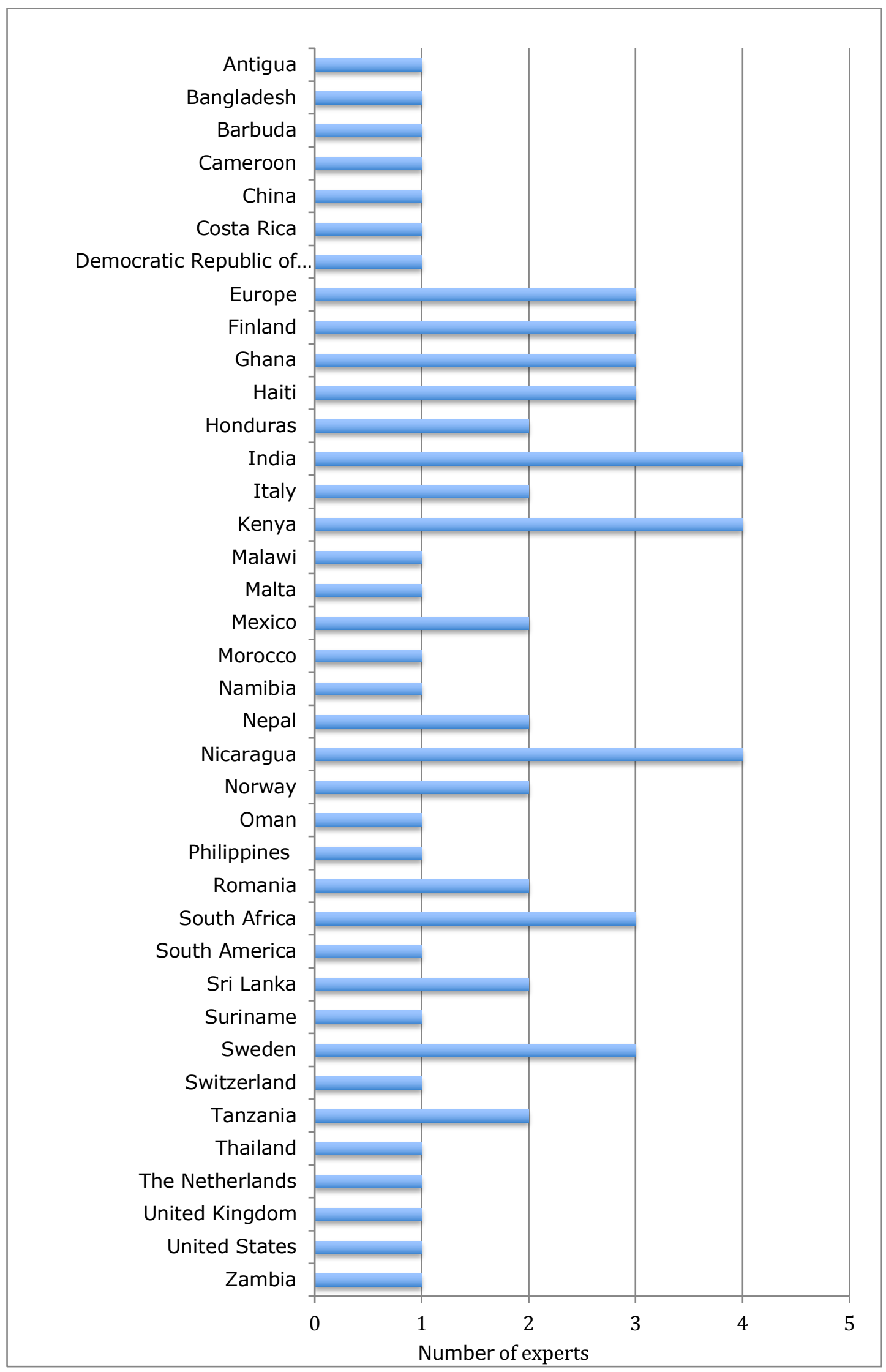


The Delphi did not ask experts to rank parts of the definition of preparation as is seen in some Delphi studies. It was not feasible to ask experts to rank multiple statements when it was likely that many components of the definition were equally important to the preparation of students. Thus, the Delphi did not utilise ranking, but rather level of agreement in the definition of preparation. A 5-point Likert scale was used, which allowed the researcher to analyse each question to find out whether it had reached consensus of $75 \%$. Most ( $84 \%$ ) of the Delphi questions reached consensus (defined as selecting 'agree' or 'strongly agree'; or similarly, 'disagree' or 'strongly disagree') of $75 \%$ or more. The following statements had $100 \%$ agreement:

1. Nursing students must acquire communication skills necessary to work in a multi-disciplinary team

2. Nursing students must provide care respecting the cultural practices in the host location

3. Nursing students must possess or acquire the reflective skills to appreciate the learning gained from studying abroad

4. Receiving institutions must confirm the students are welcome to undertake a study abroad trip to their institution

5. Receiving institutions must ensure that the roles and responsibilities allocated to students are aligned to specific needs of the local population

6. Receiving Institutions must provide appropriate preparation and orientation to students once they arrive to their study abroad location

7. Sending institutions must be responsible to prepare nursing students to study abroad

8. Sending institutions must dedicate a supporting coordinator responsible for the students to handle emergencies if they arise

9. Sending institutions must facilitate debriefing with nursing students when the study abroad is complete

10. Preparation for nursing students to study abroad should include acquisition of practical information 
11. Preparation for nursing students to study abroad should include development of communication skills, or the ability to interact with a multi-disciplinary team in the host location

12. Preparation for nursing students to study abroad should include development of cultural skills, or gaining understanding of cultural practices in the host location to best provide care within the patient's culture

13. Preparation for nursing students to study abroad should include time to reflect on the emotional reactions students may experience while abroad

The questions that did not reach consensus were included in the second round of the Delphi survey, so experts could see the group's answers as discussed in Figures 22-27. Less than half (48\%) of experts felt nursing students were adequately prepared to study abroad, and the remainder chose between 'somewhat' and 'inadequately' prepared (Figure 22). Cross tabulation revealed that the two experts who reported that students were inadequately prepared to study abroad were both responsible for sending students abroad. However, this did not reflect the views of other members in the group. The most optimistic group of experts about student preparation were those responsible for sending students abroad (58\%). Similarly, $71 \%$ of receiving coordinators felt students were adquately prepared. In terms of experience, half of the most experienced group of experts (with 11 or more years experience) reported students were only 'somewhat prepared' to study abroad. All remaining groups felt students were 'somewhat prepared' or 'inadequately prepared' more frequently than 'adequately' prepared. Figure 23 shows how prepared experts felt students were to study abroad according to their country of experience. Figure 23 did not show any relationship between wealthier or poorer countries and level of student preparedness. This supports the third theoretical statement discussed previously (see Chapter 6; Table 17, Chapter 4; Theory Development), that location of experience does not necessarily affect preparedness, and that stereotypes related to location should not affect preparation training. A wide range of countries are represented in the 
'adequately prepared' section of Figure 23. Figures 24-26 illustrate the questions that did not reach consensus.

Figure 22: In your experience, how prepared are nursing students

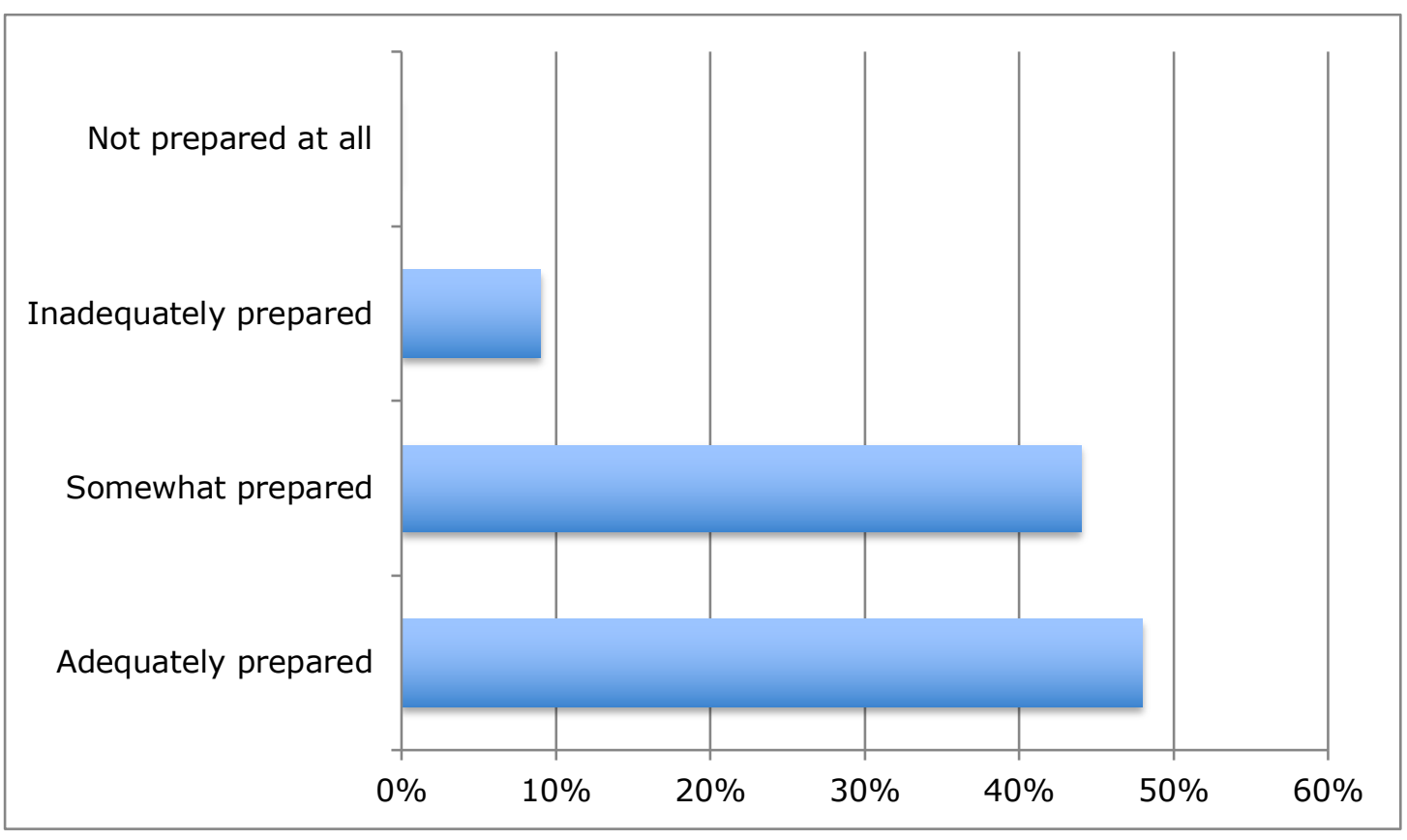


Figure 23: Student Preparation According to Location of Study Abroad Trip

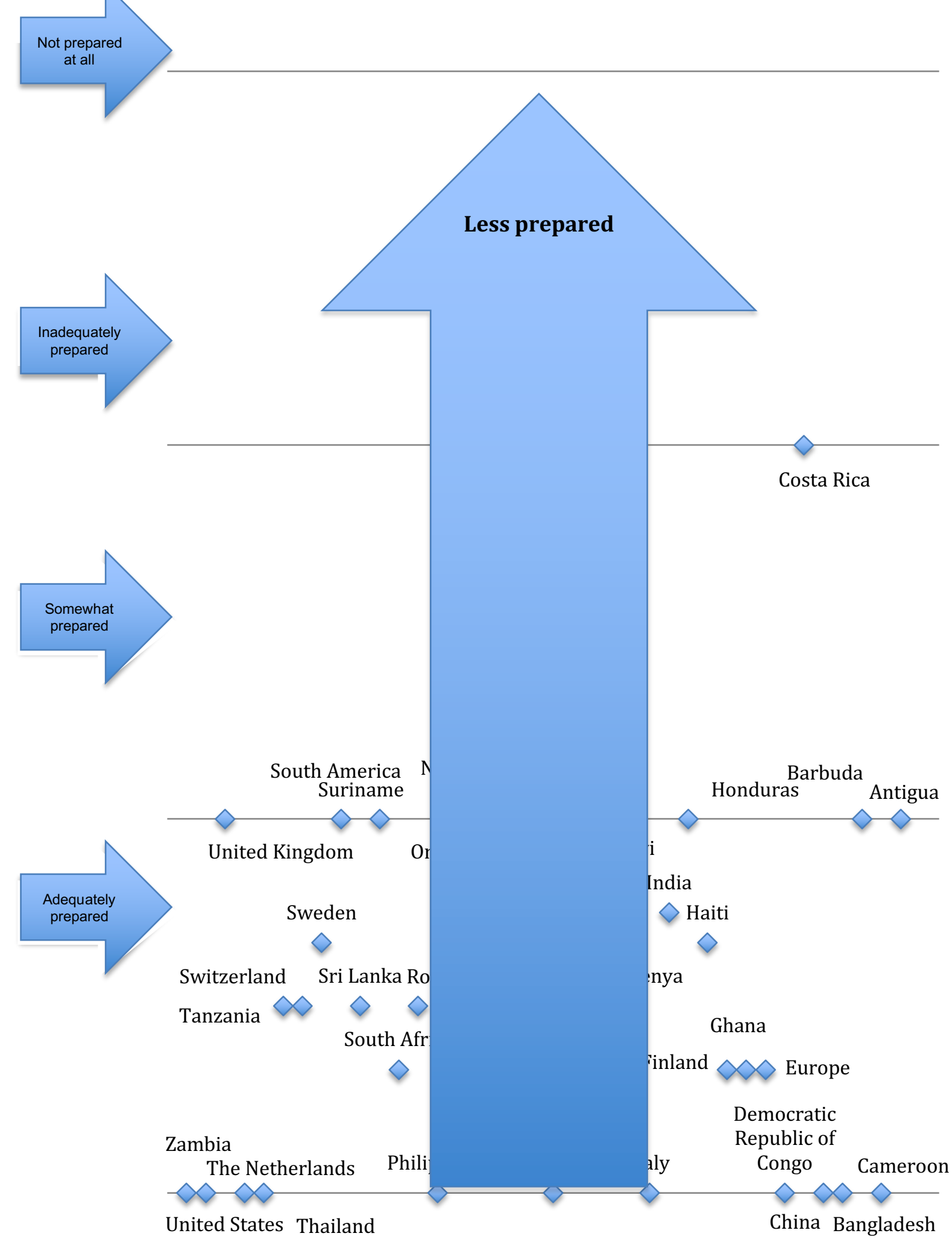


Figure 24: Nursing students preparing to study abroad should be responsible for... their own preparation to study abroad

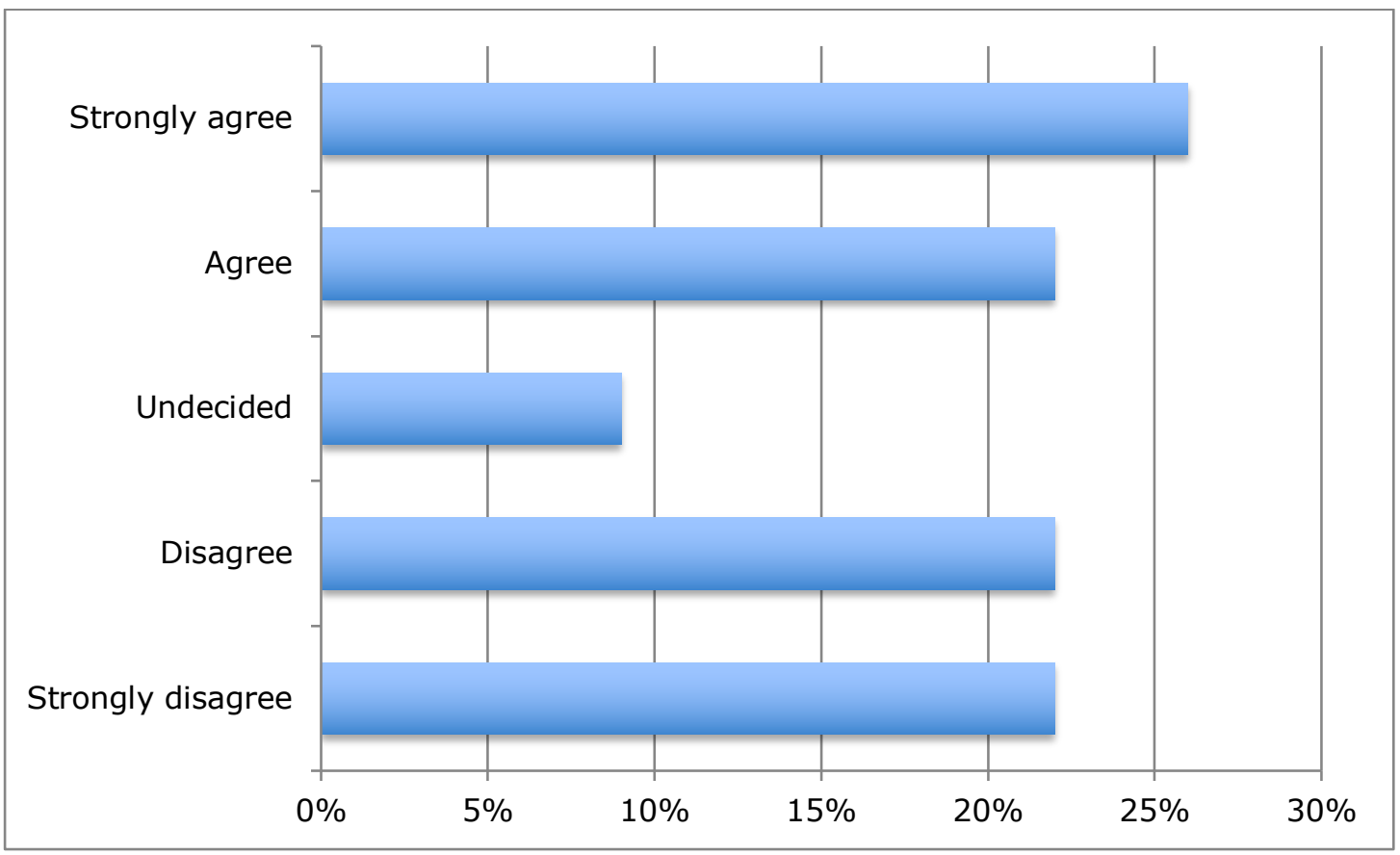

Figure 25: Nursing students preparing to study abroad do not need an overarching aim to their trip

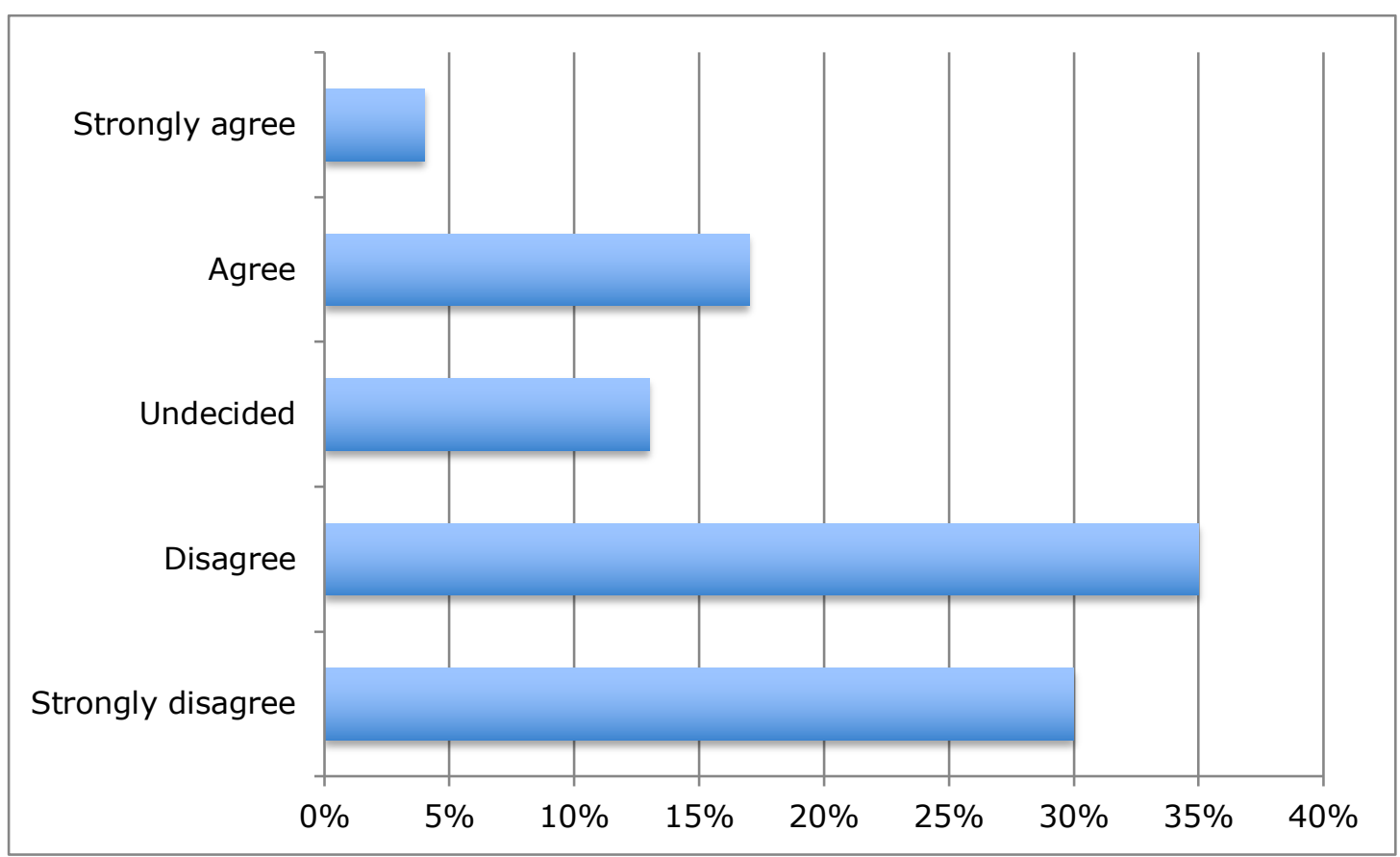


Figure 26: Preparation for nursing students to study abroad should include development of managerial skills, or the ability to manage responsibilities with autonomy

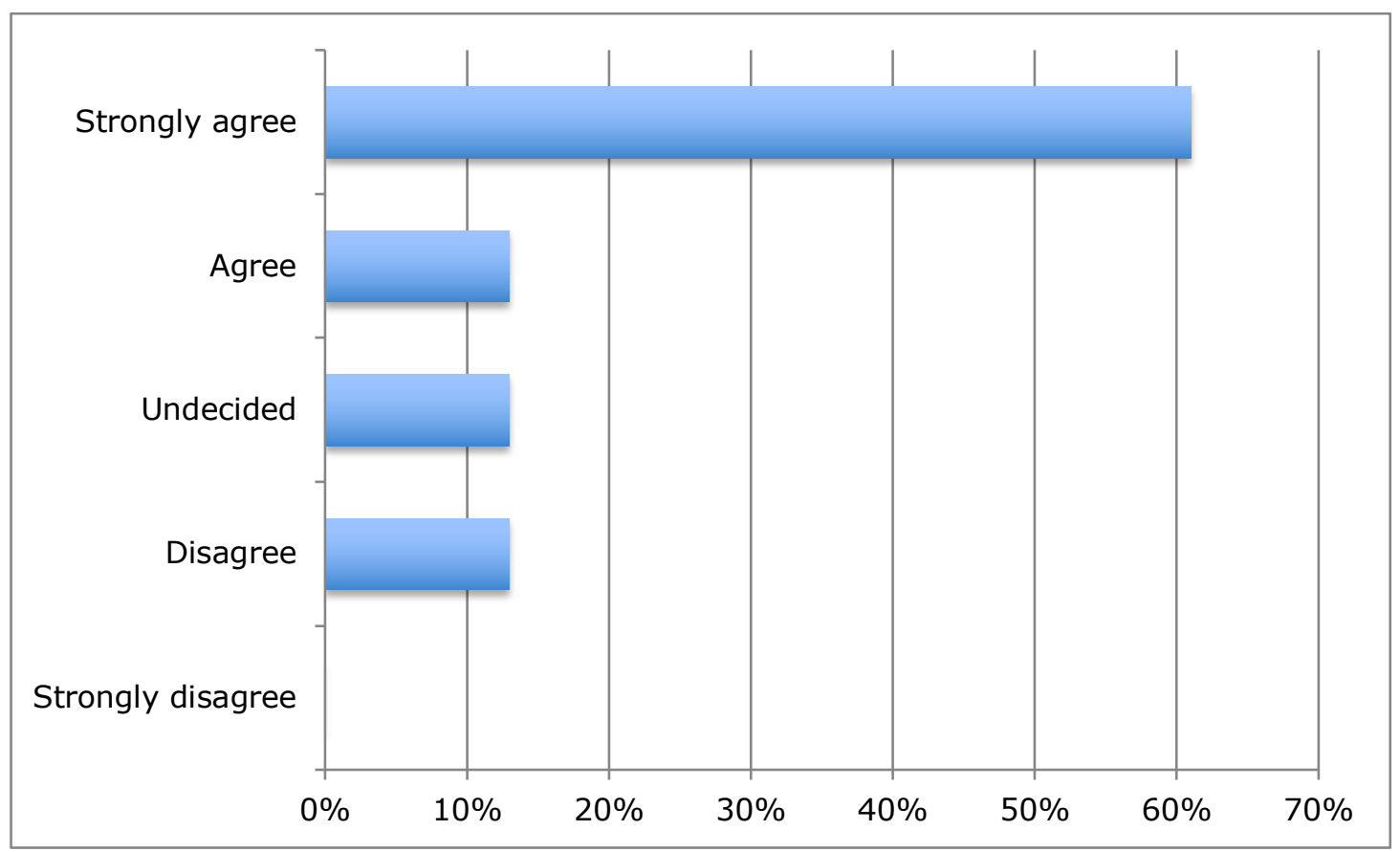

The last question of Round 1 invited experts to offer suggestions they felt should be added to the definition of preparation. Delphi studies typically do not specify the type of qualitative analysis used beyond referring to content analysis and reporting that common themes were grouped (Keeney, Hasson et al. 2006, Jacob, Duffield et al. 2017). Common themes arose in two suggested components for the definition that were grouped and made into new statements, decreasing repetitiveness. The qualitative statements offered by experts (see Figure 27). Statements showing more than one response represent repeated ideas that were grouped into one statement. The new statements that were suggested in the first round were added to the second round of the Delphi. Table 18 shows measures of central tendency for all experts on the Likert scale, with standard deviation (SD) in parentheses. The question with greatest deviation inquired as to whether students ought to be responsible for their own preparation. 
Figure 27: Please specify any further areas you believe nursing students should be prepared to study abroad

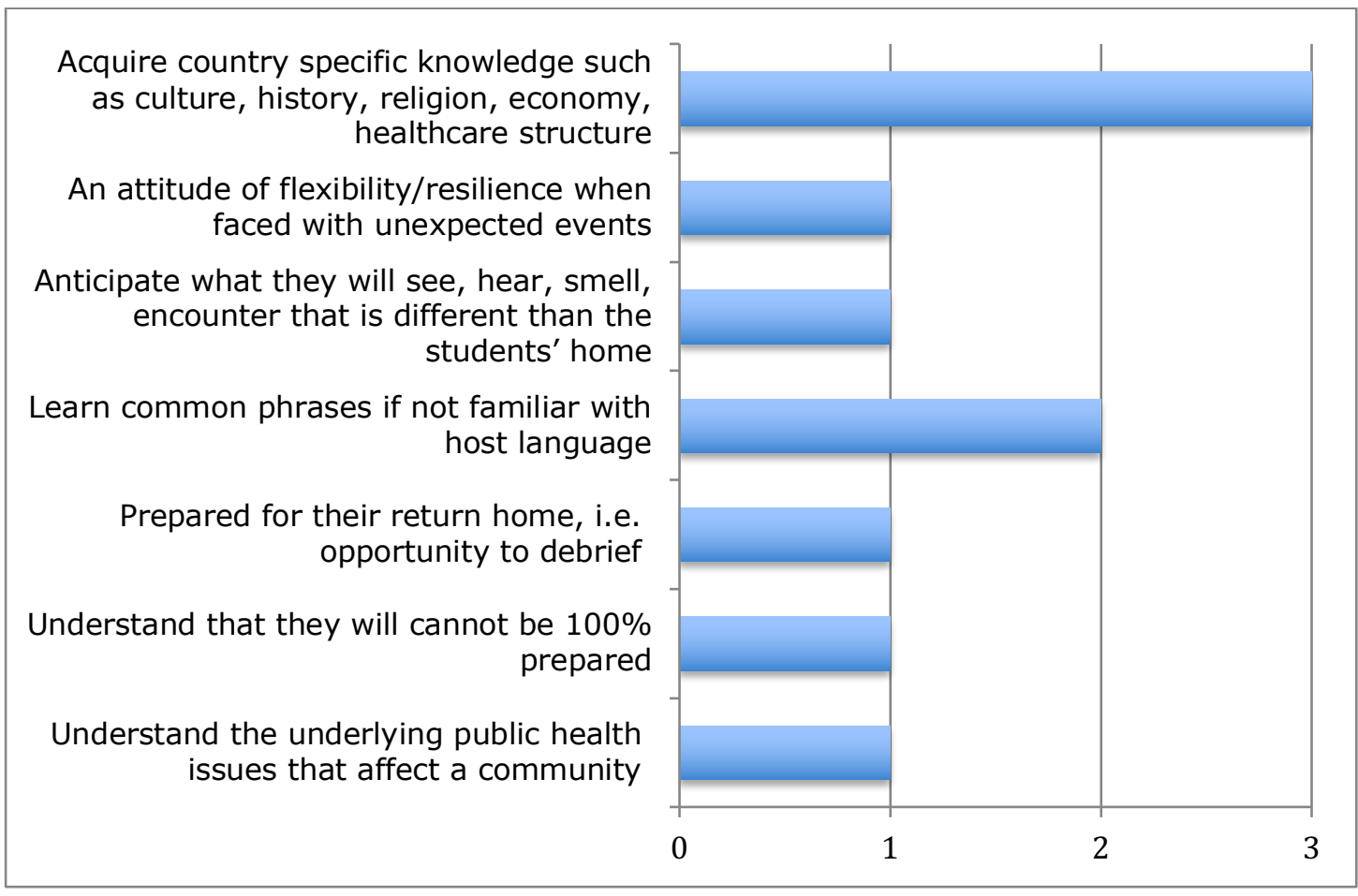

Table 18: Measures of Central Tendency

\begin{tabular}{|l|l|}
\hline Component of Definition & Mean (SD) \\
\hline How prepared & $1.61(0.66)$ \\
\hline Told what to bring & $1.48(0.73)$ \\
\hline Learning contract $\wedge$ & $1.41(0.59)$ \\
\hline Clinical skills & $1.48(0.59)$ \\
\hline Improving study abroad & $1.78(0.74)$ \\
\hline Communication skills & $1.44(0.51)$ \\
\hline Culture care & $1.22(0.42)$ \\
\hline Reflective skills $\wedge$ & $1.23(0.43)$ \\
\hline Overarching aim & $3.70(1.22)$ \\
\hline Do not need preparation & $4.61(1.03)$ \\
\hline Responsible for their own preparation & $3.04(1.52)$ \\
\hline Confirm students are welcome & $1.39(0.50)$ \\
\hline Roles and responsibilities & $1.30(0.47)$ \\
\hline Provide appropriate preparation & $1.26(0.45)$ \\
\hline Responsible to prepare & $1.30(0.47)$ \\
\hline
\end{tabular}




\begin{tabular}{|l|l|}
\hline Component of Definition & Mean (SD) \\
\hline Mission & $1.61(0.78)$ \\
\hline Supporting coordinator & $1.09(0.29)$ \\
\hline Facilitate debrief & $1.26(0.45)$ \\
\hline Practical info $\wedge$ & $1.50(0.51)$ \\
\hline Teaching focused on future & $1.74(0.75)$ \\
\hline Develop clinical skills & $1.83(0.72)$ \\
\hline Develop managerial skills & $2.26(0.86)$ \\
\hline Communication skills $\wedge$ & $1.50(0.51$ \\
\hline Cultural skills $\wedge$ & $1.27(0.46)$ \\
\hline Time to reflect & $1.17(0.39)$ \\
\hline$\wedge$ Denotes questions with one missing value; $n=22$
\end{tabular}

\section{Delphi Round 2}

Opinions from the first round were disseminated back to the panel of experts with the second round questions. Experts were asked to answer questions that did not reach consensus again, this time following a graph of responses from the first round (see Appendix $U$ ). This provided an opportunity for experts to answer the questions again in light of the rest of the panel's responses. For brevity and due to 13 of the 24 questions having $100 \%$ agreement among experts, questions that reached consensus were not asked a second time.

The second round of Delphi questions were sent to all Delphi experts, including those that responded only in the second round, having missed the cut off date for the first round. This did not pose a limitation because all experts invited to be in the study represented a panel of heterogeneous expertise. Further, no correlations were drawn between individual responses changing in subsequent rounds. Therefore all experts received invitations to each Delphi round.

Similarly, expert attrition was expected throughout each subsequent Delphi round (West et al. 2015, Parratt et al. 2016, van Houwelingen et al. 2016) posing a possibility for change in the expert panel. Attrition occurred in part because the second round of the Delphi study coincided with summer 
holidays for many of the experts. Due to an unexpectedly low number of experts completing the second round of the Delphi, an additional two weeks was factored in and a reminder email was sent which facilitated the achievement of a higher completion of the second round. The second round remained open for five weeks, longer than expected, to achieve 20 responses ( $87 \%$ response of the first round).

\section{Round 2 results}

The Delphi reached consensus in the second round. An interesting shift occurred in how prepared experts felt nursing students were to study abroad (Figure 28) from the first round of the Delphi. Figure 27 shows the results of the only question that did not reach consensus. 
Figure 28: In your experience, how prepared are nursing students to study abroad?

Round 1

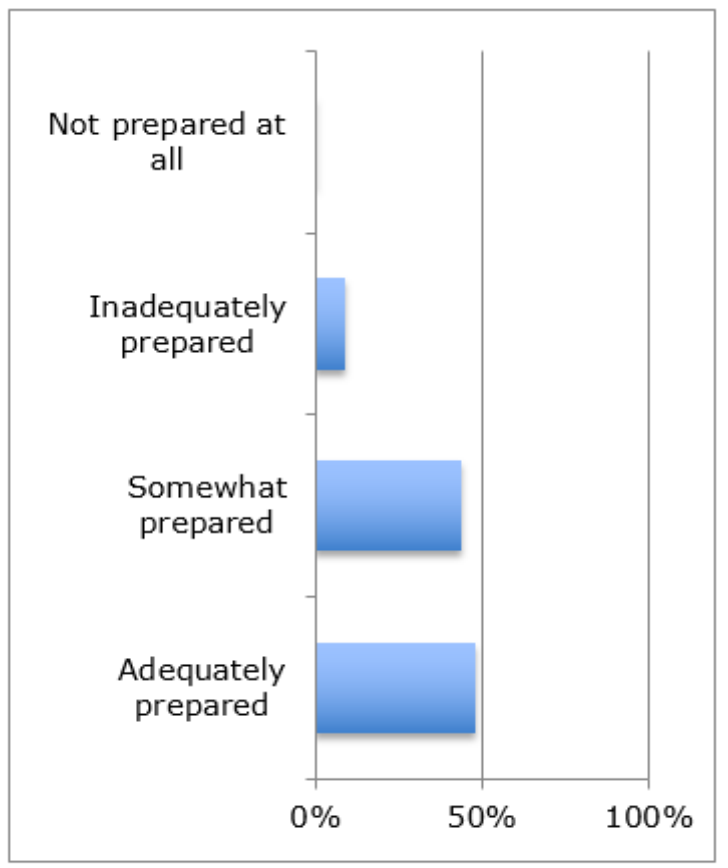

Round 1

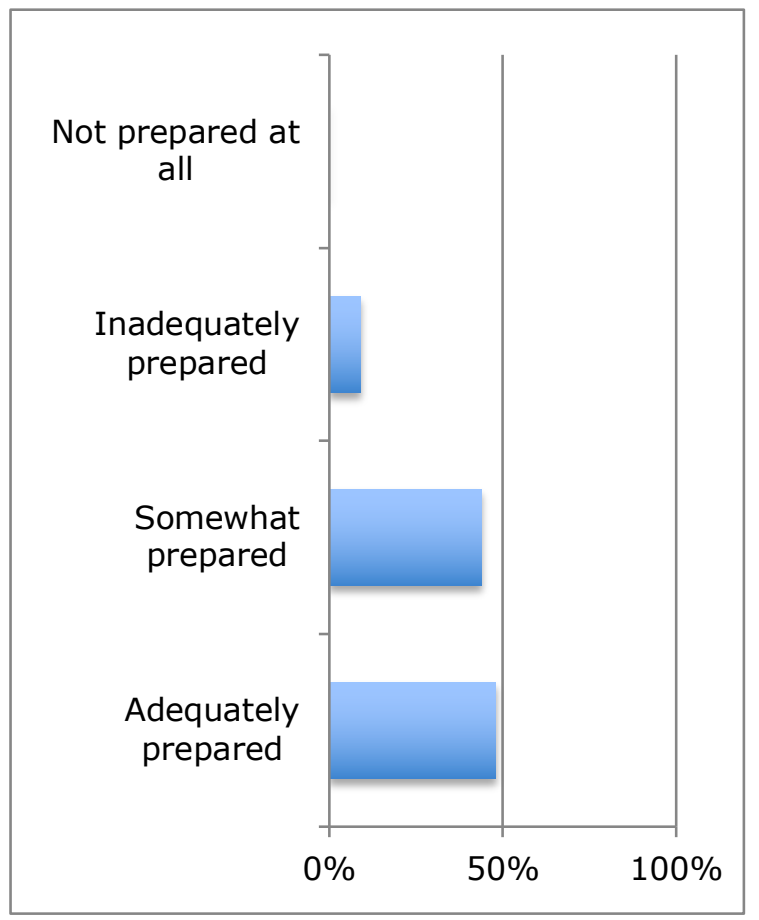

Round 2

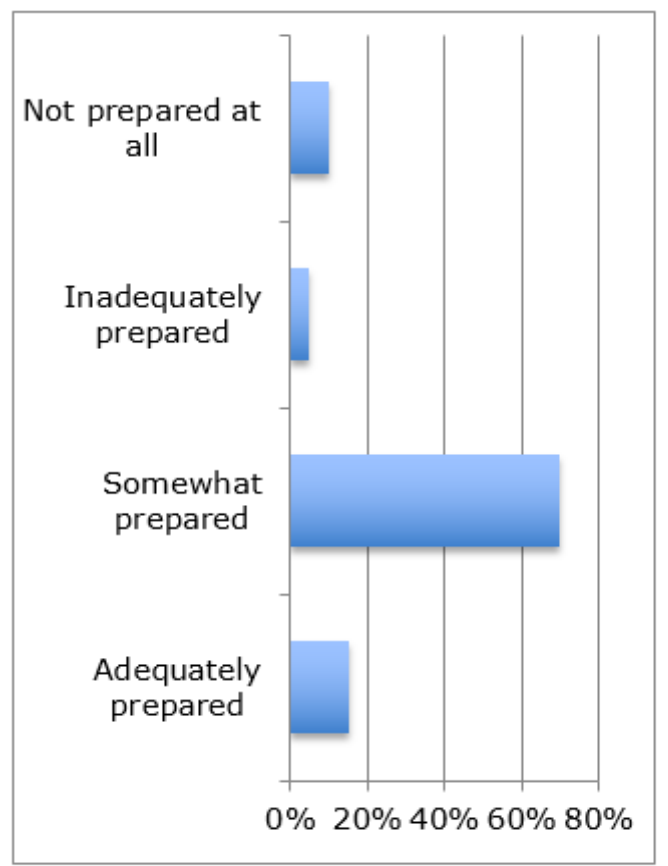

Round 2

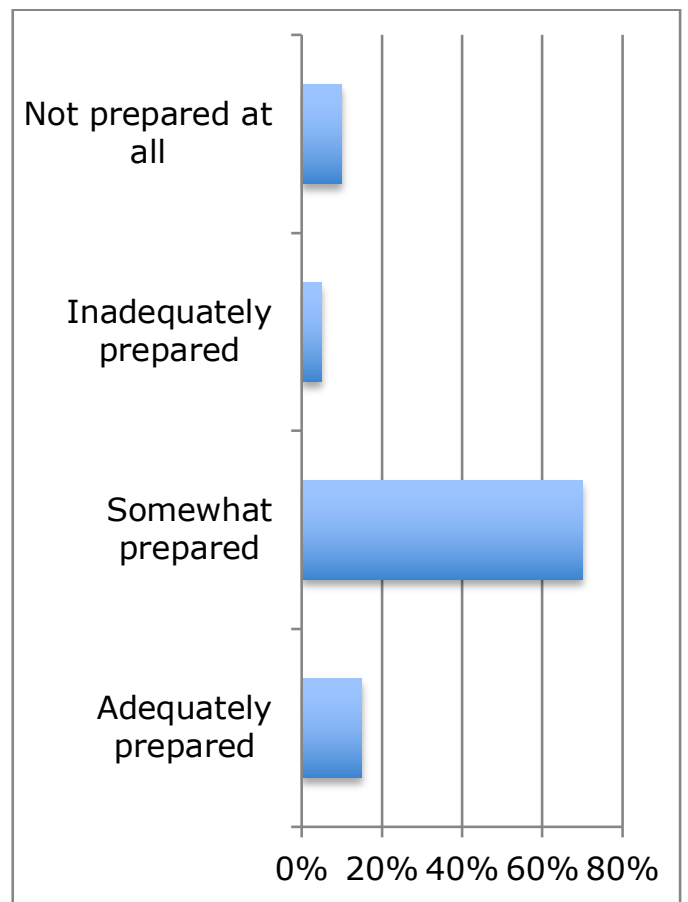

It is important to note the expert's opinions on students' level of preparedness before studying abroad. The question 'how prepared are nursing students to study abroad?' shifted in the second round of the Delphi. 
The choices ranged from pessimistic (not prepared at all) to the most optimistic choice that was still arguably indifferent (adequately prepared). Lacking an optimistic choice such as 'well prepared', the most optimistic choice still received less than half of the expert panel's vote.

The bias of social desirability may have contributed to the shift seen from the first to the second round of the Delphi. In the first round, this was one of the questions asked of experts who were involved, with ensuring students have a successful experience abroad. It is unlikely that an expert in a role related to study abroad trips would immediately choose a pessimistic view of how prepared their students are to study abroad. In fact, they would be wise to affirm the students to be well prepared. Yet after completing the remainder of the questionnaire, having read specific ways a student ought to be prepared according to various literature, it is possible that the experts began to feel that students were not so prepared after all. An alternative to the bias of social desirability is acquiescence response bias, or the tendency to simply agree with a question (Tonna, McCaig et al. 2014). Acquiescence would cause experts to rate students as more prepared in the first instance, while still accounting for the change to a less prepared response over time when given the opportunity for further reflection in the second round. The researcher suggests that the experts were ready, upon receiving the second round of the Delphi survey, to report that in fact their students were less prepared than previously reported. Further, while no experts chose 'not prepared at all' in the first round, $10 \%$ of experts selected this choice in the second round. The rise in 'somewhat prepared' in the second round is interpreted as a true representation of the perceptions of the experts as to the preparedness of students. This is evidenced by nearly half $(48 \%)$ of the experts reporting students were 'adequately prepared' in the first round, to the majority (70\%) selecting 'somewhat prepared' in the second round. The Delphi pilot had less risk for social desirability, and interestingly had the same finding for 'somewhat prepared' as the experts in the second round (see Figure 28). 
Figure 29: Nursing students preparing to study abroad should be responsible for their own preparation to study abroad

Round 1

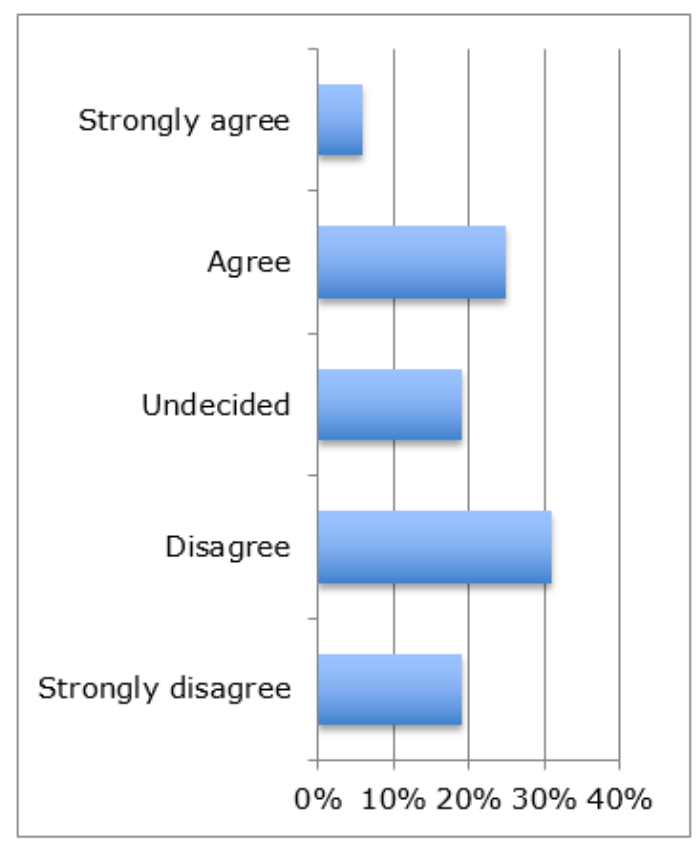

Round 2

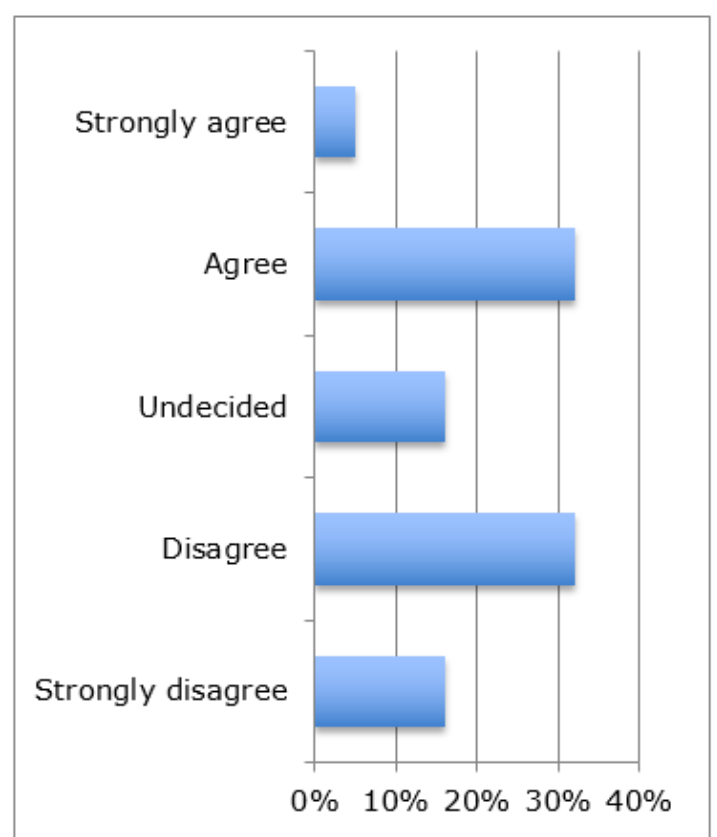


In Figure 29, there is little change between the first and second round regarding whether students should be responsible for their own preparation. Experts increased their agreement in the second round, but remained largely divided on the issue. Ultimately this question represented a component that was not included in the definition of preparation for the following reasons. Firstly, a small number of articles suggest students carry the responsibility of preparing themselves (see Chapter 2, student responsibilities). Secondly, the first round received $100 \%$ consensus on questions that placed responsibility for preparing students on the sending institutions and receiving institutions. Thus this question represents the shared responsibility required to prepare nursing students to study abroad, and the statement was removed from the definition of preparation.

\section{Analysis}

The Delphi rounds were analysed using mixed methods. Analysis of Likert scale questions, consensus, and descriptive data analysis using SPSS was identical to the methods discussed in the pilot (see Pilot of Delphi Study). Most questions were Likert five-point scale questions, analysed with statistical measurements of central tendency (including mean, median, and mode) and level of dispersion (standard deviation and interquartile range) (Hsu, Sandford 2007) (see Table 18 for mean and standard deviation). The final question which allowed experts to submit qualitative data was analysed as in the pilot: similar statements were condensed into one statement and disseminated back to the panel of experts in the subsequent round to measure consensus.

\section{Findings}

The panel of experts achieved a minimum consensus of $75 \%$ on a definition in the second round. The new and validated definition of preparation was separated to allocate responsibilities to relevant parties and specifies content that should be included. The revised definition based on the findings is below. 


\section{Definition of preparation}

Nursing students preparing to study abroad must...

1. Be told what to bring on their study abroad trip

2. Create a learning contract including educational expectations of the trip

3. Familiarise themselves with clinical skills related to prevalent diseases in the host location

4. Acquire country specific knowledge such as culture, history, religion, economy and healthcare

5. Identify ways of improving the study abroad experience for future students

6. Acquire communication skills necessary to work in a multi-disciplinary team

7. Provide care respecting the cultural practices in the host location

8. Learn common phrases to communicate basic needs if they are unfamiliar with the host country language

9. Understand the underlying public health issues (such as contaminated water, poverty, or poor hygiene) that affect a community

10. Possess or acquire the reflective skills to appreciate the learning gained from studying abroad

11. Anticipate what they will see, hear, smell and encounter that is different from their home country

12. Expect unforeseen circumstances to arise, requiring an attitude of flexibility/resilience

13.Understand they will not be $100 \%$ prepared

Receiving institutions must...

14. Confirm the students are welcome to undertake a study abroad trip to their institution

15. Ensure that the roles and responsibilities allocated to students are aligned to specific needs of the local population

16. Provide appropriate preparation and orientation to students once they arrive to their study abroad location 
Sending institutions must...

17. Be responsible to prepare nursing students to study abroad, including a delineation of approved scope of practice

18. Create a mission statement denoting the goals of the trip

19. Dedicate a supporting coordinator responsible for the students to handle emergencies if they arise

20. Facilitate debriefing with nursing students when the study abroad trip is complete, including ethical response to significant events (i.e. malpractice)

Preparation training for nursing students to study abroad should include...

21. Acquisition of practical information

22. Training that is focused on the study abroad trip and the students' future career as a nurse

23. Development of managerial skills, or the ability to manage responsibilities with autonomy

24. Development of communication skills, or the ability to interact with a multi-disciplinary team in the host location

25. Development of cultural skills, or gaining understanding of cultural practices in the host location to best provide care within the patient's culture

26. Time to reflect on the emotional reactions students may experience while abroad

27. Preparation for the return home with opportunity to debrief about their experiences whilst on the trip 


\section{Analytical Framework}

The findings from the Delphi produced a validated definition of preparation, which upon dissemination has the ability to inform best practice for nursing students preparing to study abroad. The consensus definition informed an analytical framework to analyse preparation at other HEIs (see Table 19). While preparation cannot encompass every possibility of harm or predict each student experience, the following framework is presented below.

Table 19: Analytical Framework for Nursing Student Preparation

Nursing students preparing to study abroad must...

Done Partial Not

\begin{tabular}{|l|c|c|c|}
\hline Understand what to bring & & $\mathrm{x}$ & \\
\hline Create a learning contract & & $\mathrm{x}$ & \\
\hline $\begin{array}{l}\text { Familiarise themselves with clinical skills } \\
\text { related to host location }\end{array}$ & & $\mathrm{x}$ & \\
\hline Acquire country specific knowledge & & $\mathrm{x}$ \\
\hline $\begin{array}{l}\text { Identify ways of improving the study } \\
\text { abroad experience }\end{array}$ & & & $\mathrm{x}$ \\
\hline $\begin{array}{l}\text { Acquire communication skills necessary to } \\
\text { study abroad }\end{array}$ & & $\mathrm{x}$ & \\
\hline Provide care respectful of local culture & & $\mathrm{x}$ \\
\hline Learn common phrases in local language & & $\mathrm{x}$ & \\
\hline $\begin{array}{l}\text { Understand underlying public health issues } \\
\text { in host location }\end{array}$ & & & $\mathrm{x}$ \\
\hline Possess reflective skills & & $\mathrm{x}$ \\
\hline Anticipate what would occur while abroad & & & \\
\hline Expect unforeseen circumstances & & & \\
\hline Understand preparation cannot be absolute & & & \\
\hline
\end{tabular}


Receiving institutions must...

\begin{tabular}{|c|c|c|c|}
\hline & Done & Partial & $\begin{array}{l}\text { Not } \\
\text { done }\end{array}$ \\
\hline Confirm the students are welcome & $x$ & & \\
\hline $\begin{array}{l}\text { Ensure that student roles and } \\
\text { responsibilities are clear }\end{array}$ & & $x$ & \\
\hline Provide orientation to students upon arrival & & & $x$ \\
\hline
\end{tabular}

Sending institutions must...

\begin{tabular}{|l|l|l|c|}
\hline \multicolumn{2}{l}{ Done } & Partial & \multicolumn{1}{c|}{$\begin{array}{c}\text { Not } \\
\text { done }\end{array}$} \\
$\begin{array}{l}\text { Take responsibility to prepare nursing } \\
\text { students, including a delineation of }\end{array}$ & & \\
\hline $\begin{array}{l}\text { Create a mission statement denoting the } \\
\text { goals of the trip }\end{array}$ & & & $\mathrm{X}$ \\
\hline $\begin{array}{l}\text { Dedicate a supporting coordinator } \\
\text { Facilitate debriefing, including ethical } \\
\text { response to significant events (i.e. }\end{array}$ & & & \\
malpractice) & & & $\mathrm{X}$ \\
\hline
\end{tabular}

Preparation training for nursing students to study abroad should include...

\begin{tabular}{|l|c|c|c|}
\hline \multicolumn{2}{l}{ Done } & Partial & \multicolumn{1}{c|}{$\begin{array}{c}\text { dot } \\
\text { Acquisition of practical information }\end{array}$} \\
\hline $\begin{array}{l}\text { Training that is focused on the study } \\
\text { abroad and the students' future nursing } \\
\text { career }\end{array}$ & & & $\mathrm{x}$ \\
\hline Development of managerial skills & & & \\
\hline Development of communication skills & & & $\mathrm{x}$ \\
\hline Development of cultural skills & & $\mathrm{x}$ & \\
\hline Time to reflect on emotional reactions & & & $\mathrm{x}$ \\
\hline Opportunity to debrief & & & $\mathrm{x}$ \\
\hline
\end{tabular}

The analytical framework includes the definition of preparation components, followed by columns that present whether each component of preparation was done, done partially, or not done at all. To validate the new analytical framework, 
and to show its usefulness to nursing researchers, data from the reflexive interview transcripts (Chapter 3) were placed into the framework. This allows study abroad coordinators to guide preparation according to the analytical framework, and identify gaps in preparation by scanning the columns, which easily display what is lacking.

In Chapter 3, the researcher underwent a reflexive interview in which she answered questions regarding a past study abroad trip. She is referred to as the participant. The interview transcripts were analysed using the new analytical framework to determine the preparation skills the expert received prior to her study abroad trip. The first section of Table 19 shows that none of the components of the analytical framework were followed for the participant. Preparation was followed only partially in $46 \%$ of the suggested components. The interview transcript quotes the participant as stating 'I was given kind of a loose list of things I should have' yet the list was not exhaustive, and rather confined to culturally appropriate clothing. The participant referred to anti-parasitic medication, which she learned would be a common treatment in her preparation training. She did not receive information about other common diseases and thus the component regarding what to bring on the study abroad trip was ticked as only partially complete. Country-specific knowledge was seen as partially complete, which seemed to overlap with general knowledge of the study abroad location. The participant reported wearing culturally appropriate clothing and heard a short description of the religion, resulting in a partially complete for the component inquiring as to whether care was respectful of culture. The participant also seemed to have a basic understanding of public health needs such as poverty, hygiene, and food and water insecurity. The participant possessed reflective skills, but these were acquired personally; not a skill that was cultivated in training. The remaining components were not covered.

The section that allocated responsibility according to receiving institutions was analysed next. The receiving institution answers were divided equally: one component was followed, which required confirmation that students were welcome at the receiving institution. The partially completed component stated that student roles must be clear. The responsibilities of the students may have been clear to the study abroad coordinator unbeknownst to the participant, who 
was largely unaware of her responsibilities upon arrival to the study abroad site. The last component requiring students receiving orientation upon arrival to their new work environment was not followed.

The sending institution also had answers in all three columns. A supporting coordinator was assigned by the sending institution, however the participant did not have internet access or an international mobile telephone that would have enabled communication with the coordinator had there been an emergency. Still, the sending institution did allocate a coordinator not foreseeing this lack of local infrastructure while students were abroad, and thus was analysed as a completed component of preparation. Preparation was provided by the sending institution, but upon revisiting the data from the reflexive interview, was deemed 'partial' in this analysis due to the brevity of time spent and the participant's multiple references of the unknown during her interview. A mission statement was not created in preparation for the study abroad trip; nor a time scheduled for debriefing.

According to the suggestions from the new analytical framework, content of the preparation training was found to be lacking. Only two of the seven components were partially included in the participant's preparation - acquisition of practical information, and development of cultural skills. The participant understood there was a dress code to follow related to cultural norms in the study abroad location. The participant also received a brief description of the local religion, weather, and nature of the location where she would provide care. The remaining five components were not covered in preparation training.

The analysis in Chapter 3 found that the participant was inadequately prepared for her study abroad trip. However, this information was arbitrary and difficult to discuss prior to the creation of a definition of preparation. It was too simplistic to say the participant was unprepared. The analytical framework provided a measurable tool with evidence of what was lacking, informed by a validated definition of what preparation should include. 
Table 20: Analysis by Theme and Data Source

\begin{tabular}{|c|c|c|c|c|c|c|}
\hline & Pre-interviews & Diaries & Blogs & Post-interviews & Literature review & Delphi \\
\hline Preparation & $\mathrm{x}$ & $x$ & & x (preparedness) & $\mathrm{x}$ & $\mathrm{x}$ \\
\hline $\begin{array}{l}\text { Theoretical foundation/ underpinning/ } \\
\text { support }\end{array}$ & $\mathrm{x}$ & & & & $x$ & \\
\hline Student retention of preparation & $\mathrm{x}$ & & & & & \\
\hline Enthusiastic and indifferent students & $\mathrm{x}$ & & & & $x$ & \\
\hline Informed students & $\mathrm{x}$ & & & & & $x$ \\
\hline Introspective students & $\mathrm{x}$ & & & & & \\
\hline Forward planning & $\mathrm{x}$ & & & & & \\
\hline Responsibilities & $\mathrm{x}$ & & & & $x$ & $\mathrm{x}$ \\
\hline Struggles and conflict & & $x$ & $x$ & & & \\
\hline Expectations & & $\mathrm{x}$ & & & & $\mathrm{x}$ \\
\hline $\begin{array}{l}\text { Communication with receiving } \\
\text { institution }\end{array}$ & & $\mathrm{x}$ & & $x$ & $\mathrm{x}$ & $\mathrm{x}$ \\
\hline Emotions and support systems & & $x$ & & & & $\mathrm{x}$ \\
\hline Observations and comparisons to home & & $\mathrm{x}$ & & & & \\
\hline New experiences & & & $\mathrm{x}$ & & & \\
\hline Reflections & & & $\mathrm{x}$ & & & $\mathrm{x}$ \\
\hline Risk-taking and adventures & & & $\mathrm{x}$ & $\mathrm{x}$ & $\mathrm{x}$ & \\
\hline Study abroad & & & $\mathrm{x}$ & $\mathrm{x}$ & $\mathrm{x}$ & \\
\hline Transition home & & & & $\mathrm{x}$ & & $\mathrm{x}$ \\
\hline Benefits & & & & $\mathrm{x}$ & $\mathrm{x}$ & \\
\hline Impressions & & & & $x$ & & \\
\hline Recommendations & & & & $\mathrm{x}$ & & $\mathrm{x}$ \\
\hline$*(11)$ Culture of host location & & & & & $\mathrm{x}$ & $\mathrm{x}$ \\
\hline $\begin{array}{l}\text { (9) Underpinned by theory ( } 9 \text { different } \\
\text { theories) }\end{array}$ & & & & & $\mathrm{x}$ & \\
\hline $\begin{array}{l}\text { (8) Individual or group health-teaching } \\
\text { project to be presented in host location }\end{array}$ & & & & & $\mathrm{x}$ & \\
\hline (5) Students learn language skills & & & & & $\mathrm{x}$ & $\mathrm{x}$ \\
\hline (5) Health problems in host location & & & & & $\mathrm{x}$ & $\mathrm{x}$ \\
\hline (5) Nursing/Healthcare in host location & & & & & $\mathrm{x}$ & $\mathrm{x}$ \\
\hline (4) History of host location & & & & & $\mathrm{x}$ & $\mathrm{x}$ \\
\hline $\begin{array}{l}\text { (4) Students having previously studied } \\
\text { abroad share experiences }\end{array}$ & & & & $\mathrm{x}$ & $\mathrm{x}$ & $\mathrm{x}$ \\
\hline (4) Travel itinerary & & & & & $\mathrm{x}$ & $\mathrm{x}$ \\
\hline
\end{tabular}




\begin{tabular}{|c|c|c|c|c|c|c|}
\hline & Pre-interviews & Diaries & Blogs & Post-interviews & Literature review & Delphi \\
\hline $\begin{array}{l}\text { (4) Students given preparation } \\
\text { information online }\end{array}$ & & & & & $\mathrm{x}$ & \\
\hline (4) Required readings & & & & & $\mathrm{x}$ & \\
\hline (3) Politics in host location & & & & & $\mathrm{x}$ & $\mathrm{x}$ \\
\hline (3) Customs in host location & & & & & $\mathrm{x}$ & $\mathrm{x}$ \\
\hline (3) Course requirements & & & & & $x$ & $x$ \\
\hline (3) Country specific knowledge & & & & & $\mathrm{x}$ & $\mathrm{x}$ \\
\hline (2) Values of host location & & & & & $x$ & $x$ \\
\hline (2) Economics in host location & & & & & $\mathrm{x}$ & $\mathrm{x}$ \\
\hline $\begin{array}{l}\text { (2) Students receive information from } \\
\text { international resource office }\end{array}$ & & & & & $\mathrm{x}$ & $\mathrm{x}$ \\
\hline (2) General trip details are discussed & & & & & $\mathrm{x}$ & $\mathrm{x}$ \\
\hline $\begin{array}{l}\text { (2) Students compose learning } \\
\text { objectives }\end{array}$ & & & & & $x$ & $x$ \\
\hline $\begin{array}{l}\text { (2) Students compose reflective } \\
\text { journals }\end{array}$ & & & & & $\mathrm{x}$ & $x$ \\
\hline (2) Culture in general & & & & & $\mathrm{x}$ & $\mathrm{x}$ \\
\hline $\begin{array}{l}\text { (2) Students complete cultural } \\
\text { assessment }\end{array}$ & & & & & $x$ & \\
\hline $\begin{array}{l}\text { Cultural awareness, cultural } \\
\text { competence, and cultural sensitivity }\end{array}$ & & & & & $x$ & \\
\hline Risks and potential for harm & & & & & $\mathrm{x}$ & \\
\hline Post-colonial voyeurism & & & & & $\mathrm{x}$ & \\
\hline $\begin{array}{l}\text { Nursing students preparing to study } \\
\text { abroad must... }\end{array}$ & & & & & & $x$ \\
\hline $\begin{array}{l}\text { Preparedness of nursing } \\
\text { students }\end{array}$ & & & & & & $x$ \\
\hline $\begin{array}{l}\text { Be told what to bring on their } \\
\text { study abroad trip }\end{array}$ & & & & & & $x$ \\
\hline $\begin{array}{l}\text { Create a learning contract } \\
\text { including educational } \\
\text { expectations of the trip }\end{array}$ & & & & & & $x$ \\
\hline $\begin{array}{l}\text { Familiarize themselves with } \\
\text { clinical skills related to } \\
\text { prevalent diseases in the host } \\
\text { location }\end{array}$ & & & & & & $x$ \\
\hline
\end{tabular}




\begin{tabular}{|c|c|c|c|c|c|c|}
\hline & Pre-interviews & Diaries & Blogs & Post-interviews & Literature review & Delphi \\
\hline $\begin{array}{l}\text { Acquire country specific } \\
\text { knowledge such as culture, } \\
\text { history, religion, economy and } \\
\text { healthcare }\end{array}$ & & & & & & $x$ \\
\hline $\begin{array}{l}\text { Identify ways of improving the } \\
\text { study abroad experience for } \\
\text { future students }\end{array}$ & & & & & & $x$ \\
\hline $\begin{array}{l}\text { Acquire communication skills } \\
\text { necessary to work in a multi- } \\
\text { disciplinary team }\end{array}$ & & & & & & $x$ \\
\hline $\begin{array}{l}\text { Provide care respecting the } \\
\text { cultural practices in the host } \\
\text { location }\end{array}$ & & & & & $x$ & $x$ \\
\hline $\begin{array}{l}\text { Learn common phrases to } \\
\text { communicate basic needs if } \\
\text { they are unfamiliar with the } \\
\text { host country language }\end{array}$ & & & & & & $x$ \\
\hline $\begin{array}{l}\text { Understand the underlying } \\
\text { public health issues (such as } \\
\text { contaminated water, poverty, } \\
\text { or poor hygiene) that affect a } \\
\text { community) }\end{array}$ & & & & & & $x$ \\
\hline $\begin{array}{l}\text { Possess or acquire the } \\
\text { reflective skills to appreciate } \\
\text { the learning gained from } \\
\text { studying abroad }\end{array}$ & & & & & & $x$ \\
\hline $\begin{array}{l}\text { Anticipate what they will see, } \\
\text { hear, smell and encounter that } \\
\text { is different from their home } \\
\text { country }\end{array}$ & & & & & & $x$ \\
\hline $\begin{array}{l}\text { Expect unforeseen } \\
\text { circumstances to arise, } \\
\text { requiring an attitude of } \\
\text { flexibility/resilience }\end{array}$ & & & & & & $x$ \\
\hline $\begin{array}{l}\text { Understand they will not be } \\
100 \% \text { prepared }\end{array}$ & & & & & & $x$ \\
\hline Receiving institutions must... & & & & & & $\mathrm{x}$ \\
\hline
\end{tabular}




\begin{tabular}{|c|c|c|c|c|c|c|}
\hline & Pre-interviews & Diaries & Blogs & Post-interviews & Literature review & Delphi \\
\hline $\begin{array}{l}\text { Confirm the students are } \\
\text { welcome to undertake a study } \\
\text { abroad trip to their institution }\end{array}$ & & & & & & $x$ \\
\hline $\begin{array}{l}\text { Ensure that the roles and } \\
\text { responsibilities allocated to } \\
\text { students are aligned to specific } \\
\text { needs of the local population }\end{array}$ & & & & & & $x$ \\
\hline $\begin{array}{l}\text { Provide appropriate } \\
\text { preparation and orientation to } \\
\text { students once they arrive to } \\
\text { their study abroad location }\end{array}$ & & & & & & $x$ \\
\hline Sending institutions must... & & & & & & $\mathrm{x}$ \\
\hline $\begin{array}{l}\text { Be responsible to prepare } \\
\text { nursing students to study } \\
\text { abroad }\end{array}$ & & & & & & $\mathrm{x}$ \\
\hline $\begin{array}{l}\text { Create a mission denoting the } \\
\text { goals of the trip }\end{array}$ & & & & & & $x$ \\
\hline $\begin{array}{l}\text { Dedicate a supporting } \\
\text { coordinator responsible for the } \\
\text { students to handle } \\
\text { emergencies if they arise }\end{array}$ & & & & & & $x$ \\
\hline $\begin{array}{l}\text { Facilitate debriefing with } \\
\text { nursing students when the } \\
\text { study abroad trip is complete }\end{array}$ & & & & & & $x$ \\
\hline $\begin{array}{l}\text { Preparation training for nursing } \\
\text { students to study abroad should } \\
\text { include... }\end{array}$ & & & & & & $x$ \\
\hline $\begin{array}{l}\text { Acquisition of practical } \\
\text { information }\end{array}$ & & & & & & $x$ \\
\hline $\begin{array}{l}\text { Training that is focused on the } \\
\text { study abroad trip and the } \\
\text { student's future career as a } \\
\text { nurse }\end{array}$ & & & & & $x$ & $x$ \\
\hline $\begin{array}{l}\text { Development of managerial } \\
\text { skills, or the ability to manage } \\
\text { responsibilities with autonomy }\end{array}$ & & & & & & $\mathrm{X}$ \\
\hline
\end{tabular}




\begin{tabular}{|c|c|c|c|c|c|c|}
\hline & Pre-interviews & Diaries & Blogs & Post-interviews & Literature review & Delphi \\
\hline $\begin{array}{l}\text { Development of cultural skills, } \\
\text { or gaining understanding of } \\
\text { cultural practices in the host } \\
\text { location to best provide care } \\
\text { within the patient's culture }\end{array}$ & & & & & & $x$ \\
\hline $\begin{array}{l}\text { Preparation also for their } \\
\text { return home with opportunity } \\
\text { to debrief the trip }\end{array}$ & & & & & & $x$ \\
\hline
\end{tabular}


In Table 20, the findings from the formal case study of the preparation programme in the Netherlands, the literature review, and the Delphi are displayed. Table 20 contains the content from Table 11, with the additional findings from the literature review and the Delphi. Literature themes were only included that had two or more instances of a theme of preparation. This was done to emphasize methods for preparing students that are repeated across sending institutions, and for data reduction (the amount of preparation methods used once in the literature are too numerous to consider). The Delphi study echoed themes from each type of data collected previously. This validated the assumption that the Dutch nursing students were well prepared. Preparation was a theme in every data source other than student blogs, which is to be expected as blogs were written for students' friends and family. This table shows triangulation beyond a threesource data collection method. Rather, six sources of data (pre-interviews, diaries, blogs, post-interviews, literature review, and the Delphi) are shown to cross reference themes throughout the data collection sequence and student experience.

\section{Conclusion}

A Delphi consensus research method was chosen to validate and add rigour to a working definition of preparation. In the Delphi pilot, $70 \%$ of experts felt nursing students were somewhat prepared to study abroad. Changes following the pilot included the inclusion of a new question that inquired as to the location of experience experts had in the field of nursing study abroad trips. Following the pilot, experts were recruited using snowball sampling to achieve a purposive expert sample. Experts were emailed a hyperlink to take part in the study, and after providing demographic data, ranked their agreement with the components of the working definition of preparation using a 5-point Likert scale, and recommended additional components if desired. The expert panel consisted of the three desired groups: students, receiving institutions, and receiving institutions; among other relevant groups with required study abroad involvement. Of the 37 experts who were invited to join the Delphi, 23 completed the first round. Components of the definition were largely supported by the experts, with $84 \%$ of the questions reaching consensus in the first round. In the second 
round of the Delphi, 20 experts responded. Feelings shifted regarding the preparedness of nursing students prior to studying abroad, with experts changing their answers in the second round to options denoting students were less prepared. Consensus was reached in the second round, completing the Delphi study and producing a validated definition of preparation. An analytical framework was created out of the definition, in which a table allows each component of the definition of preparation to be ticked as 'done', partial', or 'not done'; guiding and exposing gaps in preparation curriculum. The researcher analysed the results from the reflexive interview according to the new preparation definition. This produced the first example of the analytical framework and it's assessment of a study abroad preparation programme the researcher undertook and discussed in Chapter 3. The Delphi was completed in the second round after achieving a minimum consensus of $75 \%$ on a definition. The new definition of preparation allocated responsibilities to nursing students, receiving institutions, and sending institutions. Preparation training content was the final component of the new definition, offering subjects to cover for nursing students prior to studying abroad. 


\section{CHAPTER EIGHT DISCUSSION \& CONCLUSION}

This chapter discusses the findings of the thesis. Several methods were undertaken to achieve a comprehensive picture of preparation including a reflexive interview, a pilot and formal case study, and a Delphi study. The findings are discussed in terms of how the study is situated amongst the other works in this field, and organised according to issues related to nursing students, institutional organisation of sending HEIs, and content of preparation training. Following, the conclusion to this thesis includes theoretical statements put forth in Chapter 4 along with their associated outcomes. The study design and implementation, limitations and delimitations, and original contribution are discussed. Finally, future research, significance, and recommendations conclude this thesis.

The key findings from this study are organised as follows:

Experiences of Nursing Students on Study Abroad Trips

1. The contradiction in the stated justification versus the evidencebased reason to study abroad

a. Personal growth

b. Cultural competence

2. Outcomes from the reflexive interview

3. Do nursing students study abroad for an adventure?

4. Rollercoaster of emotions

5. Student struggles

6. Student retention of preparation

7. First impressions 
Institutional Organisation of Sending HEIs

8. The assumption that students are underprepared for nursing study abroad trips by their sending institutions

9. The assumption that study abroad trips may not benefit the host location

a. The study abroad trip is the preparation for students to enter the nursing workforce

10. Student applications to study abroad

11. Risk and risk-taking

12. Countries of experience

Content of Preparation Training

13. A lack of standardisation in preparation

14. Students' level of preparedness

15. Definition of preparation

16. Analytical framework of preparation

\section{Discussion of Preparation}

Preparation for nursing students prior to study abroad trips is not as comprehensive as many educators and students may have perceived. The research question (Chapter 4 ) asked how nursing students prepare to study abroad. The case studies revealed widely varying types of preparation among the students who were sent from two HEIs in Europe. One paradigmatic case study of nursing students (see Chapter 6 ) produced well prepared students, however, the same students took part in high-risk behaviour and encountered several dangerous situations that were resolved without major consequence to the students' well-being. The Delphi study found that nursing students were only somewhat prepared to study abroad. The findings from this thesis echoed that of the literature, which demonstrated nursing students' preparation lacks standardisation and criticality, finding no two sending institutions to have identical preparation methods. The literature described preparation procedures in $14 \%$ of nursing study abroad articles collected (see Chapter 2), suggesting the majority of nursing students received little or no preparation at all. The problem of 
inadequate preparation can be diminished by implementing recommendations that produced a new definition and analytical framework of preparation for nursing study abroad trips. The findings from this study are discussed below, beginning with experiences of nursing students on study abroad trips.

\section{Experiences of Nursing Students on Study Abroad Trips}

\section{The contradiction in the stated justification versus the evidence- based reason to study abroad}

The first finding in this thesis related to nursing students was the clear difference between why students say they study abroad, and the literature's reason why students study abroad. The most frequently discussed benefit in the literature following study abroad trips is personal growth. This is significant because it does not align with the justification for study abroad trips found in a majority of the literature. Nursing study abroad trips are justified in their ability to increase students' cultural competence. They provide more opportunity for students to enter the workforce as newly qualified nurses with cultural competence to better care for a diverse healthcare populations (Petzold, Peter 2015) - a view that is disputed by other authors (Foronda, Belknap 2012, Tam 2016, Kardong-Edgren, Campinha-Bacote 2008, Carpenter, Garcia 2012).

Still, the most cited benefit identified from the literature review about studying abroad is not cultural competence, but personal growth (Chapter 2, benefits of study abroad trips). Achieving personal growth, similar to Maslow's self-actualisation theory (Maslow 1943), brings little to no benefit to the patients in the host countries, revealing patients do not hold first priority. Altruism and the desire to help is quickly challenged when the beneficiary of study abroad trips is no longer the population in the host country, but the nursing students themselves and their institutions. Such practice comes to light as self-promotion, furthering the accusation of the voyeuristic nature of study abroad trips (see Chapter 2, post-colonial 
voyeurism), and clearly compromising the NMC's requirement that the patient hold top priority (Nursing Midwifery Council 2010).

A theoretical tool (detailed in Chapter 2, post-colonial voyeurism) describes three perspectives (Wright, Zerbe et al. 2001) that can be used as models to create international health programs: the traditional, transitional, and new perspectives. The three perspectives may also identify priorities of the students and sending HEIs. One of the three perspectives, the traditional perspective, views developing countries as dependent on developed countries. The developing countries 'need help' and require a one-way transfer of knowledge. If students are under the impression that they are going to a location that needs their help, the reality may be the opposite depending on the level of preparedness, including knowledge and skills students possess, to provide care. A successful study abroad trip ought to require more than good intentions to help the 'Other' or hope for a bit of adventure along the way (Racine, Perron 2012). While this is not explicitly stated in the literature, many sending HEIs appear to hold the traditional perspective by giving attention to students' personal growth at the expense of the receiving population. It is not so far-fetched to perceive HEIs have purposefully decided to benefit students only and not the local population.

\section{Personal growth}

Students in this study (see Chapters 5 and 6) reaped the benefit of personal growth from their study abroad trips, as supported in the literature (KentWilkinson, Leurer et al. 2015, Read 2011, Button et al. 2005, Duffy et al. 2005, Inglis, Rolls et al. 1998, Che, Spearman et al. 2010, Browne, Fetherston et al. 2015, Mill, Yonge et al. 2005, Kokko 2011, Davis, Wright et al. 2015, Westerbotn et al. 2015, Zanchetta, Schwind et al. 2013, Keogh, Russel-Roberts 2009). The most clearly articulated benefit was a greater respect for all persons (Chapter 6 , student post-trip interview analysis), supporting the recommendation for cultural competence language to shift toward that of cultural humility (see cultural competence). Other benefits were implicit, such as one student saying she was satisfied with fewer things than she was before her study abroad trip (Chapter 6, transition 
home). A further personal benefit was the ability to adapt between different cultures. Also reported in Chapter 5 was the Finnish student's view that she benefitted personally by gaining an increased worldview as a result of her study abroad trip (see Chapter 5, first impressions).

\section{Cultural competence}

Cultural competence is the most cited justification HEIs use for sending nursing students abroad (see Chapter 2, cultural awareness, cultural competence, and cultural sensitivity). This includes the need to expose nursing students to a culture they may not have encountered but could in the course of their future practice. The topic of cultural competence saturates the literature, emphasising the diversifying patient population and the need for newly qualified nurses to provide care appropriately (Koskinen, Tossavainen 2003, Egenes 2012, Kemppainen, Kim-Godwin et al. 2012, Kokko 2011, Ruddock, Turner 2007, Button, Green et al. 2005, Koskinen, Tossavainen 2004, Delpech 2013, Amerson 2010, Green, Comer et al. 2011, Bosworth, Haloburdo et al. 2006, Hu, Andreatta et al. 2010, Johns, Thompson 2010, Kohlbry, Daugherty 2015, Westerbotn, Kneck et al. 2015, Duffy, Farmer et al. 2005, Leh, Waldspurger et al. 2004, Kreye, OetkerBlack 2013, Gower, Dantas et al. 2018). Achieving cultural competence which arguably is not an accurate description of what a nursing student can truly achieve - through a study abroad trip is an ambitious goal that opens a myriad of risks. The researcher points to a lack of scrutiny and criticality in this practice, highlighting the ethical quandaries of what is required to reach such a competency - using often impoverished populations to allow nursing students to practice skills with little supervision or support (see Chapter 2; risks and potential for harm, post-colonial voyeurism) and compromising the NMC's educational requirement of placing first priority on patients.

The researcher concurs with the suggestion that culture is a construct, and does not need to be as prominent a theme in nursing education (Dreher, MacNaughton 2002, Kardong-Edgren, Campinha-Bacote 2008). The complexities of culture are minimised with an essentialist view (Gray, 
Thomas 2005), and nurses may enter the workforce with a false sense of comfort that they are indeed caring for patients with cultural competence (see Chapter 2, a critique of cultural competence). An emphasis on cultural care can lead to stereotypes in the workplace, brought on by the very attempt to achieve cultural competence. The NMC requires newly qualified nurses to carry out nursing assessments that take into account the patient's culture (Nursing Midwifery Council 2010). Further, the NMC requires newly qualified nurses to understand:

How behaviour, culture, socioeconomic and other factors, in the care environment and its location, can affect health, illness, health outcomes and public health priorities and take this into account in planning and delivering care (Nursing Midwifery Council 2010 p. 26).

This places a high expectation on nurses, as taking a patient's culture into account requires the nurse to understand that patient's culture. However, nurses cannot be taught every culture in their education, so while the requirement may bring about an awareness of diversity, perhaps the requirement is unattainable.

Recommendations for a new paradigm of cultural education (Kulbok, Mitchell et al. 2012, Tervalon, Murray-Garcia 1998) conflict with the status quo. Quieter voices in the literature are calling for cultural education reform towards cultural humility, requiring a move away from the current emphasis on cultural competence (see Chapter 2, a critique of cultural competence). The popular learning objective of cultural competence is recommended to be replaced by a more attainable and person-centred goal of achieving cultural humility, increasing attention to dignified care, and respect to all persons.

\section{Outcomes from the reflexive interview}

Given the closeness of the researcher to the topic and the experiences she had as a student who undertook a study abroad trip herself, it was important that she reflected on her own past experiences to provide transparency. Following the example of Rolls and Relf (2006), the 
researcher used the reflexive interview as a way of situating herself prior to studying a challenging subject matter. The reflexive interview provided an opportunity to articulate personal views and expose potential biases in the area of study abroad trips early in the research process as supported in the literature (Behar, 2014). This in turn reduced bias albeit it could not totally eliminate it. The researcher and her supervisory team published an article (Lear, Eboh et al. 2018) on the process of the reflexive interview due to the absence of a clear reflexive interview method in the literature.

The literature review did not include instances of harm to students or patients (see risk and risk-taking; student struggles), nor offer any justification of such a gap. The lack discussion about potential or caused harm may contribute to the laissez-faire approach to preparation, or lack of preparation entirely. The researcher's study abroad experiences included firstly, witnessing a peer's near death due to misdiagnosed malaria and secondly, avoiding assault by armed personnel who attacked a vehicle ahead of the one she was travelling in. Other unexpected struggles arose throughout the trip, such as the reversal from not anticipating a need for support prior to the study abroad trip, to wishing for more support during the trip. The reflexive interview provided examples of potential harm, supporting the claim throughout this thesis that students may be at risk while studying abroad, and thus require thorough preparation highlighting potential risks. The events brought forward from the reflexive interview provided examples of risk where the literature was lacking.

\section{Do nursing students study abroad for an adventure?}

A bias arose from the reflexive interview that students studied abroad to have an adventure, but this was not supported in the literature. For example in Chapter 2 (see post-colonial voyeurism), there were discussions on how researchers have called study abroad trips 'medical tourism' (Miranda, Yudkin et al. 2005), where students see 'exciting' or 'exotic' [sic] cases, which could be labelled as adventure seeking, but just as easily be explained as education. 'Developing countries' host $40 \%$ of study abroad trips (Dowell, Merrylees 2009), suggesting an appeal that makes such 
locations attractive. Unfortunately, the draw to send students to 'developing countries' may be due to the lack of oversight. Chapter 2 reports on a group of nursing students who performed their first clinical skill while studying abroad, and actions not yet allowed in their home countries (Bhat 2008) among other examples (see Chapter 2, risks and potential for harm). Perhaps this explains why students reportedly learn more when studying abroad in 'developing countries' (Miranda et al. 2005). The decision to study abroad in 'developing countries' could be explained as either voyeuristic or beneficial to students' learning, meaning this perspective is not supported by the literature however, it could still be the case.

\section{Rollercoaster of emotions}

The pilot case study revealed that the Finnish nursing student had widely varying emotions. It is important to note that the student's negative emotions, or the frequency with which the student expressed anger, elation, homesickness, etc. On top of the stressors present in a study abroad trip (inability to speak local language, distance from home and familiarity, cultural differences, local conflicts, and in some cases witnessing extreme poverty for the first time), a further source of emotional turmoil is the knowledge of events that may be happening back home (see Chapter 6, struggles and conflicts). The findings from the Finnish student's blog discussed in Chapter 5 included the difficulty of being away from her husband for so long. Likewise, students in Chapter 6 told stories of parents losing employment, the passing of loved ones, and missing their friends and family. The homesickness and sadness were peppered throughout student blogs, diaries, and interviews along with excitement and other positive emotions, demonstrating the 'emotional rollercoaster' felt by the students.

Similarly, the literature shows students' extreme anger following study abroad trips, when friends and family do not show empathy the students expected (Kirkham, Van Hofwegen et al. 2009). Emotions are equally high upon returning home after studying abroad, which is typically when selfreported surveys are completed (Durrant, Brown et al. 2008, Ingraham, Peterson 2004, Loftin, Hartin et al. 2013). Arguably, the euphoric emotions 
from returning home paired with potential biases that exist from selfreported data could compromise the trustworthiness and reliability of a selfreported survey on cultural competence (Seals 2013, Inglis et al. 1998). In a two-year follow up survey after a nursing study abroad programme, students self-reported they were still reaping benefits of cultural sensitivity and recommended that other students undertake similar trips (Duffy et al. 2005). The two-year gap in self-reported data may have controlled for the euphoric emotions felt during the trip, but does not reduce the potential bias of the students' self-reported level of cultural competence. Thus, the findings of nursing students moving towards cultural competence as a result of studying abroad may or may not be a true representation (see Chapter 2, cultural awareness, cultural competence, and cultural sensitivity), and is not sufficient evidence on which to base the reasoning behind nursing study abroad trips. This would conclude that student claims to cultural competence are substantiated and thus study abroad trips have little to no evidence that cultural competence is an outcome of such experiences.

The emotions seen both in this study and the literature arguably support the need for some sort of preparatory assessment as to the emotional wellbeing of a student before exposure to a three-month study abroad trip (the sending institution in Chapter 6 refers to student's application to the study abroad trip containing an interview similar to that of an employment interview - the student is not automatically allowed to go but must exhibit qualities expected to give the student a successful trip). Only one paper in the literature review referred to an application process, in which students were required to submit their grades, previous international experience, language skills, a personal essay, and an academic reference (Sloand, Bower et al. 2008) Another HEI (Read 2011) required students display high academic achievements in order to be eligible to study abroad. With only two examples in the literature, more sending HEIs ought to require student applications including emotional assessments of nursing students prior to studying abroad. 


\section{Student struggles}

An additional key finding that emerged from this study were the struggles endured by the students. In Chapter 6, students struggled with differences in the concept of 'time'. A time would be arranged for the students to present their work to healthcare professionals, only for the presentation time to be changed last minute. This was a surprise to the students because punctuality was important culturally in their home country. This raised the question of students' cultural expectations such as the difference between the culture of time in the Netherlands and South Africa. The frequent tea breaks taken by local staff was also a source of frustration for students, and was augmented by the difference in the culture of time, perceived as wasting time. Only one preparation course in the literature discussed the culture of time keeping (Delpech 2013).

A second area that students struggled with that arose during the Dutch students' study abroad trip was the language barrier. Language was perceived as a topic necessary for preparation, in part due to the students feeling they were the source of local staff's 'entertainment'. The local staff would reportedly look at the students, speak in a language the students did not understand, and laugh (see Chapter 6, struggles and conflicts). After deliberating amongst themselves and with their local study abroad coordinator, the students decided to ask the staff to speak English, as this was the common language between the students and staff. This showed courage and benefited the students in increasing their communication skills while resolving the problem. However, it raised the question of how students could have reacted had they not shared a language in common with the local staff. The literature offers little guidance on whether language courses should be required prior to study abroad trips (Chapter 2, preparation subjects in meetings). Some HEIs required language classes prior to studying abroad (Ter Maten, Garcia-Maas 2009, Ferranto 2013, Pross 2005, Mill et al. 2005, Currier, Omar et al. 2000), while others recommended them, not realising the courses were not offered the semester prior to the trip (Critchley, Richardson et al. 2009). 
The Finnish student also experienced challenges; she had a dispute with her study abroad coordinator back home over her lack of supervision in Kenya (see Chapter 5 risks and conflicts). No additional information was provided, and it is unclear whether this conversation led to the student receiving a local study abroad coordinator. This event raised a concern that the literature does not specify the extent to which students are supported by sending institutions while studying abroad. It is unclear if students are always accompanied by a study abroad coordinator, are left to find their own nurse to follow as a preceptor, or simply take initiative to do the patient care they choose without observation. Some literature does specify that a faculty member accompanies students abroad (Davis et al. 2015, Egenes 2012), but this gives no assurance of supervision - a point that supports the exorbitant amount of risk taken in study abroad trips (see Chapter 2, risks and potential for harm). Interestingly, students' struggles are largely absent from the literature, as are cases of malpractice and harm to students. The lack of students' struggles in the literature suggests a similar theme discussed below (risk and risk-taking) that negative effects from study abroad trips are purposely omitted from the literature.

\section{Student retention of preparation}

In Chapter 6, Dutch students displayed obvious differences in their retention of preparation training. Student $L$ had more knowledge than her peers regarding the upcoming study abroad trips, but did not have any additional preparation. She was quick with her responses in interviews, as if she had spent time thinking about the same questions the researcher asked such as what she would be doing every day, and what she hoped to achieve. An explanation may be that Student $L$ simply had more 'grit' (defined as a perseverance and passion to achieve goals) (Duckworth, Peterson et al. 2007). Similarly, the literature suggests student benefits are based on certain personality traits, such as confident students getting more experience, and thus learning, while studying abroad (Tam 2016).

All of the Dutch students took initiative in a number of ways during their study abroad trip. They gave more presentations than were required of 
them. When they felt the pace was too slow, the students split up into smaller groups to get more experience (see Chapter 6, studying abroad). Although there were obvious differences in student personalities, it appeared that the decision to split up was a collective one. This action demonstrated a positive reaction to their boredom during their clinical hours. Student $L$ exhibited the most 'grit' in the group, but Student $A$, who arguably had the least 'grit' was still able to have a successful experience abroad, showing no difference in learning outcomes than other students. In fact, Student A admitted how she remembered aspects of her preparation and avoided unsafe situations as a result. It is possible that Student A did not learn as much as the other students, but there was no evidence to support this, and perhaps the 'herd mentality' assisted her by being around a group that contained more grit than she possessed. Her indifference and lack of knowledge prior to studying abroad showed no negative effect in the bounds of this study. Amidst the differing range of student retention regarding preparation, no students left the study abroad trip early, and students displayed the skills necessary to cope with everything that came their way, displaying flexibility and resilience. The data collected in this thesis does not support or deny the claim in the literature that certain students benefited more from studying abroad than others who stayed in their own countries.

\section{First impressions}

Another finding related to student issues was their first impressions upon arrival to their study abroad location. Anecdotal evidence from the previous year's study abroad cohort helped the students anticipate some of their initial experiences. The Finnish student benefited from information from a student who had studied abroad the previous year (Chapter 5, student perspective); this was also the case with the Dutch students (see Chapter 6, discussion of preparation and preparedness; see also Chapter 2, Tables 3 \& 4). Some events, however, could not be anticipated, further supporting the need for a broad range of preparation content to equip students for unforeseen events. 
In Chapter 6, nursing students reported flying into South Africa, only to find that the person who was supposed to pick them up was not there. The students were flooded with offers by taxi drivers to take their bags and take them to their desired location. Overwhelmed, one student stepped forward and warned the others to be careful, but the taxi drivers had already demanded payment for making phone calls on behalf of the students (see Chapter 6, first impressions). This early encounter was a test of the students' preparedness when faced with a circumstance that was outside of their control.

Students quickly noticed the legacy of the former apartheid government while in South Africa. Ongoing political unrest was a potential risk, as students may not have understood their presence as white people could be seen as voyeuristic. The recent political unrest caused some discomfort in the students upon realising obvious racial divides in the health clinics, nightclubs, and rugby games (Chapter 6, first impressions). The Dutch students received information about the political climate in their preparation, as did two other HEIs discussed in the literature (Bosworth et al. 2006, Wros, Archer 2010).

Inappropriate expectations as discussed in the literature were shown to negatively affect students, as much as culture shock (Härkönen, Dervin 2016). Even when students have the appropriate information, things can still go wrong, such as the pre-arranged driver who never arrived to pick the students up from the airport. The literature contained instances of nursing students being struck by the extreme poverty they saw while studying abroad (Edmonds 2012, Arthur 2001). The students felt this was not something for which they could have prepared, but perhaps could have been warned about. The Dutch students witnessed extreme poverty during a street outreach project (Chapter 6, first impressions; struggles and conflicts) upon entering areas of South Africa where homelessness and substance abuse were prevalent. Even without the dissemination of misinformation regarding the study abroad trips, no knowledge at all could incur even worse emotional turmoil (Pross 2005). The reality that students 
can encounter unforeseen events supports a preparation approach that covers a broad range of topics. This is contradictory to the status quo of preparation, as many articles in the literature review only included one or two topics in preparation discussions (see Chapter 2, content of preparatory training). The new definition produced from the Delphi study (see Chapter 7, definition of preparation) is intended to equip students for a variety of risks and events.

\section{Institutional Organisation of Sending HEIs}

\section{The assumption that students are underprepared for nursing study abroad trips by their sending institutions}

The following two assumptions were findings that emerged during the researcher's reflexive interview (Chapter 3; identification of researcher's potential biases) at the onset of this study. Both were supported by the literature. The first assumption stated that insufficient preparation was given to students; this was reflected in $10 \%$ of the literature review articles (see Chapter 2, underpreparedness). Student's underpreparedness stemmed from multiple reasons, but a clear example in the literature was the HEI who required a six-month preparation period, yet allowed a student to join the study abroad cohort just four days prior to departure (Pross 2005). The same student expressed emotional distress, as did the students who had six months of preparation only to a lesser degree (Pross 2005). The lack of information or feedback leading up to a study abroad trip also contributed to student underpreparedness (Kydd, Tschudi-Madsen et al. 2014), as did a group of students not having information regarding their trip until immediately prior to leaving (Critchley et al. 2009).

Importantly, the $10 \%$ of articles that discussed underpreparedness only represented a small fraction of nursing study abroad trips, as $14 \%$ of the literature review articles discussed preparation (see Chapter 2, nursing study abroad preparation). Therefore, the remaining $86 \%$ of articles could be hypothesised to offer less preparation - or none at all - meaning the $10 \%$ rate of underpreparedness would be much higher in the rest of the 
articles that do not discuss preparation at all. This supports the researcher's assumption that nursing students are underprepared to study abroad.

\section{The assumption that study abroad trips may not benefit the host location}

The second assumption from the researcher's reflexive interview findings was that study abroad trips may not benefit the host location (Sherraden, Lough et al. 2008, Pfeiffer 2003, Mellett 2010). In Chapter 2 (the concept of 'underpreparedness' in current literature), students were reported to have made mistakes - but learned from their mistakes - which does not necessarily relieve concern of what exactly the mistakes were, or what harm they may have caused to the local population (Wros, Archer 2010).

Nursing study abroad trips seem to place priority on the learning opportunities for nursing students rather than patients. Nursing study abroad trips also seem to put both student and patient safety at risk. This begs the question of the role of regulatory bodies such as the NMC in providing guidance on protecting patients in host locations with the aim of preventing harmful practices that could come from study abroad trips (AllParty Parliamentary Group 2013, Papi 2013). In Chapter 2 the researcher discusses that study abroad trips themselves are in fact preparation for nursing students' future careers in nursing (see risks and potential for harm). This supports the researcher's view that the host population is not necessarily benefitting from being a source of learning for nursing students, compromising the NMC's requirements for nursing education.

Interestingly, examples of malpractice are not present in the literature, presumably due to fear of legal ramifications or damaged reputation of the sending institutions. Even if no harm comes to host populations, the NMC requirements of cultural education meeting ethical and safety requirements (NMC 2018) suggest that study abroad trips fall short due to the established risks associated with study abroad trips. Further, the NMC standards for pre-registration nursing education place a serious commitment on safeguarding the public. As discussed in Chapter 1 , the NMC requires 
patients be the first priority in nursing education, and that no student activity or learning opportunity put people's safety at risk (NMC 2010). Along the same lines, each of the students in Chapters 5 and 6 spoke of 'wanting to help' as a primary reason for studying abroad. This language is seen in the traditional, arguably colonialist perspective mentioned previously (Leh et al. 2004) (see Chapter 2, post-colonial voyeurism). The traditional perspective's desire of wanting to help is difficult when students' presence brings risk for harm, a high probability of underpreparedness, and lack of supervision. This reinforces the claim that the current cultural education standards need a paradigm shift towards that of cultural humility (see Chapter 2, a critique of cultural competence).

Study abroad trips do not necessarily benefit the host location.

\section{The study abroad trip is the preparation for students to enter the nursing workforce}

A finding related to the institutional organisation of HEIs is that students' preparation to study abroad is in fact the study abroad trip itself. In other words, instead of delineating preparation needs for nursing students prior to studying abroad, the literature keeps the focus on the future career of the nurses (Conejo, Loyd 2017, Bowker, Tomlinson 2017, Aggar, Bloomfield et al. 2017, Smallheer, Hunt et al. 2018, Øgård-Repål, De Presno et al. 2018) - paying little attention to the population at the study abroad location. Emphasizing student's cultural learning while providing care without appropriate supervision and support may increase the potential for risk and harm to both students and patients. It is also in direct contradiction to the NMC's requirement to put patients at first priority (Nursing Midwifery Council 2010). To recommend that a student learn cultural competence from an 'international Other', is somewhat naïve; the concept of cultural competence is complex and study abroad trips can provide a part but not exclusive source of this skill. Learning at the expense of the 'international Other' also undermines the safety of an often, already vulnerable population.

Nursing students in the UK as with other European countries are prepared before practicing competencies on patients in a clinical setting, ensuring no 
risk of harm to patients is present before students are allowed to practice (Nursing Midwifery Council 2010). Competencies in the UK are never achieved at the expense of the patient, but rather as an expected part of the patient's care. The patient assumes the student has been prepared to carry out the clinical skill and always has the right to refuse care from a student (Nursing Midwifery Council 2010). Thus, the same level of preparation should be expected of nursing students prior to studying abroad.

\section{Student applications to study abroad}

Student applications to study abroad are related to the previous finding regarding the rollercoaster of student emotions (as the rollercoaster of student emotions ought to initiate some assessment as to a student's emotional wellbeing). The sending institution in the Netherlands referred to student applications containing an interview similar to that of an employment interview - students were not automatically allowed to study abroad (see Chapter 6, the sending institution). Only one published article referred to an application process, in which students were required to submit an application to study abroad that included their grades, previous international experience, language skills, a personal essay, and an academic reference (Sloand et al. 2008) notwithstanding, other HEIs may have similar application processes. Another HEI (Read 2011) had an average grade students were mandated to stay above if they wanted to study abroad. The application process of the HEI in the Netherlands (see Chapter 6 , the sending institution) is not repeated in the literature. In Chapters 5 and 6 , the discussion on negative emotions of nursing students showed anger, homesickness, and quickly switched between many others (see rollercoaster of emotions). The student application process at the HEI in the Netherlands is further evidence that it is paradigmatic in its preparation process (see Chapter 6, a critical, paradigmatic, and deviant case). The unknown emotions that a student may experience whilst on a study abroad trip justifies the need for a more rigorous assessment of student wellbeing before exposure to a study abroad trip. 


\section{Risk and risk-taking}

A finding of the pilot case study was the number of dangerous events that arose. The Finnish nursing student reported contracting frequent illness, disobeyed orders not to venture outside during a terrorist threat, was near to an on-going Marbung outbreak, and even stitched a surgical patient (Chapter 5, risks and conflicts). Indeed, the Dutch students reported going to 'black nightclubs' and were the object of much attention. The Dutch students also barely escaped a dangerous car accident, and flippantly reflected on the event as a good learning opportunity (see Chapter 6, risktaking). These students may not have broken rules but did not seem to specify if their study abroad coordinators knew what they were doing. The Finnish student felt that her preparation was unduly stringent, and the Dutch students' reaction to the car accident as a good learning opportunity point towards a voyeuristic, even invincible (see Chapter 5, risks and conflicts) sense of the students (Edmonds 2012).

Discussions in the literature review did not report harm as mentioned previously (the assumption that study abroad trips may not benefit the host location; struggles and conflicts), but harm may well happen frequently without inclusion in an academic paper due to the risk of legality and the desire to avoid the appearance of poor management on the part of the HEI. Others have noticed that there is yet to be an adverse effect, or malpractice that is documented in healthcare study abroad literature (Bhat 2008). Notably, the Finnish nursing student provided numerous details of potential harm (attempted theft, sexism, racism, etc.). However, the subject is absent from the nursing study abroad literature. This suggests that in fact harm does occur both to students and patients, but is not reported. In Chapter 6, the Dutch students were the victims of a car crash, were present in a crowd when a gunman open fired and shot someone next to them, and travelled extensively without access to reliable communication (see risktaking). The researcher's own experiences of studying abroad on reflection relate to events intentionally left out of the literature, such as her peer's near death due to misdiagnosed malaria and the vehicle that was attacked ahead of the one she was traveling in (see Chapter 1, personal context). 
The lack of reporting of adverse situations in the literature may contribute to the laissez-faire approach to preparation, or lack of preparation entirely, due to the belief that nothing could really go wrong. If it had, surely, we would have heard about it. Or would we?

The literature quotes one study abroad coordinator who stated he could not even remember the amount of times students had reported stolen passports, rape, and other events when drugs and alcohol were involved (Seals 2013). But this article was not a formal reporting of harm, rather a story repeated from a study abroad coordinator in the host location as part of a general preparation guide for all university students. It is an example of what the NMC seeks to avoid in nursing student education: putting student's safety at risk (Nursing Midwifery Council 2010).

Students' risk-taking behaviour was a reminder that a broad range of preparation content is needed to equip students for unforeseen events. However, erring on the side of disproportionate caution that covers a wide variety of risks may be better than inadequate preparation. Greater awareness is needed in the literature that things can and will go wrong over the course of a study abroad trip.

\section{Countries of experience}

In the Delphi study, experts were asked to list the countries where they gained experience working with study abroad trips. This was to inquire whether a relationship existed between the level of student preparedness and location of study abroad trips. A related inquiry was whether preparation needs differed based on the location of the study abroad trip. A disadvantage to assuming different preparation needs based on location is stereotyping, or essentialising a myriad of cultures into one (Härkönen, Dervin 2016, Canales 2000). Erasmus' new learning objectives encourage students to learn to engage the 'other' in a non-essentialising manner (Härkönen, Dervin 2016). However, it is a difficult task to teach students to avoid essentialising a culture when they are given little or no cultural education prior to a study abroad trip (see Chapter 2 cultural awareness, 
cultural competence, and cultural sensitivity). Arguably, the underpreparedness seen in the literature suggests that engaging a patient in a non-essentialising manner exceeds the abilities of a preparation curriculum that has no specified content or length - if preparation happens at all.

No relationship was seen in the Delphi between level of preparedness and the country hosting the study abroad trip - more and less developed, rich and poor (see Chapter 7, Figure 3). Similarly, Chapter 6 (see Figure 12) explains that preparing for a study abroad trip based on the country's safety, power, wealth, or continent is not enough for the needs of nursing students. This study's findings support the third theoretical statement (Chapter 4; theory development), that location of experience does not necessarily affect preparedness, and that stereotypes related to location should not affect preparation training. Risks are inherent in all corners of the world, rich and poor countries alike, and a student can never be prepared for every eventuality. The researcher is not aware of this finding in extant literature, and the finding further supports the previously discussed need for preparation to cover a broad range of topics regardless of the location of the study abroad trip. Thus, based on the third theoretical statement, preparation should not be determined based on the country's safety, power, wealth, or continent.

\section{Content of Preparation Training}

\section{A lack of standardisation in preparation}

The content of preparation is widely varying, and so is the length of time reserved for preparation. The literature suggests that preparation lasts anywhere between one meeting to a semester-long course, a few hours to six months (see Chapter 2, courses; meetings). Longer preparation training was viewed as more favourable as suggested by Egenes (2012). The Dutch nursing students who had longer preparation time as discussed in Chapter 6 echoed this sentiment, speaking of the dismay they felt on behalf of the students from other institutions who received little to no preparation before 
studying abroad, which they felt put their counterparts at greater risk (see Chapter 6, discussion of preparation and preparedness). Longer preparation was thought to be the reason a group of Finnish students were more prepared than their American peers in an international cohort of students with differing preparation times (Koskinen, Jokinen 2007). A benefit of a longer duration of preparation training is relationship building (Egenes 2012). Others authors suggest students' anxieties decrease throughout the preparation process as the group's camaraderie strengthens (Lachat, Zerbe 1992). Students get to know one another and the faculty members who support them prior to travelling together. Therefore, longer periods of preparation benefit the students while allowing sufficient time to absorb the information being provided.

The Dutch students' preparation was not representative of the literature, having a longer preparation programme than any example in the literature, and covering a broad range of issues that included a heavy emphasis on safety. The literature review found 214 articles relevant to the field of nursing study abroad trips, with 30 (14\%) discussing preparation for at least one sentence. The papers that provided descriptions of student preparation were brief and had differing information regarding the length and content of the training provided. If descriptions of study abroad preparation in nursing literature are representative of the sample from which they are published, then nursing students are being prepared to study abroad only $14 \%$ of the time. Indeed, nursing was found to have the lowest rates of preparation compared to other health related fields prior to studying abroad (Kironji, Aluri et al. 2014). Given the findings from the literature, which showed no two preparation styles were repeated, the field of nursing may have as many ways of preparing students to study abroad as there are institutions sending them.

From a critical standpoint, current practice for nursing study abroad preparation lacks consistency and standardisation that is seen in other areas of standard nursing curriculum. Given the increasing frequency of study abroad trips (see Chapter 2; Study Abroad Trips), coupled with the 
support governments give to this international experience for students (see discussion of the Bologna Goal in Chapter 2; Study Abroad Trips), there needs to be more continuity of preparation for nursing students based on empirical evidence. There is a dearth of evidence on what 'preparation' and the concept of 'preparedness' for nursing students for study abroad trips should constitute. Therefore, the researcher suggests a robust strategy in the way nursing students are prepared to study abroad based on the findings of this study (see Chapter 7, analytical framework).

\section{Students' level of preparedness}

In the Delphi study, experts were asked how prepared nursing students are to study abroad. Experts changed their views of students' level of preparendess throughout the Delphi study. Their opinion began more positively (see Chapter 7, Figure 20), then grew more pessimistic in the second round (see Chapter 7, Figure 26). In the second round, the highest choice of preparedness chosen by experts stated that students were found to be 'somewhat prepared' to study abroad. This has strikingly similar language to a recent paper which reported student's views of their own preparation as 'somewhat underprepared' (Halcomb, Antoniou et al. 2018), supporting the claim that the topic of preparation remains largely unexplored in the subject of nursing study abroad trips.

As discussed in Chapter 6, there was one instance that suggested that more preparation made a difference in the success of a nursing study abroad trip. Other sending HEIs sent students to the same study abroad site, meaning the students in this study were able to see first-hand the differences in how each cohort of students was prepared. The students curiously discussed amongst themselves, some had one day of preparation; others had no preparation at all (see above, a lack of standardisation in preparation). The Dutch students remarked that they felt prepared and communicated the carelessness with which some of the other students acted who had not received as much preparation. Interestingly, the Dutch students felt their preparation was too extensive during the initial stages of their study abroad trip, but after returning home, had changed their perception of their 
preparation (see Chapter 6, student retention of preparation). This echoes the feelings of the student as presented in Chapter 5 who also felt her preparation training was unnecessarily stringent. While some students felt the preparation was more than necessary, students would think back and remember their preparation, deeming it appropriate and essential.

During the course of their time in South Africa, the Dutch students remembered their preparation training, always thinking about safety and trying to predict risks in each situation to avoid them (see do nursing students study abroad for an adventure; Chapter 6, risk-taking). The second theoretical statement from Chapter 4, which states that the case study will reveal an additional layer of student preparedness by considering their reactions in daily experiences, is supported by the point that the students' reaction to the car accident, scene of gunshots, and interpersonal conflicts with local staff indicated the students were adequately prepared. The students reacted to the stressful situations with maturity, safety, and self-reliance (see Table 16; Chapter 4 studying abroad).

\section{Definition of preparation}

The Delphi study was undertaken to define and gain consensus on what preparation is for nursing study abroad trips (Chapter 7, definition of preparation). A recommendation was followed from Chapter 4 that suggested the use of a statistical method in conjunction with a case study method, as the two complement one another (Flyvbjerg 2011) (see a defence for use of qualitative research method).

The narrative findings that describe preparation in Chapters 5 and 6 substantiate the Delphi findings. For example, a responsibility of the receiving institution is to provide an orientation to the students. This was seen in Chapter 6 (first impressions). The Dutch students' experience of feeling they were being made fun of by local staff (struggles and conflicts) supports the requirement to learn some local language (MkandawireValhmu, Doering 2012). A second example of the case study data 
substantiating the Delphi findings is managerial skills. Regardless of whether it was allowed, the Dutch students showed autonomy and managerial skills by managing their own schedules, even deciding which days they would drive to the clinic and which days they would stay home to work on their health teaching projects (Chapter 6, studying abroad). A further display of managerial skills was the delicate situation the students found themselves in with regards to unit managers (see above, student struggles). The health talks provided by students became sufficiently popular that unit managers appeared to be fighting over the students, trying to convince them to present to their staff instead of another unit manager's staff. This proved to be a difficult situation for students, who were forced to manage themselves in a way that maintained a productive work environment. This event also points to the students' isolation compared to study abroad trips with shorter durations. It is less invasive for study abroad coordinators to travel with students when study abroad trips last a week or two (see above, student struggles). The Dutch students' three-month trip made it so the local study abroad coordinator only met with the students on a weekly basis (Chapter 6, support systems). Thus, the longer length of time the Dutch students spent abroad mandated a more autonomous, managerial role, as they did not have a study abroad coordinator at their side to advocate for them on a daily basis. The Delphi study appropriately followed the pilot and formal case study, providing a statistical method of studying the concept of preparation following a case study method of studying preparation.

\section{Analytical framework of preparation}

Study abroad coordinators (Johns, Thompson 2010), researchers (Browne et al. 2015), and government agencies are calling for better prepared students and volunteers and evidence-based practice (Crisp 2007, All-Party Parliamentary Group 2013). The findings from the Delphi produced a validated definition of preparation (see Chapter 7, definition of preparation), which has the ability to inform best practice for nursing students preparing to study abroad. The validated definition of preparation subsequently informed an analytical framework to analyse preparation at other HEIs (see 
Chapter 7, analytical framework). Like the new definition of preparation, the analytical framework is an original contribution, and also one of the recommendations of this study. Each component of the definition of preparation was placed into a table with three columns, allowing the user to select whether each component was 'done, partially done, or not done at all' in the preparation programme under question. Responsibilities are separated according to the relevant parties, including nursing students, receiving institutions, sending institutions, and general content to be covered. The analytical framework allows gaps in preparation to be easily identified by looking through each column. The analytical framework represents a tool with evidence as to what information is lacking in a preparation programme.

\section{Conclusion}

The key findings of the thesis answered research questions regarding how nursing students prepare to study abroad. The key findings are discussed in terms of how the study is situated amongst the other works in this field. There is a lack of standardisation in preparation for nursing students as found in the literature and in the data collected throughout this study. A contradiction arose in the stated justification versus the evidence-based reason why nursing students study abroad. Cultural competence is saturated in the literature and leads the way in supporting the continuation of such trips. There is a lack of scrutiny and criticality in justifying study abroad trips as vehicles to equip students with cultural competence. An unexpected contradiction arose that personal growth - not cultural competence - is the most cited reason nursing students study abroad. Especially due to the frequent use of marginalised populations as study abroad sites, there are ethical quandaries that are overlooked which seem to place priority on students rather than patients, which goes against NMC requirements.

The three potential areas for bias that emerged from the reflexive interview were 1 ) that students are insufficiently prepared for nursing study abroad trips by their sending institutions, 2) that study abroad trips may not 
benefit the host location, and 3) that students merely study abroad to have an adventure. The first two biases were supported by the literature, while the third was inconclusive in the literature. Students' rollercoaster of emotions was reported both in the literature and by the students who participated in this study. It was rare to find HEIs that assessed the emotional wellbeing of nursing students prior to studying abroad. Students' struggles and conflicts were plentiful, such as cultural misunderstandings, language barriers, familial conflict back home, and disagreements with local staff and study abroad coordinators. Risks to students and patients were plentiful in the data, but not in the literature as much as the researcher had expected. The researcher surmises a lack of malpractice or harm to students in the literature stems from a desire to protect reputations. Within the lack of standardisation of preparation, nursing students also displayed a range in their retention of preparation training. After receiving identical preparation, some students understood details of the trip, and others said they would find out once they arrived. The data collected in this study does not support or deny the claim in the literature that certain students (such as confident students) reap more benefits from studying abroad than others. The students' first impressions shed light on extreme poverty, racial tensions, and potential for harm. The literature was negligible on the subject, with one paper reporting students' inaccurate expectations led to as much emotional distress as culture shock. Neither the Delphi nor the literature suggested that different host locations require unique preparation. Students planning to study abroad were found to be 'somewhat prepared' by the majority of experts in the Delphi study. The Delphi produced a new definition of preparation, validated by experts in the field. The new preparation of definition created from the findings of the Delphi informed an analytical framework for study abroad coordinators to use in guiding preparation and identifying information that is lacking. 


\section{Conclusion}

This study has demonstrated widely varying methods of preparation for nursing students intending to study abroad. The preparation content in the literature and case studies revealed a lack of evidence-based practice in the field of nursing study abroad trips as well as a lack of scrutiny and criticality. As a result, ethical concerns include potential risk to students and receiving location patient populations. Study abroad trips are preparation themselves for students' future career in nursing, providing cultural experiences that are expected to help students achieve cultural competence. Instead, the literature and results from the case studies and literature review revealed personal growth as the greatest benefit, rather than cultural competence.

The field of nursing has a rich tradition of following reflective practice and providing care with dignity. Considering their potential for harm, no one has suggested study abroad trips cease to exist. However, this study calls for increased rigour, an effort to establish guidelines, prevent harm, and follow the same ethical procedures and scrutiny as a nursing student would undergo in their home country. The status quo defines nursing study abroad trips as those that provide students with personal growth, do not necessarily increase cultural competence, and require great financial resources via an ethically questionable vehicle. An improvement must be made.

The theoretical statements from Chapter 4 were answered, as follows:

1. The case study will provide a holistic description of the process of preparing nursing students to fill knowledge gaps in the available literature.

This statement was accomplished through the case description in Chapters 5 and 6 (report of the findings). The process of preparing nursing students to study abroad was further realised by the literature review, which shed light on the widely varying methods of preparation used. In an effort to bring evidence-based practice to the current methods of preparation, the 
researcher proposes a new definition of preparation and accompanying analytical framework.

2. The case study will reveal an additional layer of student preparedness by considering their reactions in daily experiences.

The second theoretical statement was accomplished by analysing a triangulation of student data. The students remembered their preparation training in everyday scenarios, stating they were always thinking about safety and trying to predict what will happen in each situation.

3. The case study will show how preparing a student for a study abroad trip based on the country's power, wealth, or continent is not sufficient for the needs of nursing students.

This third theoretical statement inquired whether a relationship existed between the level of student preparedness and location of study abroad trips. No relationship was seen, justified by the wide range of countries (more and less developed, rich and poor) represented in the 'adequately prepared' section (see Chapter 7, Figure 21). This supports that location of experience does not necessarily affect preparedness, and that stereotypes related to location should not affect preparation training. Risks are inherent in all corners of the world, and a student can never be prepared for every possibility of harm.

\section{Study design and implementation}

This study was complex and used various methods to achieve a holistic description of student preparation. Due to the researcher's personal experience studying abroad (see Chapter 1; Personal Context), a reflexive interview was undertaken at the beginning of this study to expose implicit biases related to the subject under study. A pilot case study confirmed methodological procedures for a formal case study of a preparation programme nursing students received prior to studying abroad. Triangulation was employed via data source and type. Triangulation was 
further employed across six methods of data collection (see Discussion, Table 20). A Delphi study validated a new definition of preparation, completing analysis.

\section{Limitations and delimitations}

This study began with a standpoint from the researcher related to her past experiences studying abroad which potentially could bias the whole research process. It is impossible to remove all biases, however the researcher followed recommended procedures to minimize bias; including undertaking a reflexive interview, piloting interview prompts, triangulation of data sources and data types, and adhering to validated methods for qualitative research. Other challenges included sampling difficulties, ranging from sample size to the unavailability of receiving institution study abroad coordinators. Another limitation was the student blogs, which were written in Dutch and to a specific audience, leading to complexities around sanitising the data. Finally, a limitation of this research is the possibility that preparation is conducted more often than is reported in the literature. The limitations and delimitations did not compromise the integrity of this study.

\section{Original contribution}

Considering what is required to systematically prepare a nursing student to study abroad, surely preparation to practice clinical nursing in a foreign context has been studied before, has been disseminated to the field of nursing, and has been implemented across NGO's, HEIs, and in public policy. This thesis presents the first known holistic description, validated definition, evidence-based recommendation, and analytical framework in the nursing literature.

The original contribution of this research includes eight components. Each represents a new contribution to the body of knowledge and the potential to improve nursing study abroad trips.

1. There is a lack of scrutiny and criticality in nursing study abroad practice, revealing the need for better preparation and a review of ethical procedures. 
2. Impoverished populations allow nursing students to practice skills with little oversight, in the name of acquiring cultural competency.

3. Personal growth is the most cited benefit that justifies why nursing students study abroad. This is contradictory to the justification given for study abroad trips: for students to achieve cultural competence prior to entering a diverse workforce.

4. Nursing students do not necessarily achieve cultural competence from studying abroad.

5. The literature review produced a statistic that $14 \%$ of study abroad trips discuss preparation for one sentence or more. Therefore, lack of mention in the remaining $86 \%$ of articles suggests the associated HEIs offer less preparation - or none at all. Thus, the researcher posits that $86 \%$ of nursing students are inadequately prepared to study abroad.

6. Study abroad trips are preparation for nursing students' future careers in nursing.

7. Thus, preparation is not recognised as obligatory for study abroad trips.

8. The Dutch students underwent formal student application processes to study abroad - an act almost completely absent from the literature.

9. The literature does not specify the degree of oversight students have while studying abroad. It is unclear if students are always accompanied by a study abroad coordinator, are left to find their own nurse to follow as a preceptor, or simply take initiative to perform skills they wish sans observation.

10. There is yet to be an adverse effect, or malpractice that is documented in healthcare study abroad literature. This suggests that negative effects from study abroad trips are purposely omitted from the literature.

11. Preparing for a study abroad trip based on the country's safety, power, wealth, or continent is not enough for the needs of nursing students. Rather, preparation content must be based on empirical evidence. 
Future research will build on the original contributions put forth in this study. The researcher recognised culture as a saturated topic in the nursing study abroad literature, with a dearth of research on the following topics.

\section{Future Research}

There was no substantive evidence that emerged that could predict the type of student who would have a successful experience abroad. More research may be necessary looking at larger sample sizes of students, personality traits, and their reactions to stressful situations. This research might predict whether students possess the life skills to have a successful trip, and produced data to minimise culture shock.

The study of 'impact' was considered and excluded early in this research due to the impossibility of the researcher measuring such a variable without visiting the study abroad host locations. While this was outside the scope of this study, it would be a worthwhile topic of future research. Benefits to the local population were the least frequently discussed in nursing study abroad literature.

Risk-taking behaviour and the potential to cause harm are another topic needing further research. The lack of evidence on possibility of malpractice during study abroad trips, and otherwise harm is a topic worthy of further research. The lack of exploration in the literature to the potential for harm during nursing study abroad trips may contribute to the common laissezfaire approach to preparation, or lack of preparation in its entirety, due to the belief that nothing could really go wrong. If it had, surely we would have heard about it. Or would we?

A study on HEIs intentions behind the decision to send students abroad requires further research, such as who is intended to benefit from the trips - students, local populations, or both. It is a question worth researching from the perspective of sending HEIs. 


\section{Significance}

The significance of this study is focused toward the hundreds of nursing students who study abroad each year. This study offers increased knowledge in the field of nursing study abroad trips. Furthermore, the analytical framework provides greater understanding and awareness of areas that need better preparation. Lastly, other professional groups who go overseas for volunteerism or studies may benefit from the findings of this study. The findings are potentially transferable to other disciplines such as allied health professions and social work. This thesis is a first step in answering the call for better prepared students and volunteers undertaking international health partnerships. The researcher believes this work to be transferable to inform preparation in other disciplines, but suggests preparation remain specific to the skill set of the group studying abroad.

This thesis adds to the body of knowledge by presenting the first case study of a nursing study abroad preparation programme. This thesis also presents the first researcher reflexivity of a nursing study abroad preparation programme. And finally, this thesis presents the first definition of preparation and subsequently, analytical framework, which was validated by a panel of experts in the field.

\section{Recommendations}

1. The researcher recommends cultural education reform from the quieter voices in the literature (see Chapter 2, a critique of cultural competence), including the use of Aristotle's moral principle to treat all humans with value and respect, and cultural humility (Kulbok, Mitchell et al. 2012). The popular learning objective of cultural competence is recommended by the researcher to be replaced by a more worthwhile goal of achieving cultural humility, increasing attention to dignified care, and respect to all persons.

2. Sending HEIs ought to require student applications to include emotional assessments of nursing students prior to studying abroad.

3. Preparation ought to cover a broad range of topics, because it is impossible to prepare for everything. This supports a preparation 
approach that equips students for a variety of events as seen in the new definition produced from the Delphi study (see Chapter 7 , findings).

4. Risks are inherent in all corners of the world, richer and poorer countries, and a student can never be prepared for every possibility of harm. Therefore, preparation should follow an evidence-based approach rather than guide preparation according to stereotypes of the host location.

5. The researcher recommends nurse researchers use reflexive interviews in qualitative and quantitative research. Reflexive interviews are a valuable tool to explore researcher biases. Use is also recommended early in the research process in studies that carry emotionally challenging subject matters, to expose bias prior to making research decisions. The recommendation for this reflexive method is justified in that it allows for introspection, reduces bias, and adds rigour.

6. The researcher would recommend future nursing study abroad trips follow a thorough and empirically based preparation method such as the new definition and analytical framework put forth in this thesis. 


\section{REFERENCES}

Aarts, C., Nordstrom, P., Koskinen, L., Juhansoo, T., Mitchell, M., Marquis, F., Chassé, F., Critchley, K., Campbell, B., and Hemingway, A., 2010. Enabling nursing students to focus on the Ottawa charter and the nurses role in tackling inequalities in health through international exchange. Nurse Education Today, 30(5), pp. 448-452.

Adamshick, P. and August-Brady, M., 2012. Reclaiming the essence of nursing: The meaning of an immersion experience in Honduras for RN to Bachelor of Science Students. Journal of Professional Nursing, 28(3), pp. 190-198.

Adler, M. and Ziglio, E., 1996. Gazing into the oracle: The Delphi method and its application to social policy and public health. Jessica Kingsley Publishers.

Aggar, C., Bloomfield, J.G., Frotjold, A., Thomas, T.H. and Koo, F., 2017. A time management intervention using simulation to improve nursing students' preparedness for medication administration in the clinical setting: A quasi-experimental study. Collegian, 25(1), pp. 105-111. Ajzen, I., 1991. The theory of planned behavior. Organizational Behavior and Human Decision Processes, 50, pp. 179-211.

Ajzen, I., 1985. From intentions to actions: A theory of planned behavior. In Action control (pp. 11-39). Springer, Berlin, Heidelberg.

Alaszewski, A., 2006. Using diaries for social research. Sage.

All-Party Parliamentary Group, 2013. Improving health at home and abroad. APPG, London.

Amerson, R., 2010. The impact of service-learning on cultural competence. Nursing Education Perspectives, 31(1), pp. 18-22.

Anderson, J., Perry, J., Blue, C., Browne, A., Henderson, A., Khan, K.B., Kirkham, S.R., Lynam, J., Semeniuk, P. and Smye, V., 2003. 'Rewriting' cultural safety within the postcolonial and postnational feminist project: Toward new epistemologies of healing. Advances in Nursing Science, 26(3), pp. 196-214.

Anderson, K.H., Friedemann, M., Büscher, A., Sansoni, J. and Hodnicki, D., 2012. Immersion research education: Students as catalysts in international collaboration research. International Nursing Review, 59(4), pp. 502-510.

Arthur, N., 2001. Using critical incidents to investigate cross-cultural transitions. International Journal of Intercultural Relations, 25(1), pp. 4153.

Bakhtin, M.M., 2006. The dialogic imagination: Four essays (University of Texas Press Slavic Series).

Bakhtin, M.M., 1984. Problems of Dostoevsky's poetics. Minneapolis: University of Minnesota Press.

Begley, C.M., 1996. Triangulation of communication skills in qualitative research instruments. Journal of Advanced Nursing, 24(4), pp. 688-693. 
Bell, C. and Newby, H., 1977. Doing sociological research. Free press.

Bell, H., 2014. Becoming a successful student in pre-registration nurse education: A qualitative multiple case study, University of East Anglia.

Bender, A. and Walker, P., 2013. The obligation of debriefing in global health education. Medical Teacher, 35(3), pp. 1027-1034.

Bennett, M.J., 1986. Towards ethnorelativism: A developmental model of intercultural sensitivity. In: R.M. Paige, ed, Education for the intercultural experience. Yarmouth, ME: Intercultural Press., pp. 21-71.

Bennett, M., 1993. Toward ethnorelativism: A development model of intercultural sensitivity. In: R.M. Paige, ed, Education for the intercultural experience. Yarmouth: Intercultural Press.

Bertrand, C. and Bourdeau, L., 2010. Research interviews by skype: A new data collection method, Academic conferences proceedings of the 9th European conference of research methodology for business and management studies 2010, pp. 70-79.

Bhat, S.B., 2008. Ethical coherency when medical students work abroad. Blood, R., 2000. Weblogs: A history and perspective. Rebecca's pocket, 7(9), pp. 2000.

Boehrer, J. and Linsky, M., 1990. Teaching with cases: Learning to question. New directions for teaching and learning, 1990(42), pp. 41-57.

Bohman, D.M. and Borglin, G., 2014. Student exchange for nursing students: Does it raise cultural awareness'? A descriptive, qualitative study. Nurse Education in Practice, 14(3), pp. 259-264.

Bosworth, T.L., Haloburdo, E.P., Hetrick, C., Patchett, K., Thompson, M.A. and Welch, M., 2006. International partnerships to promote quality care: Faculty groundwork, student projects, and outcomes. Journal of Continuing Education in Nursing, 37(1), pp. 32-38.

Bowker, D.M. and Tomlinson, B.J., 2017. Preparedness education in the baccalaureate nursing curriculum: An authentic clinical experience. Nursing Education Perspectives, 38(6), pp. 358-359.

Brewer, J. and Hunter, A., 1989. Multimethod research: A synthesis of styles. Sage publications.

Brod, M., Tesler, L.E. and Christensen, T.L., 2009. Qualitative research and content validity: Developing best practices based on science and experience. Quality of Life Research, 18(9), pp. 1263-1278.

Broome, M.E., 2000. Integrative literature reviews for the development of concepts. Concept development in nursing: foundations, techniques and applications. Philadelphia: WB Saunders Company, pp. 231-250.

Brown, C.L., 2017. Linking public health nursing competencies and servicelearning in a global setting. Public Health Nursing, 34(5), pp.485-492.

Browne, C.A., Fetherston, C.M. and Medigovich, K., 2015. International clinical placements for Australian undergraduate nursing students: A systematic thematic synthesis of the literature. Nurse Education Today, 35(10), pp. 1028-1036. 
Button, L., green, B., Tengnah, C., Johansson, I. and Baker, C., 2005. The impact of international placements on nurses' personal and professional lives: Literature review. Journal of Advanced Nursing, 50(3), pp. 315-324.

Caldwell, P. and Purtzer, M.A., 2015. Long-term learning in a short-term study abroad program: 'Are we really truly helping the community?'. Public Health Nursing, 32(5), pp. 577-583.

Campbell, D.T. and Fiske, D.W., 1959. Convergent and discriminant validation by the multitrait-multimethod matrix. Psychological Bulletin, 56(2), pp. 81.

Campinha-Bacote, J., 2002. The process of cultural competence in the delivery of healthcare services: A model of care. Journal of Transcultural Nursing, 13(3), pp. 181-184.

Canales, M.K., 2000. Othering: Toward an understanding of difference. Advances in Nursing Science, 22(4), pp. 16-31.

Carpenter, L.J. and Garcia, A.A., 2012. Assessing outcomes of a study abroad course for nursing students. Nursing Education Perspectives, 33(2), pp. 85-89.

Che, S., Spearman, M. and Manizade, A., 2010. Constructive disequilibrium. In: R. Lewin, ed, The handbook of practice and research in study abroad: Higher education and the quest for global citizenship. Routledge, pp. 99-116.

Chipps, J., 2010. The use of synchronous videoconferencing teaching to increase access to specialist nurse education in rural Kwazulu-Natal, South Africa. Knowledge Management \& E-Learning: An international journal, 2(2), pp. 154-168.

Chisholm, G. and Pettigrew, L., 2012, The volunteer journey: Potential benefits, barriers, challenges and solutions, viewed 8 December 2014, $<$ http://www.thet.org/volunteer-poster $>$.

Cho, J. and Trent, A., 2006. Validity in qualitative research revisited. Qualitative Research, 6(3), pp. 319-340.

Citrin, D.M., 2011. 'Paul Farmer made me do it': A qualitative study of short-term medical volunteer work in remote Nepal, (Doctoral dissertation, University of Washington).

Cole, D., 2016, The risks (and unexpected benefits) of sending health students abroad, viewed 16 August 2018, < https://www.npr.org/sections/goatsandsoda/2016/02/11/465428990/the -risks-and-unexpected-benefits-of-sending-health-students-abroad $>$.

Conejo, T. and Loyd, L., 2017. Transition to baccalaureate nursing practice: Preparing practicing nurses for professional advancement. Teaching and Learning in Nursing, 13(2), pp.119-121.

Cooper, H.M., 1998. Synthesizing research: A guide for literature reviews. Sage.

Corbin, J. and Strauss, A., 1998. Basics of qualitative research:

Techniques and procedures for developing grounded theory. 4th edn.

Thousand Oaks: Sage. 
Couper, M.P., 2011. The future of modes of data collection. Public Opinion Quarterly, 75(5), pp. 889-908.

Creswell, J.W., 2012. Qualitative inquiry and research design: Choosing among five approaches. Sage.

Creswell, J.W. and Miller, D.L., 2000. Determining validity in qualitative inquiry. Theory into Practice, 39(3), pp. 124-130.

Crisp, N., 2007. Global health partnerships the UK contribution to health in developing countries.

Critchley, K.A., Richardson, E., Aarts, C., Campbell, B., Hemmingway, A., Koskinen, L., Mitchell, M.P. and Nordstrom, P., 2009. Student experiences with an international public health exchange project. Nurse Educator, 34(2), pp. 69-74.

Crump, J.A., Sugarman, J. And working group on ethics guidelines for global health training, 2010. Ethics and best practice guidelines for training experiences in global health. The American Journal of Tropical Medicine and Hygiene, 83(6), pp. 1178-1182.

Currier, C., Omar, M., Talarczyk, G. and Guerrero, R.D., 2000.

Development and implementation of a semester program in Mexico for senior nursing students. Journal of Professional Nursing, 16(5), pp. 293299.

Curtin, A.J., Martins, D.C. and Schwartz-Barcott, D., 2015. A mixed methods evaluation of an international service learning program in the Dominican Republic. Public Health Nursing, 32(1), pp. 58-67.

Curtin, A.J., Martins, D.C., Schwartz-Barcott, D., Dimaria, L. and Ogando, B.M.S., 2013. Development and evaluation of an international service learning program for nursing students. Public Health Nursing, 30(6), pp. 548-556.

Czanderna, K.H., 2013. A qualitative study on the impact of a short-term global healthcare immersion experience in Bachelor of Science Nursing students.

Davis, L.I., Wright, D.J., Gutierrez, M.S., Nam, J.J., Nguyen, J. and Waite, A.T., 2015. Interprofessional global service learning: A pharmacy and nursing practice experience in Botswana. Currents in Pharmacy Teaching and Learning, 7(2), pp. 169-178.

De Natale, M.L. and Waltz, C.L., 2015. Reflections of nursing students travel abroad experiences in Ireland: A global nursing perspective. Nursing Education Perspectives, 36(3), pp. 188-189.

Decamp, M., 2007. Scrutinizing global short-term medical outreach. Hastings Center Report, 37(6), pp. 21-23.

Delpech, P.A., 2013. Developing a short-term international study-abroad program: From beginning to end. Prism: A Journal of Regional Engagement, 2(2), pp. 5.

Denzin, N., 1970. Strategies of multiple triangulation. The research act in sociology: A theoretical introduction to sociological method, 297, p. 313. 
Denzin, N.K. and Lincoln, Y.S., 2014. The SAGE handbook of qualitative research. 4th edn. Sage.

Denzin, N.K. and Lincoln, Y.S., 2011. Introduction: The discipline and practice of qualitative researchers. The SAGE handbook of qualitative research. 4th edn. Thousand Oaks, CA: Sage.

Department of Health and Department for International Development, 2014, Engaging in global health: The framework for voluntary engagement in global health by the UK health sector, viewed 8 December 2014, <www.gov.uk/dh>.

Diamond, I.R., Grant, R.C., Feldman, B.M., Pencharz, P.B., Ling, S.C., Moore, A.M. and Wales, P.W., 2014. Defining consensus: A systematic review recommends methodologic criteria for reporting of Delphi studies. Journal of Clinical Epidemiology, 67(4), pp. 401-409.

Dobrowolska, B., McGonagle, I., Jackson, C., Kane, R., Cabrera, E., Cooney-Miner, D., Di Cara, V., Pajnkihar, M., Prlić, N. and Sigurdardottir, A., 2015. Clinical practice models in nursing education: Implication for students' mobility. International Nursing Review, 62(1), pp. 36-46.

Dooley, L.M., 2002. Case study research and theory building. Advances in developing human resources, 4(3), pp. 335-354.

Dowell, J. and Merrylees, N., 2009. Electives: Isn't it time for a change? Medical Education, 43(2), pp. 121-126.

Doyle, R.M., 2004. Applying new science leadership theory in planning an international nursing student practice experience in Nepal. The Journal of Nursing Education, 43(9), pp. 426-429.

Dreher, M. and MacNaughton, N., 2002. Cultural competence in nursing: Foundation or fallacy? Nursing Outlook, 50(5), pp. 181-186.

Dreyfus, H.L. and Dreyfus, S.E., 1986. Mind over machine: The power of human intuition and expertise in the era of the computer. New York: Free Press.

Duckworth, A.L., Peterson, C., Matthews, M.D. and Kelly, D.R., 2007. Grit: Perseverance and passion for long-term goals. Journal of Personality and Social Psychology, 92(6), pp. 1087.

Duffy, M., Farmer, S., Ravert, P. and Huittinen, L., 2005. International community health networking project: Two year follow-up of graduates. International Nursing Review, 52(1), pp. 24-31.

Durrant, M.B., Brown, R.B., Cluff, J.B. and Bevell, J.W., 2008. Mentored service learning and rigorous academics: Keys to successful international study abroad programs. Community college national centre for community engagement.

Edmonds, M.L., 2012. An integrative literature review of study abroad programs for nursing students. Nursing Education Perspectives, 33(1), pp. 30-34.

Edmonds, M.L., 2010. The lived experience of nursing students who study abroad: A qualitative inquiry. Journal of studies in international education, 14(5), pp.545-568. 
Egenes, K.J., 2012. Health care delivery through a different lens: The lived experience of culture shock while participating in an international educational program. Nurse Education Today, 32(7), pp. 760-764.

Erickson, F., 1986. Qualitative methods in research on teaching. In: M. Wittrock, ed, Handbook of research on teaching. New York: Macmillan.

Fakude, L., 2003. Journaling: A quasi-experimental study of student nurses' reflective learning ability. Curationis, 26(2), pp. 49-55.

Falleiros De Mello, D., Larcher Caliri, M.H., Villela Mamede, F., Fernandes de Aguiar Tonetto, E.M. and Resop Reilly, J., 2018. An innovative exchange model for global and community health nursing education. Nurse Educator, 43(3), pp. 1-4.

Farmer, S., Raver, P. and Huittinen, L., 2003. Institutional issues in the implementation of an international student exchange program. Journal of Nursing Education, 42(9), pp. 399.

Ferranto, M.L.G., 2013. An interpretive qualitative study of baccalaureate nursing students following an eight-day international cultural experience in Tanzania. (Doctoral dissertation, Kent State University).

Finlay, L., 2002. Negotiating the swamp: The opportunity and challenge of reflexivity in research practice. Qualitative Research, 2(2), pp. 209-230.

Flyvbjerg, B., 2011. Case study. In: N.K. Denzin and Y.S. Lincoln, eds, The SAGE handbook of qualitative research. Sage, pp. 301-316.

Folse, V.N., Jarvis, C.M., Swanlund, S.L. and Timan, M.R., 2015. The creation of a synchronous learning environment to support a study abroad program for nursing majors at a traditional liberal arts university. Journal of Professional Nursing, 31(3), pp. 233-241.

Foronda, C.L. and Belknap, R.A., 2012. Short of transformation: American ADN students' thoughts, feelings, and experiences of studying abroad in a low-income country. International Journal of Nursing Education

Scholarship, 9(1).

Foth, T., Efstathiou, N., Vanderspank-Wright, B., Ufholz, L., Dütthorn, N., Zimansky, M. and Humphrey-Murto, S., 2016. The use of Delphi and nominal group technique in nursing education: A review. International Journal of Nursing Studies, 60, pp. 112-120.

Gallagher, R.W. and Polanin, J.R., 2015. A meta-analysis of educational interventions designed to enhance cultural competence in professional nurses and nursing students. Nurse Education Today, 35(2), pp. 333-340.

Geertz, C., 1995. After the fact: Two countries, four decades, one anthropologist. Cambridge, MA: Harvard University Press.

George, A.L. and Bennett, A., 2005. Case studies and theory development in the social sciences. MIT press.

Gibbs, G., 1988. Learning by doing: A guide to teaching and learning methods. Oxford: Further Education Unit, Oxford Polytechnic.

Gillon, R., 1994. Medical ethics: Four principles plus attention to scope. British Medical Journal (Clinical Research ed.), 309(6948), pp. 184-188. 
Goldberg, L.K. and Brancato, V.C., 1998. International education: A United Kingdom nursing student partnership. Nurse Educator, 23(5), pp. 30-34.

Goodman, B., Jones, R. and Macias, M.S., 2008. An exploratory survey of Spanish and English nursing students' views on studying or working abroad. Nurse Education Today, 28(3), pp. 378-384.

Gower, S., Dantas, J.A., Duggan, R. and Boldy, D., 2018. The influence of international nursing placements on cultural competence and career planning. Australian Nursing and Midwifery Journal, 26(1), pp. 41-41.

Gower, S., Duggan, R., Dantas, J.A. and Boldy, D., 2017. Something has shifted: Nursing students' global perspective following international clinical placements. Journal of Advanced Nursing, 73(10), pp. 2395-2406.

Gozu, A., Beach, M.C., Price, E.G., Gary, T.L., Robinson, K., Palacio, A., Smarth, C., Jenckes, M., Feuerstein, C. and Bass, E.B., 2007. Selfadministered instruments to measure cultural competence of health professionals: A systematic review. Teaching and Learning in Medicine, 19(2), pp. 180-190.

Gray, D.P. and Thomas, D., 2005. Critical analysis of 'culture' in nursing literature: Implications for nursing education in the United States. Annual Review of Nursing Education, 3(1), pp. 249-273.

Greatrex-White, S., 2008. Uncovering study abroad: Foreignness and its relevance to nurse education and cultural competence. Nurse Education Today, 28(5), pp. 530-538.

Green, B.F., Johansson, I., Rosser, M., Tengnah, C. and Segrott, J., 2008. Studying abroad: A multiple case study of nursing students' international experiences. Nurse Education Today, 28(8), pp. 981-992.

Green, S.S., Comer, L., Elliott, L. and Neubrander, J., 2011. Exploring the value of an international service-learning experience in Honduras. Nursing Education Perspectives, 32(5), pp. 302-307.

Green, W., Gannaway, D., Sheppard, K. and Jamarani, M., 2015. What's in their baggage? The cultural and social capital of Australian students preparing to study abroad. Higher Education Research \& Development, 34(3), pp. 513-526.

Gross, N.C., Giacquinta, J.B. and Bernstein, M., 1971. Implementing organizational innovations: A sociological analysis of planned educational change. Basic Books.

Groves, M. and Mundt, K., 2015. Friend or foe? Google translate in language for academic purposes. English for Specific Purposes, 37, pp. 112-121.

Guba, E.G., 1990. The paradigm dialog. Sage publications.

Guba, E.G., 1981. Criteria for assessing the trustworthiness of naturalistic inquiries. ECTJ, 29(2), pp. 75-91.

Halcomb, E., Antoniou, C., Middleton, R. and Mackay, M., 2018. The experiences of Australian undergraduate nursing students of a clinical placement in Cambodia. Collegian, 25(3), pp.313-318.

Hall, E.T., 1989. Beyond culture. Anchor. 
Hall, E.T., 1976. Beyond culture. Garden City, NY: Anchor Press. Hanna, P., 2012. Using internet technologies (such as skype) as a research medium: A research note. Qualitative Research, 12(2), pp. 239242.

Härkönen, A. and Dervin, F., 2016. Study abroad beyond the usual 'imagineering'? The benefits of a pedagogy of imaginaries. East Asia, 33(1), pp. 41-58.

Hawamdeh, S. and Raigangar, V., 2014. Qualitative interviewing: Methodological challenges in Arab settings. Nurse Researcher, 21(3), pp. 27-31.

Herring, S.C., Scheidt, L.A., Bonus, S. and Wright, E., 2004. Bridging the gap: A genre analysis of weblogs, system sciences, 2004. Proceedings of the 37th annual Hawaii international conference on 2004, pp. 11 pp.

Heuer, L., Russell, L. and Kahlstorf, H., 1997. Short-term cultural immersion in russia. The Prairie Rose, 66(1), pp. 7-11.

Hofstede, G., 1984. Cultural dimensions in management and planning. Asia Pacific Journal of Management, 1(2), pp. 81-99.

Hollway, W., 2016. Emotional experience plus reflection: countertransference and reflexivity in research. The Psychotherapist, 62. Hookway, N., 2008. Entering the blogosphere: Some strategies for using blogs in social research. Qualitative Research, 8(1), pp. 91-113.

Howell, W.S., 1982. The empathic communicator. Belmont, CA:

Wadsworth Publishing Company.

Hsu, C. and Sandford, B.A., 2007. The Delphi technique: Making sense of consensus. Practical Assessment, Research \& Evaluation, 12(10), pp. 1-8.

$\mathrm{Hu}$, J., Andreatta, S., Yu, L. and Li, S., 2010. A collaborative international community health nursing: Clinical experience in China. Home Health Care Management \& Practice, 22(7), pp. 499-506.

Huff, C.A., 1985. British women's diaries: A descriptive bibliography of selected nineteenth-century women's manuscript diaries. New York: AMS Press.

Inglis, A., Rolls, C. and Kristy, S., 1998. The impact of participation in a study abroad programme on students' conceptual understanding of community health nursing in a developing country. Journal of Advanced Nursing, 28(4), pp. 911-917.

Inglis, A., Rolls, C. and Kristy, S., 2000. The impact on attitudes towards cultural difference of participation in a health focused study abroad program. Contemporary Nurse, 9(3-4), pp. 246-255.

Ingraham, E.C. and Peterson, D.L., 2004. Assessing the impact of study abroad on student learning at Michigan State University. Frontiers: The Interdisciplinary Journal of Study Abroad, 10, pp. 83-100.

Institute for the International Education of Students, 2008, The IES abroad map for study abroad programs, viewed 21 August 2018, 
<https://www.iesabroad.org/export/sites/default/resources/pdf/advisors n faculty/ies map book.pdf $>$.

Jacob, E., Duffield, C. and Jacob, D., 2017. A protocol for the development of a critical thinking assessment tool for nurses using a Delphi technique. Journal of Advanced Nursing, 73(8), pp.1982-1988.

Jacobs, A., 2012. Cross-cultural communication. Noordhoff.

Jarrell, K., Ozymy, J., Gallagher, J., Hagler, D., Corral, C. and Hagler, A., 2014. Constructing the foundations for compassionate care: How servicelearning affects nursing students' attitudes towards the poor. Nurse Education in Practice, 14(3), pp. 299-303.

Jefford, E. and Sundin, D., 2013. Post-structural feminist interpretive interactionism. Nurse Researcher, 21(1), pp. 14-22.

Jeffreys, M.R. and Smodlaka, I., 1996. Steps of the instrument design process: An illustrative approach for nurse educators. Nurse Educator, 21(6), pp. 47-52.

Johns, A. and Thompson, C.W., 2010. Developing cultural sensitivity through study abroad. Home Health Care Management \& Practice, 22(5), pp. 344-348.

Jones, S.R., Torres, V. and Arminio, J., 2013. Negotiating the complexities of qualitative research in higher education: Fundamental elements and issues. Routledge.

Jones, J. and Hunter, D., 1995. Consensus methods for medical and health services research. British Medical Journal (clinical research ed.), 311(7001), pp. 376-380.

Joplin, L., 1981. On defining experiential education. Journal of Experiential Education, 4(1), pp. 17-20.

Kardong-Edgren, S. and Campinha-Bacote, J., 2008. Cultural competency of graduating us Bachelor of Science Nursing students. Contemporary Nurse, 28(1-2), pp. 37-44.

Keeney, S., Hasson, F. and Mckenna, H., 2006. Consulting the oracle: Ten lessons from using the Delphi technique in nursing research. Journal of Advanced Nursing, 53(2), pp. 205-212.

Keikelame, M.J., 2018. 'The tortoise under the couch': An African woman's reflections on negotiating insider-outsider positionalities and issues of serendipity on conducting a qualitative research project in Cape Town, South Africa. International Journal of Social Research Methodology, 21(2), pp. 219-230.

Kelly, N.A., 2000. Deciding to become an overseas volunteer. Hospital Physician, 36(6), pp. 72-78.

Kemppainen, J.K., Kim-Godwin, Y.S., Mechling, B., Kanematsu, Y. and Kikuchi, K., 2012. Promoting cultural awareness in nursing education through international videoconferences. International Journal of Nursing Practice, 18(2), pp. 56-61.

Kent-Wilkinson, A., Leurer, M.D., Luimes, J., Ferguson, L. and Murray, L., 2015. Studying abroad: Exploring factors influencing nursing students' 
decisions to apply for clinical placements in international settings. Nurse Education Today, 35(8), pp. 941-947.

Kent-Wilkinson, A., Starr, L., Dumanski, S., Fleck, J., Lefebvre, A. and Child, A., 2010. International nursing student exchange: Rural and remote clinical experiences in Australia. Journal of Agromedicine, 15(1), pp. 58-65.

Keogh, J. and Russel-Roberts, E., 2009. Exchange programmes and student mobility: Meeting student's expectations or an expensive holiday? Nurse Education Today, 29(1), pp. 108-116.

Kirkham, S.R., Van Hofwegen, L. and Pankratz, D., 2009. Keeping the vision: Sustaining social consciousness with nursing students following international learning experiences. International Journal of Nursing Education Scholarship, 6(1).

Kironji, A., Aluri, J., Decamp, M., Carroll, B., Cox, J., Fofana, M., Lie, E., Moran, D., Tackett, S. and Chen, C., 2014. Gaps in predeparture training and postexperience debriefing in global health experiences: A survey of health professions students. Annals of Global Health, 80(3), pp. 166-167.

Kohlbry, P. and Daugherty, J., 2015. International service-learning: An opportunity to engage in cultural competence. Journal of Professional Nursing, 31(3), pp. 242-246.

Kokko, R., 2011. Future nurses' cultural competencies: What are their learning experiences during exchange and studies abroad? A systematic literature review. Journal of Nursing Management, 19(5), pp. 673-682.

Koskinen, L., Campbell, B., Aarts, C., Chassé, F., Hemingway, A., Juhansoo, T., Mitchell, M.P., Marquis, F.L., Critchley, K.A. and Nordstrom, P.M., 2009. Enhancing cultural competence: Trans-Atlantic experiences of European and Canadian nursing students. International Journal of Nursing Practice, 15(6), pp. 502-509.

Koskinen, L. and Tossavainen, K., 2004. Study abroad as a process of learning intercultural competence in nursing. International Journal of Nursing Practice, 10(3), pp. 111-120.

Koskinen, L. and Tossavainen, K., 2003. Benefits/problems of enhancing students' intercultural competence. British Journal of Nursing, 12(6), pp. 369-377.

Koskinen, L. and Jokinen, P., 2007. Multicultural healthcare: A transatlantic project. Nurse Educator, 32(2), pp. 89-93.

Kreye, J. and Oetker-Black, S., 2013. A global service-learning experience for nursing students in Tanzania: A model for collaboration, Nursing Forum 2013, Wiley Online Library, pp. 256-261.

Kulbok, P.A., Mitchell, E.M., Glick, D.F. and Greiner, D., 2012. International experiences in nursing education: $A$ review of the literature. International Journal of Nursing Education Scholarship, 9(1).

Kumagai, A.K. and Lypson, M.L., 2009. Beyond cultural competence: Critical consciousness, social justice, and multicultural education. Academic Medicine: Journal of the Association of American Medical Colleges, 84(6), pp. 782-787. 
Kydd, A., Tschudi-Madsen, C., Chaves, C. and Tricas-Sauras, S., 2014. A qualitative evaluation study of Erasmus intensive programs (IP) - A contribution to transcultural nursing? Journal of Teaching and Education, 3(1), pp. 609-616.

Lachat, M.F. and Zerbe, M.B., 1992. Planning a baccalaureate clinical practicum abroad. International Nursing Review, 39(2), pp. 53-5, 52.

Langer, E.J., 1992. Mindfulness. 4th edn. Addison-Wesley/Addison Wesley Longman.

Langer, E.J., 1989. Minding matters: The consequences of mindlessnessmindfulness. Advances in Experimental Social Psychology, 22, pp. 137-173.

Lasater, K., Upvall, M., Nielsen, A., Prak, M. and Ptachcinski, R., 2012.

Global partnerships for professional development: A Cambodian exemplar. Journal of Professional Nursing, 28(1), pp. 62-68.

Le, Q.V. and Schuster, M., 2016, A neural network for machine translation, at production scale, viewed 19 March 2018,

$<$ https://research.googleblog.com/2016/09/a-neural-network-formachine.html>.

Lear, H., Eboh, W. and Diack, L., 2018. A nurse researcher's guide to reflexive interviewing. Nurse Researcher, 25(4), pp.35-42.

Leary, T., 1957. Interpersonal diagnosis of personality; a functional theory and methodology for personality evaluation. Wipf and Stock Publishers.

Lee, N., 2004. The impact of international experience on student nurses' personal and professional development. International Nursing Review, 51(2), pp. 113-122.

Leh, S.K., Waldspurger, R., Wendy, J. and Albin, B., 2004. The student/faculty international exchange: Responding to the challenge of developing a global perspective in nursing education. Nursing Education Perspectives, 25(2), pp. 86-90.

Leininger, M., 1996. Culture care theory, research, and practice. Nursing Science Quarterly, 9(2), pp. 71-78.

Leininger, M.M. and McFarland, M.R., 2002. Transcultural nursing:

Concepts, theories, research and practice.

Lenz, B.K. and Warner, S., 2011. Global learning experiences during a domestic community health clinical. Nursing Education Perspectives, 32(1), pp. 26-29.

Li, J.H., Gao, P., Shen, X.Y. and Liu, X., 2014. A process model of emotional labor of nursing: Case study of two Chinese public hospitals. International Journal of Public Administration, 37(10), pp. 695-707.

Liamputtong, P., 2010. Performing qualitative cross-cultural research. Cambridge University Press: Cambridge.

Liberati, A., Altman, D.G., Tetzlaff, J., Mulrow, C., Gøtzsche, P.C., Ioannidis, J.P., Clarke, M., Devereaux, P., Kleijnen, J. and Moher, D., 2009. The PRISMA statement for reporting systematic reviews and metaanalyses of studies that evaluate health care interventions: explanation and elaboration. Annals of Internal Medicine, 151(4), pp. 65-94. 
Liebow, E., 1967. Tally's corner. Boston: Rowman \& Littlefield.

Lincoln, Y.S. and Guba, E.G., 1985. Naturalistic inquiry. Beverly Hills: Sage.

Loftin, C., Hartin, V., Branson, M. and Reyes, H., 2013. Measures of cultural competence in nurses: An integrative review. The Scientific World Journal.

Luzón, M., 2018. Constructing academic identities online: Identity performance in research group blogs written by multilingual scholars. Journal of English for Academic Purposes, 33, pp. 24-39.

Lynd, R.S. and Lynd, H.M., 1937. Middletown in transition: A study in cultural conflicts.

Macfarland, A., 1970. The family life of Ralph Josselin: A seventeenthcentury clergyman. An essay in historical anthropology. Cambridge, MA: Cambridge University Press.

Maginnis, C. and Anderson, J., 2017. A discussion of nursing students' experiences of culture shock during an international clinical placement and the clinical facilitators' role. Contemporary Nurse, 53(3), pp. 348-354.

Maslow, A.H., 1943. A theory of human motivation. Psychological Review, 50(4), pp. 370.

Mellett, J., 2010. For whose benefit? Host community perceptions of the role of short-term international volunteers in development., Kimmage Development Studies Centre, Dublin.

Melrose, S., 2009. Naturalistic generalization.

Merriam, S.B., 1998. Qualitative research and case study applications in education. Revised and expanded from 'Case Study Research in Education.'. San Francisco, CA: Jossey-Bass Publishers.

Merton, R.K., Reader, G. and Kendall, P.L., 1957. The student physician: Introductory studies in the sociology of medical education. Cambridge, MA: Harvard University Press.

Miles, M.B. and Huberman, A.M., 1994. Qualitative data analysis: An expanded sourcebook. Beverly Hills: Sage.

Mill, J.E., Yonge, O.J. and Cameron, B.L., 2005. Challenges and opportunities of international clinical practica. International Journal of Nursing Education Scholarship, 2(1).

Miranda, J.J., Yudkin, J.S. and Willott, C., 2005. International health electives: Four years of experience. Travel Medicine and Infectious Disease, 3(3), pp. 133-141.

Mkandawire-Valhmu, L. and Doering, J., 2012. Study abroad as a tool for promoting cultural safety in nursing education. Journal of Transcultural Nursing, 23(1), pp. 82-89.

Morgan, D.A., 2012. Student nurse perceptions of risk in relation to international placements: A phenomenological research study. Nurse Education Today, 32(8), pp. 956-960.

Morrell-Scott, N., 2018. Using diaries to collect data in phenomenological research. Nurse Researcher, 25(4), pp. 26-29. 
Moustakas, C., 1994. Phenomenological research methods. Sage

Publications.

Mundt, K. and Groves, M., 2016. A double-edged sword: The merits and the policy implications of google translate in higher education. European Journal of Higher Education, 6(4), pp. 387-401.

Munhall, P.L., 2012. Nursing research. Jones \& Bartlett Learning.

Myhre, K., 2011. Exchange students crossing language boundaries in clinical nursing practice. International Nursing Review, 58(4), pp. 428-433.

Myles, W., 2013. Developing co-curricular volunteer opportunities abroad: Canadian and Southern African partner perspectives on the benefits and constraints of a guided learning approach. Kingston, ON: Queen's University International Centre.

NHS, 2010. The framework for NHS involvement in international development. Department of Health.

Nursing Midwifery Council (NMC), 2018, Realising professionalism: Standards for education and training. Part 1: Standards framework for nursing and midwifery education, viewed 20 August 2018, $<$ https://www.google.com/url?sa $=$ t\&rct $=j \& q=\& e s r c=s \&$ source $=$ web\&cd $=3$ \&cad=rja\&uact $=8 \&$ ved $=2$ ahukewidgpkg9 vcahug2imkhtyjbq4afjacegaicba c\&url=https\%3a\%2f\%2fwww.nmc.org.uk\%2fglobalassets $\% 2$ fsitedocumen ts $\% 2$ feducation-standards $\% 2$ feducationframework.pdf\&usg=aovvaw3n6trqxdhqdujzkfz2aj z>.

NMC, 2010, Standards for pre-registration nursing education, viewed 8 October, 2018, https://www.nmc.org.uk/globalassets/sitedocuments/standards/nmcstandards-for-pre-registration-nursing-education.pdf $>$.

Oberg, K., 1960. Cultural shock: Adjustment to new cultural environments. Practical Anthropology, 7(4), pp. 177-182.

Øgård-Repål, A., De Presno, Åk. and Fossum, M., 2018. Simulation with standardized patients to prepare undergraduate nursing students for mental health clinical practice: An integrative literature review. Nurse Education Today, 66, pp. 149-157.

Onwuegbuzie, A.J. and Leech, N.L., 2007. A call for qualitative power analyses. Quality \& Quantity, 41(1), pp. 105-121.

Open Doors, 2017, Fast facts open doors 2017, viewed 13 December 2017, $<$ https://www.iie.org/research-and-insights/open-doors/fact-sheets-andinfographics/fast-facts>.

Papi, D., 2013, Viewpoint: Is gap year volunteering a bad thing?, viewed 17 October 2013, <www.bbc.co.uk/news/magazine-22294205>.

Parratt, J.A., Fahy, K.M., Hutchinson, M., Lohmann, G., Hastie, C.R., Chaseling, M. and O'Brien, K., 2016. Expert validation of a teamwork assessment rubric: A modified Delphi study. Nurse Education Today, 36, pp. 77-85.

Peattie, L., 2001. Theorizing planning: Some comments on Flyvbjerg's rationality and power. International Planning Studies, 6(3), pp. 257-262. 
Peña, E.D., 2007. Lost in translation: Methodological considerations in cross-cultural research. Child Development, 78(4), pp. 1255-1264.

Petzold, K. and Peter, T., 2015. The social norm to study abroad:

Determinants and effects. Higher Education, 69(6), pp. 885-900.

Pfeiffer, J., 2003. International NGOs and primary health care in Mozambique: The need for a new model of collaboration. Social Science \& Medicine, 56(4), pp. 725-738.

Pinto, A.D. and Upshur, R.E., 2009. Global health ethics for students. Developing World Bioethics, 9(1), pp. 1-10.

Pressman, J.L. and Wildavsky, A., 1973. Implementation: How great expectations in Washington are dashed in Oakland. Berkeley, California: University of California Press.

Pross, E., 2005. International nursing students: A phenomenological perspective. Nurse Education Today, 25(8), pp. 627-633.

Punch, K.F., 2013. Introduction to social research: Quantitative and qualitative approaches. Sage.

Purnell, L., 2002. The Purnell model for cultural competence. Journal of Transcultural Nursing, 13(3), pp. 193-6.

Puskar, K., Rudolph, M. and Shi, X., 2017. NCLEX RN exam: A university school of nursing case study of preparation strategies. Journal of Nursing Education and Practice, 7(11), pp. 37.

Racine, L. and Perron, A., 2012. Unmasking the predicament of cultural voyeurism: A postcolonial analysis of international nursing placements. Nursing Inquiry, 19(3), pp. 190-201.

Ramsden, I., 2002. Cultural safety and nursing education in Aotearoa and Te Waipounamu, (Doctoral dissertation, Victoria University of Wellington).

Ray, M.A., 2010. Transcultural caring dynamics in nursing and health care. Philadelphia: FA Davis.

Read, C.Y., 2011. Semester abroad opportunities in baccalaureate nursing programs. Journal of Professional Nursing, 27(4), pp. 221-226.

Redlich, F., 1975. Autobiographies as sources for social history: A research program. VSWG: Vierteljahrschrift Für Sozial-Und Wirtschaftsgeschichte, 62(3), pp. 380-390.

Reid-Searl, K., Dwyer, T., Moxham, L., Happell, B. and Sander, T., 2011. Rediscovering the essence of nursing: Exploring the impact of in clinical experience in Thailand for undergraduate nursing students from Australia. Nurse Education Today, 31(8), pp. 892-897.

Riessman, C.K., 1993. Narrative analysis. Sage.

Riner, M.E., 2011. Globally engaged nursing education: An academic program framework. Nursing Outlook, 59(6), pp. 308-317.

Ritchie, J., Lewis, J., Nicholls, C.M. and Ormston, R., 2013. Qualitative research practice: A guide for social science students and researchers. Sage. 
Rolls, C., Inglis, A. and Kristy, S., 1997. Study abroad programs: Creating awareness of and changing attitudes to nursing, health and ways of living in other cultures. Contemporary Nurse, 6(3-4), pp. 152-156.

Ruddock, H.C. and Turner, D.S., 2007. Developing cultural sensitivity: Nursing students' experiences of a study abroad programme. Journal of Advanced Nursing, 59(4), pp. 361-369.

Ruemler, S.P., 2016. Analyzing the opinion of industry professionals on model-based definition datasets to determine the most efficient method. (Masters thesis, Purdue university).

Ryan, L. and Lörinc, M., 2016. 'Getting your foot in the door': The role of serendipity, heightened sensitivity and social networks in recruiting education research participants. Ciaiq, 5, pp. 87-96.

Ryan, M., Gwinner, K., Mallan, K. and Livock, C., 2017. Preparing workready nurses: Reflexive learning for diverse students in the Australian vocational education and training sector. Studies in Continuing Education, 39(3), pp.268-285.

Saenz, K. and Holcomb, L., 2009. Essential tools for a study abroad nursing course. Nurse Educator, 34(4), pp. 172-175.

Sandelowski, M., 1995. Triangles and crystals: On the geometry of qualitative research. Research in Nursing \& Health, 18(6), pp. 569-574.

Sandrey, M.A. and Bulger, S.M., 2008. The Delphi method: An approach for facilitating evidence based practice in athletic training. Athletic Training Education Journal, 3(4), pp. 135-142.

Seale, C., 1999. The quality of qualitative research. London: Sage.

Seals, M.A., 2013. Going global: Preparing college students for travel abroad. National Social Science Journal, 40(2), pp. 100.

Shailer, B., 1997. Clinical electives: The challenges and benefits of student choice. British Journal of Nursing, 6(10), pp. 575-583.

Sherraden, M.S., Lough, B. and McBride, A.M., 2008. Effects of international volunteering and service: Individual and institutional predictors. Voluntas: International Journal of Voluntary and Nonprofit Organizations, 19(4), pp. 395-421.

Sherraden, M., Bopp, A. and Lough, B.J., 2013. Students serving abroad: A framework for inquiry. Journal of Higher Education Outreach and Engagement, 17(2), pp. 7-42.

Skulmoski, G.J., Hartman, F.T. and Krahn, J., 2007. The Delphi method for graduate research. Journal of Information Technology Education, 6, pp. 1.

Sloand, E., Bower, K. and Groves, S., 2008. Challenges and benefits of international clinical placements in public health nursing. Nurse Educator, 33(1), pp. 35-38.

Smallheer, B., Hunt, J. and Smith, J., 2018. Using critical care simulations to prepare nursing students for capstone clinical experiences. Dimensions of Critical Care Nursing, 37(2), pp. 69-77. 
Smith, J.K. and Weaver, D.B., 2006. Capturing medical students' idealism. The Annals of Family Medicine, 4(1), pp. 32-37.

Smith, K. and Curry, K., 2011. Is it worth it? Measuring the long-term effects of an international experience for nursing students in Ecuador. Journal of Community Health Nursing, 28(1), pp. 14-22.

Sochan, A., 2008. Relationship building through the development of international nursing curricula: A literature review. International Nursing Review, 55(2), pp. 192-204.

Souza, M.T.D., Silva, M.D.D. and Carvalho, R.D., 2010. Integrative review: What is it? How to do it? Einstein (São Paulo), 8(1), pp. 102-106.

Stainton, H. and Iordanova, E., 2017. An ethical perspective for researchers using travel blog analysis as a method of data collection. Methodological Innovations, 10(3), pp. 2059799117748136.

Stake, R.E., 1995. The art of case study research. Sage.

Strauss, A. and Corbin, J., 2007. Basics of qualitative research: Procedures and techniques for developing grounded theory. 3rd edn. Thousand Oaks, CA: Sage.

Tam, A.C.F., 2016. The romance and the reality between pre-service teachers' beliefs about the potential benefits of a short-term study abroad programme and their practices. Teachers and Teaching, 22(7), pp. 765781.

Ter Maten, A. and Garcia-Maas, L., 2009. Dutch advanced nursing practice students: Role development through international short-term immersion. Journal of Nursing Education, 48(4), pp. 226.

Tervalon, M. and Murray-Garcia, J., 1998. Cultural humility versus cultural competence: A critical distinction in defining physician training outcomes in multicultural education. Journal of Health Care for the Poor and Underserved, 9(2), pp. 117-125.

Tjoflåt, I., Razaonandrianina, J., Karlsen, B. and Hansen, B.S., 2017. Complementary knowledge sharing: Experiences of nursing students participating in an educational exchange program between Madagascar and Norway. Nurse Education Today, 49, pp. 33-38.

Tonna, A., McCaig, D., Diack, L., West, B. and Stewart, D., 2014. Development of consensus guidance to facilitate service redesign around pharmacist prescribing in UK hospital practice. International Journal of Clinical Pharmacy, 36(5), pp. 1069-1076.

Trompenaars, F. and Hampden-Turner, C., 1998. Riding the waves of culture. McGraw-Hill, New York.

Tuckett, A. and Crompton, P., 2014. Qualitative understanding of an international learning experience: What Australian undergraduate nurses and midwives said about a Cambodia placement? International Journal of Nursing Practice, 20(2), pp. 135-141.

United Nations, 2014, Millenium development goals and beyond 2015, viewed 6 May 2014, <http://www.un.org/millenniumgoals/>. 
United Nations Educational, Scientific and Cultural Organization (UNESCO), 2018, Global flow of tertiary-level students, viewed 30 November 2018, $<$ http://uis.unesco.org/en/uis-student-flow $>$.

Van Houwelingen, C.T., Moerman, A.H., Ettema, R.G., Kort, H.S. and Ten Cate, O., 2016. Competencies required for nursing telehealth activities: A Delphi-study. Nurse Education Today, 39, pp. 50-62.

Van Manen, M., 2015. Researching lived experience: Human science for an action sensitive pedagogy. Left Coast Press.

Walsh, L.V. and DeJoseph, J., 2003. 'I saw it in a different light':

International learning experiences in baccalaureate nursing education. The Journal of Nursing Education, 42(6), pp. 266-272.

Webb, E.J., Campbell, D.T., Schwartz, R.D. and Sechrest, L., 1966. Unobtrusive methods: Nonreactive research in the social sciences. Chicago: Rand McNally.

West, L.M., Diack, L., Cordina, M. and Stewart, D., 2015. Applying the Delphi technique to define 'medication wastage'. European Journal of Hospital Pharmacy, 22(5), pp.274-279.

Westerbotn, M., Kneck, A, Hovland, O.J., Elrond, M., Pedersen, I., Lejonqvist, G., Dulavik, J., Ecklon, T., Nilsson, I. and sigurdardottir, Ák., 2015. Taking part in nordic collaboration; Nursing students' experiences and perceptions from a learning perspective: A qualitative study. Nurse Education Today, 35(5), pp. 712-717.

Westie, F.R., 1957. Toward closer relations between theory and research: A procedure and an example. American Sociological Review, 22(2), pp. 149-154.

Whittemore, R. and Knafl, K., 2005. The integrative review: Updated methodology. Journal of Advanced Nursing, 52(5), pp. 546-553.

Williams, J.B. and Jacobs, J.S., 2004. Exploring the use of blogs as learning spaces in the higher education sector. Australasian Journal of Educational Technology, 20(2), pp. 232-247.

Wirihana, L., Welch, A., Williamson, M., Christensen, M., Bakon, S. and Craft, J., 2018. Using Colaizzi's method of data analysis to explore the experiences of nurse academics teaching on satellite campuses. Nurse Researcher, 25(4), pp. 30-34.

Wojnar, D.M. and Swanson, K.M., 2007. Phenomenology: An exploration. Journal of Holistic Nursing, 25(3), pp. 172-80.

Wright, D.J., 2010. Planning a study abroad clinical experience. Journal of Nursing Education, 49(5), pp. 280-286.

Wright, M.M., Zerbe, M. and Korniewicz, D.M., 2001. A critical-holistic analysis of nursing faculty and student interest in international health. Journal of Nursing Education, 40(5), pp. 229.

Wros, P. and Archer, S., 2010. Comparing learning outcomes of international and local community partnerships for undergraduate nursing students. Journal of Community Health Nursing, 27(4), pp. 216-225.

Yin, R.K., 2011. Applications of case study research. Sage. 
Yin, R.K., 1982. Studying the implementation of public programs. In: W. Williams, R. Elmore, J. Hall, M.K. Jung and S. Macmanus et al., eds, Studying Implementation: Methodological and Administrative Issues. Chatham, New Jersey: Chatham House Publishers.

Yin, R.K., 2014. Case study research: Design and methods. 5th edn. Los Angeles: Sage.

Zanchetta, M., Schwind, J., Aksenchuk, K., Gorospe, F.F., and Santiago, L., 2013. An international internship on social development led by Canadian nursing students: Empowering learning. Nurse Education Today, 33(7), pp. 757-764.

Zorn, C.R., 1996. The long-term impact on nursing students of participating in international education. Journal of Professional Nursing, 12(2), pp. 106-110. 


\section{APPENDIX A}

LITERATURE REVIEW TABLE: ARTICLES THAT DESCRIBE PREPARATION BEFORE NURSING STUDY ABROAD TRIPS

\begin{tabular}{|c|c|c|c|c|c|c|c|}
\hline & Author & Title & Publisher & Countries & Preparation & Summary & Method \\
\hline 1. & $\begin{array}{l}\text { Duffy ME; } \\
\text { Farmer S; } \\
\text { Ravert P; } \\
\text { Huittinen L }\end{array}$ & $\begin{array}{l}\text { Institutional } \\
\text { issues in the } \\
\text { implementation } \\
\text { of an } \\
\text { international } \\
\text { student } \\
\text { exchange } \\
\text { program. }\end{array}$ & $\begin{array}{l}\text { Journal of } \\
\text { Nursing } \\
\text { Education } \\
2003\end{array}$ & $\begin{array}{l}\text { USA, } \\
\text { Finland, UK, } \\
\text { Portugal }\end{array}$ & $\begin{array}{l}\text { Two-credit course, semester before } \\
\text { exchange covering culture of host } \\
\text { country. }\end{array}$ & $\begin{array}{l}\text { Design of exchange } \\
\text { programs; related } \\
\text { issues }\end{array}$ & $\begin{array}{l}\text { Participatory } \\
\text { action } \\
\text { research; } \\
\text { Evaluation of } \\
\text { the institution }\end{array}$ \\
\hline 2. & $\begin{array}{l}\text { Goldberg } \\
\text { LK; } \\
\text { Brancato } \\
\text { VC }\end{array}$ & $\begin{array}{l}\text { International } \\
\text { education: a } \\
\text { United Kingdom } \\
\text { nursing student } \\
\text { partnership }\end{array}$ & $\begin{array}{l}\text { Nurse } \\
\text { Educator } 1998\end{array}$ & USA, UK & $\begin{array}{l}\text { One evening orientation session } \\
\text { covering course requirements, cultural } \\
\text { similarities and differences, and travel } \\
\text { itinerary. }\end{array}$ & $\begin{array}{l}\text { Share and exchange } \\
\text { information between } \\
\text { countries }\end{array}$ & $\begin{array}{l}\text { Description of } \\
\text { experience; } \\
\text { Evaluation }\end{array}$ \\
\hline 3. & $\begin{array}{l}\text { De Natale, } \\
\text { ML; Waltz, } \\
\text { CL }\end{array}$ & $\begin{array}{l}\text { Reflections of } \\
\text { Nursing } \\
\text { Students Travel } \\
\text { Abroad } \\
\text { Experiences In } \\
\text { Ireland: A } \\
\text { Global Nursing } \\
\text { Perspective. }\end{array}$ & $\begin{array}{l}\text { Nursing } \\
\text { Education } \\
\text { Perspectives } \\
2015\end{array}$ & Ireland, USA & $\begin{array}{l}\text { Pre-immersion seminar meetings, } \\
\text { selected journal readings, and } \\
\text { collaborative preparation for a health- } \\
\text { teaching project that provided } \\
\text { opportunities for dialogue with Irish } \\
\text { nurses at a local hospital. The time } \\
\text { given to the preparation was valuable } \\
\text { in building community among the } \\
\text { nursing students before they began the } \\
\text { study abroad experience. }\end{array}$ & $\begin{array}{l}\text { Follow up of nursing } \\
\text { students' reflection } \\
\text { two years after study } \\
\text { abroad }\end{array}$ & $\begin{array}{l}\text { Follow up } \\
\text { reflection }\end{array}$ \\
\hline
\end{tabular}




\begin{tabular}{|c|c|c|c|c|c|c|c|}
\hline & Author & Title & Publisher & Countries & Preparation & Summary & Method \\
\hline 4. & Shailer, B & $\begin{array}{l}\text { Clinical } \\
\text { electives: The } \\
\text { challenges and } \\
\text { benefits of } \\
\text { student choice }\end{array}$ & $\begin{array}{l}\text { British Journal } \\
\text { of Nursing } \\
1997\end{array}$ & $\begin{array}{l}\text { UK, USA, } \\
\text { West Indies, } \\
\text { Canada }\end{array}$ & $\begin{array}{l}\text { Preparatory discussions with students } \\
\text { by faculty. Students responsible to } \\
\text { seek out their own preparation through } \\
\text { university's international department. } \\
\text { Students write contract of what they } \\
\text { hope to achieve during elective course. }\end{array}$ & $\begin{array}{l}\text { Nursing students may } \\
\text { benefit from having } \\
\text { more say in their } \\
\text { electives }\end{array}$ & $\begin{array}{l}\text { Two phased } \\
\text { semi- } \\
\text { structured } \\
\text { questionnaire } \\
\text { on } \\
\text { satisfaction of } \\
\text { elective } \\
\text { experience; } \\
\text { content } \\
\text { analysis }\end{array}$ \\
\hline 5. & Read, CY & $\begin{array}{l}\text { Semester } \\
\text { Abroad } \\
\text { Opportunities in } \\
\text { Baccalaureate } \\
\text { Nursing } \\
\text { Programs }\end{array}$ & $\begin{array}{l}\text { Journal of } \\
\text { Professional } \\
\text { Nursing } \\
2011\end{array}$ & USA & $\begin{array}{l}\text { Preparation is presented in terms of } \\
\text { curriculum. Students are presented } \\
\text { with two tracks: those who will study } \\
\text { abroad and those who will not. } \\
\text { Students are guided on how to plan } \\
\text { courses differently if they intend to } \\
\text { study abroad, and states the HEI's } \\
\text { infrastructure can assist students with } \\
\text { common limitations such as } \\
\text { transferring credits and housing while } \\
\text { abroad. }\end{array}$ & $\begin{array}{l}\text { The number of } \\
\text { undergraduate nursing } \\
\text { schools that offer } \\
\text { study abroad } \\
\text { experiences \& the } \\
\text { number of students } \\
\text { who participate. In the } \\
\text { study, the majority } \\
\text { ( } 76 \% \text { ) of HEIs } \\
\text { reported that } 0 \%-5 \% \\
\text { of nursing students } \\
\text { enroll in semester-long } \\
\text { study abroad } \\
\text { programmes. }\end{array}$ & Survey \\
\hline 6. & Egenes, KJ & $\begin{array}{l}\text { Health care } \\
\text { delivery } \\
\text { through a } \\
\text { different lens: } \\
\text { The lived } \\
\text { experience of }\end{array}$ & $\begin{array}{l}\text { Nurse } \\
\text { Education } \\
\text { Today } \\
2012\end{array}$ & US, UK & $\begin{array}{l}\text { Students attend four three-hour } \\
\text { seminars monthly during the fall } \\
\text { semester. Content includes a brief } \\
\text { overview of British history, culture, } \\
\text { economics, politics, and customs, with } \\
\text { an emphasis on nursing in England. }\end{array}$ & $\begin{array}{l}\text { Four-week study } \\
\text { abroad trip focusing on } \\
\text { culture shock. Culture } \\
\text { shock is studied via } \\
\text { student journals and } \\
\text { analysed through the }\end{array}$ & Qualitative \\
\hline
\end{tabular}




\begin{tabular}{|c|c|c|c|c|c|c|c|}
\hline & Author & Title & Publisher & Countries & Preparation & Summary & Method \\
\hline & & $\begin{array}{l}\text { culture shock } \\
\text { while } \\
\text { participating in } \\
\text { an international } \\
\text { educational } \\
\text { program }\end{array}$ & & & $\begin{array}{l}\text { Suggests faculty should familiarise } \\
\text { themselves with culture shock prior to } \\
\text { the trip to support students who are } \\
\text { struggling in their new environment }\end{array}$ & $\begin{array}{l}\text { four stages of culture } \\
\text { shock according to } \\
\text { Oberg (1960) and } \\
\text { excerpts are provided } \\
\text { for each stage. }\end{array}$ & \\
\hline 7. & $\begin{array}{l}\text { Saenz, K; } \\
\text { Holcomb, L }\end{array}$ & $\begin{array}{l}\text { Essential Tools } \\
\text { for a Study } \\
\text { Abroad Nursing } \\
\text { Course }\end{array}$ & \begin{tabular}{|l|} 
Nurse \\
Educator \\
2009
\end{tabular} & Honduras & $\begin{array}{l}\text { Four global health modules labeled as } \\
\text { prerequisites include epidemiology, } \\
\text { environmental health, community } \\
\text { resources, and the role of the nurse in } \\
\text { healthcare. While not defined as } \\
\text { preparatory, these modules are } \\
\text { required for students to study abroad }\end{array}$ & $\begin{array}{l}\text { Modules lead up to } \\
\text { study abroad course. } \\
\text { Aim of study abroad } \\
\text { trip is to improve } \\
\text { cultural competence }\end{array}$ & Descriptive \\
\hline 8. & Doyle, RM & $\begin{array}{l}\text { Applying new } \\
\text { science } \\
\text { leadership } \\
\text { theory in } \\
\text { planning an } \\
\text { international } \\
\text { nursing student } \\
\text { practice } \\
\text { experience in } \\
\text { Nepal }\end{array}$ & $\begin{array}{l}\text { Journal of } \\
\text { Nursing } \\
\text { Education } \\
2004\end{array}$ & $\begin{array}{l}\text { Nepal, } \\
\text { Canada }\end{array}$ & $\begin{array}{l}\text { Conforming to new science leadership } \\
\text { theory, students were given autonomy } \\
\text { and told to prepare for a study abroad } \\
\text { trip autonomously. Student-led } \\
\text { preparation included reading books and } \\
\text { articles, examining web sites, and } \\
\text { discussing with other individuals who } \\
\text { had recently worked in Nepal }\end{array}$ & $\begin{array}{l}\text { New science leadership } \\
\text { theory informed the } \\
\text { preparation for this } \\
\text { study abroad trip. No } \\
\text { evaluation is provided } \\
\text { of the laissez-faire } \\
\text { approach to } \\
\text { preparation }\end{array}$ & Descriptive \\
\hline 9. & $\begin{array}{l}\text { Anderson } \\
\text { KH; } \\
\text { Friedeman } \\
\text { n ML; } \\
\text { Büscher A; } \\
\text { Sansoni J; } \\
\text { Hodnicki, D }\end{array}$ & $\begin{array}{l}\text { Immersion } \\
\text { research } \\
\text { education: } \\
\text { students as } \\
\text { catalysts in } \\
\text { international } \\
\text { collaboration }\end{array}$ & $\begin{array}{l}\text { International } \\
\text { Nursing } \\
\text { Review } \\
2012\end{array}$ & $\begin{array}{l}\text { USA, } \\
\text { Germany, } \\
\text { Italy, } \\
\text { Columbia, } \\
\text { Austria, } \\
\text { Thailand }\end{array}$ & $\begin{array}{l}\text { Students take a course providing } \\
\text { training in applied research strategies, } \\
\text { global health/health disparities, and } \\
\text { expectations of daily activities while } \\
\text { abroad. A three-week online seminar is } \\
\text { mandatory for students, which details } \\
\text { the culture and values of the host }\end{array}$ & $\begin{array}{l}\text { Conducting research in } \\
\text { other countries about } \\
\text { chronic illnesses within } \\
\text { family units, available } \\
\text { to minority students } \\
\text { only. }\end{array}$ & Descriptive \\
\hline
\end{tabular}




\begin{tabular}{|c|c|c|c|c|c|c|c|}
\hline & Author & Title & Publisher & Countries & Preparation & Summary & Method \\
\hline & & research. & & & $\begin{array}{l}\text { country. Students are connected with a } \\
\text { contact person in the host country with } \\
\text { whom they dialogue about the } \\
\text { research topic to be addressed upon } \\
\text { arrival. }\end{array}$ & & \\
\hline 10. & $\begin{array}{l}\text { Ter Maten } \\
\text { A; } \\
\text { Garcia- } \\
\text { Maas, L }\end{array}$ & $\begin{array}{l}\text { Dutch } \\
\text { advanced } \\
\text { nursing practice } \\
\text { students: role } \\
\text { development } \\
\text { through } \\
\text { international } \\
\text { short-term } \\
\text { immersion. }\end{array}$ & $\begin{array}{l}\text { The Journal Of } \\
\text { Nursing } \\
\text { Education } \\
2009\end{array}$ & $\begin{array}{l}\text { USA, The } \\
\text { Netherlands }\end{array}$ & $\begin{array}{l}\text { A timetable is provided of required } \\
\text { actions leading up to the study abroad } \\
\text { trip. Six months in advance students } \\
\text { compose curriculum vitae and begin } \\
\text { speaking host country language at } \\
\text { meetings. All preparation in the } \\
\text { timetable encompasses language, } \\
\text { travel logistics, or presentations to be } \\
\text { given while abroad. }\end{array}$ & $\begin{array}{l}\text { Developing the new } \\
\text { role and identity of } \\
\text { Nurse Practitioner in } \\
\text { The Netherlands } \\
\text { through an } \\
\text { international exchange } \\
\text { to the US }\end{array}$ & $\begin{array}{l}\text { Pretest/postte } \\
\text { st, statistical } \\
\text { analysis }\end{array}$ \\
\hline 11. & $\begin{array}{l}\text { Bosworth, } \\
\text { TL; } \\
\text { Haloburdo, } \\
\text { EP; } \\
\text { Hetrick, C; } \\
\text { Patchett, } \\
\text { K; } \\
\text { Thompson, } \\
\text { MA; Welch, } \\
\text { M }\end{array}$ & $\begin{array}{l}\text { International } \\
\text { partnerships to } \\
\text { promote quality } \\
\text { care: faculty } \\
\text { groundwork, } \\
\text { student } \\
\text { projects, and } \\
\text { outcomes. }\end{array}$ & $\begin{array}{l}\text { Journal Of } \\
\text { Continuing } \\
\text { Education In } \\
\text { Nursing } \\
2006\end{array}$ & $\begin{array}{l}\text { USA, } \\
\text { Guyana }\end{array}$ & $\begin{array}{l}\text { US students took a course on } \\
\text { international health, globalisation, } \\
\text { history, and culture of Guyana, were } \\
\text { given information on the economics, } \\
\text { politics, and health problems in } \\
\text { Guyana. Students then identified a } \\
\text { topic of health education for a health } \\
\text { talk, and finally wrote research } \\
\text { questions about the beliefs, health, } \\
\text { and culture of the Guyanese. }\end{array}$ & $\begin{array}{l}\text { Study abroad trip to } \\
\text { developing country for } \\
\text { the purpose of } \\
\text { promoting quality } \\
\text { care. Students gave } \\
\text { health talks and } \\
\text { increased in self- } \\
\text { confidence and } \\
\text { empathy. }\end{array}$ & Descriptive \\
\hline 12. & $\begin{array}{l}\text { Lachat, } \\
\text { MF; } \\
\text { Zerbe, MB }\end{array}$ & $\begin{array}{l}\text { Planning a } \\
\text { baccalaureate } \\
\text { clinical } \\
\text { practicum }\end{array}$ & $\begin{array}{l}\text { International } \\
\text { Nursing } \\
\text { Review } \\
1992\end{array}$ & USA, various & $\begin{array}{l}\text { Explanation of how the institution, } \\
\text { students, and faculty should prepare } \\
\text { for a study abroad trip alongside } \\
\text { Georgetown's procedure. Faculty }\end{array}$ & $\begin{array}{l}\text { A } 1992 \text { publication } \\
\text { with rich description of } \\
\text { the planning behind a } \\
\text { study abroad course }\end{array}$ & Descriptive \\
\hline
\end{tabular}




\begin{tabular}{|c|c|c|c|c|c|c|c|}
\hline & Author & Title & Publisher & Countries & Preparation & Summary & Method \\
\hline & & abroad. & & & $\begin{array}{l}\text { preparations including selecting } \\
\text { international site, receiving } \\
\text { authorization from host location's } \\
\text { health authority, arranging for student } \\
\text { accommodations. Students are given } \\
\text { schedules and maps outlining the study } \\
\text { abroad itinerary. They prepare } \\
\text { presentations to present while abroad. } \\
\text { The article states that students' } \\
\text { anxieties decrease throughout the } \\
\text { preparation process as the group's } \\
\text { camaraderie strengthens, but does not } \\
\text { actually describe how students meet } \\
\text { for this to occur. }\end{array}$ & & \\
\hline & $\begin{array}{l}\text { Wros, P; } \\
\text { Archer, S }\end{array}$ & $\begin{array}{l}\text { Comparing } \\
\text { learning } \\
\text { outcomes of } \\
\text { international } \\
\text { and local } \\
\text { community } \\
\text { partnerships for } \\
\text { undergraduate } \\
\text { nursing } \\
\text { students }\end{array}$ & $\begin{array}{l}\text { Journal of } \\
\text { Community } \\
\text { Health } \\
\text { Nursing } \\
2010\end{array}$ & $\begin{array}{l}\text { Cameroon; } \\
\text { USA }\end{array}$ & $\begin{array}{l}\text { Faculty began preparing for the study } \\
\text { abroad trip with a scout trip; students } \\
\text { prepared by attending prerequisite } \\
\text { weekend classes covering Cameroon's } \\
\text { history, geography, sociopolitics, } \\
\text { culture, and customs. They explored } \\
\text { health problems and health practice, } \\
\text { and oriented students about the local } \\
\text { NGO with which they would work. } \\
\text { Although preparation is reported to } \\
\text { have happened, the authors reported } \\
\text { that students made mistakes. }\end{array}$ & $\begin{array}{l}\text { One study abroad trip } \\
\text { and one local effort. } \\
\text { Both are options for } \\
\text { everyone as not all } \\
\text { students can afford to } \\
\text { travel internationally }\end{array}$ & Descriptive \\
\hline 14. & $\begin{array}{l}\text { Curtin, AJ; } \\
\text { Martins, } \\
\text { DC; } \\
\text { Schwartz- }\end{array}$ & $\begin{array}{l}\text { Development } \\
\text { and Evaluation } \\
\text { of an } \\
\text { International }\end{array}$ & $\begin{array}{l}\text { Public Health } \\
\text { Nursing } \\
2013\end{array}$ & $\begin{array}{l}\text { USA, } \\
\text { Guatemala }\end{array}$ & $\begin{array}{l}\text { Four two-hour and one full day } \\
\text { educational sessions covering what } \\
\text { Riner (2011) calls Global health Core } \\
\text { Content, including country-specific }\end{array}$ & $\begin{array}{l}\text { Creation of new study } \\
\text { abroad course } \\
\text { underpinned by Riner's } \\
\text { Global health core }\end{array}$ & Descriptive \\
\hline
\end{tabular}




\begin{tabular}{|c|c|c|c|c|c|c|c|}
\hline & Author & Title & Publisher & Countries & Preparation & Summary & Method \\
\hline & $\begin{array}{l}\text { Barcott, D; } \\
\text { DiMaria, L; } \\
\text { Ogando, } \\
\text { BMS }\end{array}$ & $\begin{array}{l}\text { Service } \\
\text { Learning } \\
\text { Program for } \\
\text { Nursing } \\
\text { Students }\end{array}$ & & & $\begin{array}{l}\text { knowledge, service learning, and social } \\
\text { consciousness. Students were assigned } \\
\text { readings, prepared presentations, and } \\
\text { developed educational health projects } \\
\text { based on the host country's needs. }\end{array}$ & content & \\
\hline & $\begin{array}{l}\text { Delpech, } \\
\text { PA }\end{array}$ & $\begin{array}{l}\text { Developing a } \\
\text { Short-term } \\
\text { International } \\
\text { Study- abroad } \\
\text { Program: From } \\
\text { Beginning to } \\
\text { End }\end{array}$ & $\begin{array}{l}\text { PRISM: A } \\
\text { Journal of } \\
\text { Regional } \\
\text { Engagement } \\
2013\end{array}$ & $\begin{array}{l}\text { Grenada; } \\
\text { USA }\end{array}$ & $\begin{array}{l}\text { Detailed pre-departure phase section. } \\
\text { Appointed liaison in Grenada to be in } \\
\text { charge of groundwork. Weekly } \\
\text { meetings with faculty and students } \\
\text { including } 3 \text { sessions, including a liaison } \\
\text { in Grenada contributed to preparation } \\
\text { by telling oral histories. Grenada's } \\
\text { health system compared to the USA. } \\
\text { Final pre-departure meetings covered } \\
\text { culture, time, and Hall's (1976) } \\
\text { Iceburg Concept of Culture to prepare } \\
\text { students for study abroad; students } \\
\text { prepared health talks to present in } \\
\text { Grenada and kept reflective journals. }\end{array}$ & $\begin{array}{l}\text { Creation of a study } \\
\text { abroad course with a } \\
\text { goal of increasing } \\
\text { cultural competence in } \\
\text { nursing students. }\end{array}$ & Descriptive \\
\hline & $\begin{array}{l}\text { Ferranto, } \\
\text { MLG }\end{array}$ & $\begin{array}{l}\text { An interpretive } \\
\text { qualitative } \\
\text { study of } \\
\text { baccalaureate } \\
\text { nursing } \\
\text { students } \\
\text { following an } \\
\text { eight-day } \\
\text { international } \\
\text { cultural } \\
\text { experience in } \\
\text { Tanzania }\end{array}$ & $\begin{array}{l}\text { PhD } \\
\text { dissertation } \\
2013\end{array}$ & Tanzania & $\begin{array}{l}\text { Required coursework attendance at six } \\
\text { seminars discussing language, social } \\
\text { norms, rituals, traditions, worldview, } \\
\text { and an overview of ethnic groups in } \\
\text { the host location. Seminars were } \\
\text { underpinned by Langer's theory of } \\
\text { Mindfulness, Campinha-Bacote's } \\
\text { Process of Cultural Competence in the } \\
\text { Delivery of Healthcare, and Bennett's } \\
\text { Developmental Model of Intercultural } \\
\text { Sensitivity (DMIS). Also used was the }\end{array}$ & $\begin{array}{l}\text { A thesis on the } \\
\text { meaning of study } \\
\text { abroad experiences } \\
\text { and how the } \\
\text { experiences influence } \\
\text { students' future role } \\
\text { as nurses }\end{array}$ & $\begin{array}{l}\text { Interpretive } \\
\text { qualitative }\end{array}$ \\
\hline
\end{tabular}




\begin{tabular}{|c|c|c|c|c|c|c|c|}
\hline & Author & Title & Publisher & Countries & Preparation & Summary & Method \\
\hline & & & & & $\begin{array}{l}\text { Culture General Assimilator tool and } \\
\text { cross-cultural sensitizer. Students } \\
\text { stopped in Geneva on their way to } \\
\text { Tanzania for additional meetings and } \\
\text { training in an environment that was } \\
\text { foreign but thought to have had more } \\
\text { similarities to the students' home } \\
\text { culture than Tanzania. }\end{array}$ & & \\
\hline 17. & $\begin{array}{l}\text { Czanderna, } \\
\mathrm{KH}\end{array}$ & $\begin{array}{l}\text { A Qualitative } \\
\text { Study on the } \\
\text { Impact of a } \\
\text { Short-Term } \\
\text { Global } \\
\text { Healthcare } \\
\text { Immersion } \\
\text { Experience in } \\
\text { Bachelor of } \\
\text { Science Nursing } \\
\text { Students }\end{array}$ & $\begin{array}{l}\text { PhD } \\
\text { dissertation } \\
2013\end{array}$ & $\begin{array}{l}\text { USA, India, } \\
\text { Ecuador, } \\
\text { South } \\
\text { Africa, The } \\
\text { Netherlands }\end{array}$ & $\begin{array}{l}\text { Study abroad course including various } \\
\text { requirements. Students were also } \\
\text { given information from many sources. } \\
\text { The physician coordinator of the trip } \\
\text { handed out instructions for the trip. } \\
\text { Advice from previous study abroad } \\
\text { students added to the preparation } \\
\text { process. The international resource } \\
\text { office offered guidebooks of the host } \\
\text { country. Students were required to } \\
\text { attend meetings, complete assigned } \\
\text { readings and paperwork as well as } \\
\text { attend discussion forums. Preparation } \\
\text { was underpinned by Jeffrey's Cultural } \\
\text { Competence and Confidence model. } \\
\text { (Jeffreys \& Smodlaka, 1996) }\end{array}$ & $\begin{array}{l}\text { The impact of a study } \\
\text { abroad course looking } \\
\text { at pre, current, and } \\
\text { post trip data from } \\
\text { students }\end{array}$ & Descriptive \\
\hline & $\begin{array}{l}\text { Davis, LI; } \\
\text { Wright, DJ; } \\
\text { Gutierrez, } \\
\text { MS; } \\
\text { Nam, JJ; } \\
\text { Nguyena, } \\
\text { J; Waite, }\end{array}$ & $\begin{array}{l}\text { Interprofession } \\
\text { al global } \\
\text { service } \\
\text { learning: A } \\
\text { pharmacy and } \\
\text { nursing practice } \\
\text { experience in }\end{array}$ & $\begin{array}{l}\text { Currents in } \\
\text { Pharmacy } \\
\text { Teaching and } \\
\text { Learning } \\
2015\end{array}$ & $\begin{array}{l}\text { Botswana; } \\
\text { USA }\end{array}$ & $\begin{array}{l}\text { Faculty members on trip served as } \\
\text { preceptors and arranged clinical sites } \\
\text { prior to arrival; however not until } \\
\text { arrival were lodging, travel and food } \\
\text { arranged. Faculty members } \\
\text { coordinated with local hospital and } \\
\text { church for students to observe }\end{array}$ & $\begin{array}{l}\text { Pharmacy and nursing } \\
\text { students went to } \\
\text { Botswana on a } \\
\text { Christian service trip. } \\
\text { HIV work and } \\
\text { observation. The study } \\
\text { abroad trip was meant }\end{array}$ & $\begin{array}{l}\text { Qualitative } \\
\text { survey }\end{array}$ \\
\hline
\end{tabular}




\begin{tabular}{|c|c|c|c|c|c|c|c|}
\hline & Author & Title & Publisher & Countries & Preparation & Summary & Method \\
\hline & AT & Botswana & & & $\begin{array}{l}\text { surgeries, etc. and be involved in } \\
\text { religious activities. Students debriefed } \\
\text { daily with a faculty member. Students } \\
\text { attended additional training on HIV. } \\
\text { Students met several times to learn } \\
\text { about their host location where they } \\
\text { learned about the host country, } \\
\text { prevalent diseases, learned from online } \\
\text { resources, and learned from students } \\
\text { who had studied abroad previously. }\end{array}$ & $\begin{array}{l}\text { to teach pharmacy and } \\
\text { nursing students to } \\
\text { work collaboratively. }\end{array}$ & \\
\hline 19. & Bohman, D & $\begin{array}{l}\text { Student } \\
\text { exchange for } \\
\text { nursing } \\
\text { students: Does } \\
\text { it raise cultural } \\
\text { awareness'? A } \\
\text { descriptive, } \\
\text { qualitative } \\
\text { study }\end{array}$ & $\begin{array}{l}\text { Nurse } \\
\text { Education in } \\
\text { Practice } 2013\end{array}$ & $\begin{array}{l}\text { Sweden, } \\
\text { South Africa }\end{array}$ & $\begin{array}{l}\text { Preparation is discussed as students } \\
\text { reading about the placement location } \\
\text { online, preparation meetings, and } \\
\text { individual consultations with the study } \\
\text { coordinator. }\end{array}$ & $\begin{array}{l}\text { Cultural awareness is } \\
\text { the focus of this } \\
\text { article. Preparations } \\
\text { before studying abroad } \\
\text { are discussed, as well } \\
\text { as students' } \\
\text { motivations to study } \\
\text { abroad, and their } \\
\text { experiences while } \\
\text { abroad. }\end{array}$ & $\begin{array}{l}\text { Project } \\
\text { evaluation; } \\
\text { narrative } \\
\text { inquiry }\end{array}$ \\
\hline 20. & Kreye, J & $\begin{array}{l}\text { A Global } \\
\text { Service- } \\
\text { Learning } \\
\text { Experience for } \\
\text { Nursing } \\
\text { Students in } \\
\text { Tanzania: A } \\
\text { Model for } \\
\text { Collaboration }\end{array}$ & $\begin{array}{l}\text { Nursing } \\
\text { Forum } \\
2013\end{array}$ & $\begin{array}{l}\text { USA, } \\
\text { Tanzania }\end{array}$ & $\begin{array}{l}\text { Students prepared to team teach in } \\
\text { Tanzania and took a semester-long } \\
\text { transcultural nursing course } \\
\text { underpinned by Ray's ( } 2010 \text { ) } \\
\text { transcultural caring dynamics. }\end{array}$ & $\begin{array}{l}\text { A study abroad trip } \\
\text { was planned following } \\
\text { an American nursing } \\
\text { school's evaluation of } \\
\text { the host location: a } \\
\text { Tanzanian school of } \\
\text { nursing. The } \\
\text { evaluation was done } \\
\text { according to WHO's } \\
\text { Summary of the Global } \\
\text { Standards for the }\end{array}$ & $\begin{array}{l}\text { Program } \\
\text { evaluation }\end{array}$ \\
\hline
\end{tabular}




\begin{tabular}{|c|c|c|c|c|c|c|c|}
\hline & Author & Title & Publisher & Countries & Preparation & Summary & Method \\
\hline & & & & & & $\begin{array}{l}\text { Initial Education of } \\
\text { Professional Nurses } \\
\text { and Midwives. } \\
\text { Following the study } \\
\text { abroad trip, American } \\
\text { students were asked } \\
\text { questions about their } \\
\text { general experiences } \\
\text { studying abroad. }\end{array}$ & \\
\hline 21. & $\begin{array}{l}\text { Green, B; } \\
\text { Johansson, } \\
\text { I; Rosser, } \\
\text { M; } \\
\text { Tengnah, } \\
\text { C; Segrott, } \\
\text { J }\end{array}$ & $\begin{array}{l}\text { Studying } \\
\text { abroad: A } \\
\text { multiple case } \\
\text { study of } \\
\text { nursing } \\
\text { students' } \\
\text { international } \\
\text { experiences }\end{array}$ & \begin{tabular}{|l} 
Nurse \\
Education \\
Today \\
2008
\end{tabular} & UK, Sweden & $\begin{array}{l}\text { Students are prepared to study abroad } \\
\text { with individual and group meetings. } \\
\text { Details of the trip as well as objectives } \\
\text { are discussed. Students are given } \\
\text { instruction on lines of support and } \\
\text { communication. Information packets } \\
\text { are distributed that include previous } \\
\text { study abroad student experiences. The } \\
\text { authors suggest a change is needed in } \\
\text { current preparation practice and } \\
\text { monitoring of students who study } \\
\text { abroad. The authors further call for } \\
\text { greater engagement with partner HEIs, } \\
\text { and more effective training of staff. }\end{array}$ & $\begin{array}{l}\text { A multiple case study } \\
\text { of two universities that } \\
\text { sends nursing students } \\
\text { on study abroad trips. } \\
\text { Data collection } \\
\text { included interviews } \\
\text { and documentary } \\
\text { analysis to describe } \\
\text { the students' } \\
\text { experiences abroad. }\end{array}$ & Case study \\
\hline 22. & $\begin{array}{l}\text { Koskinen, } \\
\text { L; Jokinen, } \\
\text { P }\end{array}$ & $\begin{array}{l}\text { Multicultural } \\
\text { healthcare: A } \\
\text { transatlantic } \\
\text { project }\end{array}$ & $\begin{array}{l}\text { Nurse } \\
\text { Educator } \\
2007\end{array}$ & $\begin{array}{l}\text { Finland, } \\
\text { England, } \\
\text { Sweden, } \\
\text { USA }\end{array}$ & $\begin{array}{l}\text { Students had the option of completing } \\
\text { an intercultural orientation credit } \\
\text { course prior to studying abroad. } \\
\text { The courses varied based on the } \\
\text { university from which students studied } \\
\text { abroad. Preparation may have included } \\
\text { virtual learning that included games. }\end{array}$ & $\begin{array}{l}\text { A nursing exchange } \\
\text { between American and } \\
\text { European universities. } \\
\text { The aim of the trip was } \\
\text { to increase cultural } \\
\text { competence in order } \\
\text { for newly graduated }\end{array}$ & Descriptive \\
\hline
\end{tabular}




\begin{tabular}{|c|c|c|c|c|c|c|c|}
\hline & Author & Title & Publisher & Countries & Preparation & Summary & Method \\
\hline & & & & & $\begin{array}{l}\text { Courses were underpinned by two } \\
\text { theories, Howell's (1982) } \\
\text { communication theory and Bennett's } \\
\text { (1993) developmental theory of } \\
\text { intercultural sensitivity. However, } \\
\text { between the six universities in the } \\
\text { article, there was variance in how the } \\
\text { theories were taught to students. The } \\
\text { Finnish students were more prepared } \\
\text { than the American students due to a } \\
\text { longer preparation period. The } \\
\text { preparation described was in relation } \\
\text { to achieving cultural competence more } \\
\text { than to the trip in general. }\end{array}$ & $\begin{array}{l}\text { nurses to care for a } \\
\text { diverse population. }\end{array}$ & \\
\hline 23. & Pross, E & $\begin{array}{l}\text { International } \\
\text { nursing } \\
\text { students: a } \\
\text { phenomenologi } \\
\text { cal perspective }\end{array}$ & $\begin{array}{l}\text { Nurse } \\
\text { Education } \\
\text { Today } \\
2005\end{array}$ & $\begin{array}{l}\text { USA, } \\
\text { Mexico, } \\
\text { Guatemala, } \\
\text { Norway, } \\
\text { Russia, } \\
\text { Honduras, } \\
\text { China, West } \\
\text { Africa, New } \\
\text { Zealand, } \\
\text { and } \\
\text { The } \\
\text { Mediterrane } \\
\text { an }\end{array}$ & $\begin{array}{l}\text { Nursing students began planning } \\
\text { 'anywhere from one week to a year } \\
\text { prior to departure' (p. 629). } \\
\text { Preparation ranged from researching } \\
\text { culture, studying the local language, } \\
\text { fund raising, and preparing educational } \\
\text { materials. One student applied to study } \\
\text { abroad only four days before } \\
\text { departure. She reported bawling the } \\
\text { entirety of the first day of the study } \\
\text { abroad trip, stating 'it was so horrible' } \\
\text { (p. } 630 \text { ). The author refers to a six } \\
\text { month group preparation, however the } \\
\text { student above was allowed to study } \\
\text { abroad without the group preparations. } \\
\text { This article contains student quotes of }\end{array}$ & $\begin{array}{l}\text { A study abroad trip } \\
\text { focused on preparing } \\
\text { students for an } \\
\text { increasingly global } \\
\text { population. Data were } \\
\text { collected from nursing } \\
\text { students in North } \\
\text { Dakota via mail } \\
\text { surveys and } \\
\text { interviews. }\end{array}$ & $\begin{array}{l}\text { Phenomenolo } \\
\text { gy }\end{array}$ \\
\hline
\end{tabular}




\begin{tabular}{|c|c|c|c|c|c|c|c|}
\hline & Author & Title & Publisher & Countries & Preparation & Summary & Method \\
\hline & & & & & being afraid, hearing gun shots, etc. & & \\
\hline 24. & $\begin{array}{l}\text { Currier, C; } \\
\text { Omar, M; } \\
\text { Talarczyk, } \\
\text { G; Diaz, } \\
\text { RG }\end{array}$ & $\begin{array}{l}\text { Development } \\
\text { and } \\
\text { implementation } \\
\text { of a semester } \\
\text { program in } \\
\text { Mexico for } \\
\text { senior nursing } \\
\text { students }\end{array}$ & $\begin{array}{l}\text { Journal of } \\
\text { Professional } \\
\text { Nursing, } 2000\end{array}$ & USA, Mexico & $\begin{array}{l}\text { Students attended preparation } \\
\text { meetings prior to departure and after } \\
\text { arriving in Mexico. Meetings were } \\
\text { focused on the transition of students } \\
\text { living in Mexico, navigating their life } \\
\text { and work whilst speaking Spanish, and } \\
\text { culture shock. A conference was held } \\
\text { to communicate course expectations } \\
\text { and create personal learning } \\
\text { objectives. Upon arrival in Mexico, } \\
\text { students received an orientation on } \\
\text { basic requirements such as the } \\
\text { transportation system. }\end{array}$ & $\begin{array}{l}\text { A study abroad } \\
\text { programme that allows } \\
\text { American students to } \\
\text { complete a semester } \\
\text { of nursing studies in } \\
\text { Mexico. }\end{array}$ & Descriptive \\
\hline 25. & $\begin{array}{l}\text { Inglis, } \mathrm{A} ; \\
\text { Rolls, C; } \\
\text { Kristy, S }\end{array}$ & $\begin{array}{l}\text { The impact on } \\
\text { attitudes } \\
\text { towards } \\
\text { cultural } \\
\text { difference of } \\
\text { participation in } \\
\text { a health } \\
\text { focused study } \\
\text { abroad } \\
\text { program }\end{array}$ & $\begin{array}{l}\text { Contemporary } \\
\text { Nurse } \\
2000\end{array}$ & $\begin{array}{l}\text { Australia, } \\
\text { Nepal }\end{array}$ & $\begin{array}{l}\text { One sentence description of } \\
\text { preparation included lectures on the } \\
\text { health care system of Nepal, health } \\
\text { problems of women and children and } \\
\text { Nepalese culture. }\end{array}$ & $\begin{array}{l}\text { A study assessing } \\
\text { changes in attitude } \\
\text { between nursing } \\
\text { students who studied } \\
\text { abroad and those who } \\
\text { did not. Students who } \\
\text { studied abroad were } \\
\text { shown to change } \\
\text { cultural attitudes while } \\
\text { their fellow students } \\
\text { who did not study } \\
\text { abroad had no shift. }\end{array}$ & $\begin{array}{l}\text { Questionnaire } \\
\text {, control } \\
\text { group }\end{array}$ \\
\hline 26. & $\begin{array}{l}\text { Rolls, C; } \\
\text { Inglis, } \mathrm{A} ; \\
\text { Kristy, S }\end{array}$ & $\begin{array}{l}\text { Study abroad } \\
\text { programs: } \\
\text { Creating } \\
\text { awareness of }\end{array}$ & $\begin{array}{l}\text { Contemporary } \\
\text { Nurse } \\
1997\end{array}$ & $\begin{array}{l}\text { Australia, } \\
\text { Thailand }\end{array}$ & $\begin{array}{l}\text { Students attend four workshops that } \\
\text { cover Thai culture and etiquette. } \\
\text { Literature is provided for students to } \\
\text { read about the Thai health system, }\end{array}$ & $\begin{array}{l}\text { Study abroad program } \\
\text { that taught students } \\
\text { increased confidence } \\
\text { and an understanding }\end{array}$ & Descriptive \\
\hline
\end{tabular}




\begin{tabular}{|c|c|c|c|c|c|c|c|}
\hline & Author & Title & Publisher & Countries & Preparation & Summary & Method \\
\hline & & $\begin{array}{l}\text { and changing } \\
\text { attitudes to } \\
\text { nursing, health } \\
\text { and ways of } \\
\text { living in other } \\
\text { cultures }\end{array}$ & & & $\begin{array}{l}\text { practices, and needs. Finally, students } \\
\text { are encouraged to undertake their own } \\
\text { preparation. }\end{array}$ & $\begin{array}{l}\text { of different cultures to } \\
\text { prepare for future } \\
\text { careers caring for a } \\
\text { diverse population }\end{array}$ & \\
\hline 27. & $\begin{array}{l}\text { Critchley, } \\
\text { K; } \\
\text { Richardson } \\
\text {, E; Aarts, } \\
\text { C; } \\
\text { Bergknut, } \\
\text { E; } \\
\text { Campbell, } \\
\text { B; } \\
\text { Hemmingw } \\
\text { ay, A; } \\
\text { Koskines, } \\
\text { L; } \\
\text { Juhansoo, } \\
\text { T; Mitchell, } \\
\text { M; } \\
\text { Nordstrom, } \\
\text { P }\end{array}$ & $\begin{array}{l}\text { Student } \\
\text { experiences } \\
\text { with an } \\
\text { international } \\
\text { public health } \\
\text { exchange } \\
\text { project }\end{array}$ & $\begin{array}{l}\text { Nurse } \\
\text { Educator, } \\
2009\end{array}$ & $\begin{array}{l}\text { Canada, } \\
\text { USA, UK, } \\
\text { Finland, } \\
\text { Estonia, } \\
\text { Sweden }\end{array}$ & $\begin{array}{l}\text { Preparation began with a faculty site } \\
\text { visit, and ample opportunity for faculty } \\
\text { to become acquainted. Blackboard } \\
\text { software that all students and faculty } \\
\text { could meet on electronically was } \\
\text { available to ask questions and share } \\
\text { information. HEIs came up with } \\
\text { parameters for location of study } \\
\text { abroad trips, i.e. rural or urban, } \\
\text { observation or hands-on. Language } \\
\text { courses were recommended, however } \\
\text { the HEI language courses were not } \\
\text { always offered at the appropriate } \\
\text { semester before students would study } \\
\text { abroad, complicating students' ability } \\
\text { to prepare linguistically. Some } \\
\text { students expressed difficulty } \\
\text { anticipating their preparation needs, } \\
\text { not knowing certain details of the trip } \\
\text { until immediately before departure. } \\
\text { However, most students reported they } \\
\text { felt the preparation was 'good'. }\end{array}$ & $\begin{array}{l}\text { A description of a } \\
\text { study abroad program } \\
\text { attempting to increase } \\
\text { work experiences } \\
\text { abroad, allow nursing } \\
\text { students to move } \\
\text { about more freely, and } \\
\text { collaborate more easily } \\
\text { with international } \\
\text { colleagues. }\end{array}$ & Descriptive \\
\hline 28 & $\begin{array}{l}\text { Mill JE; } \\
\text { Yonge, OJ } \\
\text {; Cameron, }\end{array}$ & $\begin{array}{l}\text { Challenges and } \\
\text { opportunities of } \\
\text { international } \\
\text { clinical practica }\end{array}$ & $\begin{array}{l}\text { International } \\
\text { Journal of } \\
\text { Nursing }\end{array}$ & $\begin{array}{l}\text { Canada, } \\
\text { Guatemala, } \\
\text { Ghana }\end{array}$ & $\begin{array}{l}\text { Preparation process includes general } \\
\text { knowledge about the destination } \\
\text { country, culture, healthcare systems, }\end{array}$ & $\begin{array}{l}\text { Presents the origins of } \\
\text { study abroad trips in } \\
\text { nursing, along with }\end{array}$ & Descriptive \\
\hline
\end{tabular}




\begin{tabular}{|c|c|c|c|c|c|c|c|}
\hline & Author & Title & Publisher & Countries & Preparation & Summary & Method \\
\hline & $\mathrm{BL}$ & & $\begin{array}{l}\text { Education } \\
\text { Scholarship } \\
2005\end{array}$ & & $\begin{array}{l}\text { role of nurses, common health } \\
\text { conditions, and language training. } \\
\text { Perhaps the greatest emphasis of the } \\
\text { preparation is for students to be } \\
\text { culturally aware and sensitive to the } \\
\text { differences in health and clinical } \\
\text { practices. The authors stress the need } \\
\text { to teach safe sex, safety regarding } \\
\text { drug and alcohol use, and worker's } \\
\text { compensation - implying risk } \\
\text { management of sending students } \\
\text { abroad is becoming more complex. }\end{array}$ & $\begin{array}{l}\text { their challenges, a } \\
\text { description of } \\
\text { experiences, evidence } \\
\text { to support study } \\
\text { abroad trips. States } \\
\text { benefits are greater in } \\
\text { students who study in } \\
\text { developing countries, } \\
\text { as opposed to } \\
\text { developed countries. }\end{array}$ & \\
\hline 29. & $\begin{array}{l}\mathrm{Hu}, \mathrm{J} ; \\
\text { Andreatta, } \\
\mathrm{S} ; \\
\text { Yu, L; Li, S }\end{array}$ & $\begin{array}{l}\text { A collaborative } \\
\text { international } \\
\text { community } \\
\text { health nursing: } \\
\text { Clinical } \\
\text { experience in } \\
\text { China }\end{array}$ & $\begin{array}{l}\text { Home Health } \\
\text { Care } \\
\text { Management } \\
\text { and Practice } \\
2010\end{array}$ & China, USA & $\begin{array}{l}\text { Preparation included students selecting } \\
\text { various health related topics in the } \\
\text { region, and made presentations on } \\
\text { symptom awareness. Students also } \\
\text { chose topics of history, culture, etc. to } \\
\text { make presentations and share with } \\
\text { their classmates before the study } \\
\text { abroad trip. No meetings are } \\
\text { mentioned, but must have occurred in } \\
\text { order for students to make } \\
\text { presentations to one other. }\end{array}$ & $\begin{array}{l}\text { A study abroad trip } \\
\text { from USA to China to } \\
\text { increase student } \\
\text { cultural competence. } \\
\text { Refers to } \\
\text { States six domains } \\
\text { that positively affect } \\
\text { students who study } \\
\text { abroad: 'decision } \\
\text { making, role of } \\
\text { learner, role of } \\
\text { teacher, role of peers, } \\
\text { evaluation, and view } \\
\text { of knowledge, truth, or } \\
\text { reality for nursing } \\
\text { students. However, } \\
\text { these forms of } \\
\text { cognitive growth were } \\
\text { not as apparent in }\end{array}$ & Descriptive \\
\hline
\end{tabular}




\begin{tabular}{|c|c|c|c|c|c|c|c|}
\hline & Author & Title & Publisher & Countries & Preparation & Summary & Method \\
\hline & & & & & & $\begin{array}{l}\text { students who did not } \\
\text { participate in a study } \\
\text { abroad program } \\
\text { (Frisch, 1990; Zorn, } \\
\text { Ponick, \& Peck, 1995).' }\end{array}$ & \\
\hline 30. & $\begin{array}{l}\text { Johns, A; } \\
\text { Thompson, } \\
\text { C }\end{array}$ & $\begin{array}{l}\text { Developing } \\
\text { cultural } \\
\text { sensitivity } \\
\text { through study } \\
\text { abroad }\end{array}$ & $\begin{array}{l}\text { Home Health } \\
\text { Care } \\
\text { Management } \\
\text { \& Practice } \\
2010\end{array}$ & $\begin{array}{l}\text { Guatemala, } \\
\text { USA }\end{array}$ & $\begin{array}{l}\text { The university is small, with no prior } \\
\text { experience sending students to study } \\
\text { abroad trips. A decision was made to } \\
\text { outsource the study abroad logistics to } \\
\text { a local religious organisation familiar } \\
\text { with volunteer trips to low-income } \\
\text { countries, including Guatemala. } \\
\text { The religious organisation had logistical } \\
\text { details in place from prior trips } \\
\text { (including vaccination requirements, } \\
\text { travel arrangements, personal safety } \\
\text { provisions, etc.), allowing the faculty } \\
\text { extra time to prepare students for the } \\
\text { nursing-related aspects of the trip. } \\
\text { States faculty met with the students } \\
\text { 'regularly' leading up to the trip. } \\
\text { Discussions focused on culture wherein } \\
\text { the faculty gave examples of cultural } \\
\text { norms students could expect to see in } \\
\text { Guatemala. Students were required to } \\
\text { keep a journal as part of their } \\
\text { preparation, writing their reflections of } \\
\text { preparation discussions prior to } \\
\text { entering into a different cultural } \\
\text { context. Students completed a cultural } \\
\text { assessment test prior to departure. }\end{array}$ & $\begin{array}{l}\text { Descriptive article of a } \\
\text { study abroad program } \\
\text { to Guatemala with a } \\
\text { purpose of developing } \\
\text { cultural sensitivity. }\end{array}$ & Descriptive \\
\hline
\end{tabular}


* Did not offer preparation training; offered discussion of what ought to be done

$\wedge$ Did not offer preparation training; students were already studying abroad when study was done

Key:

Course for credit

Meeting

Content of course or meeting

Students led preparation

Faculty responsibilities

Mention/implication of preparation failture 


\section{APPENDIX B}

\section{PERMISSION FROM DAVID CITRIN}

DC David Citrin <dcitrin@uw.edu>

Fri 12/20/2013, 1:36 AM

HOLLY LEAR (1315092); Winifred Eboh (fns) $\approx$

Inbox

Dear Holly,

You are welcome to use my thesis as a jumping off point for your own questions/study. I'm very glad you enjoyed it, please let me know if I can help in any other way.

Best regards,

David

On Thu, Dec 19, 2013 at 2:31 AM, Holly Lear < h.m.lear@rgu.ac.uk> wrote: Dear David,

My name is Holly Lear, and I am a PhD student studying at Robert Gordon University in Aberdeen, Scotland.

I would be very grateful if you would give me permission to adapt your methodology used in your master's thesis, "Paul Farmer Made Me Do It": A Qualitative Study of Short-Term Medical Volunteer Work In Remote Nepal. Your work is closely related to my topic, which is the preparedness of volunteer nurses in communities without access to adequate healthcare. I am interested in adapting your questions for use in my own research. I look forward to hearing from you, and I enjoyed reading your thesis.

Kind regards and Merry Christmas,

Holly Lear, RN MPH 


\section{APPENDIX C \\ INTERVIEW QUESTIONS FROM DAVID CITRIN'S PAPER}

Group I: Medical volunteers

(1) Why did you come to volunteer in Nepal?

(2) What are the specific goals

i. Of the participating organisation here in Nepal? [Before]

ii. For you as a volunteer?

iii. Do you feel as though you accomplished your goals?

(3) What do you think are some of the benefits and limitations of short-term volunteer work (e.g., w/ NGOs, at private and teaching hospitals, at government or NGO (sub-) health posts, at health camps)?

(4) What are some of the ethical issues involved in short-term volunteer work?

(5) What might be some of the impacts of medical volunteer work?

(6) What other stories would you offer in light of your volunteer experience?

(7) What suggestions do you have for the organisation you are affiliated with, or others, to improve future medical volunteer programs?

(8) What suggestions do you have for future medical volunteers coming to remote parts of Nepal?

(9) What suggestions do you have for a potential "International Medical Volunteer Code of Conduct"?

Group II: Humli villagers who interact with medical volunteers

(1) Why did you seek out this person's medical care?

(2) What was your experience of interacting with the medical volunteer?

(3) Was the reason you came addressed?

(4) Are you satisfied with your interaction with the medical volunteer?

Groups III \& IV: Nepali Health Workers and NGO Staff

(1) What has been your experience working with medical volunteers?

(2) What do you think are some of the benefits and limitations of short-term

volunteer work (e.g., w/ NGOs, at private and teaching hospitals, at government 
or NGO (sub-) health posts, at health camps)?

(3) What are some of the ethics involved in short-term volunteer work?

(4) What might be some of the impacts of medical volunteer work?

(5) What other stories would you offer in light of your experience working with volunteers?

(6) What suggestions do you have for the organisation you are affiliated with, or others, to improve future medical volunteer programs?

(7) What suggestions do you have for future medical volunteers coming to remote parts of Nepal?

(8) What suggestions do you have for a potential "International Medical Volunteer Code of Conduct"? 


\section{APPENDIX D \\ REFLEXIVE INTERVIEW QUESTIONS}

Questions regarding time before studying abroad

(1) Why do you want to study abroad in Kenya?

(2) What are the specific goals

i. Of the participating organisation here in Kenya?

ii. For you as a student

(3) Do you feel prepared for the work you are about to do?

(4) What are some health needs in the area where you are going?

(5) What might be some of the impacts of your work?

Questions regarding time after studying abroad

(1) Why did you come to study abroad in Kenya?

(2) What has been your experience providing care (ethnonursing) as a nursing student?

(3) How prepared did you feel during your short-term study?

(4) What do you feel were some of the impacts of your study abroad trip?

(5) What other stories would you offer in light of your volunteer experience?

(6) What suggestions do you have for the organisation you are affiliated with, or others, to improve future nursing study abroad programmes?

(7) What suggestions do you have for future nursing students coming to Kenya?

(8) What suggestions do you have for future nursing students about preparing before they arrive?

Questions adapted with permission (see Appendix B) from:

Citrin DM (2011) 'Paul Farmer made me do it': A qualitative study of shortterm medical volunteer work in remote Nepal. Doctoral dissertation, University of Washington. 


\title{
APPENDIX E
}

\section{SCHOOL OF NURSING AND MIDWIFERY ETHICS REVIEW PANEL APPROVAL}

\author{
Holly Lear \\ Research student \\ Robert Gordon University \\ Date: $8^{\text {th }}$ April 2014
}

Research proposal number: $14 / 04$

Research proposal title: The preparedness and perceived impact of transcultural volunteer nurses and nursing students in low resource settings

Dear Holly

The School of Nursing and Midwifery Ethics Review Panel has now reviewed the above research proposal in view of the amendments you submitted. Please find details of the outcome and recommended actions below.

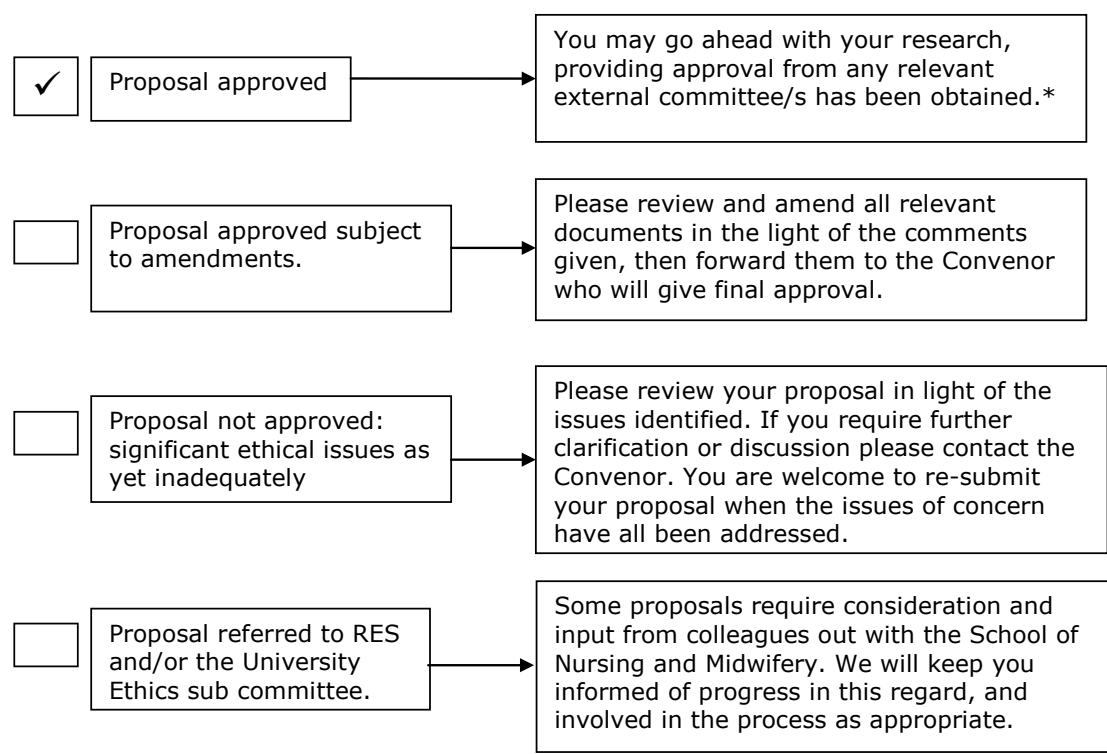

* Where research involves NHS staff or patients, approval through the NRES system must be obtained. Members of the School Panel can advise on this process if necessary. 


\section{Comments}

Thank you very much for submitting full responses to comments and questions raised in our response to your SERP application. We are now pleased to give approval for you to go ahead with your proposed study. However, if your supervisor feels review of your information sheet regarding blog requirements and diary entries is necessary (following Phase 1) we would be most willing to check them over. In addition, we do still feel Citrin's questionnaire is quite medically focused and may require some additional reworking to take a nursing perspective.

As you proceed, please do not hesitate to get in touch with SERP again with questions regarding ethical issues that may arise. We would be very pleased to help in any way we can. This is an important area of research and we wish you well as you begin the study and your PhD. It would be interesting to hear how you progress and at a later stage, the outcomes of your work.

Yours sincerely,

\section{Signatures of Panel members}

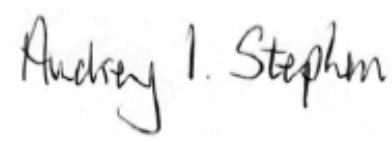

\section{Position held:}

Research Fellow/SERP Convenor, School of Nursing and Midwifery Robert Gordon University

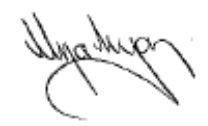

Lecturer

Robert Gordon University

If you require further information please contact the Panel Convenor, Audrey Stephen, on 01224263150.

When you have completed your research project, please send a copy of your final report to:

Dr Audrey Stephen

School of Nursing and Midwifery

Robert Gordon University 


\section{APPENDIX F \\ PERMISSION FROM HEI IN FINLAND}

KAJAANIN

AMMATTIKORKEAKOULU

UNIVERSITY OF APPLIED SCIENCES
Letter of Permission

9.6.2014

Holly Lear

20 Wingate Place

Aberdeen

AB24 2TD

Scotland, UK

Holly Lear is allowed to carry out this research for the purpose of completing a PhD, will be given information about Health Africa, is allowed to interview student nurses and trained nurses who are planning to go or have returned from a volunteer trip to Africa, and allowed to access blogs and diaries to collect data for her research.

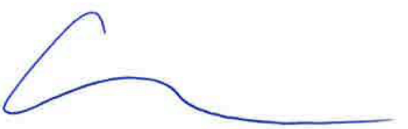

Turo Kilpeläinen

President

KAMK University of Applied Sciences

PO Box 52

87101 Kajaani

Finland

gsm: +358447101600

email: turo.kilpelainen@kamk.fi www.kamk.fi

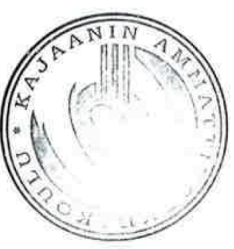

PL 52/P.O.BOX 52, Ketunpolku 3 | 87101 Kajaani, Finland | Puh./Tel. +358 (0)8618 991 | Faksi/Fax +358 (0)8 61899603 | www.kajak.fi 
APPENDIX G

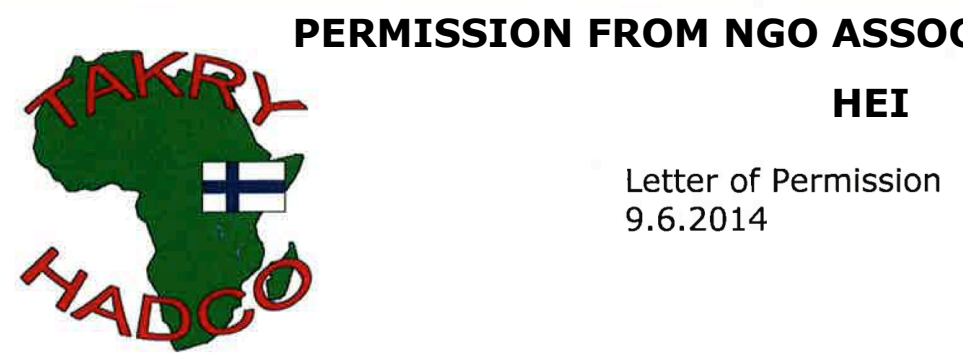

Holly Lear

20 Wingate Place

Aberdeen

AB24 2TD

Scotland, UK

Holly Lear is allowed to carry out this research for the purpose of completing a PhD, will be given information about Health Africa Programmes, is allowed to interview student nurses and trained nurses who are planning to go or have returned from a volunteer trip to Africa, and allowed to access blogs and diaries to collect data for her research.

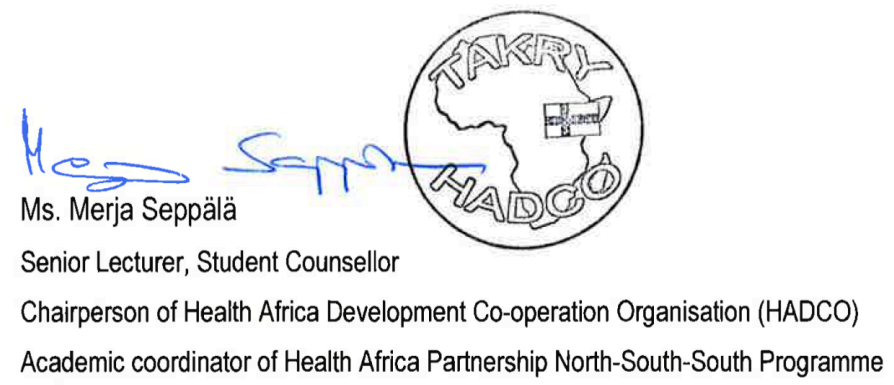

Terve Afrikka Kehitysyhteistyö ry - Health Africa Development Co-operation Organisation

C/o Centria University of Applied Sciences

Unit of Kokkola - Pietarsaari

Terveystie 1

Mobile $\quad+358447250562$

E-mail_merja.seppala@centria.fi 


\section{APPENDIX H \\ PERMISSION FROM HEI IN THE NETHERLANDS}

Faculteit Gezondheidszorg

Nieuw Eyckholt 300, 6419 DJ Heerlen

Postbus 550, 6400 AN Heerlen

Telefoon +31 (0)45400 60 60

info@zuyd.nl, www.zuyd.nl

\section{Zuyd Hogeschool}

Holly Lear

20 Wingate Place

Aberdeen

AB24 2TD

Scotland, UK
Plaats
Datum
Onderwerp
Heerlen
05.03.2014
Invitation Mrs. Holly Lear

Dear Holly,

It is with great pleasure that I can write you that Holly Lear is welcome to do a part of your PhD research at Zuyd University of applied sciences, Faculty of Health.

Holly is allowed to carry out this research for the purpose of completing a $\mathrm{PhD}$, will be given information about ZUYD and the International Office (more specifically: the YPO programme), is allowed to interview student nurses and trained nurses who are planning to go or have returned from a volunteer trip to South Africa, and allowed to access blogs and diaries (after given permission by the students) to collect data for my research.

With best regards,

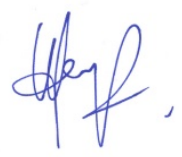

Ruud Heijnen

Contact person Ruud Heijnen

Telephone $+31(0) 454006302$

GSM: +3161478 2034

E-mail ruud.heijnen@zuyd.nl 


\section{APPENDIX I CONSENT FORM FOR STUDY ABROAD COORDINATORS}

Title of project: The preparedness and perceived impact of transcultural volunteer nurses and nursing students in low resource settings

Name of Researcher: Holly Lear, PhD student at the Institute of Health Welfare Research, Robert Gordon University

Thank you for participating in this research project. Please initial box

1. I agree to my interview being audio recorded for research purposes.

2. I agree to allow my anonymised quotes to be used in any research output (e.g. academic articles, professional papers, conference presentations) from this study.

3. I understand that I have the right to withdraw from this study at any time.

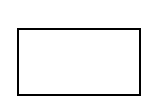

$$
\text { withdraw from this study at any time. }
$$

Name of student Date Signature

Name of person taking consent Date Signature

When complete, please scan and email this form to the researcher at h.m.lear@rgu.ac.uk

Please keep a copy of this form for your own records. 


\section{APPENDIX J \\ CONSENT FORM FOR STUDENTS}

Title of project: The preparedness and perceived impact of transcultural volunteer nurses and nursing students in low resource settings

Name of Researcher: Holly Lear, PhD student at the Institute of Health Welfare Research, Robert Gordon University

Thank you for participating in this research project. Please initial box

4. I agree to my interview being audio recorded for research purposes.

5. I agree to keep a blog that will include writing and pictures about my experiences at least once a week.

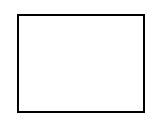

6. I agree to keep a diary about my feelings as I volunteer and encounter the change in culture and healthcare practices.

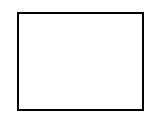

7. I agree to allow my anonymised quotes to be used in any research output (e.g. academic articles, professional papers, conference presentations) from this study.

8. I understand that I have the right to withdraw from this study at any time.

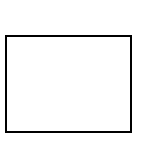

Name of student Date Signature

Name of person taking consent Date Signature

When complete, please scan and email this form to the researcher at h.m.lear@rgu.ac.uk

Please keep a copy of this form for your own records. 


\section{APPENDIX K \\ EXEMPTION FROM FURTHER ETHICS REVIEW PANEL APPROVAL}

Dear Holly,

Thank you very much for letting us know of your plan to widen your recruitment net to include students at the Finnish University. You will not need to make a formal SERP application for this purpose. We have noted your amendment and trust you will adhere to the previously agreed recruitment and data collection procedures. I hope you have a positive response and the data you collect from them usefully adds another perspective.

Best wishes,

Audrey

Dr Audrey Stephen

Research Fellow/SERP convenor

School of Nursing and Midwifery

Faculty of Health and Social Care

The Robert Gordon University

Garthdee Road

Aberdeen

AB10 7QG

01224263150 


\section{APPENDIX L \\ INFORMATION SHEET FOR PARTICIPANTS}

\section{YOU WILL BE GIVEN A COPY OF THIS INFORMATION SHEET}

I would like to invite you to participate in an original research project. Before you decide whether you want to take part, it is important for you to understand why the research is being done and what your participation will involve. Please take time to read the following information carefully and discuss it with others if you wish. Please ask if there is anything that is not clear or if you would like more information. You should only participate if you want to. Choosing not to take part will not disadvantage you in any way and you may drop out of the study at any time without question.

\section{Research Aims}

I am interested in your experiences before and during your volunteer trip to South Africa. I am interested in how prepared you feel before going, and how prepared you feel while you volunteer. I am also interested in whether you feel you made lasting impacts on the community after you volunteered. Specifically, I want to research how you would describe your preparation process before your trip, and how you perceive the impacts to local communities. My goal for this project is to provide new information for future nursing volunteer trips. At the conclusion of this study, I will provide you with a summary of the main findings.

Who Has Been Asked to Participate?

I am inviting student nurses and nurses from an academic institution in Holland to take part in this research study. I am inviting people from this academic institution because it has a reputation for equipping volunteers prior to sending medical trips to South Africa.

\section{Who Must Be Excluded?}

Unfortunately, I must ask you not to participate if you are volunteering in South Africa at any time other than September through December of 2014. This is because the memory of your preparation process needs to be recent in your mind.

When and Where Will the Study Take Place?

The study will take place before and after your volunteer trip to South Africa. I will begin collecting data about your academic institution in April 2014 and will begin collecting data from you as your prepare to leave for South Africa in August 2014. I will conduct interviews in Holland in early 2015 after you have returned from volunteering.

What Will You Be Asked to Do?

- You will be asked to talk about how prepared you felt prior to your volunteer trip. You will be asked to talk about how you felt when you arrived in South Africa, and how prepared you felt as your work began. 
- You will be asked to talk about the community you served. You will be asked to talk about how you felt you impacted them.

- You will be asked to keep a blog during your volunteer trip. This will include regularly uploading pictures, writing about events that happen and your experiences while volunteering. Should you wish to participate, I will provide you with a document containing more information about the blog requirements.

- You will be asked to keep a personal diary while you are in South Africa. This should include your thoughts and feelings about the volunteer experience. You may write about the change in culture, the differences in healthcare structures, the way the hospital is run, or other experiences you have while volunteering. Should you wish to participate, I will provide you with a document containing more information about the diary requirements.

\section{Why Am I Collecting This From You?}

Every year, thousands of medical professionals go on overseas volunteer trips. Just like you, they try to prepare the best they can. In this study, I am collecting information from you (the sample) to determine how ready you feel for the journey ahead of you. The information gathered will be analysed and will be the main focus of my study.

\section{Will You Compensate Me for My Time?}

No. However to thank you for taking the time to participate, your academic institution will recognise your trip to South Africa, and the information you provide will be used to make future trips even better. You will not benefit financially from the research.

\section{Are There Any Risks Involved in Participating?}

The risks involved in participating are minimal. The interview may be mildly distressing for some of you, if you begin talking about an experience that was particularly difficult. If there are questions that you find distressing or intrusive, you are free to not answer those questions or to withdraw from participating. Remember you can withdraw from participation at any time without penalty.

Are There Any Benefits Involved in Participating? I will send you the major findings at the conclusion of the project. I will alert you to any research publications generated from the project.

How Will I Maintain Your Privacy and Confidentiality?

Everything you tell me will remain completely confidential within the limits of the law.

I will give you an identification number to replace any information I have in the data file that identifies your name, your blog URL or any other contact 
details I have for you. The information you give me during the interview will be completely anonymised and the only thing to identify you will be a numerical ID. Please remember that what you post on your blog is public domain and a reader may be able to trace your blog from my research project.

Your responses during interviews will remain completely confidential unless you tell me something to indicate that your own health and safety is in danger.

\section{Who is Organising the Research?}

The Principle Investigator for this research is Holly Lear, who is a doctoral student at Robert Gordon University in Aberdeen, Scotland. The Principle Supervisor for this study is Dr. Winifred Eboh.

What If I Have Questions about the Project?

Please contact Holly by email at h.m.lear@rgu.ac.uk, or by post at Institute for Health \& Welfare Research, Robert Gordon University, Garthdee House, Garthdee Road, Aberdeen, AB10 7QB, Scotland, United Kingdom

It is up to you to decide whether to take part or not. If you decide to take part you are still free to withdraw at any time and without giving a reason. You may withdraw your data from the project at any time up until this project is submitted (anticipated summer 2016). If you do decide to take part you will be given this information sheet to keep and be asked to sign a consent form. 


\section{APPENDIX M \\ GUIDELINES FOR BLOGS AND DIARIES}

\section{PLEASE KEEP A COPY OF THIS INFORMATION}

\section{South Africa Nursing Student Volunteer Experience Study}

Thank you for taking part in this research project. The guidelines below will help you know what to include in each entry, but feel free to include other related topics. Remember you have the right to withdraw from the study at any time without giving a reason. Thank you for your time.

\section{Diaries}

While you are in South Africa, please keep an audio diary on your mobile phone or computer. Feel free to record sounds around you that are typical of your daily activities at work and where you are staying. Try not to let the diary change how you would go about your day. Share thoughts and experiences in your diary that you would give the researcher a deeper insight into your whole experiences.

- Record an entry in your diary once a week at a time that suits you.

- Begin your entry saying, "This is [your name] and today is [date]."

- Tell me some experiences that have happened this week at work or in your free time.

- Try to remember your thoughts and feelings at the time of the experiences you're talking about. (What happened in a typical day in your work environment? How did you manage your time or situation that arose? Were you prepared for events of that day/week? Do you feel you have made an impact on the people around you?)

- Give an assessment of your week as a whole. Use terms which best capture your thoughts, emotions, aspirations or overall experience on this journey. When you are finished, email the entry to the researcher.

\section{Blogs}

While you are in South Africa, please keep a blog as suggested by your university. Remember that blogs are public and others will be able to read your entries. Try not to let the blog change how you would go about your day.

- Create a blog entry once a week.

- Please feel free to post pictures or videos you take. It is important that you gain permission before you take a picture or video of a person.

- Be interactive with each other's blogs by posting comments.

- If possible share your blog entries with friends and family so they can see how your experience is unfolding whilst you are in South Africa.

If you have any questions about this project, please contact Holly by email at h.m.lear@rgu.ac.uk 


\section{APPENDIX N \\ INTERVIEW PROMPTS FOR HEI - PILOT}

- Profile of the International Office

- How are you involved with the International Office?

- How would you describe the purpose of this programme?

- Where are students able to travel with this organisation?

- What criteria are used to select students?

- Historical data of how the international internship programme began

- When did this internship programme begin?

- What is the average number of students each year and to which institutions?

- Relational information on how organisations in South Africa were chosen as the internship site for nursing students and nurses to volunteer

- Where is the students site in South Africa?

- How was this site selected?

- Do students receive any additional training once they arrive at this site?

- Preparation and training material given to students prior to travelling to South Africa

- How does the International Office prepare students for traveling to South Africa?

- What is the rationale for sending students to Africa?

- What are the benefits to Zuyd University for sending out these students?

- What are the benefits to students who go to South Africa?

- Risk assessment data that has been collected to ensure health and safety for students while in South Africa

- Are students screened for health problems before and after volunteering?

- Are vaccinations required before leaving on volunteer trips?

- Is there a person the student/nurse should alert at the university if a volunteer posts something in a blog that is inappropriate or suggests an unmet need?

- Who is responsible for the students from ZUYD should something go wrong at the site in South Africa?

- Are there counsellors available for nurses and student nurses to talk to on their return should they experience recall anxiety following interviews. 
- Planned time for additional information, including overall success of the internship program, strengths and weaknesses, miscellaneous information interviewee wishes to share with the researcher.

\section{Miscellaneous}

Do nurses and student nurses learn about the laws and health policies in South Africa before arriving?

Are pictures usually included in student blogs and should this be required in my study?

How often do students write in their blogs?

Do all the students speak English fluently, or should I find an interpreter? 


\section{APPENDIX 0 \\ INTERVIEW QUESTIONS FOR STUDENTS}

Before Questions (15 minutes)

(1) How did you decide to go on the internship to $?$

(2) What do you know about this area where you are going, and the organisation you will be working with?

Help: The health needs, healthcare structure in the area

(3) Can you describe to me what you will be doing during your internship?

(4) What do you hope to gain from this internship, and how might this affect your future nursing career?

i. What do you hope to offer to the people you will be caring for during the internship?

(5) How have you prepared for this internship?

(6) We all have a culture we learn from our family and friends, and you will be entering into a new culture. Imagine a line, with a scale from 0 to 10. On the 0 side you feel separate or outside of the new culture. On the other side you feel you fit in to the new culture. Where do you think you will be on this line when you arrive in South Africa?

Thank you for your time, you have my contact details if you need to reach me. Have a wonderful trip.

After Questions (60 minutes)

(1) What was your initial reaction to the change in food, water, and where you lived? (Maslow)

(2) Tell me what you did on a typical day.

i. What were some of your experiences providing care for people?

(3) Did your training prepare you for what you experienced when you were in South Africa/Kenya?

i. What aspect of your training enabled you to feel prepared?

(4) Were your expectations met of:

i. What you wanted to gain from the placement?

ii. What you wanted to offer the people you cared for? 
(5) Has this experience changed you?
i. Personally
ii. As a future nurse, your life plans or ambitions?

(6) Do you remember the model we talked about, with the line from 1 to 6 ? From feeling like an outsider to feeling comfortable in the new culture? (Bennett)

i. Did your position change during your placement?

(7) What suggestions do you have for:

i. The preparation you received from your HEI, to assist future internships?

ii. The receiving organisations in SA?

iii. Future volunteers about preparing for a placement like this?

Is there anything else you would like to share that my questions have not covered?

Thank you for your time. I am expected to finish my study in 2016, I would be happy to share the results of my study with you. You have my contact details if you need to reach me. 


\section{APPENDIX P}

\section{INTERVIEW PROMPTS FOR HEI}

The following areas will inform the questions asked during Phase 1 of this study. The researcher will conduct a cross sectional survey of the academic institution in The Netherlands April $18^{\text {th }} 2014$. This institution is the sending body through which nurses and nursing students enrol to volunteer in South Africa.

Interview with Ruud Heijnen \& Claudy Cobben-Crefcouer, coordinator of Young Professionals Overseas (YPO).

- Profile of the International Office

- How are you involved with the International Office?

- How would you describe the purpose of this programme?

- Where are volunteers able to travel with this organisation?

- What criteria are used to select volunteers?

- Historical data of how the international internship programme began

- When did this internship programme begin?

- What is the average number of volunteers each year and to which institutions?

- Preparation and training material given to volunteers prior to travelling to South Africa

- How does the International Office prepare volunteers for traveling to South Africa?

- Relational information on how organisations in South Africa were chosen as the internship site for nursing students and nurses to volunteer

- Where is the volunteer site in South Africa?

- How was this site selected?

- Do volunteers receive any additional training once they arrive at this site?

- Risk assessment data that has been collected to ensure health and safety for volunteers while in South Africa

- Are volunteers screened for health problems before and after volunteering?

- Are vaccinations required before leaving on volunteer trips?

- Is there a person the student/nurse should alert at the university if a volunteer posts something in a blog that is inappropriate or suggests an unmet need? 
- Who is responsible for the volunteers from ZUYD should something go wrong at the site in South Africa?

- Are there counsellors available for nurses and student nurses to talk to on their return should they experience recall anxiety following interviews.

- Planned time for additional information, including overall success of the internship program, strengths and weaknesses, miscellaneous information interviewee wishes to share with the researcher.

\section{Miscellaneous}

Do nurses and student nurses learn about the laws and health policies in South Africa before arriving?

Are pictures usually included in student blogs and should this be required in my study?

How often do students write in their blogs? 


\section{APPENDIX $Q$}

\section{EXAMPLE OF DATA ANALYSIS}

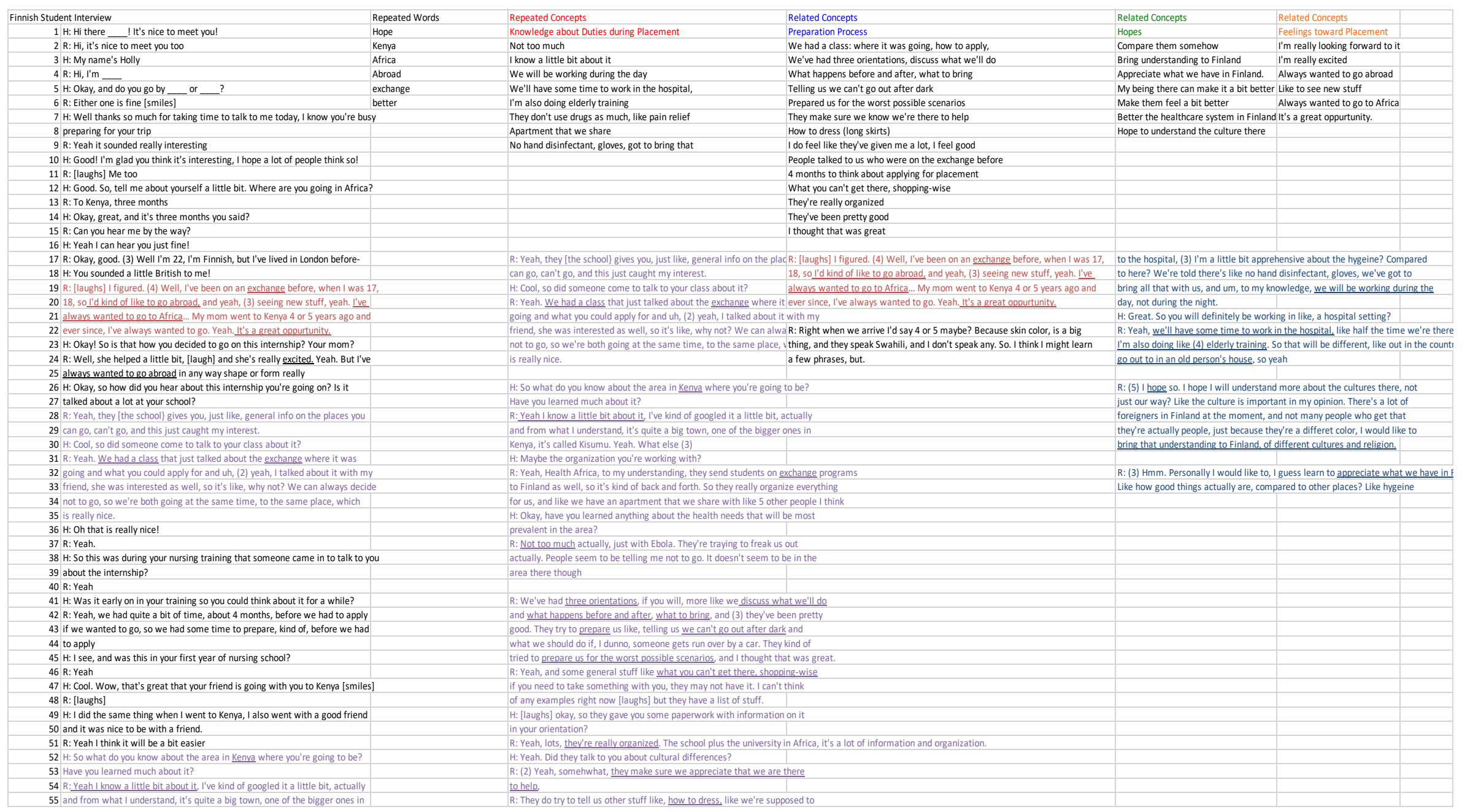




\section{APPENDIX R \\ TRANSLATION REQUEST}

\section{Dutch to English}

Note from translator: We edited the text a bit, strengthening the flow and readability. I just added a few verbs to make the English understandable. Nothing major. Content is the same.

\section{Student M, 9-17-2014}

\section{Professional Translation}

\section{MOZAMBIQUEEEE}

Thursday evening, we departed after some visa stress with Mozambique. Ten hours of travel later, we arrived at the border for a weekend away. A security officer asked us for our passports, since apparently we did not have all of the required stamps. Once we had all of our stamps, we were picked up by the shuttle and driven to the hostel. As you can see in one of the photos it was impossible to drive there ourselves. The hostel looked beautiful... Following a fat power nap on the scenic beach, we went to a local joint for a bite to eat. A man who worked at the hostel had shown us this place and recommended it. This joint looked extremely local; however the food was very good. After dinning, we toured the vibrant night life of Mozambique, which was largely absent during this weekend.

The next morning we were picked up early by the owner of a scuba diving business. Yes, indeed, diving in the Indian Sea was on our program. He gave us his detailed explanation about everything; then we practiced in the swimming pool. The man was very patient with us.

Then it was time for the real thing, so we jumped into the sea! What a wonderful experience! I saw beautiful coral and fish etc etc. Eventually, we reached a depth of almost $50 \mathrm{ft}$. And this was definitely not the last time for me. That night, the hostel chef prepared a tasty fish meal on the grille for us. We had an early evening since we had to rise early in the morning. 
Swimming dolphins, something I always had wanted to see. They should not be in an aquarium but in the wild. So a bit of luck would come in handy for us. During our search for the dolphins we found a whale with a young calf along with some other dolphins. Depending on their mood, dolphins will show an interest in you, while you are snorkeling in the water.

Unfortunately, these dolphins were in a 'resting mood' so they took no real interested in us. They did swim under us, while we were snorkeling. It was such a beautiful sight and gave us kicks seeing them. After some leisure time, we were able to enjoy the beach for a while Ionger. Unfortunately, it was time again to head out for the 10-hour return trip to Pretoria since we had to report back at our internship location.

\section{Google translate \\ MOZAMBIQUEEEE}

Thursday night we left after some visa stress to Mozambique. To travel for a weekend away, after 10 hours we arrived at the border. Luckily a security guard even appealed to us to show our passports because apparently we did not have any stamps. After complete to have all the stamps we were picked up by the transport to the hostel. As seen on one of the pictures, it was not doing it to yourself to drive to. The hostel looked very nice .. After a big power nap on the beautiful beach we have the evening to eat. Somewhere in a local shop A man that worked at the hostel had brought us and this is recommended. The tent looked very local, but the food was super tasty. After this we went looking for the sparkling stage lives of Mozambique, but it was this weekend to look far ..

The next morning we were picked up early by the owner of a scuba diving thing. Yes indeed, diving in the Indian Ocean was on the schedule. He explained us everything fine and after we started practicing in the pool. What patience that man ..

Now it's time for the real thing, was the sea! And what a great experience that was. Very nice coral and fish etc etc spotted. Eventually we went $14 \mathrm{~m}$ deep. And this was certainly not the last time for me. That evening the husband of the hostel super tasty fish on the braai for us and we made it not late because we had to leave early! 
Dolphins swim always wanted, in a container just in the wild. So a little luck would have been beautiful. While searching for the dolphins we saw a whale with a juvenile against and fortunately the dolphins. Depending on their mood it depends whether the dolphins pay attention to you while you lie with your snorkel in the water. These dolphins were 'resting mood so did not make much sense in us. However, they swam right under us while we were snorkeling. And was very nice / kiks to see. After some free time we went to enjoy the beach. Unfortunately, it was again time to 10 hours to drive back to Pretoria and we had to return to stage. schrievesj Up!

\section{Student A, 10-14-2014}

\section{Professional Translation}

\section{New Adventures!}

Last week Friday, the weekend started once again in vibrant South Africa. On that Friday, we began our weekend with a visit to a cozy market in the shopping mall, here in Brooklyn. You can taste everything there, and unbelievably... We even snacked on some truly Dutch croquettes!

On Saturday, we attended a festival with deep house music. It was a small festival, yet extremely enjoyable. On Sunday, I fulfilled another one of my dreams with a visit to a lion park. Here, I had the opportunity to cuddle and play with the lions. It was amazing to hear the tremendous knowledge these people had about the lions. The lions were so very playful.

On Monday evening we returned to Johannesburg for a sight seeing tour of the city. With a guide, we took a tour on foot. In the meantime, we stopped at several local food joints and enjoyed an array of wonderful African dishes. I still don't remember exactly what we ate. I beat my own record this morning having eaten a fish with my bare hands (yes, indeed, without any cutlery). By the end of the tour, we expected a surprise. At first, I was a bit skeptical. We were taken to an apartment building in the center of Johannesburg. Our host pressed number 52 in the elevator. I still did not 
have a clue, until we departed the elevator. We had a truly magnificent view of Johannesburg with beautiful lights.

Last weekend, naturally we did not stay at home. Friday, after our internship we immediately drove 5 hours in our vehicle to Blyde River Canyon. As soon as we arrived at our hostel, we went to bed. Early Saturday morning at 6 am, we took the car to tour canyons. Unfortunately, due to poor weather, we were unable to complete the trip. We followed a panoramic route through the Blyde River Canyon. Yet due to heavy fog we only enjoyed the vistas from a couple of view points. So this weekend we intend to take this tour once again. This time we expect to see the lovely vistas as well as tour some canyons.

Everything progresses as planned with my internship. My project is also going well. On Thursday, I will give a lecture on TBC. Tonight, we plan to out and feed the homeless and to provide them with information.

Tot binnenkort maar weer!

\section{Google translate}

Last Friday began the weekend course in the vibrant South Africa. We started on Friday evening with a cozy marketplace in the shopping mall to go here in Brooklyn. You can taste everything here, and not to believe ........ We have eaten real Dutch croquettes!

Saturday we went to a festival with deep house music, it was a small festival but obviously very cozy. The Sunday I again repeated my dream, I am this time went to another lion park. Here I was able to hug all morning with lions and play. It was incredible to hear how much knowledge that people have about these lions and how playful they were!

Monday night we went back to Johannesburg there to do a tour to see some more of Johannesburg. We are here to do a walking tour with a guide, in between we stopped at local eateries and we ate delicious African. What we all have eaten just that I still do not know, but I've surpassed myself and 
we ate a fish with your bare hands (Jahoor without utensils). At the end of the tour would wait for us a surprise, at first I thought it will be. We were taken to an apartment building between Johannesburg, was pressed at number 52 in the elevator. There was then still not really a light on until we got off the elevator and had a great but also great views over Johannesburg with beautiful lights.

Last weekend we have obviously not been home, we are training on Friday after similar weather got in the car to drive five hours to the Blyde River Canyon. Once we are tasty crept into our hostel in bed Saturday morning we sat at 6.00 in the morning again to do in the car kloofing. Unfortunately the bad weather this can not continue. We also drove the scenic route to Blyde River Canyon but unfortunately the fog we have only a few viewpoints that can see beauty. This weekend we will therefore also again going to do about it to have beautiful viewpoints and of course to do kloofing.

On stage is still all business as usual, my project has been running well. I will provide information about TBC Thursday. Tonight we take to the streets to give homeless people food and to provide information to the homeless.

See you soon again! 
APPENDIX S

QUESTIONS FOR DELPHI STUDY PILOT

Please indicate your role/s from the following (tick all that apply):

- Student with study abroad experience

- Study abroad coordinator at Higher Educational Institution

- Study abroad coordinator at Non-Governmental Organisation

- Professor/lecturer involved with study abroad trips

- Person responsible for sending students on study abroad trips

- Person responsible for receiving students on study abroad trips

o Other: (please specify your role)

How many years have you been involved in nursing study abroad trips? (tick the appropriate response):

- Less than one year

○ 1-2 years

- 3-5 years

- 6-10 years

○ $11+$ years

- Not applicable

In your experience, how prepared are nursing students to study abroad?

- Adequately prepared

- Somewhat prepared

- Inadequately prepared

- Not prepared at all 


\begin{tabular}{|c|c|c|c|c|c|}
\hline $\begin{array}{l}\text { Nursing students preparing to study abroad ... } \\
\text { (Please tick your agreement with the following } \\
\text { statements) }\end{array}$ & $\begin{array}{l}\text { Strongly } \\
\text { agree }\end{array}$ & Agree & Undecided & Disagree & $\begin{array}{l}\text { Strongly } \\
\text { disagree }\end{array}$ \\
\hline Should be told what to bring on their study abroad trip & & & & & \\
\hline $\begin{array}{l}\text { Must create a learning contract including educational } \\
\text { expectations of the trip }\end{array}$ & & & & & \\
\hline $\begin{array}{l}\text { Must familiarize themselves with clinical skills related to } \\
\text { prevalent diseases in the host location }\end{array}$ & & & & & \\
\hline $\begin{array}{l}\text { Need to identify ways of improving the study abroad } \\
\text { experience for future students }\end{array}$ & & & & & \\
\hline $\begin{array}{l}\text { Must understand and acquire the communication skills } \\
\text { necessary to work in a multi-disciplinary team }\end{array}$ & & & & & \\
\hline $\begin{array}{l}\text { Must provide care respecting the cultural practices in the } \\
\text { host location }\end{array}$ & & & & & \\
\hline $\begin{array}{l}\text { Must possess or acquire the reflective skills to appreciate } \\
\text { the learning gained from studying abroad }\end{array}$ & & & & & \\
\hline
\end{tabular}




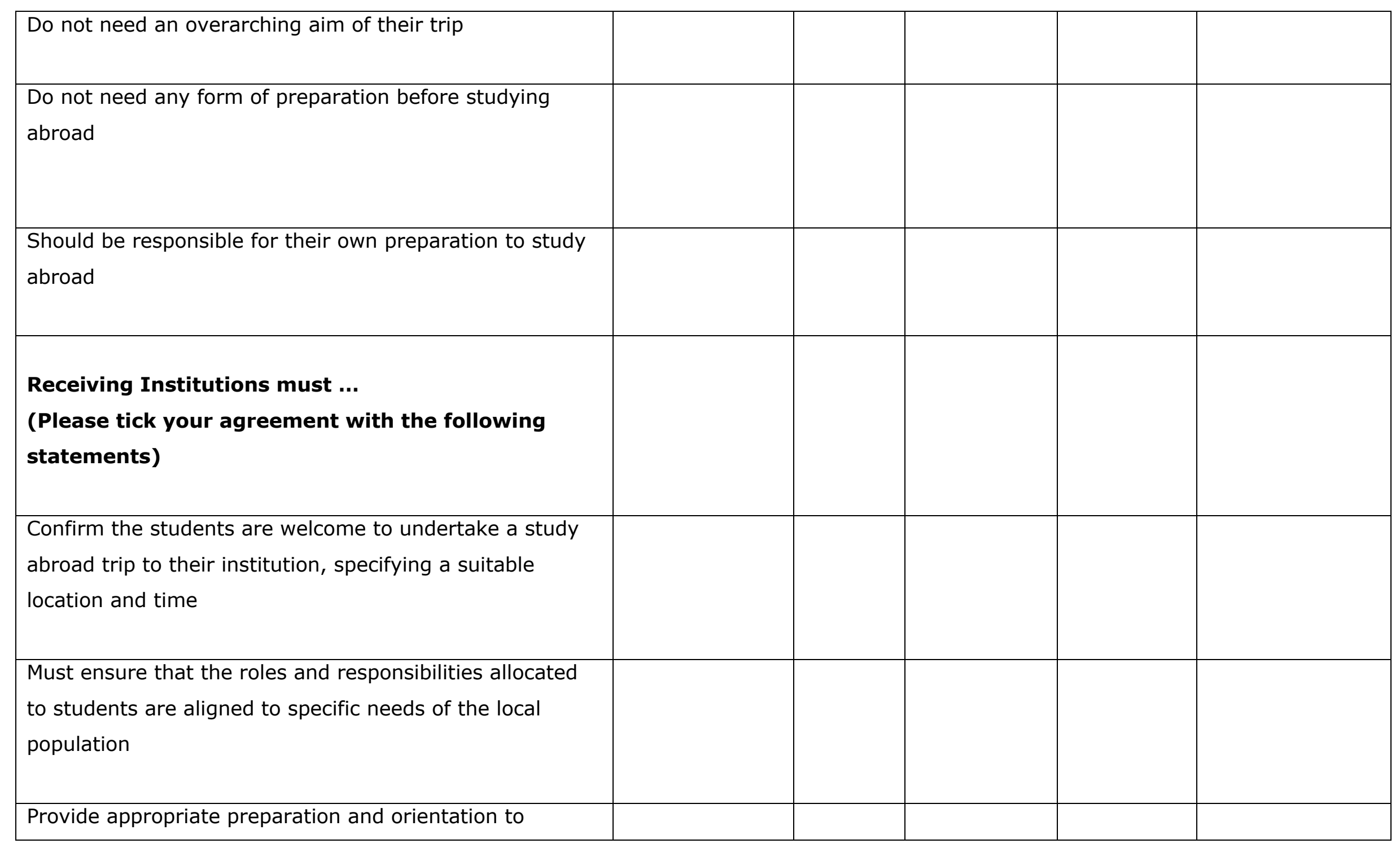




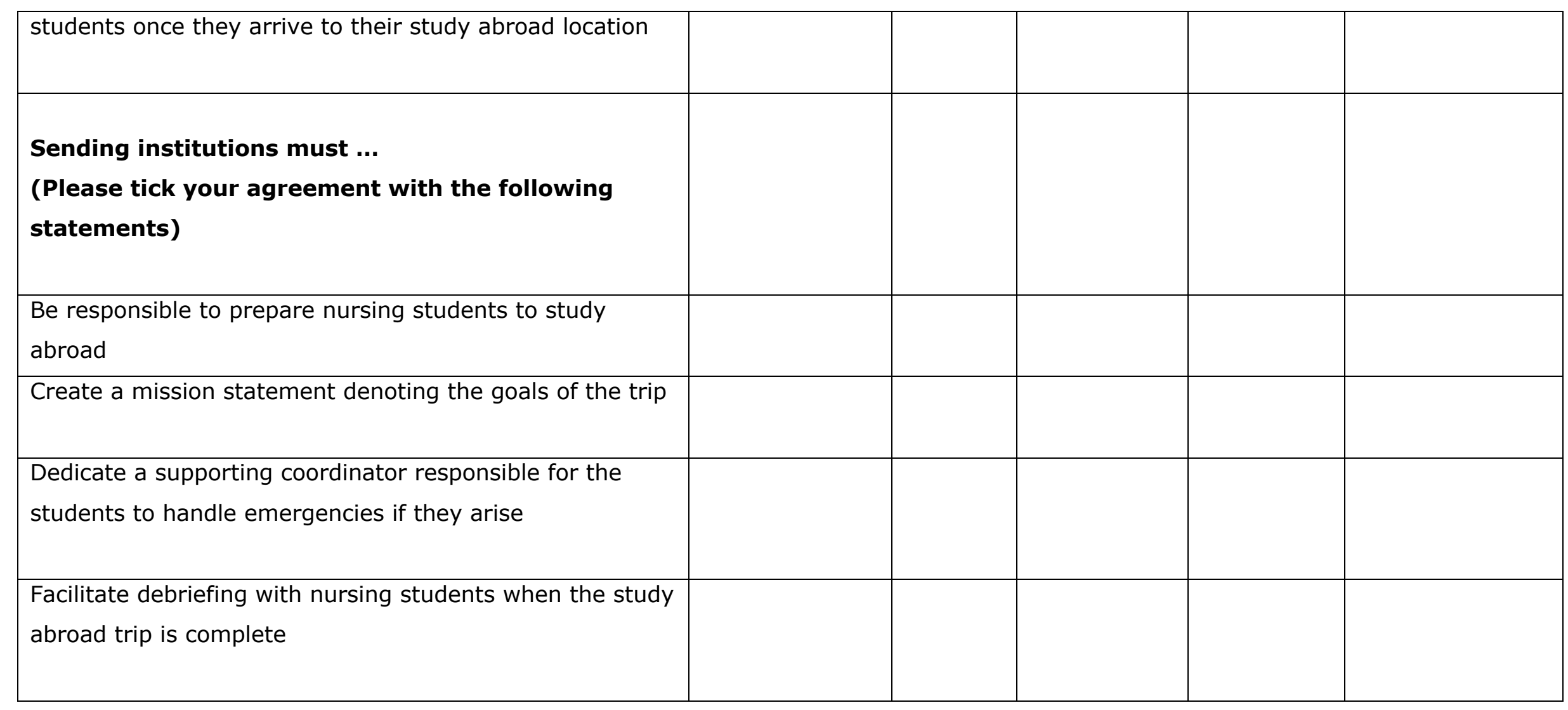


The following is the working definition of preparation, informed by a literature review. Please rate the following working definition.

\begin{tabular}{|c|c|c|c|c|c|}
\hline $\begin{array}{l}\text { Preparation for nursing students to study abroad } \\
\text { should include... } \\
\text { (Please tick your agreement with the following } \\
\text { statements) }\end{array}$ & $\begin{array}{l}\text { Strongly } \\
\text { agree }\end{array}$ & Agree & Undecided & Disagree & $\begin{array}{l}\text { Strongly } \\
\text { disagree }\end{array}$ \\
\hline a.) Acquisition of practical information & & & & & \\
\hline $\begin{array}{l}\text { b). Development of clinical skills, especially those related } \\
\text { to prevalent diseases in the host location that may be } \\
\text { uncommon in the students' country of residence; }\end{array}$ & & & & & \\
\hline $\begin{array}{l}\text { c). Development of managerial skills, or the ability to } \\
\text { overcome a lack of resources; }\end{array}$ & & & & & \\
\hline $\begin{array}{l}\text { d). Development of communication skills, or the ability tc } \\
\text { interact with a multi-disciplinary team in the host } \\
\text { location; }\end{array}$ & & & & & \\
\hline $\begin{array}{l}\text { e). Development of cultural skills, or gaining } \\
\text { understanding of cultural practices in the host location to } \\
\text { best provide care within the patient's culture; }\end{array}$ & & & & & \\
\hline
\end{tabular}




\begin{tabular}{|l|l|l|l|l|}
\hline $\begin{array}{l}\text { f). Time to reflect on the emotional reactions students } \\
\text { may experience while abroad. }\end{array}$ & & & & \\
\hline
\end{tabular}

Please specify any further areas you believe nursing students should be prepared to study abroad 


\section{APPENDIX T \\ QUESTIONS FOR DELPHI STUDY ROUND 1}

Please indicate your role/s from the following (tick all that apply):

- Student with study abroad experience

- Study abroad coordinator at Higher Educational Institution

- Study abroad coordinator at Non-Governmental Organisation

- Professor/lecturer involved with study abroad trips

- Person responsible for sending students on study abroad trips

- Person responsible for receiving students on study abroad trips

o Other: (please specify your role)

How many years have you been involved in nursing study abroad trips? (tick the appropriate response):

- Less than one year

- 1-2 years

○ 3-5 years

- 6-10 years

○ $11+$ years

- Not applicable 
Where have you had experience with nursing study abroad trips? Include your home country if you receive study abroad trips to your country (tick all that apply):
- Kenya
- South Africa
- Nigeria
○ Nepal
- India
- Mexico
- Other: (please specify your role)

In your experience, how prepared are nursing students to study abroad?
- Adequately prepared
- Somewhat prepared
- Inadequately prepared
- Not prepared at all 


\begin{tabular}{|c|c|c|c|c|c|}
\hline $\begin{array}{l}\text { Nursing students preparing to study abroad ... } \\
\text { (Please tick your agreement with the following } \\
\text { statements) }\end{array}$ & $\begin{array}{l}\text { Strongly } \\
\text { agree }\end{array}$ & Agree & Undecided & Disagree & $\begin{array}{l}\text { Strongly } \\
\text { disagree }\end{array}$ \\
\hline Should be told what to bring on their study abroad trip & & & & & \\
\hline $\begin{array}{l}\text { Must create a learning contract including educational } \\
\text { expectations of the trip }\end{array}$ & & & & & \\
\hline $\begin{array}{l}\text { Must familiarize themselves with clinical skills related to } \\
\text { prevalent diseases in the host location }\end{array}$ & & & & & \\
\hline $\begin{array}{l}\text { Need to identify ways of improving the study abroad } \\
\text { experience for future students }\end{array}$ & & & & & \\
\hline $\begin{array}{l}\text { Must provide care respecting the cultural practices in the } \\
\text { host location }\end{array}$ & & & & & \\
\hline
\end{tabular}




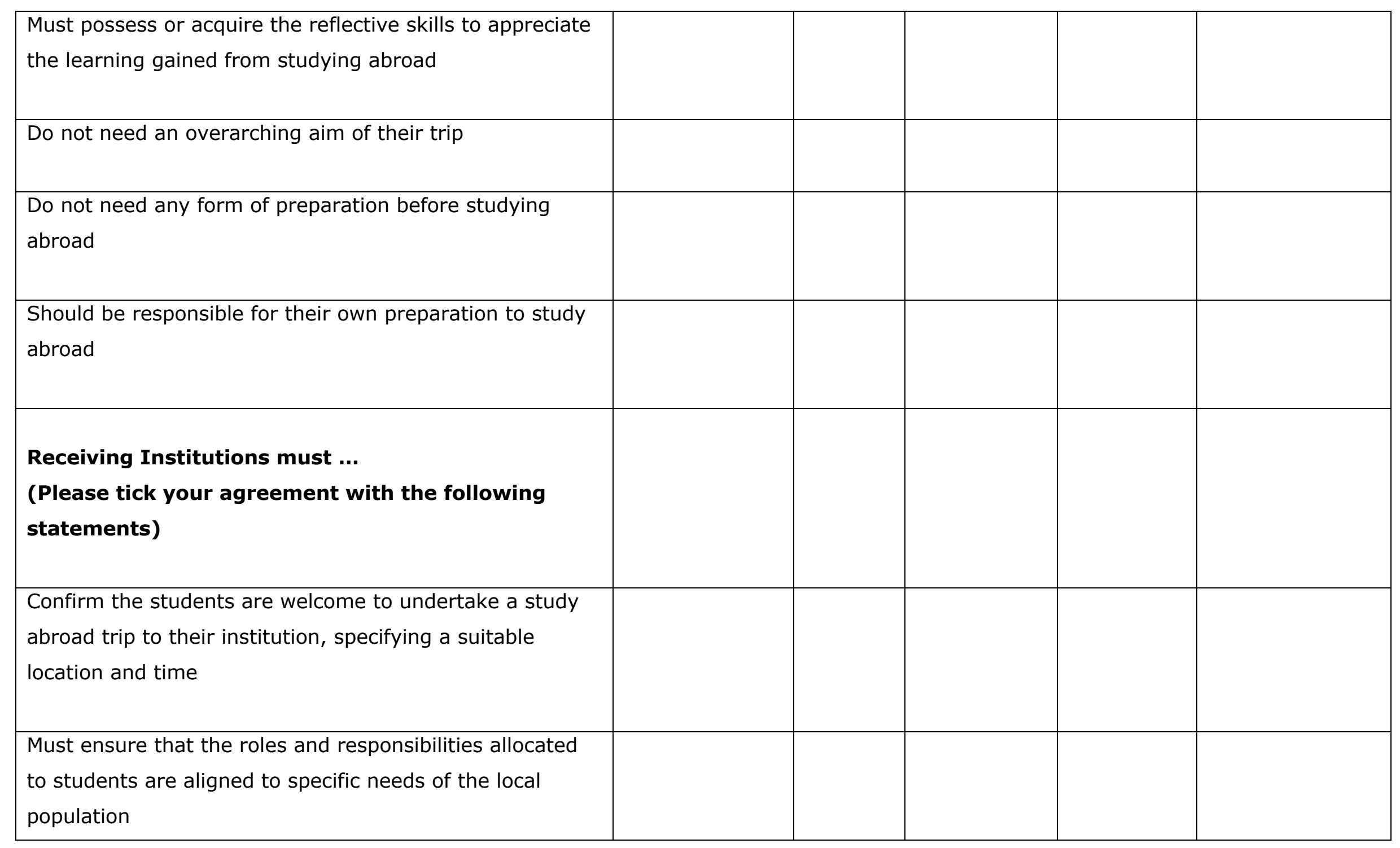




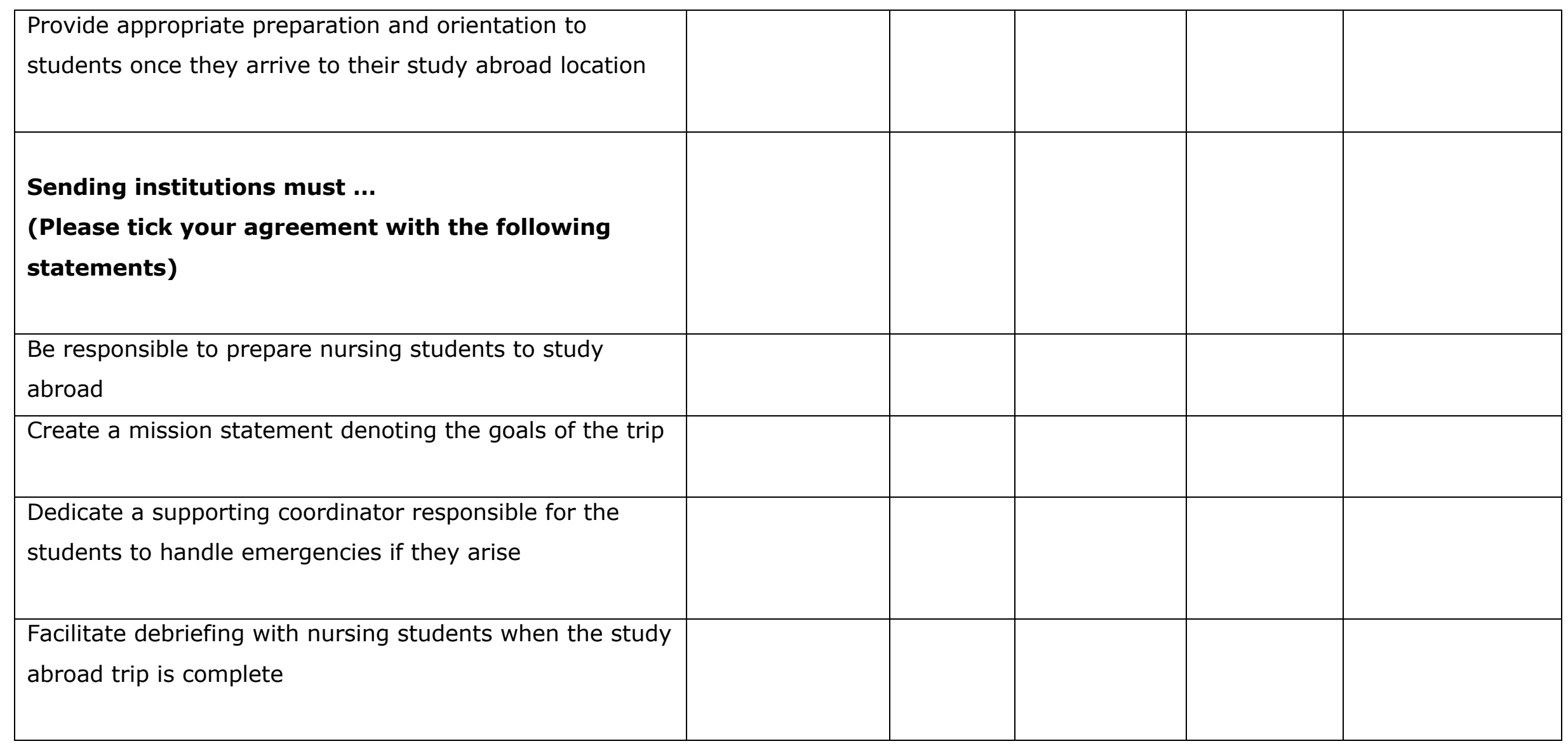


The following is the working definition of preparation, informed by a literature review. Please rate the following working definition.

\begin{tabular}{|c|c|c|c|c|c|}
\hline $\begin{array}{l}\text { Preparation for nursing students to study abroad } \\
\text { should include... } \\
\text { (Please tick your agreement with the following } \\
\text { statements) }\end{array}$ & $\begin{array}{l}\text { Strongly } \\
\text { agree }\end{array}$ & Agree & Undecided & Disagree & $\begin{array}{l}\text { Strongly } \\
\text { disagree }\end{array}$ \\
\hline a.) Acquisition of practical information & & & & & \\
\hline $\begin{array}{l}\text { c). Development of clinical skills, especially those related } \\
\text { to prevalent diseases in the host location that may be } \\
\text { uncommon in the students' country of residence; }\end{array}$ & & & & & \\
\hline $\begin{array}{l}\text { e). Development of communication skills, or the ability to } \\
\text { interact with a multi-disciplinary team in the host } \\
\text { location; }\end{array}$ & & & & & \\
\hline f). Development of cultural skills, or gaining & & & & & \\
\hline
\end{tabular}




\begin{tabular}{|l|l|l|l|l|}
\hline $\begin{array}{l}\text { understanding of cultural practices in the host location to } \\
\text { best provide care within the patient's culture; }\end{array}$ & & & \\
\hline $\begin{array}{l}\text { g). Time to reflect on the emotional reactions students } \\
\text { may experience while abroad. }\end{array}$ & & & & \\
\hline
\end{tabular}

Please specify any further areas you believe nursing students should be prepared to study abroad 


\section{APPENDIX U \\ QUESTIONS FOR DELPHI STUDY ROUND 2}

Thank you for your participation in this Delphi study. Delphi studies consist of rounds, in which the respondents are given feedback on their previous responses, and may change their answers based on what other respondents have expressed. This is the second round of the Delphi study, and should take less than ten minutes to complete.

In the first round, $84 \%$ of the Delphi questions reached consensus. The questions that did not reach consensus are below with findings displayed in bar graphs. Please answer the few questions that did not reach consensus one more time, keeping in mind that the questions will be omitted from the definition of preparation if the second round data finds less than $75 \%$ consensus.

Finally, some respondents offered suggestions to add to the definition of preparation. Please rank your agreement with these new statements.

Thank you for your time. 
Below are the results from a question regarding the preparadness of nursing students to study abroad. Please answer one more time, keeping in mind

this question does not need to reach consesus, but had a wide range of answers in the first round.

Findings from Round 1:

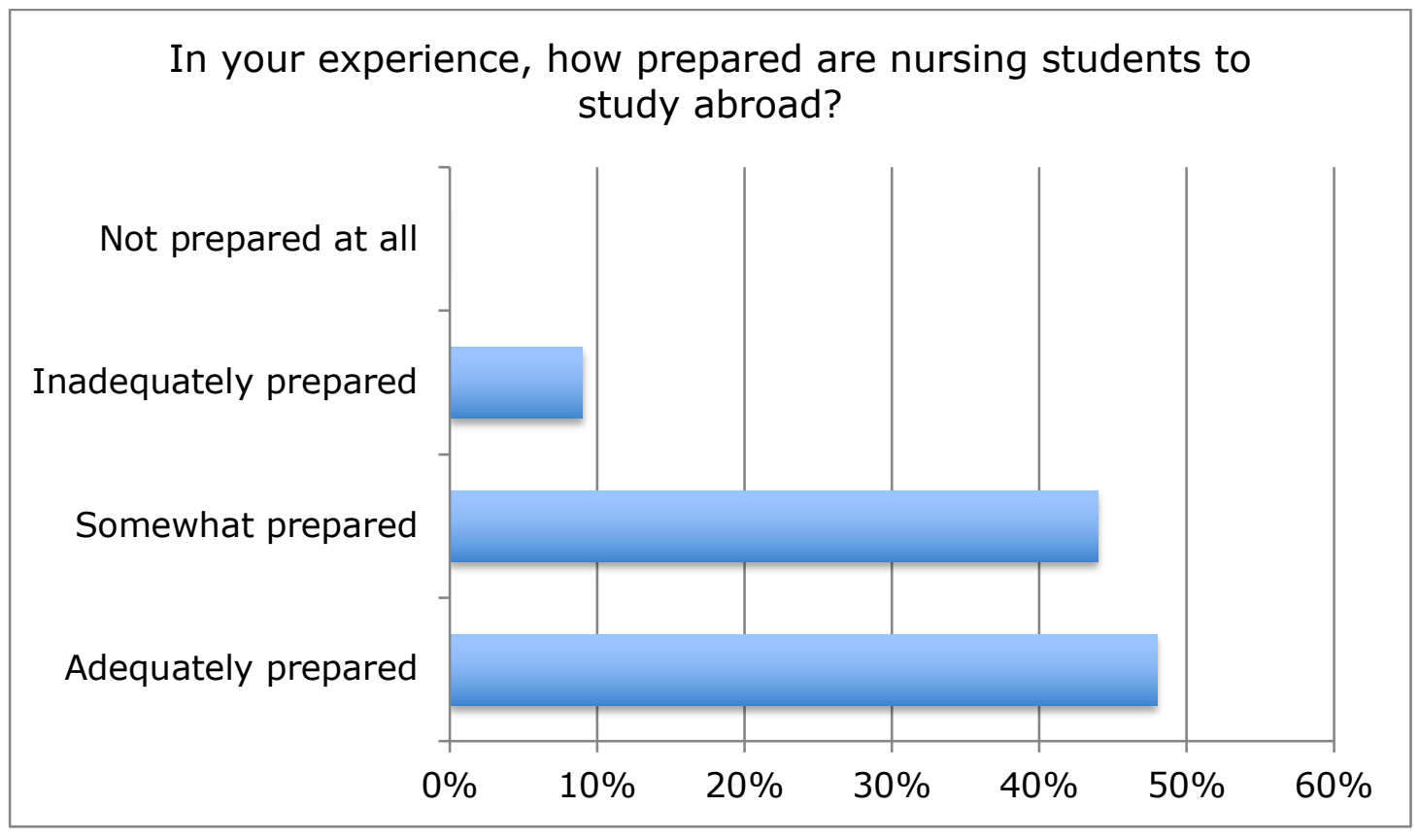


In your experience, how prepared are nursing students to study abroad?

- Adequately prepared

- Somewhat prepared

- Inadequately prepared

- Not prepared at all

The following questions will be omitted from the definition of preparation if the second round data finds less than $75 \%$ consensus.

Findings from Round 1:

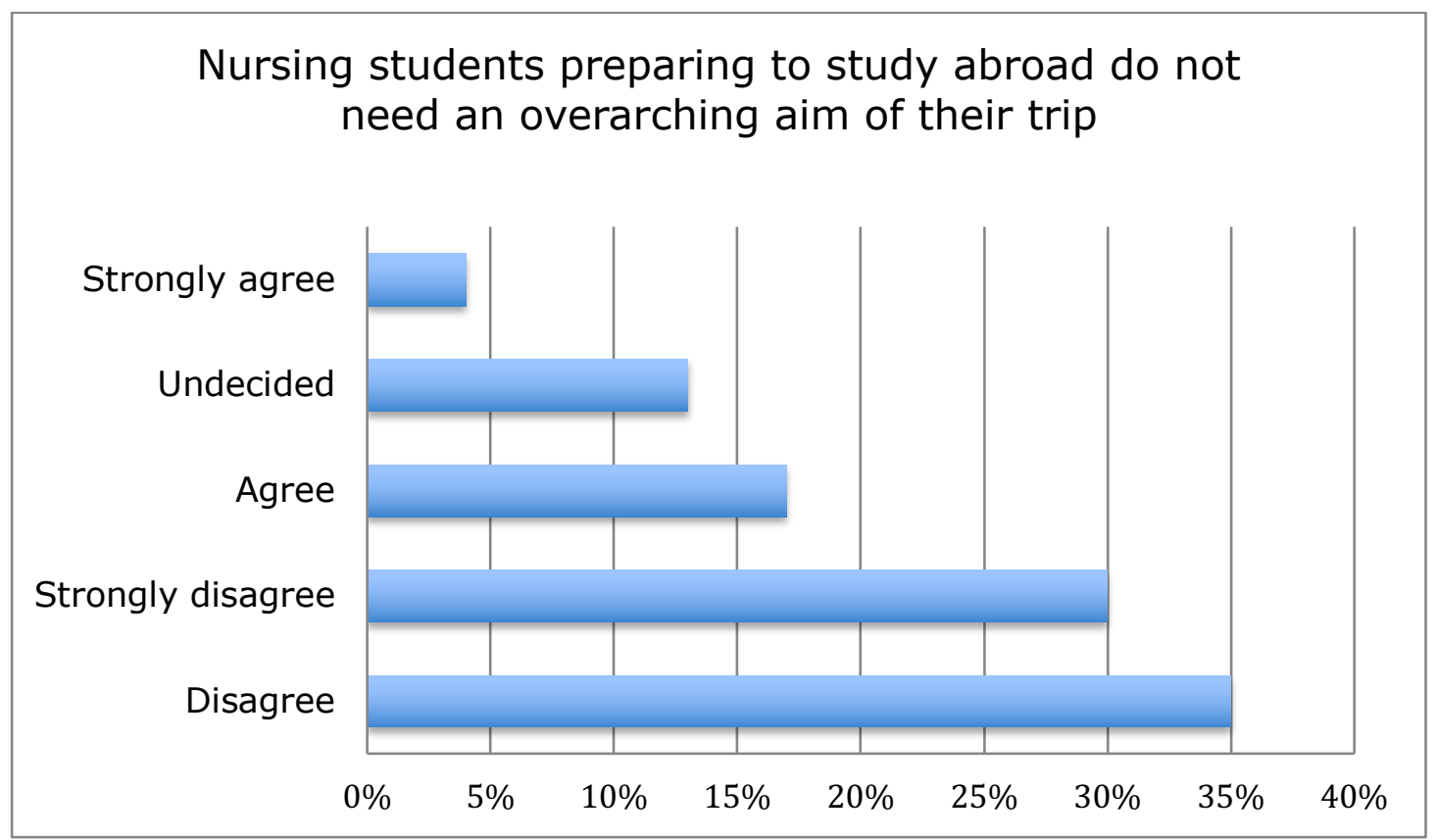




\begin{tabular}{|l|l|l|l|l|l|}
\hline $\begin{array}{l}\text { Nursing students preparing to } \\
\text { study abroad ... } \\
\text { (Please tick your agreement with } \\
\text { the following statements) }\end{array}$ & $\begin{array}{l}\text { Strongly } \\
\text { agree }\end{array}$ & Agree & Undecided & Disagree & $\begin{array}{l}\text { Strongly } \\
\text { disagree }\end{array}$ \\
\hline $\begin{array}{l}\text { Do not need an overarching aim of } \\
\text { their trip }\end{array}$ & & & & & \\
\hline
\end{tabular}




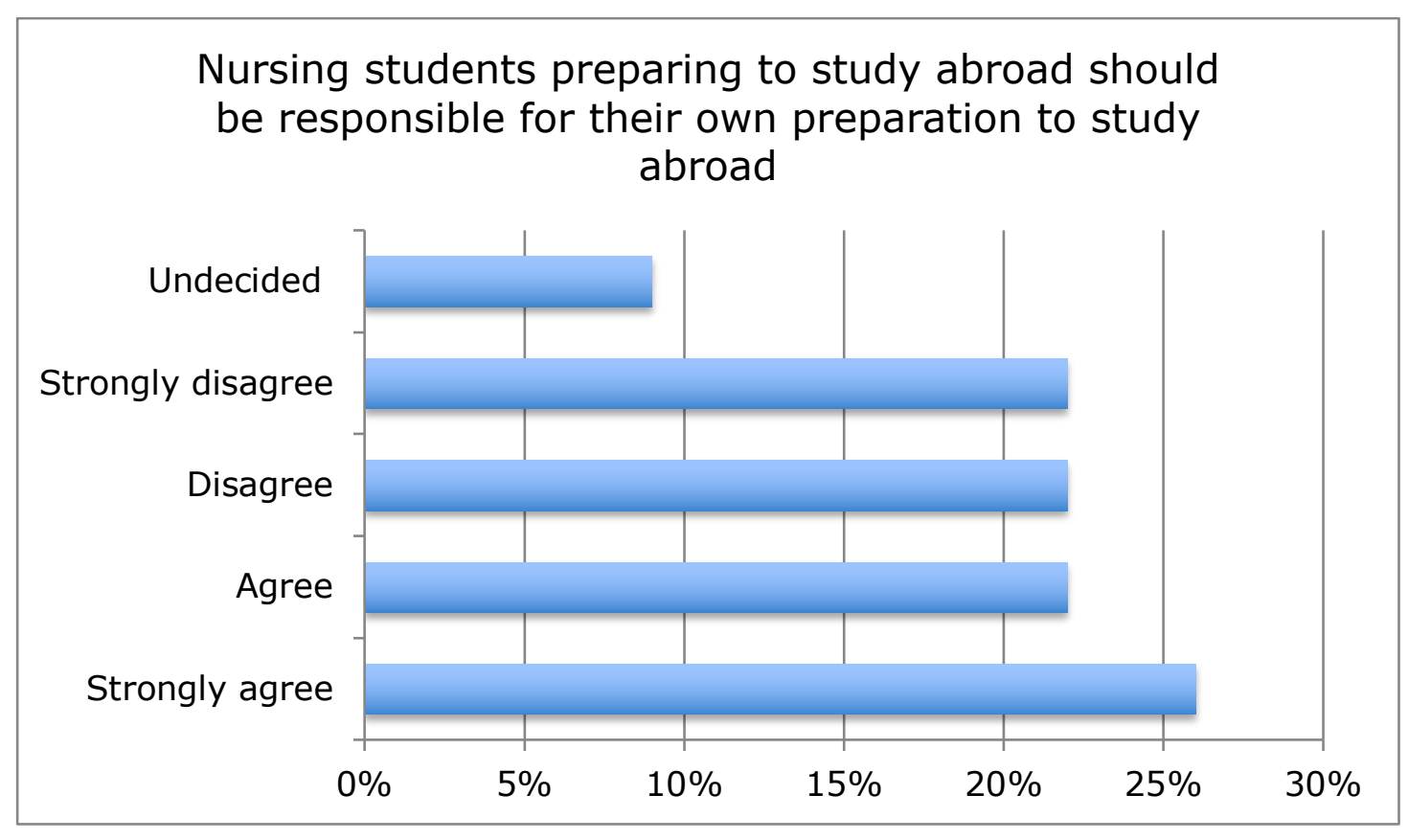

\begin{tabular}{|l|l|l|l|l|l|}
\hline $\begin{array}{l}\text { Nursing students preparing to } \\
\text { study abroad ... } \\
\text { (Please tick your agreement } \\
\text { with the following statements) }\end{array}$ & $\begin{array}{l}\text { Strongly } \\
\text { agree }\end{array}$ & Agree & Undecided & Disagree & $\begin{array}{l}\text { Strongly } \\
\text { disagree }\end{array}$ \\
\hline $\begin{array}{l}\text { Should be responsible for their own } \\
\text { preparation to study abroad }\end{array}$ & & & & & \\
\hline
\end{tabular}




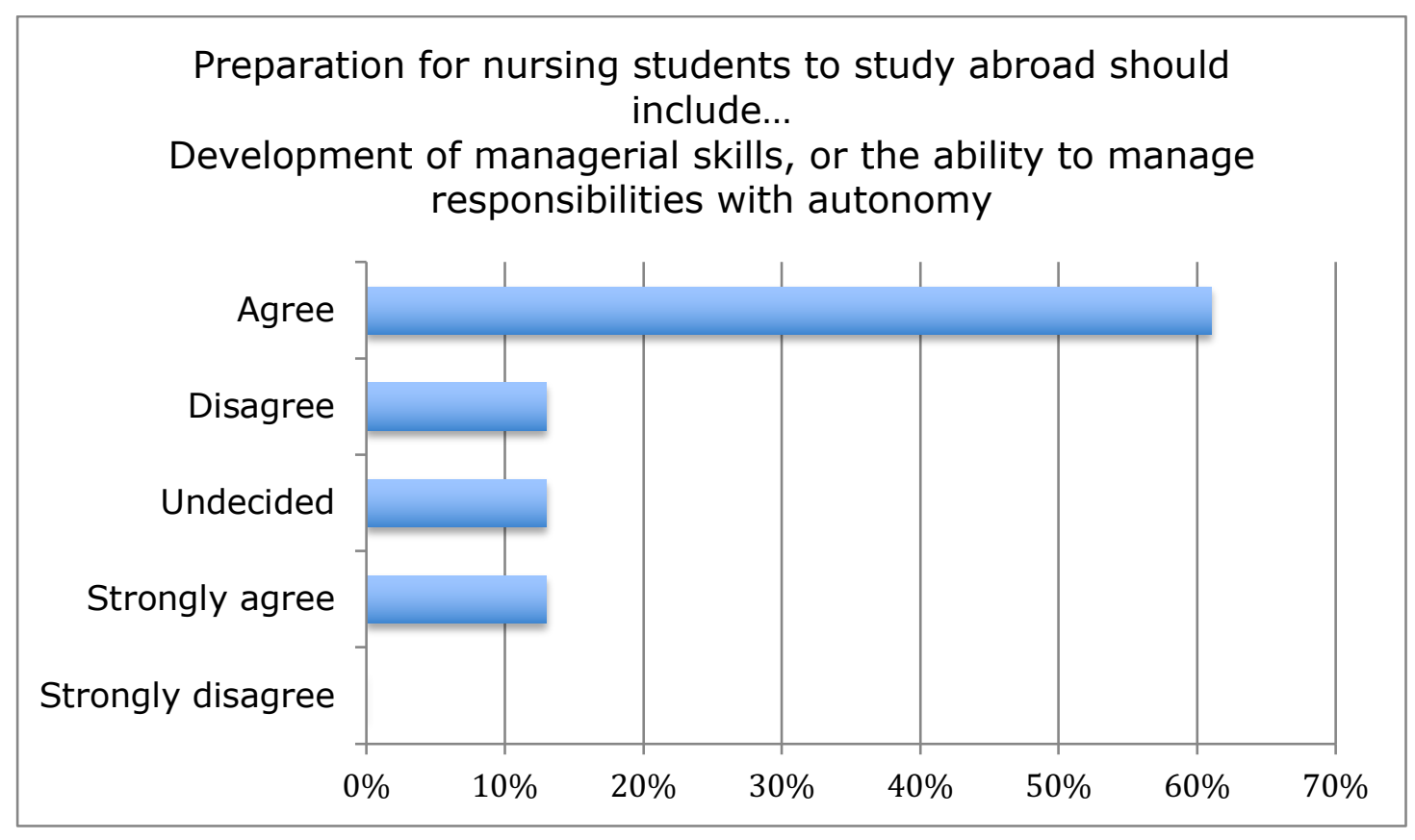

\begin{tabular}{|l|l|l|l|l|l|}
\hline $\begin{array}{l}\text { Nursing students preparing to } \\
\text { study abroad ... } \\
\text { (Please tick your agreement with } \\
\text { the following statements) }\end{array}$ & $\begin{array}{l}\text { Strongly } \\
\text { agree }\end{array}$ & Agree & Undecided & Disagree & $\begin{array}{l}\text { Strongly } \\
\text { disagree }\end{array}$ \\
\hline $\begin{array}{l}\text { Development of managerial skills, or } \\
\text { the ability to manage responsibilities } \\
\text { with autonomy }\end{array}$ & & & & & \\
\hline
\end{tabular}


Respondents offered statements they felt could be added to the definition of preparation. Statements were grouped when similar. The following chart shows the suggested additions to the definition with the number of respondents in agreement. Please rank your agreement with each statement.

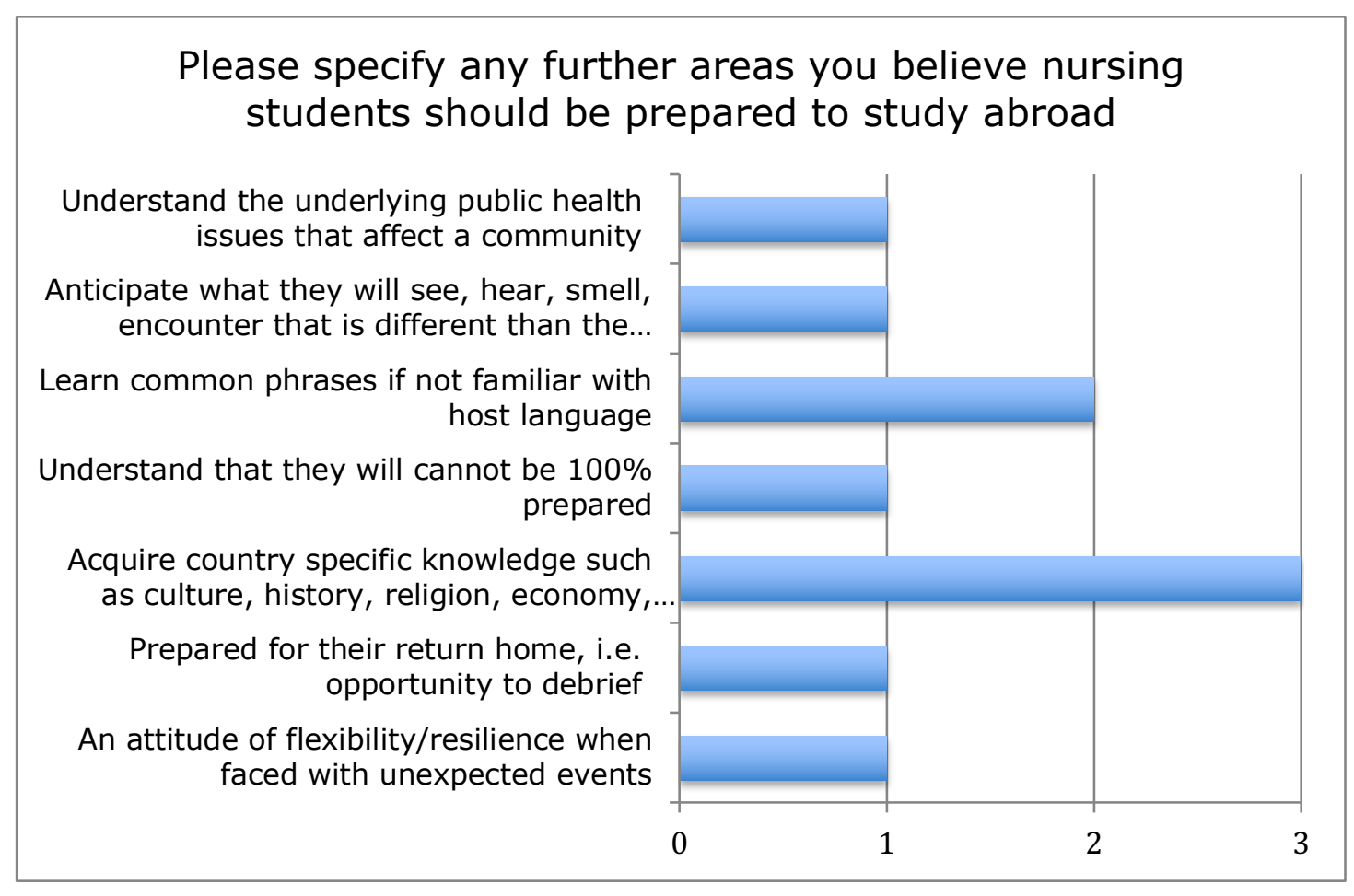




\begin{tabular}{|c|c|c|c|c|c|}
\hline $\begin{array}{l}\text { Nursing students preparing to } \\
\text { study abroad should... } \\
\text { (Please tick your agreement that } \\
\text { the following statements be added } \\
\text { to the definition of preparation) }\end{array}$ & $\begin{array}{l}\text { Strongly } \\
\text { agree }\end{array}$ & Agree & Undecided & Disagree & $\begin{array}{l}\text { Strongly } \\
\text { disagree }\end{array}$ \\
\hline $\begin{array}{l}\text { Anticipate what they will see, hear, } \\
\text { smell, and encounter that is different } \\
\text { from their home country }\end{array}$ & & & & & \\
\hline $\begin{array}{l}\text { Learn common phrases to } \\
\text { communicate basic needs if they are } \\
\text { unfamiliar with the host country } \\
\text { language }\end{array}$ & & & & & \\
\hline $\begin{array}{l}\text { Understand they will not be } 100 \% \\
\text { prepared }\end{array}$ & & & & & \\
\hline $\begin{array}{l}\text { Acquire country specific knowledge } \\
\text { such as culture, history, religion, } \\
\text { economy, healthcare }\end{array}$ & & & & & \\
\hline $\begin{array}{l}\text { Prepare also for their return home } \\
\text { with opportunity to debrief the trip }\end{array}$ & & & & & \\
\hline Expect unforeseen circumstances to & & & & & \\
\hline
\end{tabular}




\begin{tabular}{|l|l|l|l|l|l|}
\hline $\begin{array}{l}\text { arise, requiring an attitude of } \\
\text { flexibility/resilience }\end{array}$ & & & & & \\
\hline $\begin{array}{l}\text { Understand the underlying public } \\
\text { health issues (such as contaminated } \\
\text { water, poverty, or poor hygiene) that } \\
\text { affect a community }\end{array}$ & & & & & \\
\hline
\end{tabular}

